\title{
European Banking : Market Power and Efficiency
}

Citation for published version (APA):

Bos, J. W. B. (2002). European Banking : Market Power and Efficiency. [Doctoral Thesis, Maastricht University]. Datawyse / Universitaire Pers Maastricht. https://doi.org/10.26481/dis.20020531jb

Document status and date:

Published: 01/01/2002

DOI:

10.26481/dis.20020531jb

Document Version:

Publisher's PDF, also known as Version of record

\section{Please check the document version of this publication:}

- A submitted manuscript is the version of the article upon submission and before peer-review. There can be important differences between the submitted version and the official published version of record.

People interested in the research are advised to contact the author for the final version of the publication, or visit the DOI to the publisher's website.

- The final author version and the galley proof are versions of the publication after peer review.

- The final published version features the final layout of the paper including the volume, issue and page numbers.

Link to publication

\footnotetext{
General rights rights.

- You may freely distribute the URL identifying the publication in the public portal. please follow below link for the End User Agreement:

www.umlib.nl/taverne-license

Take down policy

If you believe that this document breaches copyright please contact us at:

repository@maastrichtuniversity.nl

providing details and we will investigate your claim.
}

Copyright and moral rights for the publications made accessible in the public portal are retained by the authors and/or other copyright owners and it is a condition of accessing publications that users recognise and abide by the legal requirements associated with these

- Users may download and print one copy of any publication from the public portal for the purpose of private study or research.

- You may not further distribute the material or use it for any profit-making activity or commercial gain

If the publication is distributed under the terms of Article $25 \mathrm{fa}$ of the Dutch Copyright Act, indicated by the "Taverne" license above, 
European Barnking: Market Power and Efficiency 
This book was written in $\mathrm{H}_{\mathrm{T}} \mathrm{X}$ and typeset by the author using Scientific Workplace 3.0 and MiKTex in a modified version of the Springer-Verlag style, with references set in Econometrica style.

\section{(C) Jaap Bos, Maastricht}

All rights reserved. No part of this publication may be reproduced, stored in a retrieval system, or transmitted, in any form, or by any means, electronic, mechanical, photocopying, recording or otherwise, without the prior permission in writing, from the author.

Published by Universitaire Pers Maastricht

ISBN 9052783470

Printed in the Netherlands by Datawyse 


\title{
European Banking: Market Power and Efficiency
}

\author{
PROEFSCHRIFT
}

ter verkrijging van de graad van doctor aan de Universiteit Maastricht

op gezag van de Rector Magnificus,

Prof. dr. A.C. Nieuwenhuijzen Kruseman, volgens het besluit van het College van Decanen, in het openbaar te verdedigen op vrijdag 31 mei 2002 om 12.00 uur

door

Jaap Bos 


\section{Promotor:}

Prof. dr. C.J.M. Kool

\section{Beoordelingscommissie:}

Prof. dr. J. Muysken (voorzitter)

Prof. dr. F. C. Palm

Prof. dr. E. Sterken (Rijksuniversiteit Groningen)

Dr. T. van Veen 


\section{Contents}

Acknowledgements vii

1 An Intro to European Banking Markets 1

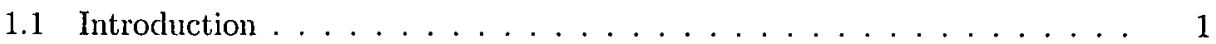

1.2 Problem Statement . . . . . . . . . . . . . . . . . . . . . . . . . . . . . . . .

1.3 Place in the Literature . . . . . . . . . . . . . . . . . . . . . . . . . . . . . . .

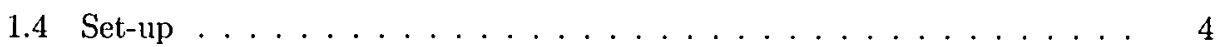

2 Market Power in European Banking: A Critical Review of the SCP Approach

2.1 Introduction . . . . . . . . . . . . . . . . . . . 7

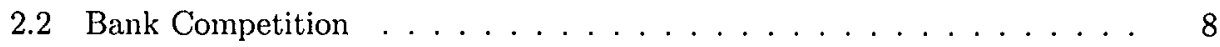

2.2 .1 Intermediation . . . . . . . . . . . . . . . . 9

2.2 .2 Beyond Intermediation . . . . . . . . . . . . . . . 11

2.3 The SCP Hypothesis . . . . . . . . . . . . . . . . . . . . . . . . . . . . . . . . .

2.3 .1 The SCP Model . . . . . . . . . . . . . . . . . . . . . . . . . . . . 12

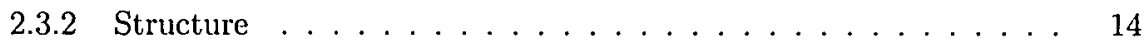

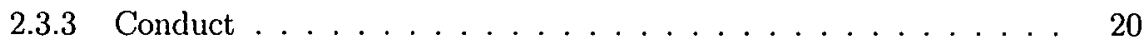

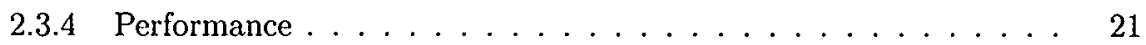

2.4 Empirical Matters . . . . . . . . . . . . . . . . . . . . . . . . 23

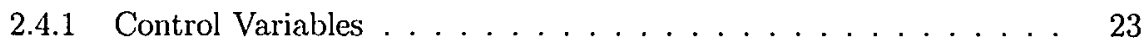

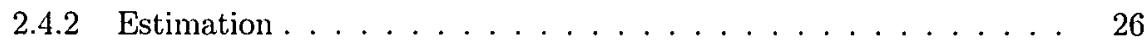

2.4 .3 Objective Functions . . . . . . . . . . . . . . . . . . 28

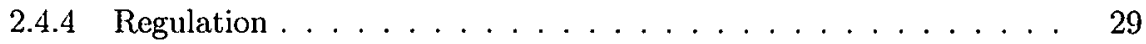

2.5 Conclusion . . . . . . . . . . . . . . . . 31

3 Explaining Bank Performance through Efficiency: A Guide through the Theory

3.1 Introduction . . . . . . . . . . . . . . . . . . 33

3.2 From Market Power to Alternative Explanations for Firm Performance . 34

3.2 .1 Incentive Problems . . . . . . . . . . . . . . . . 34

3.2 .2 Inefficiency Problems . . . . . . . . . . . . . . 36

3.3 From Economic Rationality to Production Functions . . . . . . . . . . 37

3.4 From Production Functions to Cost and Profit Functions . . . . . . . . 41

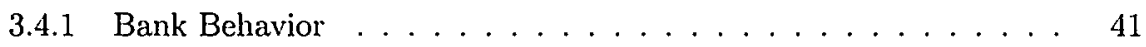

3.4 Duality ........................ 42 
3.4 .3 Bank production $\ldots \ldots \ldots \ldots \ldots \ldots \ldots \ldots \ldots$

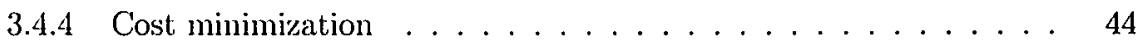

3.4 .5 Profit maximization . . . . . . . . . . . . . . . . 45

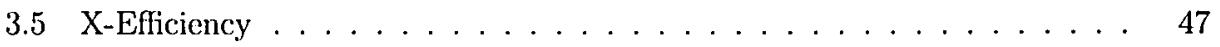

3.5.1 Parametric Versus Non-Parametric . . . . . . . . . . . 48

3.5 .2 Stochastic Frontier Analysis . . . . . . . . . . . . 51

3.5 .3 Specification . . . . . . . . . . . . . . 51

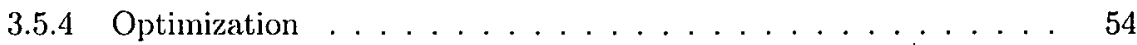

3.5.5 Maximum Likelihood Estimator . . . . . . . . . . . . . . 56

3.6 Conclusion . . . . . . . . . . . . . . . . . . . . . . 57

4 Bank Size, Specialization and Efficiency in the Netherlands: 1992-1998 59

4.1 Introduction . . . . . . . . . . . . . . . . . 59

4.2 The Dutch Banking Market . . . . . . . . . . . . . . 60

4.3 Estimation Results . . . . . . . . . . . . . . . . . . . . 64

4.3.1 Estimated Cost and Profit Frontiers . . . . . . . . . . . 64

4.3 .2 Efficiency Scores . . . . . . . . . . . . . . . 68

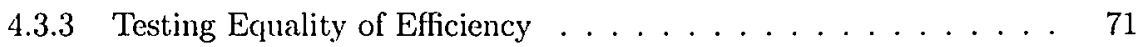

4.4 Conclusion . . . . . . . . . . . . . . . . . . . . . 74

5 Market Power in the Dutch Banking Market: Empirical Evidence 1992$1998 \quad 77$

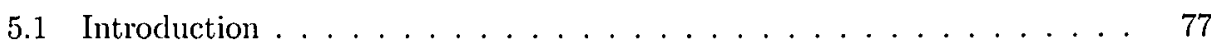

5.2 The Dutch Banking Market $\ldots \ldots \ldots \ldots \ldots \ldots$

5.2 .1 Market Definition . . . . . . . . . . . . . 78

5.2 .2 Market Power . . . . . . . . . . . . . . . . . 80

5.3 The SCP Model . . . . . . . . . . . . . . . . . . . . . 83

5.3 .1 Model Setup . . . . . . . . . . . . . . . . . . 83

5.3 .2 Variables. . . . . . . . . . . . . . . . . 83

5.3 .3 Results . . . . . . . . . . . . . . . . . . 85

5.4 The Cournot Model . . . . . . . . . . . . . . . . . . . . 87

5.4 .1 Model Setup . . . . . . . . . . . . . . . . . . . 87

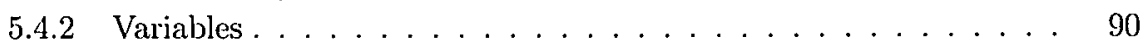

5.4 .3 Results . . . . . . . . . . . . . . . . . . 91

5.5 The Efficiency Hypothesis . . . . . . . . . . . . . . . . 91

5.5 .1 Model Setup . . . . . . . . . . . . . . . . . . . . 92

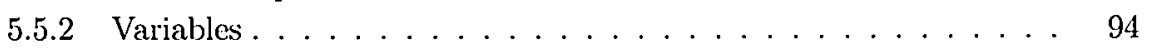

5.5 .3 Results . . . . . . . . . . . . . . . . . . . 94

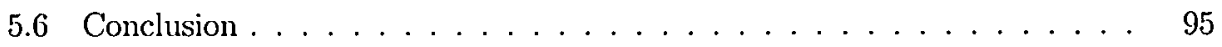

5.7 Appendix: The Stigler Approach . . . . . . . . . . . . . 96

6 Large Bank Efficiency in Europe and the United States 99 


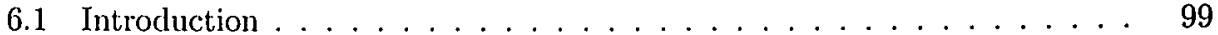

6.2 Literature . . . . . . . . . . . . . . . . . . . 100

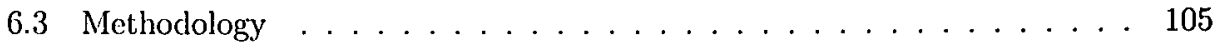

6.3 .1 Optimization . . . . . . . . . . . . . 105

6.3.2 Profit and Cost Frontiers in Europe and the U.S. . . . . . . . 107

6.4 Data . . . . . . . . . . . . . . . . . . . . . . 108

6.4 .1 Sample Data . . . . . . . . . . . . . . . . 108

6.4 .2 Variables. . . . . . . . . . . . . . . 110

6.5 Results . . . . . . . . . . . . . . . . . . . . . . 112

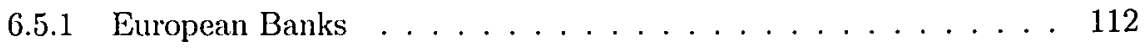

6.5 .2 U.S. Banks . . . . . . . . . . . . . . . . . 115

6.5.3 European and U.S. Banks Combined . . . . . . . . . . . 118

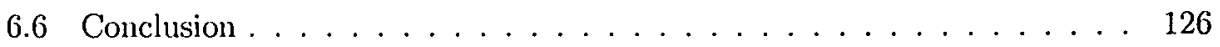

7 Bank Efficiency: The Role of Local Market Conditions 127

7.1 Introduction . . . . . . . . . . . . . . . . . . . 127

7.2 Developments in Local Banking Markets . . . . . . . . . . . . . . 130

7.3 Literature . . . . . . . . . . . . . . . . . . . . . . . 132

7.4 Rabobank . . . . . . . . . . . . . . . . . . 135

7.4 .1 Local Banks . . . . . . . . . . . . . . . . . . . 135

7.4.2 Rabobank Netherlands . . . . . . . . . . . . . . 136

7.5 Methodology . . . . . . . . . . . . . . . . . . . 138

7.6 Data . . . . . . . . . . . . . . . . . . . . . . 139

7.7 Results . . . . . . . . . . . . . . . . . . . . 143

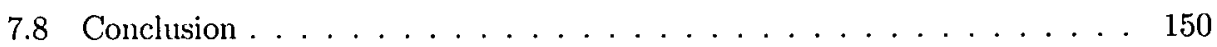

8 Conclusion 153

8.1 Limitations . . . . . . . . . . . . . . . . . . . . 153

8.1 .1 Market Power . . . . . . . . . . . . . . . 153

8.1 .2 Efficiency . . . . . . . . . . . . . . 153

8.1 .3 Problem Statement . . . . . . . . . . . . . . . . . . 154

8.2 Recapitulating. . . . . . . . . . . . . . . . . . 154

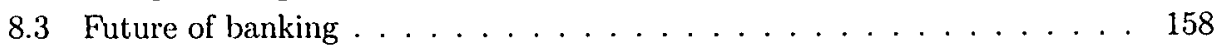

$\begin{array}{ll}\text { References } & 159\end{array}$

Samenvatting (Summary in Dutch) $\quad 174$

$\begin{array}{ll}\text { Professional Curriculum Vitae } & 179\end{array}$ 


\section{List of Tables}

1.1 Structure of European Banking Markets . . . . . . . . . . . . . . . 2

4.1 Types of Banks . . . . . . . . . . . . . . . . 61

4.2 Frequency per Year . . . . . . . . . . . . . . . 62

4.3 Banks Included . . . . . . . . . . . . . . . . . . . 63

4.4 Summary Statistics . . . . . . . . . . . . . . . . . . . . . . . . . . . . . . . . . . . 64

4.5 Likelihood Ratio Test . . . . . . . . . . . . . . . . . . . . . . . 66

4.6 Estimation Results under Cost Minimization (Model 1) . . . . . . . . 67

4.7 Estimation Results under Profit Maximization (Model 2) . . . . . . . . . 68

4.8 Summary Statistics Cost Efficiency and Profit Efficiency . . . . . . . . 69

4.9 Independent Samples Large Vs Small Banks . . . . . . . . . . . . . . . . 72

4.10 Independent Samples Test Large and Small General Banks . . . . . . . . 73

4.11 Independent Samples Tests Small General and Specialized Banks . . . . . 73

4.12 Independent Samples Tests Large General and Small Specialized Banks . 74

5.1 Structure Dutch Deposit Market . . . . . . . . . . . . . . . . 81

5.2 Descriptives Full Sample . . . . . . . . . . . . . . . . . . 84

5.3 SCP Model with $\mathrm{C}_{3}$ Concentration Ratio . . . . . . . . . . . . . . . 86

5.4 SCP Model with HH Concentration Variable . . . . . . . . . . . . . 86

5.5 The Cournot Model . . . . . . . . . . . . . . . . . . . . 91

5.6 SCP-Model with Traditional Efficiency Hypothesis . . . . . . . . . . . . . 92

5.7 SCP-Model with Modified Efficiency Hypothesis . . . . . . . . . . . . . . . . . 94

5.8 Cournot-model with Efficiency Hypothesis . . . . . . . . . . . . 95

6.1 Synopses of European Bank Efficiency Studies . . . . . . . . . . . . . 102

6.2 Descriptives . . . . . . . . . . . . . . . . . 111

6.3 Cost and Profit Frontier Models for European Banks . . . . . . . . . . . 114

6.4 Economies of Scale Results for European Banks . . . . . . . . . . . . . 115

6.5 Economies of Scale Results for U.S. Banks . . . . . . . . . . . . . . . 116

6.6 Cost and Profit Frontier Models for U.S. Banks . . . . . . . . . . . . . . 117

6.7 Tests for Mean Differences in Economies of Scale in Europe and U.S. . . 118

6.8 Dummy Cost Frontier Models (Dummies) . . . . . . . . . . . . . . 119

6.9 Dummy Cost Frontier Models . . . . . . . . . . . . . . . . . . . . 120

6.10 Cost Efficiency: Independent Sample Tests . . . . . . . . . . . . . . . 121

6.11 Dummy Profit Frontier Models (Dummies) . . . . . . . . . . . . . . . 122

6.12 Dummy Profit Frontier Models . . . . . . . . . . . . . . . 123 
6.13 Profit Efficiency: Independent Sample Tests . . . . . . . . . . . . 124

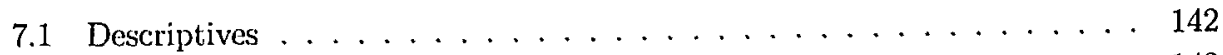

7.2 Table Cost Efficiency . . . . . . . . . . . . . . . . . . . . . . . . . . . . . . . . . 14

7.3 Cost Frontier . . . . . . . . . . . . . . . . . . . . . . . . . . . . . . . . . . . . . . . . 14

7.4 Cost Efficiency - Regional Impact . . . . . . . . . . . . 146

7.5 Cost Efficiency - Provincial Impact . . . . . . . . . . . . . . . . . . 146

7.6 Table Profit Efficiency . . . . . . . . . . . . . . . . . . . . . . . . . . . . . . . . . . . . . . .

7.7 Profit Frontier . . . . . . . . . . . . . . . . . . . . . . . . . . . . . . . . . . . . . .

7.8 Profit Efficiency - Regional Impact . . . . . . . . . . . . . . . . 149

7.9 Profit Efficiency - Provincial Impact . . . . . . . . . . . . . 150 


\section{List of Figures}

2.1 The Price-Concentration Relationship . . . . . . . . . . . . . 16

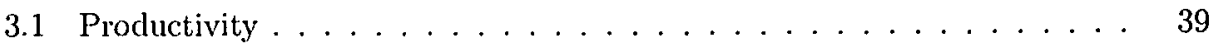

3.2 Efficiency ............................ 40

4.1 Distribution Bank Specific Cost Efficiency Scores . . . . . . . . . . . 65

4.2 Distribution Bank Specific Profit Efficiency Scores . . . . . . . . . . . 65

4.3 Scatter Plot of Cost Efficiency and Profit Efficiency . . . . . . . . . . 69

4.4 Cost Efficiency Trend . . . . . . . . . . . . . . . . . . . 70

4.5 Profit Efficiency Trend . . . . . . . . . . . . . . . 70

5.1 Structure Dutch Deposit Market . . . . . . . . . . . . . . . . . 80

5.2 Lorenz Curve Dutch Deposit Market . . . . . . . . . . . . 82

6.1 Mean Cost and Profit Efficiency for Large Banks by Country . . . . . . . 125

7.1 Organization Structure Rabobank . . . . . . . . . . . . . . . . . . . . . . . . . . .

7.2 The Netherlands . . . . . . . . . . . . . . . . . . . . . . . . . . . . . . . . . . . . . . . . . . . . . .

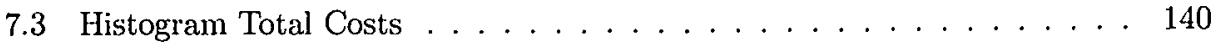

7.4 Histogram Profit . . . . . . . . . . . . . . . . . . . . . . . . . . . . . . . . . . . . . . . . . .

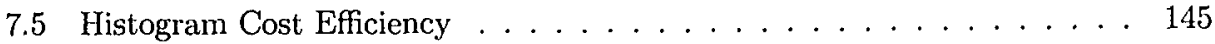

7.6 Histogram Profit Efficiency . . . . . . . . . . . . . . . . 147 


\section{Acknowledgements}

Writing a thesis is like playing a waterpolo match. In waterpolo, I have always felt comfortable playing defense, while keeping true to the saying that 'offense is the best defense'. In doing so, however, I enjoy giving a good pass more than scoring. I think that, combined, these preferences have put their mark on this thesis.

Looking back, I hope the thesis captures the spirit of constructive criticism. Also, in keeping with the comparison in the opening sentence of these acknowledgements, the thesis reflects my interest in applying techniques and empirical work. I have tried, however, to 'play' with the right mix of technical skills, strategic skills, endurance and strength. Much aware of my own limitations in this respect, I thank the reader for bearing with me and express the hope that he/she finds this thesis interesting reading.

Writing a thesis is like playing a waterpolo match: finishing the match in style requires a team effort. I cherish good team play and feel fortunate to have been a member of several excellent teams.

First, I want to thank my colleagues at the department of economics of Maastricht University for their advice, encouragement and criticism. My special thanks for their contributions goes to Bertrand Candelon, Erik de Regt, Mark Sanders, Maarten-Pieter Schinkel and Bas ter Weel. Also, I want to thank Sylvia Beenen and Susan Roggen for making my working life easier and more fun.

Second, I want to thank my supervisory committee for their criticism. I enjoyed your comments, and feel my work has greatly benefited from your critique.

Writing a thesis is like playing a waterpolo match: preparation is everything. For his part in helping me prepare for the defense, I want to say thanks to Johan van Amersfoort. Also, I want to thank Jack de Weerdt for his kind assistance with 'defense day' arrangements.

Writing a thesis is like playing a waterpolo match: feedback is essential. For his highly critical attitude and unusually useful comments throughout I thank Allard Bruinshoofd. I look forward to joint research. Likewise, I want to thank Franz te Lam, who is the reason I use waterpolo analogies in the first place. I am greatful for years of real team play and many a lesson in 'sportiviteit'.

Writing a thesis is like playing a waterpolo match: cooperation is everything. I thank Rabobank Nederland for keeping true to their cooperative nature. Your openness, help and involvement made working with you a true pleasure. I especially want to thank Wim Boonstra, Paul van de Velde and Cees van der Woude for their ongoing support. 
Writing a thesis is like playing a waterpolo match: international games are especially rewarding. For their support, enthusiasm and great hospitality I thank the Hansen family, San Antonio, Texas.

I also want to express my thanks to Karie and Wes Kolari, College Station, Texas. I hold you responsible for my totally biased view of the wonderful climate, academic and otherwise, in Aggieland. Gig 'em.

Writing a thesis is like playing a waterpolo match: it takes three to make a good defense. I thank Mindel van de Laar and Ben Kriechel for being 'paranimf'. Their constructive remarks, kind assistance and many critical comments (personal and otherwise) benefitted my work greatly. Many thanks, and I hope to return the favor.

Writing a thesis is like playing a waterpolo match: good coaches are hard to get by. I first thank my assistant coach, Jim Kolari. I am still amazed by the fact that upon our first meeting you took the risk of collaborating with me. Working with you has been rewarding in every way, and I hope we can continue the collaboration for many years to come.

I express special thanks to Clemens Kool. It has been instructive, rewarding and fun to work with you. Looking back, I realize how my gratitude extends far beyond this thesis. And looking forward, I am grateful and excited that we can continue working together.

Writing a thesis is like playing a waterpolo match: nothing like a good home crowd. I believe that a sense of curiosity and an interest in learning are first and foremost the result of upbringing. I credit my parents, Jaap and Mieke Bos, for this belief. I am grateful for their support, especially given the fact that it always came without pressure but with genuine interest.

Writing a thesis is like playing a waterpolo match: there is more in life. For her relentless support, her efforts correcting this thesis and her patience, I thank Brooke. For her interest in my 'hobby', her friendship and her trust I thank her. For making me see that there is more in life and for her love, I am more grateful than I can say. 


\section{An Intro to European Banking Markets}

\subsection{Introduction}

Most industries go through waves of consolidation and expansion, as firms are taken over, merge, enter and exit. As a market develops, opportunities arise, niches develop and new firms may enter. The market expands and firms grow in size. In a fast-paced rat race, where the motto appears to be 'eat or be eaten', mergers make the headlines. CEOs cite 'synergy', 'shareholder value' and 'positioning' as reasons for aggresive growth strategies. When the market slowly becomes saturated, demand weakens and firms develop survival strategies. A renewed interest in cost cutting and lay-offs accompanies a focus on 'core competencies' and the possible sale of previously diversified assets. During this mayhem, the small rogue player may enter the market and the big players prove whether they are indeed 'too big to fail'. After a consolidation wave, when the dust has settled, survivors take time to survey the battlefield before the game starts over.

These archetypical business cycles drive investments, stimulate (job) growth and help shape the economy. This holds even more so when the industry that rides these waves is the banking industry. Through their traditional role as intermediaries and their subsequent involvement in capital allocation, banks play a crucial role in most economies. In Europe, where bank-based systems (as opposed to market-based systems) dominate, this role carries particular weight. European banks, especially on the continent, are among the largest and most influential firms when it comes to size, profits and their role in the (national) economy. Table 1.1 demonstrates that in many European countries total deposits amount to over $100 \%$ of GNP ('Capitalization').

Striking in this respect is the fact that a significant portion of this capital is in the hands of a very small number of players. For example, the five largest banks own over $70 \%$ of the market in Denmark and Greece, and over $80 \%$ in the Netherlands (cf. 'Concentration' in table 1.1). Filtering out public banks and mutual banks would further increase this number. As a matter of fact, deposits held by commercial banks are in the hands of a few firms in most European markets. What is more, the same holds for loans, mortgages and even - albeit to a lesser extent - brokerage services. And in most countries the market share of foreign banks is still small (cf. 'Foreign' in table 1.1).

Important is the relationship banks maintain with their clients. Wholesale banking is in many countries a matter of 'relationship banking'. Banks have significant shareholdings in major companies, sit on boards and engage in preferential lending. Companies in return are supposedly rewarded by better lending conditions, as their 'Hausbank' is better able to assess risk and return of investments. Likewise, in retail banking cross-selling is an important feature. Demand deposits become not just a product in themselves, but the 
beginning of a customer relationship that leads from car and travel insurance to mortgages and investment services. In short, banks are keen on establishing close ties with their customers, and they are known be successful at it: switching costs are high, both for wholesale and retail banking.

TABLE 1.1: Structure of European Banking Markets

\begin{tabular}{lrrrrr}
\hline Country & Donestic $^{a}$ & Foreign $^{a}$ & MS $^{b}$ & Concentration $^{c}$ & Capitalization $^{d}$ \\
\hline Austria & 0.4 & - & - & - & - \\
Belgium & 37.0 & 35.2 & 64.3 & 59.3 & 161.4 \\
Denmark & & & & \\
Finland & 69.5 & - & 92.2 & 73.5 & 87.1 \\
France & 44.5 & 0.8 & - & & - \\
Germany & 24.2 & 13.5 & 53.6 & 41.2 & 79.6 \\
Greece & 32.0 & 1.8 & 39.7 & 27.2 & 191.4 \\
Ireland & 11.0 & 5.3 & - & 77.6 & 106.7 \\
Italy & 61.7 & 21.4 & - & - & 105.9 \\
Luxembourg & 12.3 & 3.0 & 56.4 & 35.6 & 116.4 \\
Netherlands & - & - & - & 29.9 & - \\
Norway & 61.2 & 13.0 & 47.8 & 84.4 & 221.2 \\
Portugal & 41.2 & - & - & - & - \\
Spain & 6.8 & 4.2 & - & 55.8 & 88.3 \\
Sweden & 49.0 & 11.0 & 52.6 & 45.0 & 123.4 \\
Switzerland & 52.9 & 2.9 & - & - & - \\
United Kingdom & 53.4 & 11.2 & - & - & - \\
a & 31.8 & 53.3 & 56.7 & 38.1 & 186.1 \\
\hline 1988, \% of summed total assets. 'Domestic'measures only conmercial banks (not
\end{tabular}

including public and mutual banks), ${ }^{b}=$ combined market share in deposits of commercial banks (including foreign, excluding savings banks). ${ }^{c}=$ market share, \% of total assets of the

five largest banks, ${ }^{d}=$ deposits in \% of GNP, 1986 - for France interbank deposits.are excluded, ${ }^{e}=\%$ of total deposits, ${ }^{f}=$ Foreign banks included are branches, ${ }^{a}=\%$ of total credit. Sources: Gardener and Molyeneux (1990), Molyneux, Altumbas, and Gardener (1997) and Economic: Rescarch Lt.d. (1997).

Finally, evidence suggest that the tidal movement from consolidation to expansion is to a large extent absent in banking. Of course, diversification has led to an increase in the number of services offered by banks. But direct competition from non-bank financial institutions was until relatively recently not very important. And what is more, the entire 20th century shows the same picture: a constantly consolidating banking industry, where ever more is owned by ever few. ${ }^{1}$

That picture however, changes during the $1990 \mathrm{s.}^{2}$ In the European Union, the combination of the creation of the Single Market, further deregulation, globalization and increased

\footnotetext{
${ }^{1}$ Cf. DNB (1986).

${ }^{2}$ For excellent overviews, see Molyneux, Altunbas, and Gardener (1997) and Canals (1994).
} 
competition from non-bank financial institutions led to possible opportunities for market entrants and potentially stepped-up competition. At the same time, technological advancements, ICT investments and the increased pressure from the stock market had a less uniform impact on the face of Europe's financial landscape. In a recent overview of developments in European banking, Phil Molyneux states that "[G]iven the increasingly wide range of financial service providers, the larger 'domestic' market created by EMU and the current competitive environment, concentration in domestic commercial banking markets is becoming a less relevant antitrust issue" [Molyneux (2000), p. 1]. However, partially spurred by these developments, the beginning of the 1990 s saw a new merger wave. Driven by earlier mergers, this new trend led to what was conceived by many as a critical situation: now, market concentration rose to levels where serious concern was raised over the impact mergers had on competition. This concern was also fed by what was generally expected to be the next step: a series of cross-border mergers.

\subsection{Problem Statement}

This thesis coincides and sympathizes with the above-raised concern. In what follows, I try to find explanations for European bank performance and behavior in the 1990s. In particular, I analyze two possible types of bank behavior. On the one hand, I consider the premise that a bank may exploit its relative size and market positition and reap excess profits. On the other hand, I consider a bank that - possibly driven by competitive forces - strives for an efficient, profitable production. And I keep in mind that both types of behavior are not necessarily mutually exclusive.

Important in the light of the description of the banking industry in the previous section is the fact that the extent to which banks engage in one type of behavior rather than the other has an impact on how we should perceive, criticize, govern and regulate that banking industry. A merger truly based on efficiency enhancements merits approval. It will, ceteris paribus, benefit customers who receive better service and/or pay lower prices. This merger then in turn improves asset allocation, lowers risk, stimulates investment and benefits the whole economy. However, if market power appears to be the real motive for that same merger, customers can be expected to suffer from worse service and/or higher prices. Other banks, and their customers, may then suffer as well. The main question raised in this thesis is therefore: to what extent is bank performance driven by market power and to what extent is it driven by efficiency?

\subsection{Place in the Literature}

In order to answer the above raised questions, I relate to two broad types of literature. First, I relate to market power studies of European banking markets. These studies attempt to provide a direct measure of the way market power influences bank performance. Thus, in an indirect way, they try to capture bank behavior, as market power results from 
oligopolistic (and possible collusive) behavior. Market power studies in banking abound for the United States. They are of a very applied nature and often lack real theoretical underpinning. Most popular is the so-called structure-conduct-performance paradigm, which relates performance to market structure. The rise in concentration of most European banking markets as well as the increased availability of firm-level data explain the increase in market power studies of European banking markets that started already in the second half of the 1980s and continued in the 1990s. Evidence however is mixed and therefore far from conclusive.

Second, I use developments in efficiency benchmarking. The rise in concentration as well as advances in econometric techniques, the increased availability of firm-level data and the increased integration of the European economies have sparked interest in and enabled measurements of the relative efficiency of Europe's banks. As a result, two streams of efficiency literature have developed. One stream is carried by economists who previously applied their techniques to agriculture, manufacturing and other industries where efficiency benchmarking has a long tradition, where production functions are relatively straightforward and where data are of high quality. These studies focus mostly on methodology, and spend less time on choice of data and interpretation of results. The other stream stems from the same economists that developed a large portfolio of market power studies. These studies are largely of an applied nature, and difficult to compare since information on estimation techniques and robustness of results is scarce. Both streams however, provide intricate supportive evidence for an analysis of bank behavior. But they seldom capitalize on the relationship between efficiency, bank performance and bank behavior.

In the following chapters I try to take the best of both worlds. I employ market power models and efficiency models separately as well as combined. I also try to overcome some of the weaknesses signaled here to enhance my analysis of the role of market power and efficiency in explaining European bank performance - even if in doing so I must sometimes limit the geographic scope of the analysis.

\subsection{Set-up}

In chapter 2, I present a critical analysis of structure-conduct-performance studies of European banking markets. I explain the weaknesses in tests of this hypothesis and related market power models. Also, I emphasize how the changes in European banking should lead to adaptations of the traditional models by recapitulating the major trends in European banking. I additionally suggest some improvements to these models.

Subsequently, in chapter $3 \mathrm{I}$ turn to efficiency models for alternative and additional explanations of bank performance. I first shortly review bank behavior and try to shed additional light on the inadequacy of many market power models to fully incorporate it. I build a simple analytical framework that allows me to track how behavior translates into production and onwards to efficiency measurement. In doing so, I keep in mind the relationship between efficiency and competition and I distinguish between cost minimization 
and profit maximization. Then, I introduce a range of efficiency measures and explain my preference for one of them in the light of the discussion in this dissertation. I end by describing an efficiency benchmarking model that I will use in subsequent chapters.

Starting with chapter 4 , I present an empirical investigation into the relationship between efficiency and competition. I analyze the Dutch banking market, a forerunner in Europe with respect to many of the trends signalled in chapter 2 and the market with the highest concentration. In particular, I investigate the efficiency of different types of banks. From this I then draw lessons for the competitive conditions in this highly concentrated market.

Chapter 5 follows naturally. In it, I return to the traditional market power models of chapter 2. I start with a structure-conduct-performance model and use it to assess competitive conditions on the Dutch banking market again. Next, I present an alternative model that is intended to solve many of the problems associated with the structureconduct-performance model. I compare results of both models. And I use the findings from chapter 4 to further improve results. Combined, chapters 4 and 5 then present a more complete picture of the relationship between performance, market power and efficiency on a banking market.

In chapter 6, I expand the definition of that banking market while narrowing the selection of banks. In an effort to put the European situation in perspective, I compare the efficiency of independent large banks in Europe and the United States. Again comparing cost minimization with profit maximization, I can infer possible explanations for efficiency differences and relate them to differences in market structures, regulation and economic structures. In doing so, I solve many of the data problems typically associated with efficiency studies. And I look at what is generally considered to be the next consolidation wave: cross-border mergers.

A different focus leads to chapter 7. In it, I assess the role of local market conditions in explaining efficiency. In particular I ask the question to what extent a bank's efficiency is influenced by the conditions in the market, and to what extent it is the result of managerial decisions. In doing so, I distinguish between wholesale and retail banking. I also single out location decisions as an important explanatory factor.

Summing up, chapters 2 and 3 present the theoretical framework for this thesis. In chapters 4 and 5, I use the Dutch banking market as a case study to apply, evaluate and refine this theoretical framework on a single market. Chapters 6 and 7 then focus in on the potential for mergers and the role of local market conditions, respectively. Finally, in chapter $8 \mathrm{I}$ review and integrate the evidence found. I emphasize limitations of the analyses presented here. And I draw some lessons for the future of European banking. 



\section{Market Power in European Banking: A Critical Review of the SCP Approach}

\subsection{Introduction}

As explained in the previous chapter, Europe's banking markets have gone through a series of drastic changes in the last two decades. In the European Union (EU), the market for financial services was liberalized with the First Bank Coordination Directive of 1977, establishing among other things the free movement of capital. The White Paper of 1985 and the Second Banking Coordination Directive of 1988 built on it by establishing a single market for financial services. As of January 1, 1993, the EU's banking markets were subject to the principle of Home Country Control; EU banks operating in another EU country could do so under the condition that they met regulatory standards in their home country. Likewise for banks from outside the EU it was now sufficient to obtain a banking license in one EU country in order to be allowed to provide financial services throughout the EU.

At the same time, technological advances and an increasingly market-based economy were seen as driving forces behind a long series of mergers and takeovers that led to consolidation in most of Europe's banking markets. ${ }^{\text {I }}$ Designed to ensure a healthy and competitive banking industry, the deregulation was intended to increase competition and consumer welfare by lowering entry barriers, removing price constraints and promoting the free movement of capital. In practice however, it may have contributed to the higher concentration in Europe's banking markets. The combination of both consolidation and deregulation has therefore proven to be a fertile soil for analyses of the competitive dynamics of European banking markets. The objective of most studies is to analyze the competitive dynamics of a banking market, with the possibility of singling out specific players in this market (e.g. merged banks) and the determinants of their (relative) performance. The literature presents several ways to conduct such an analysis. To start with, there exists a vast array of research on the estimation of production functions to evaluate the presence and importance of economies of scope and scale in banking. Recent work in this area hinges on the choice of bank- and/or branch-specific analysis. I will review this literature in more depth in chapter 7. Another field of interesting research is that on hazard rate studies, where the probability of a bank's survival is modelled to be a function of market and firm characteristics.

\footnotetext{
${ }^{1}$ For the purposes of the present study, there is no significant difference between a merger and a takeover. A possible merger premium may lead to a (temporary) decrease in carnings per share, compared to a (hostile) takeover. Performance as it is measured here, however, is always based on profits per se and generally independent of market capitalization.
} 
In this chapter, I present a critical review of the use and usefulness of the most popular type of analysis of market power in European banking. I focus on studies that test the Structure-Conduct-Performance hypothesis [SCP hypothesis]. ${ }^{2}$ Used extensively in the Anglo-Saxon literature since the 1950s, the SCP hypothesis is a basic blueprint in which to capture the impact (a change in) market structure has on the performance of the companies in the market. The SCP hypothesis and related hypotheses allows for a comparison between firms in different locations (with correspondingly different market structures) or between firms in the same location over time (when market structure changes). Moreover, more recent SCP analyses also use the concept of strategic groups, mobility barriers, and firm-specific characteristics to account for intra-industry heterogeneity and performance variation.

For the United States, empirical evidence abounds. It is also for the United States that the above-mentioned concepts are most commonly used, which is no surprise given that they are mostly based on existing regulatory barriers. For European banking markets, the number of studies is more limited but nevertheless extensive. ${ }^{3}$

In the next section, I give a short description of some of the essential characteristics of banking markets. In section 2.3, I describe the SCP hypothesis and give a short overview of studies employing the SCP hypothesis to study the existence of market power on European banking markets. The roles of structure, conduct and performance are discussed, with emphasis on the problems encountered in the literature. Section 2.4 continues with a critical discussion of some empirical matters that recur in estimations of SCP models. I conclude in section 2.5 .

\subsection{Bank Competition}

"A bank is a financial intermediary that participates in the payment system and finances entities in financial deficit (typically the public sector, non-financial firms, and some households) using the funds of entities in financial surplus (typically households)". "In order to specify more precisely what a bank is, I start with a closer look at the concept of intermediation in section 2.2.1. In section 2.2.2, I analyze the role of banks as financial intermediators.

\footnotetext{
${ }^{2}$ Throughout this chapter, I refer to Structure-Conduct-Performance [SCP] analyses in several ways. This practice is in line with most of the literature on the subject. The term 'SCP analysis' is used as a general reference to the subject. The terms 'SCP hypothesis' refers to the conceptual aspects of the SCP analysis, also known as the SCP paradigm. The term 'SCP model' refers to the model to be estimated.

${ }^{3}$ See Molyneux and Thornton (1994) for an overview.

${ }^{4}$ Dewatripont and Tirole (1994), p. 13.
} 


\subsubsection{Intermediation}

An intermediary is "one who buys in order to sell again from a principle of gain". 5 Financial intermediation in its purest form entails buying funds (taking deposits), and then selling them (extending loans). Economic agents may decide on using intermediaries instead of going to the markets directly. First of all, financial intermediation can enlarge the consumption/investment possibilities of economic agents: it makes it possible for any individual agent to spread his/her consumption over time. A second reason, dependent on the overall degree of risk aversion in the economy, is the fact that banks can spread risks more efficiently (i.e. less costly) and to a larger extent than individual economic agents. To the economy as a whole, the presence of banks then improves the terms of trade and through a "redistribution of saving[s] and investment [results in] a more efficient way of allocating resources" (Yanelle (1989), p. 295). This in turn promotes economic growth and is a Pareto improvement for the economy as a whole.

A first reason why banks can perform this intermediation role is because of transaction costs. Banks are more efficient in finding c.q. bringing together borrowers and lenders than individual borrowers and lenders are. In their role as financial intermediaries, banks can transform size, maturity and (liquidity) risk of funds. Put differently, from a cost perspective it is assumed to be less costly to bring together both loans and deposits in one place. Banks then do nothing but make use of the existing economies of scale in intermediation.

Secondly, banks can solve problems caused by asymmetric information. They are assumed to have a better overview of the (quality and quantity of) excess supply of and demand for funds that exists in the economy. As a consequence they can allocate these resources in a more efficient way. In doing so they are also able to decrease the overall risk that economic agents rum, both by spreading it and by pricing it more accurately. It is worthwhile in this respect to mention the increase of securitization of loans in Europe, following the trend set by U.S. banks. Note that even if information is available at the same costs to both intermediaries and other economic agents, the latter can - as a group - be better off with banks than without: this is the case because of free-riding. With free-riding behavior "customers of a bank have little individual incentive to perform [...] monitoring functions" (Dewatripoint and Tirole (1994), p. 32). ${ }^{6}$

The equilibrium number of banks that is required to optimally perform the role of financial intermediary is not clear-cut. One extreme case is when the equilibrium number of financial intermediaries is zero. This is the case where either banks have no comparative advantage (over financial markets) at all, or do not come into existence for game

${ }^{5}$ Yanelle (1989), p. 294. The quote is based on an article by James Stewart (1770), "An inquiry into the principles of political economy: Being an essay on the science of domestic policy in free nations" (J.J. Tourneisen, Basel).

"In fact, Dewatripoint and Tirole (1994) use this so-called 'representation hypothesis' to explain the specific governance and regulation of banks 
theoretical reasons. Yanelle (1989) explores both Walrasian general equilibrium theory and Bertrand type game theory. He finds a Walrasian model by its very nature (and the assumptions that describe it) not fit to explain the existence of financial intermediaries. Without a Walrasian auctioneer, and with the introduction of strategic behavior, a Bertrand approach seems better suited for an analysis of intermediation. A problem is the fact that intermediation means offering two prices at the same time. Think in this respect of two Bertrand models mirroring each other. A related problem then is whether intermediation (i.e. two prices offered by one economic agent) by definition excludes direct transactions taking place. Yanelle argues to the contrary and with the help of a model by Diamond (1984) concludes that "intermediation takes place if and only if indirect finance involves lower transaction costs than direct finance." Put differently, when economies of scale are absent every economic agent performs his/her own role as an intermediary. ${ }^{\top}$

Another extreme case is when the number of financial intermediaries is one. This would be the case of a natural monopoly. Or as Yanelle (1989) puts it: "[I]f intermediation takes places, then all transactions take place through the mediation of a single bank, which makes zero profits (because of the competitive pressure that the other banks exert on it)" (p. 289). ${ }^{8}$ This result is again based on the often cited Diamond model (Diamond (1984)). Diamond himself is aware of the limited potential of this model, and even though "the situation he describes is that of a natural monopoly $[\ldots]$ it is not clear what the market outcome should be in such a situation [i.e.: direct or indirect finance]" (Yanelle (1989), p. 289). The kind of contestable markets suggested here requires that there are no entry barriers of any significance, which in banking seems far from realistic. The key thought is that if there are economies of scale in financial intermediation, the ideal case would be a situation where these economies of scale are realized to their full extent, while at the same time competitive pricing takes place. However, this is by no means only possible with a natural monopoly and no entry barriers. Franklin Allen in this respect notes that "[I]f there are differences in information sets, an increase in the number of banks the firm deals with may be advantageous for all. The problems associated with co-ordinating negotiations that are likely to occur as the number of banks increases, however mean that it will usually be worth only a few banks lending" (Mayer and Vives (1992), p. 102). Therefore, according to Allen, "[B]anks will be a good way to provide finance in traditional industries [...] where the technology is well known and there is a wide consensus on how things should be done. Here banks can monitor firms effectively and take advantage of the scale economies in monitoring" (idem). In a multi-market setting the same analysis can lead to the extreme result that market power on one market (e.g. the market for loans) requires control of the other market (e.g. the market for deposits). ${ }^{9}$

${ }^{7}$ One can also think of this as an outcome in which the number of financial intermediaries is inifinite, or equal to the number of economic agents.

${ }^{8}$ See also chapter 1 of Freixas and Rochet (1997).

${ }^{9}$ See also Ali and Greenbaum (1977) and more recently Chiappori, Perez-Castrilo, and Verdier (1995). 
Thirdly, there may be a finite number of financial intermediaries. Bester (1995) introduces a 'bargaining model of financial intermediation' in which he focuses on the fact that banks employ funds that are not their own. The investor relies on the bank to negotiate a contract with an entrepreneur, in what is called delegated bargaining. Thus, banks face only limited liability. This can lead banks to prefer very risky investments. The way economic agents can keep banks from doing this is by "mak[ing] search for low-risk projects sufficiently attractive for the intermediary" (Bester (1995), p. 212). The investor then rewards the intermediary with a profit for selecting (low-risk) projects. As a result the number of intermediaries depends on the search costs, and the profits they make are a result of the extent to which the investors can monitor the intermediaries. In addition, banks may use tied sales contracts (Chiappori, Perez-Castrilo, and Verdier (1995)). Tied sales contracts are for instance attractive in the case of deposit rate regulation, where undercutting is ruled out for deposits, and the profit margin on deposits is not subject to any price competition. This was for instance the case in France and Spain, where deposit regulation was in place and eventually led to an over-expansion of the banking market. ${ }^{10}$

Recapitulating, from the number of banks present on a market little can be concluded about the competitive conditions in that market. The (geographic) definition of the market and its contestability can also make it difficult to assess whether banks are capable of capturing monopoly rents. This is another set of reasons that help explain why in SCP and related studies bank behavior is deduced from the relation between structure and performance rather than from market structure per se. It may also help explain why even for highly concentrated banking markets evidence found in favor of market power is sometimes scarce.

\subsubsection{Beyond Intermediation}

Sofar I discussed the intermediary role of banks: the provision of deposits and loans to households and firms. In most SCP analyses this constitutes the core of banking. In reality of course there is a whole range of other activities in which banks engage. These activities include investment or corporate banking, insurance activities and investment/pension funds.

According to Steinherr and Huveneers, "the question whether universal banking is more efficient than specialised banking depends on whether there are economies of scope or not" (Steinherr (1992), p. 53). It is not difficult to see the relation with SCP analyses: whenand wherever economies of scope exist there are more profit opportunities. Steinherr and Huveneers give three arguments in favor of economies of scope as a driving force behind universal banking. First, the average cost of a service can be lower if a bank offers a wide range of services. This could give a bank a competitive edge in certain markets. Second, since financial institutions produce highly substitutable goods diversified banks

\footnotetext{
${ }^{10}$ See Melitz (1990) for the French banket market and Fuentelsaz and Salas (1994) for a discussion of the Spanish banking market. Note that these tied sales contracts are a very special kind of economies of scope, possible only with the right regulatory framework.
} 
can more easily react to possible substitutions of consumers of one service (e.g. a savings deposit) with another service (e.g. an investment fund). The third argument relates to the role of asymmetric information in universal banking: the existence of economies of scale in information gathering means banks are able to spread the fixed costs of information gathering over a wider array of services.

Summing up, the extension from pure financial intermediation to universal banking can be explained in much the same way as the existence of banks per se.

\subsection{The SCP Hypothesis}

In the previous section, I highlighted some of the essential characteristics of banks. This section continues with a discussion of how SCP analyses are used to measure competitive forces on the markets in which banks operate. It discusses a series of SCP analyses on both U.S. and European banking markets. The emphasis is not so much on the results obtained by different authors, under different circumstances, in different markets. Rather, the discussion centers on recurring obstacles, where they come from and how they are dealt with. Section 2.3 discusses the fundamentals of the SCP hypothesis. First, in section 2.3.1 I introduce the basic setup for a test of the SCP hypothesis. Next, in section 2.3.2 I discuss the way market structure is incorporated in SCP analyses. In section 2.3.3, I briefly investigate the role of conduct. Then, in section 2.3.4 I discuss performance measurement and other variables included in SCP analyses. In section 2.4, I continue with a number of empirical issues. I briefly return to the role of regulation in section 2.4.4. In section 2.4.2, I discuss some estimation problems encountered and in section 2.4.3 I investigate some alternatives to the assumption that banks are pure profit maximizers. Finally, in section $2.4 .4 \mathrm{I}$ briefly summarize the role of regulation as a catalyst and a restriction in SCP analyses.

\subsubsection{The SCP Model}

SCP models are loosely based on Chamberlin's oligopoly theory (Chamberlin (1933)) and seek to explain firm performance through market structure conditions, such as number and size distribution of firms and entry condition in the market. The hypothesis that structure determines performance relies on the assumption that firm conduct is the direct result of market structure. The bulk of the more recent studies originates from the late 1980 s and early 1990s. ${ }^{11}$

Rationales for testing the SCP hypothesis on banks include the stability, efficiency and competitiveness of banking markets and are usually based on concerns about the effects of bank consolidation on consumers (Molyneux, Altunbas, and Gardener (1997) and Economic Research Ltd. (1997)). Especially in Europe's highly concentrated banking

\footnotetext{
"After that, attention shifted from market power studies to more direct tests of the differences in performance between financial institutions. An example is the analysis in chapter 5 .
} 
markets, banks might be able to reap oligopoly profits on their home markets - perhaps to cross-subisidize their international competitive efforts (see also Cecchini (1988) and Price Waterhouse (1988)).

The basic SCP model can be formulated as follows (where $t$ is time): ${ }^{12}$

$$
P_{t}=f\left(M_{t}, D_{t}, C_{t}\right)
$$

where $P$ is a performance measure, $M$ a set of market structure variables, $D$ a set of demand variables and $C$ a set of firm/product-specific control variables such as cost variables.

Since a solid theoretical foundation of the model is missing, the role of conduct is not clear. In addition, although both for performance measurement and market structure measures there is a wide range of variables used in the literature, no agreement whatsoever exists as to which measures are superior. ${ }^{13}$ Performance measures range from purely financial measures such as profits, return on equity [ROE], and return on assets [ROA] to more eclectic measures such as market share stability, expenses and the number of bank employees.

Market structure variables used include a Herfindahl index, the combined percentage market share of the three or five largest banks, and the total number of banks. Demand variables $D$ control for market changes and include such variables as total demand and GNP. Firm-specific control variables $C$ are as wide ranging as cost/income ratios, capital ratios, typology dummies and firm size.

Closely related to the SCP hypothesis is the Efficiency hypothesis, which attributes differences in performance to differences in efficiency (Goldberg and Rai (1996) and Smirlock (1985))..$^{1-4}$ According to the Efficiency hypothesis, both high concentration and good performance result from high efficiency. When this hypothesis is tested against the SCP hypothesis, it leads to identification problems, since the same market structure variable behaves similarly for both cases [see also the discussion in section 5.5].

Another alternative hypothesis is the so-called 'Quiet Life' hypothesis. It states that banks with market power will be able to achieve a superior risk/return relationship than banks without market power. Tests of this hypothesis can be found in e.g. Clark (1986) and Gilbert (1984). As reported by Molyneux, Altunbas, and Gardener (1997), results from test of this hypothesis frequently show that the opposite holds. This obervation in turn is related to the 'too big to fail' argument that large banks expecting a bail-out demonstrate moral hazard behavior.

\footnotetext{
${ }^{12}$ See Molyneux, Altunbas, and Gardener (1997), p. 97. A seminal reference is Rhoades (1977).

${ }^{13}$ See chapter 4 and appendix I of Molyneux, Altunbas, and Gardener (1997), Gilbert (1984), Heggestad (1979) and Berger (1995) for overviews of SCP studies of banking markets.

1.'Additional 'alternative' hypotheses are the Market Share Hypothesis, the Product Differentiation Hypothesis, the Expense Preference Hypothesis, and the Edwards-Heggestad-Mingo Hypothesis. I refer to Molyneux, Altunbas, and Gardener (1997) for an overview.
} 
Despite its popularity, the SCP approach has encountered criticism as well, mainly from the recent developments in the field of industrial organization (IO). This research strand emphasizes the necessity of adapting the standard micro-economic analysis when studying the banking sector. More precisely, a renewed interest in the process of (financial) intermediation has put the use of any standard competition framework underlying the SCP framework in question. Examples include spatial competition models, multi-contact theory (multi-products, multi-markets), a micro-economic analysis of cross-subsidization and the effects of minimum/maximum (deposit) rates, and the paradoxical relationship between 'natural' oligopolies and efficiency. Combined, these analyses have the potential to provide excellent tools for explaining a significant part of the characteristics of current banking markets and significantly alter the traditional SCP analysis. However, the difficulty in obtaining sufficient and reliable micro data is even more apparent in this kind of research, and at present serves as a hard-to-infringe threshold for empirical analysis. As a result, mostly these alternative market power models may offer theoretical advances, but do not differ much when tested empirically.

\subsubsection{Structure}

One of the prime 'exogenous' variables in any SCP analysis is a concentration ratio. In general it is meant to be a proxy for the degree of competition in the market. A high concentration ratio indicates little competition and vice versa. And a high degree of competition in turn suppresses profits.

In general, the structure of a market is characterized by the number of firms and the distribution of market shares over these firms. Although some authors (Gilbert (1984), Altunbas and Molyneux (1996b)) have also included the number of banks, most research is limited to the inclusion of one or more concentration ratios.

Haaf (2000) classifies concentration measures by weighting schemes and structure. ${ }^{15}$ Banks can be weighted by size or rank, with larger or smaller banks weighted more heavily. Concentration measures have a discrete structure if they include a discrete portion of the banks in the market. A summary structure results if the size distribution of all banks is used in constructing the concentration measure. In the literature, a wide range of concentration measures is in use. Most common is a simple concentration ratio:

$$
C_{m}=\sum_{i=1}^{m}\left(a_{i}\right)
$$

where $a_{i}$ is firm i's percentage market share, with $a_{i}>a_{i+1}>\ldots>a_{m}$. In a market with $n$ firms $m / n \leq C_{m} \leq 10$ for $m<n$. The majority of the SCP analyses use either a $C_{3}$ or a $C_{5}$ index. $^{16}$ Another concentration ratio that is often used is the Hirschman-

\footnotetext{
${ }^{15}$ See also Stich (1995).

${ }^{16}$ To my mind the most important reason for this is simply the fact that it has become common coin.
} 
Herfindahl-index: ${ }^{17}$

$$
H H=\sum_{i=1}^{n}\left(a_{i}^{2}\right)
$$

with $0<H H \leq 10,000$. This index emphasizes the relatively large firms in the market. A different approach, seldom used in SCP analyses, is the so-called Theil-coefficient:

$$
T H=\sum_{i=1}^{n}\left(a_{i} * \ln \left(\frac{1}{a_{i}}\right)\right)
$$

where $a_{i}$ is the market share in percentages. The larger $T H$, the less concentrated the market is.

A critique of structural measures like the simple concentration ratio is that there is no apriori cut-off point for banks to include in the concentration measure. Most common are $C_{3}$ and $C_{5}$ ratios. The choice for a specific number of banks to include seems to follow more from previous studies than from underlying fundamentals in the market. In addition, structural changes in other parts of the market are not captured by discrete measures. Summary measures, on the other hand, suffer from a different and more intrinsic problem: "it is possible to find corresponding measures of inequality for every summary measure of concentration" [Haaf (2000), p. 4].

To see why from a microeconomic point of view the choice of a concentration measure is far from trivial, one must recall the definition of market structure mentioned above. The structure of a market was said to be characterized by the number of firms and the distribution of market shares over these firms. Of the three concentration measures explained, the Theil index is best capable of taking this structure into account and give weight to average size and size differences. If all companies are of the same size, the Theil index is $\ln \left(\frac{1}{a}\right)$. The so-called redundancy coefficient, $R$, is defined as $\ln \left(\frac{1}{a}\right)-T H$. The smaller $R$, the more even the distribution of market shares in the market is. Thus, the redundancy coefficient allows for distinguishing between a numerical effect (the change in $\ln \left(\frac{1}{a}\right)$ ) and a distribution effect (the change in $T H$ ). A higher $R$ means the number of firms has gone up and/or market shares are more evenly distributed.

Another example of the impact of choosing a specific concentration measure was given by Heggestad (1984). In general, "the more concentrated a market, the greater is the probability that a firm will achieve the monopoly price-output configuration" (Stigler (1964), quoted on p. 649 of Heggestad (1984)). Heggestad and Mingo juxtapose Cournotand Bertrand-types of competition, and use the former to make a point: mutual interdependence and the recognition of it by all market participants finally leads to monopoly prices. More precisely, this will happen starting at a certain (relatively high) degree of

${ }^{17}$ Alternatives are the Rosenbluth index and the Hall-Tideman index. 
concentration. As Heggestad and Mingo put it, 'effective competition' is by then no longer existent. The situation is best represented by figure 2.1. ${ }^{18}$

FIGURE 2.1: The Price-Concentration Relationship

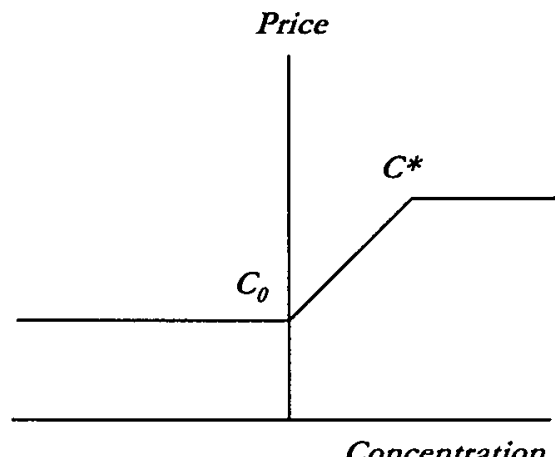

Here $C_{0}$ is the highest concentration ratio where perfect competition still exists. Beyond $C^{*}$ the departure of a bank from the market no longer influences price-setting by the other banks, who set their prices as if they were monopolists. From a cross-section survey of (car) loan and deposit prices in banking markets, Heggestad and Mingo estimate $C_{0}$ and $C^{*}$. The statistical evidence for effective competition (the area to the left of $C_{0}$ ) in banking markets is very weak. There are two other main determinants of prices in these banking markets: cost differences and differences in the price elasticity of demand. Regarding the former, Heggestad (1984) claim that "estimates indicate scale economies exist in banking but are small in magnitude" (p. 653). With respect to the elasticity of demand, per capita income and the growth of market demand are included as control variables. The evidence presented by Heggestad and Mingo therefore suggests that in highly concentrated markets the price effect that is supposed to result in monopoly rents is hard to measure. This is evidence in favor of the SCP analysis, which tries to circumvent this problem by not including prices and instead looking at the relationship between market structure and performance. But it also functions as a warning, making it even less easy to interpret the black box called 'conduct' in SCP analyses.

Summing up, there is little or no theoretical basis for the choice of a specific ratio. First, no relationship is established between a specific concentration ratio and the degree of (effective) competition. Second, there is no formal link between concentration on the one hand and average size - and standard deviation from it - of the firms in the market on the other hand. Third, a description of the two-way impact from/to concentration and other (control) variables like market size and the number of competitors is lacking.

${ }^{18}$ Adapted from Heggestad and Mingo (1977), p. 650. 
Aside from the more fundamental problems with measuring market structure, there are a number of empirical problems as well. Several authors have tried to compare different SCP studies, looking for differences and similarities and giving explanations for the 'performance' of SCP models.

Gilbert (1984), in a survey on both the SCP hypothesis and Efficiency hypothesis reviewed no less than 45 studies. Taking into account that several studies contain more than one version of an SCP model, the survey evaluates the performance of no fewer than 112 SCP analyses. In 61 cases, the concentration ratio used was significant. But in most of the SCP analyses reviewed, the authors found there was little - if any -difference between different concentration ratios. ${ }^{19}$ The final choice of a certain ratio was based on either previous studies, or quite simply on the fact that the ratio of choice was most significant.

The above-raised doubts with respect to the use of concentration ratios to capture market structure in SCP analyses merit a look at the ways (European) banking markets differ from other markets. First, for reasons mentioned before, banking markets are highly regulated. In most countries, the past ten years have shown a significant degree of deregulation. Still, banks face tighter regulation than most other companies, notably some of their competitors (insurance companies, securities agencies, etc.).

Second, entry barriers are relatively high. Many regulatory barriers have been broken down or at least lowered over the past years: minimal capital requirements, solvency ratios, bank reserves, and so on. But other, non-regulatory barriers are at least as important. Examples include the bank-client relationship; banks know their clients and are better suited (theoretically at least) to offer high quality services at the correct price than anyone else. On top of that, search and transportation costs make it costly for the client to switch from one bank to another. Also, the client information handled by banks, is - certainly compared to non-financial institutions - of a delicate nature. But most importantly in the context of the present analysis, this bank-client relationship has special dimensions because of the intermediary function that banks have. This creates incentives for banks to cross-subsidize, which in turn stimulates the bank to establish a close relationship with its clients. In a partial equilibrium framework with Cournot behaviour, VanHoose (1988) evaluates the impact of deregulation on entry/exit on the 'oligopolistic rivalry' in the market. He comes to the conclusion that "the fundamental implication of the analysis [...] is that equilibrium adjustments [...] are much more complicated in a deregulated environment than in one in which the number of bank rivals is determined exogenously via regulation on entry and exit" (p. 299).

\footnotetext{
${ }^{19}$ Most of the explanatory variables in an SCP analysis originate from banks' balance shects and profit and loss accounts, either directly or (in the case of e.g. market share) more indirectly. They are determined simultaneously, and can be expected to be highly correlated. Therefore, although the choice between one concentration ratio or another may or may not alter the significance of this variable, that does not mean that it has no impact on the SCP analysis as a whole (and single variables within that analysis).
} 
Compared to most of the U.S. research, the role of entry barriers merits special attention. If banking services are provided on a European market, this puts the high concentration in national markets in perspective. Evidence of the existence of (non-legal) entry barriers is scarce. Casual evidence does exist, however, that for many products European banking markets are still predominantly national. In this respect, Fase and Winder (1993) and Fase (1997) examine the cross-border substitutability of deposits and find that it is low. ${ }^{20}$ On a more ad hoc level, most mergers and acquisitions in Europe still take place within national boundaries.

Another important characteristic of banking markets is the fact that it is hard to define the market. There are several reasons for this problem. First, banks are by definition active on at least two markets (loan and deposit). As Altunbas and Molyneux (1996b) put it "[B]ecause banking is a multi-product industry, a simple all-inclusive market area is difficult to delineate and no single measure of structure precisely reflects the degree of monopoly, nor does economic theory help choose which measure is most important" ( $p$. 100). It is often difficult to see where a market begins and where it ends. Product substitutability typically plays a huge role in financial services, where (technical) innovation, internationalization and deregulation have led to an enormous expansion of the range of products offered.

Geographically speaking, SCP analyses of U.S. banking markets almost by definition take SMSAs (Statistical Metropolitan Areas) as the 'market'. However, there is one major problem with SCP analyses for European banking markets: a lack of data. No such databases as for the SMSAs in the U.S. exist in Europe, at least not over longer periods.

In practice almost all SCP analyses are limited to either loans or deposits and an analysis of one national market. There are two reasons for this limitation. Most importantly, most authors feel expanding the scope of the analysis, whether geographically or into other products, has little added value for an SCP analysis. Second, some authors consider a one market/one product situation close to reality. Hannan (1991) describes this belief as the view that banking markets are essentially local in nature. When looking at U.S. markets for commercial loans, he notes that the existence of a national market for funds does not directly influence the market power of local competitors, since it does not affect local loan demand. He then concludes that "arguments that relate to the demand for loans by bank customers, rather than the supply of funds to banks, are more fundamental to the issue" (p. 134). Outside competition can reduce the extent to which market concentration results in higher profits. Essential, therefore, is the price elasticity of demand for loans. For traditional banking products like commercial loans and demand/savings deposits the subject of most SCP analyses - differences between the U.S. and European countries like Germany, the Benelux and (from the 1990s onwards) France are negligible. Hannan's findings are highly intricate in this respect: he concludes that commercial loans markets are indeed very local, or - in U.S. terms - approximately restricted to SMSAs. The prob-

\footnotetext{
${ }^{20}$ Sce also chapter 5 .
} 
lem can be expected to be worse in Europe, where no comparable market measure exists in Europe, certainly not one that can be used for different countries.

The two 'product markets' that are most often used are deposits and loans. In short, most authors opt for deposits, usually combining demand and savings deposits. Information on deposits is, in comparison to most other products, easy to retrieve and quite comparable. Also, at least for demand deposits the problem of related or rivalry products is not much of an issue. The costs of deposits are less obvious though: most SCP analyses, if they include costs, are confined to distant proxies like average salaries paid to personnel. In Europe, where banking markets, at least in the 1980s, were less homogeneous than in the U.S., not all deposits are comparable. For example, in France, where the interest rate on deposits was regulated, one may end up with an underestimation of market power.

Whereas most deposit markets are quite homogeneous, this condition does not (necessarily) hold for loan markets. Comparing the prices of loans is far more difficult than doing the same for deposits. Additionally, even loans of the same amount and with the same interest can differ, mainly due to differences in (estimated) risk. Also, there exist a number of substitutes for many types of loans. Paradoxically, the market for loans seems a lot more interesting from an SCP perspective than the market for deposits, but largely for reasons that make it intrinsically difficult to capture its dynamics and range in an SCP analysis. Again, this holds to a relatively large extent in Europe where banking markets are liberalized and (almost) no barriers to competition between a range of financial institutions exist.

Summing up, there is no straightforward choice of a product(s)/market(s) combination for an SCP analysis on European banking markets. An SCP analysis of the competitive conditions within the EU, as an aid to possible changes in European banking regulation, will most likely 'stick to' deposits, since that 'voluntary' limitation already makes such a survey quite a task. On the other hand, if the Spanish bank Banco Santander wishes to include an SCP analysis into its strategic decision-making, these same limitations seem inappropriate and unsatisfactory. In that light, there is an 'ideal' product(s)/market(s) combination, process depending on the purpose the analysis serves and the country (or countries) it covers.

Finally, data availability is a general problem in SCP analyses, but this point is of even greater weight when the spotlight is on banks. An example will illustrate: I argued that in the case of loans, one has to try to keep track of the price-risk relationship attached to these loans. In fact, some authors argue that risk should be one of the central themes in bank market SCP analyses. One way to try to incorporate risk considerations by banks into an SCP analysis is by introducing loan loss reserves as a variable. However, Dutch banks ABN AMRO and ING for instance only made these reserves public in 1995 and 1996, since they were obliged to do so to be listed on the New York Stock Exchange. For smaller banks without such a listing, no such requirements exist.

Concluding, the measurement of the structure of European banking markets is subject to many critical remarks. From a theoretical point of view, the choice of one market struc- 
ture variable over another is not obvious. Empirically, few authors justify their choice of market, market structure variable and (in the case of a structural rather than a summary measure) the number of large banks to be included. To put these comments into perspective, it is important to realize that qualitatively, the choice of concentration measure appears to have little impact on the outcomes of most SCP studies (cf. Gilbert (1984) and Molyneux, Altunbas, and Gardener (1997)). This does not mean the way of measuring concentration per se is trivial. It does focus attention on the role market structure plays in the SCP hypothesis. I therefore take a closer look at 'conduct', as a catalyst between 'structure' and 'performance'.

\subsubsection{Conduct}

As the second step in an SCP analysis, 'Conduct' encompasses the way in which market structure induces and allows strategic behavior, which then leads to higher profits. In most SCP analyses this mechanism is supported by a series of implicit assumptions. First, banks are assumed to be profit maximizing firms. Second, banks face price competition. Third, banks compete with other (similar) banks, and not with other financial institutions that offer possible substitutes. ${ }^{21}$ Fourth, the number of competitors is, most of the time, an exogenous variable (for instance a control variable).

Each of these assumptions can be challenged. There is an expanding strand of theoretical literature on rent seeking and other types of non-profit maximizing behavior in banking. ${ }^{22}$ As a matter of fact, research on scale and scope economies cannot explain the consolidation wave that took place in the 1990s in many European countries. Also, deregulation and financial innovation have sparked a renewed rivalry between traditional financial intermediaries and insurance companies, brokers, etc. Likewise, the system of home country control has led to a marked change in the way banks can compete internationally. Obtaining a bank license in another EU country has become easier and more frequent. Whereas some of the banks that enter the market this way operate as (semi)independent entities, others are little more than service points for foreign businesses. This behavior in turn has important consequences on the profit-maximizing behavior of these banks, who - in the latter case - may just want to break even.

'Conduct' then boils down to one central question: "whether banks typically behave competitively or strategically" (Calem and Carlino (1990), p. 268). Competitive behavior translates into competitive performance, with zero monopoly rents. In the short run, differences in performance can then be explained through differences in cost structures and efficiency; in the long run only cost-minimizing, efficient banks survive. Strategic behavior on the other hand means a bank's position in the market (market share, price elasticity of demand, product-substitutability) is important in explaining its performance.

${ }^{21}$ This explains for instance the absence of cross-price elasticities.

${ }^{22}$ See also chapter 3. 
Differences in performance can therefore be explained by what is collectively termed 'market power'. The central question is what kind of behavior dominates.

For Europe, not much empirical research has been done in this area (see also chapter 5). As an important insight, in an article on U.S. deposit markets Calem and Carlino (1990) ask themselves the same question, and try to answer it by adapting a standard SCP analysis. Their empirical model is a reduced-form interest rate equation estimated for a sample of U.S. banks. The inclusion of the rate of per capita immigration into an SMA is crucial. It is used to as a proxy for the price elasticity of the supply of deposits in a market under the assumption that immigrants have a more elastic supply. Behind this assumption is the fact that immigrants face set-up costs, which will make them more interest sensitive than other customers, since "they transfer their account balances into the market only when the interest differential and convenience factors offset their set-up costs, at which point they transfer their entire account balances" (Calem and Carlino (1990), p. 268). In the model, the price elasticity of the supply of deposits elasticity will influence deposit rates if and only if banks behave strategically. The coefficient of the rate of per capita immigration is found to be significant and non-negative, which means that an increase in the inflow of immigrants increases the interest rate prevalent in the market. Calem and Carlino (1990) mention reasons why banks may still behave non-competitively, including price leadership, product differentiation and the existence of consumer search costs.

\subsubsection{Performance}

I now take a look at the two basic kinds of performance measures that can be used in an SCP analysis: those based on the prices of the products offered and those based on the 'profits' earned from offering these products. I will start with the performance measure that is the least often used, prices, and explain why this is the case. Then I will review profit as a performance measure.

Prices are not often used as measures or estimates of the performance of banks. 'Prices' here should be seen as a rather elastic notion of the costs to consumers of consuming the product. The choice for prices as performance measure contains two slightly related difficulties. First, there is an inherent difficulty in attaching a price to many of the products that banks offer. An example will illustrate: a consumer pays interest on the loan he gets from the bank. The typical SCP analysis will then include the average loan rate as the price of the loan. ${ }^{23}$ However, "the numerator is annual expense flow (income flow in the case of loans), but the denominator is a balance sheet item recorded at a point in time, which may be different from the average [loan] balance over the year" (Altunbas and Molyneux (1996a), p. 109). The same of course goes for deposit rates.

The other, related difficulty with choosing prices as performance measures is caused by the fact that SCP analyses typically do not feature prices, but only proxies of prices.

\footnotetext{
${ }^{23}$ Including specific (instead of average) rates would make the model unclear.
} 
Smirlock (1985) has evaluated several of these proxies. The first proxy is the one most used: the 'service charge revenue per dollar' of demand deposits. It is easy to see that this "is not conceptually a price" (Smirlock (1985), p. 183). Much the same, although to a lesser extent, goes for 'the service-charge revenue per demand account' and 'the explicit service charge for an account with specified characteristics', the other two proxies evaluated in the study. ${ }^{2 \cdot 1}$

A more predominant performance measure is profit. Profit measures used vary from Return on Assets [R.O.A.] to Return on Capital [R.O.C.], and from pre- to post-tax profits. The choice of profit as a performance measure often suffers from what Cowling (1976) calls an error of commission. Using R.O.E. or R.O.A. as a performance measure automatically raises the need for "variables explaining imperfections of the capital market, which need not be directly related with product market power, and would also justify the use of a capital-output ratio variable on the right-hand side of the equation" (Cowling (1976), p. 11).

On the whole, for SCP analyses on U.S. banking markets, little difficulties arise with the use of different 'profit' indicators. In addition, all profit indicators tend to outperform any other performance measures. ${ }^{25}$ The choice for R.O.A. as a performance measure can therefore be explained best by the fact that it is relatively easy to obtain and relatively adequate. ${ }^{26}$ In general, an advantage of consolidation is that it bypasses problems related to cross-subsidization (Molyneux and Forbes (1995)).

For European banking markets, there are some additional arguments that help decide upon a performance measure. Empirically, prices as performance measures are of little or no use for European banking markets. Aside from regulatory differences, information on prices is simply too fragmentary to be of any use. Reflecting upon the choice between R.O.A. and R.O.E., Canals (1994) argues in favor of the latter since "it facilitates the comparison of profitability between different industries and takes into account the debt strategy of the bank" (p. 63). Although the former argument becomes redundant for

${ }^{2 \cdot 4}$ What Smirlock does is both simple and appealing; it amounts to checking the correlation between these proxies and some of the actual prices [Smirlock takes the actual 'price' of a demand deposit when the deposit-holder writes $6,20,42$ and 84 checks per month]. Not only is the correlation found for all three proxies very low - at most around .30 - but also "while the third proxy correlated better [...] its regression equation comes no closer to the price equations in the sense of capturing the significant influences on price" [Smirlock (1981), p. 184]. A comforting thought is perhaps the fact that when he compares proxy and price regressions, Smirlock finds that "no coefficient estimate is significant in both a price and a proxy equation".

${ }^{25}$ See Molyneux, Altunbas, and Gardener (1997), pp. 113-114 and Berger and Humphrcy (1997).

${ }^{26}$ Although accounting standards converge, they do so at a slow enough pace to still make it difficult to compare profits across European countries. In addition, consolidated balances do not make 'national' comparisons any easier. A significant part of this problem will gradually be solved as national regulations evolve due to international standards (Economic Research Ltd. (1997)). 
a comparative analysis of banks, the latter regarding fragmentary prices merits some attention. Rose (1999) describes R.O.A. as an indicator of managerial efficiency, whereas R.O.E. is a "measure of the rate of return flowing to the bank's shareholders" (p.159). Recapitulating, the choice between both measures hinges on two questions examined next.

First, do I wish to take into account a bank's debt strategy? The answer is of course 'yes'. In choosing R.O.E. as a performance measure, I do not just take the indebtedness of a bank into account, but also make that same indebtedness indistinguishable from its actual performance. In short, by choosing R.O.A. as a performance measure and including a control variable measuring a bank's debt strategy, I can measure and distinguish between both.

A second question relates to the assumptions behind the SCP model. Banks are assumed to be profit-maximizers. The question that arises is which variable is best capable of capturing this behavioral assumption and measuring how it is affected by a bank's competitive position. In this respect, recall that - at least theoretically - a bank is indifferent between debt and equity financing. Relative debt levels vary from country to country, often for reasons beyond the control of bank management. As a consequence, it is no surprise that R.O.E. values for bank-based southern-European countries are higher than, and moving towards, market-based countries like the U.K. Importantly, there is no reason why this trend - from which R.O.A. does not suffer - should reflect bank performance.

To conclude, I have reviewed a number of bank performanc measures. Prices were discarded, but mostly for empirical reasons. More fundamental reasons underly the choice for R.O.A. over R.O.E.

\subsection{Empirical Matters}

Now that I have examined the respective pillars of the SCP hypothesis, I turn in a more focused way to their use in empirical analyses. I start by discussing control variables used in the estimation of the SCP model. Next, I describe and criticize the way in which SCP models are commonly estimated. On a somewhat more reflective note, I finally turn to the role of regulation and objective functions, respectively.

\subsubsection{Control Variables}

Control variables are included in SCP analyses to control for bank-specific characteristics. Although they also improve the fit of SCP models, the fact that they are generally derived from a bank's balance sheet causes multicollinearity problems that usually make it difficult to interpret the significance of any single control variable. In addition, a theoretical underpinning of the use of specific control variables is generally lacking. Most control variables are closely related to a bank's cost structure. Examples include debt/equity ratios, loan/deposit ratios, net interest margins and operational costs/assets. 
Gilbert (1984) identifies six stages in the development of the literature on the cost structures of banks. At first, research focused on balance sheet measures like loans plus investments and total deposits as cost generators. With the evolution of banking, a second consecutive line of research changed its scope to total bank revenue. This of course reflects the increase in off-balance sheet activities by banks. A third type of research takes functional cost accounting (FCA) data as its starting point. "The FCA data include information on the number of customer accounts a bank services in various categories of banking services and the allocation of bank expenses to those service categories" (Gilbert (1984), p. 637). The fourth step in research on bank costs was the clear distinction in cost functions of unit banks, branch banks and affiliates of bank holding companies. Fifthly, the translog functional form was introduced and proof of U-shaped cost curves was established. Research by Benston, Hanweck, and Humphrey (1982) and Flanner (1983) proved that the costs of operating a banking office as a unit bank are as low or lower than operating it as a branch of a larger bank. A sixth and final type of cost studies tests for joint costs in the supply/production of different banking services, with "significant joint costs for at least some categories of bank output, and economies of scale over only a limited range of bank output" (Gilbert (1984), p. 638).

Almost all SCP analyses that use costs make no specific assumptions about the cost structures of offering certain products and assume either a linear or no specific relation between this performance measure and concentration. Exceptions include Mester (1996), Jagtiani and Khanthavit (1996), Bauer and Cromwell (1991) and Heggestad and Mingo (1976) who try to find proof of an explicit non-linear relationship. ${ }^{27}$ Most importantly; this strand of research seeks to test the validity of the assumption that the competitive process as tested by the SCP analysis is continuous. Proof of this not being the case could for instance result in threshold levels of competition and the consequent decision to analyse specific segments of a banking market (e.g. large banks, or co-operative banks). At present, however, evidence is mixed.

An important reason for including these control variables in SCP analyses is the Efficiency hypothesis. In fact, costs are the precise area where the effects of the Efficiency hypothesis postulate themselves: greater efficiency leads to lower average costs, which in turn results in a bigger market share and eventually better performance (i.e. higher profits). Notice the paradox in this analysis: if higher efficiency translates into a bigger market share, than the relatively efficient bank should pass this efficiency on to its clients, through lower prices/fees. If a bank acts that way, how can it end up with higher profits from higher efficiency? There is only one possible answer to this question; the bank must be able to keep a sufficient part of its efficiency gains, while at the same time transferring the remainder on to its customers. There are two necessary conditions for this to happen. On the one hand, the bank has make sure is is not 'undercut' by other banks. Pricing

\footnotetext{
${ }^{27}$ Note that this 'cost-debate' is separate from the internal costs in banking that feature in most SCP analyses that try to account for the Efficiency hypothesis, i.e. economies of scale.
} 
depends on the behavior of the banks already in the market and the likelihood of entry of new banks in the market. If the market is not contestable, there is room for firms to raise prices to such an extent that they make an excess profit while at the same time keeping it unprofitable for new firms to enter the market. Molyneux and Thornton (1994) use the so-called 'Rosse-Panzar 'H-statistic' to evaluate the contestability of European banking markets. The H-statistic "measures the sum of elasticities of total revenue of the firm with respect to the firm's input prices" (Molyneux and Thornton (1994), p. 448). The H-statistic is unity in two cases: when there is perfect competition and when there is a natural monopoly operating in a perfectly contestable market. In other words, finding proof of a H-statistic of ' 1 ' would at the same time rule out strategic behavior and non-contestable markets - two potential distortions when testing the Efficiency hypothesis.

Molyneux and Thornton (1994) report some interesting findings from a cross-sectional Rosse-Panzar test on individual European banking markets. Both German, UK, French and Spanish banking markets appear to be subject to monopolistic competition. Findings on the Italian banking market seem to report a monopoly or oligopoly.

A second possible foundation for the relationship between efficiency and profits that is tested as the Efficiency hypothesis can be found on the demand side. As stated before, if demand for loans is not completely elastic, then the extent to which it is not is exactly the leeway banks need to make a profit. Unfortunately, research specifically into the demand elasticities on European banking markets is scarce. The closest to any affirmative findings on imperfect elasticity are to be found in an indirect way: by looking at the definitions of a market. Most researchers agree that, certainly with respect to loans/deposits, competition is primarily 'local' ${ }^{28}$ The step from that inference to the efficiency-profits relationship requires an important and logical assumption: if competition is local, then the price elasticity of demand can be expected to be relatively low and this gives banks the opportunity to reap a great part of the fruits of their own efficiency.

Concluding, the use of control variables in SCP analyses is subject to some criticism. Empirically, the role and significance of individual variables is hard to describe. This is a potential problem given the role cost structures were shown to play in the relationship between performance and concentration. A fundamental problem of a different nature underlies the use of control variables to distinguish between the SCP hypothesis and the Efficiency hypothesis. Bank-specific cost structures say little about bank efficiency, which relies on the choice and implementation of optimal cost structures. As a result, most of the literature is deceivingly convinced of the ability to test both hypotheses simultaneously. I return to this issue in chapter 5 , where I propose a solution to this problem.

${ }^{28}$ See Fase and Winder (1993) and Fase (1997) for an overview. 


\subsubsection{Estimation}

I now concentrate on a description of the way SCP models are estimated. To do so, I start by briefly recapitulating some of the characteristics of banks as financial intermediaries.

As stressed before, one of the main features of banks is the multi-product/multisegment character of their business. Banks are intermediators, using their information advantage to supply economic agents with the risk/return combinations they want and perhaps otherwise cannot get (at a lower cost). One of the major characteristics of the intermediary role is the fact that this multi-product/multi-segment competition involves decisions that are both interdependent and taken at the same time. Banks' balance sheet decisions are a continuum, rather than a specific sequence. In SCP terms; 'deposit market' decisions are the consequence of earlier 'loan market' decisions, which in turn are the consequence of 'deposit market' decisions, etc. This seems a reasonable assumption, with as its most important impact the fact that the best approximation of the situation that was just described is a setting where decisions on both sides are taken simultaneously.

The latter comment is at the same time a weakness of the OLS regressions used in most of the SCP analyses surveyed in this paper. In other words, these SCP analyses neglect the simultaneity issue by representing only the reduced-form variables that are very weak proxies of the original ones. ${ }^{29}$

A better depiction of the real situation with respect to the SCP relationship on banking markets would be one where no implicit ex ante relationships between the variables that are part of the SCP analysis is assumed. In a very general way, such a picture would have to contain two ingredients. Firstly, it would have to possible for there to be several exogenous variables at the same time [cf. the objective function debate in section 2.4.3]. Secondly, it would have to be possible to incorporate direct relationships rather than the indirect ones that feature in the OLS-type SCP regressions. The vital question is whether it is possible to identify the structural form from this reduced form. This is only possible if the number of explanatory variables in the reduced form is larger than the number of variables in the original, structural form. If this is not the case OLS is inconsistent. An ideal solution to this problem would then be to forego the reduced form, and estimate the whole set of structural equations. In fact, this is what 2-Stage Least Squares [2SLS] does.

Essentially, there are two ways to model an SCP analysis in a 2SLS setting. The first is to 'expand' the regression by adding variables that are (cor)related to the 'exogenous' variables in the original OLS regression. Another way to use 2SLS in an SCP analysis is by trying to model the different markets and products involved in banking. Naturally, these two options are, at least in theory, not mutually exclusive.

${ }^{29}$ Mitchell and Onvural (1996) propose the use of the so-called 'Fourier Flexible Functional form'. From a test on five groups of sample banks, they draw several conclusions. First, they find that the cost function(s) of commercial banks can not be estimated with a translog model. Second, they claim that Fourier Flexible Functional form cost estimates have a better fit than 'traditional' cost estimates. 
The first option sees the bank as a (profit-)maximizing firm. This maximization is then present in the original regression. What is essentially added is a number of constraints to this maximization. There are two main types of constraints: those related to risk(aversion) and those related to regulation c.q. business constraints. Clark (1986) starts out by "maximising expected utility", which is "equivalent to maximising the certainty equivalent of profit" (p. 297). A certainty equivalent corrects for a given utility function an uncertain mean return to get an equivalent amount under certainty. This 'certainty equivalent' does nothing more than correct profit for the way it is expected to vary over time, by dividing it by its variance. A second way profit is limited is by regulatory or other restrictions with the same effect; minimum reserve requirements, liquidity constraints, shareholder demands, and other regulatory and organizational structures that are imposed on banks. In fact, Clark (1986) breaks his model down into four major components: a profit equation, a risk equation, an asset equation and a liability equation. The real merits of not only incorporating these limitations, but doing so in a 2SLS framework, lie in the fact that OLS estimates of the reduced form are more appropriate "for prediction purposes rather than for directly testing the validity of the [SCP hypothesis] in banking" (Clark (1986), p. 305). In an OLS regression it is difficult if not impossible to separate direct effects from the indirect effects. This OLS estimates can therefore at best provide indirect support for the SCP hypothesis.

The starting point in the second type of 2SLS model is the concept of a bank as a financial intermediary with a multi-product/multi-segment character. The result is a focus on the "simultaneity of bank input, output and pricing decisions", "view[ing] the bank as a multi-product, multi-factor, profit-maximizing economic operative" (Graddy and Kyle (1979), p. 1). In this case, as in the previous example, a system of simultaneously estimated regressions is constructed. Graddy and Kyle (1979) construct a model that can be cut up in two main parts: regressions that are meant to capture the dynamics on the input side (= deposits) and on the output side (= loans). They state that "[M]ost [SCP] studies have simply postulated a relationship within a geographic market".

The difficulty however is that "[W]hether regulators are effective in controlling [this] risk in other than very general ways is debatable" (Mingo and Wolkowitz (1977), p. 1605). In principle, a system with simultaneously estimated equations should alleviate "the identification of the junctures where market structure might impinge on bank behaviour" (idem). Put differently, this amounts to estimating "the concentration-profits relationship [...] using a system of structural equations which allows them [i.e. researchers] to investigate [...] the nature of the structural parameters" (Molyneux, Altunbas, and Gardener (1997), p. 132). When discussing this issue, Gilbert (1984) already concludes that the "only way to avoid [..] problems in specifying equations is to specify demand functions of bank customers, supply functions of banks, and derive reduced form relations between performance variables and measures of market structure. Authors of bank market structures have not used such rigorous analysis in deriving the equations they estimate 
but have estimated relationships that are not supply equations, demand equations, or reduced forms" (p. 86).

\subsubsection{Objective Functions}

Until now, an important assumption for SCP analyses has been that banks' main (if not sole) objective is to maximize profits. 'Performance' therefore translated either directly into a 'profit' variable, or in something that was closely related to it [e.g. prices and fees]. This assumption is used in the vast majority of the SCP analyses. As a consequence, in the existing literature on SCP analyses for banking markets, the picture of a bank as a pure profit-maximizer is omnipresent. I have already touched upon the fact that banks may have other objectives than profit-maximization. ${ }^{30}$ Interestingly, a more direct incorporation of the profit-maximization objective in the SCP analysis can help improve the interpretation of tests of the SCP hypothesis significantly.

In an article on the 'concentration/conduct' relationship, Calem and Carlino (1990) start from a different setting than the standard SCP regression. Their extension of a 'liquidity management' model is based on the same set of assumptions as a standard SCP analysis and yields a concave expected profit function, which is basically a reducedform interest rate equation. Ruthenberg and Ellias (1996), who use a translog function in their SCP analysis, take an alternative approach. As a performance measure they use a so-called Lerner index which is constructed as a markup ratio over marginal costs, minus the net interest margin, which allows them to distinguish between cost- and price-effects in the SCP analysis. ${ }^{31}$

The precise formulation of this particular objective function is not of major importance. Rather, what matters is the way it is constructed: as a set of equally important minimum levels to be reached simultaneously. Each of the separate parts of this objective is a 'conditio sine qua non'. Put differently, the fact that $\mathrm{P}$, profit is the dependent variable in the above-mentioned objective function, is not of crucial importance; it is very well possible to enlarge this objective function with variables other than the strict 'balance sheet' variables Calem and Carlino (1990) use, as long as these new variables fit within the same set of assumptions. In fact, the authors themselves mention as potential candidates price leadership, product differentiation and consumer search costs (imperfect information). Unfortunately, they choose not to elaborate on the issue. Instead, they successfully prove the existence of non-competitive behavior in unconcentrated markets, and thus endorse the necessity and benefits of future research in this area.

Summing up, it is fairly straightforward to establish a more formal test of the SCP hypothesis.

\footnotetext{
${ }^{30}$ Sce also chapter 3.

${ }^{31}$ I will introduce a similar performance variable in section 5.4 .
} 


\subsubsection{Regulation}

Regulation is both a catalyst and an obstacle in SCP analyses. In general, there "is reason to believe $[. .$.$] that changes in regulation do affect the [SCP] relationship. Consider the$ influence of entry regulation. With entry controlled by regulators, the degree to which the pricing and availability of services reflects the monopolistic or competitive behavior is the determined by the local firms already in the market. With unrestricted entry into banking markets, in contrast, pricing of banking services would be influenced by the threat of entry by firms not already in the market, irrespective of the existing structure of the market. Thus, eliminating entry regulation would tend to weaken the structureperformance relationship in banking markets" (Gilbert (1984), p. 627). A change in bank regulation is therefore in itself a motivation for an SCP analysis.

On the other hand, Lloyd-Williams, Molyneux, and Thornton (1994) argue that regulation still "permits market forces to work and only changes the intensity of their effects" (p. 438). In addition, they claim that banks' returns are seldom regulated directly, and that regulation is just one of many constraints that banks face when maximizing profits.

First, this raises a more general question on why are banks regulated. Dewatripoint and Tirole (1994) investigate this issue by looking at the way banks are governed. Because of free-riding behavior, "customers of a bank have little individual incentive to perform [...] monitoring functions" (p. 32). This lack of monitoring creates the need for either private or public representation of depositors, what Dewatripoint and Tirole (1994) call the 'representation hypothesis'. This need is different for banks than for other companies since banks' stakeholders (= depositors) are more dispersed than for any other type of firm. Of course, these depositors could invest in the banks' equity rather than in debt liabilities. Dewatripoint and Tirole (1994) give three reasons why they do not. First, households are risk averse. Second, the small investor wants to "hold a safe claim in order not to 'lose [his] shirt' against insiders/speculators who are better informed about the value of a [more] risky claim when they need to sell it for liquidity purposes" (p. 34). Third, these low-risk claims reduce the monitoring costs of an agent's real value of claims, and that way smoothen the payment system, which is to the household's benefit.

An example of a type of regulation that directly affects the way banks maximize profits is the concept of interest rate ceilings. To the extent that other charges are of little significance, interest rate ceilings function as price caps in loan and/or deposit markets. The concept itself can be observed from many different angles: as a tool for (monetary) policy makers (Molyneux, Altunbas, and Gardener (1997) and Melitz (1990)) and as an adaptation of a spatial model of the banking industry (Chiappori, Perez-Castrilo, and Verdier (1995)). In the light of SCP analyses of banking markets, there are two particular features of interest rate ceilings that deserve the most attention. First of all, they have consequences for the branching decisions of banks. Secondly, there is their impact on the cross-subsidization. The two are related of course: interest rate ceilings in deposit markets can serve as an indirect subsidy to banks, by allowing them to raise their profits from supplying loans. This subsidy subsequently stimulates non-price competition. After 
the implementation of the Second Banking Directive and the establishment of the single market for capital, non-price competition for regulatory reasons became impossible as banking laws were further harmonized.

Banking regulation and supervision is mostly a continuing quest for the perfect balance between efficiency and stability. Naturally, this holds in much the same way for many sectors of an economy. Banks distinguish themselves in a crucial way from other firms: a failure of one bank can lead to a crisis for all banks in the market. This happens not (necessarily) because this one bank is of such a size that its bankruptcy changes the face of the market. "In a fragile financial system continued normal functioning can be disrupted by some not unusual event" (Benink (1996), p. 9). Banking fragility has a mixture of origins: from the (risk) awareness of economic agents to the lack of prudent supervision of banks, and from financial innovations to the risk preference of individual banks in the market.

In an SCP analysis, banking fragility can play several roles. First, "[I]ncreased competition [can lead] both to a weakening of the profitability of banks' traditional activities (price effect) and to a shift of many of the larger clients to direct finance on the money and capital markets (quantity effect). [...] Faced with a potential downsizing of their operations, many banks [respond] to this new, less friendly environment by increasing the riskiness of their portfolios" (Benink (1996), p. 22). Put differently, there is an increase in the variance of the most used performance measure in SCP analyses: profit (or R.O.A.). Secondly, "For incompetent managers not being able to prove their ability in the new competitive environment, taking excessive risk may have been a rational strategy for the sake of survival" (Benink (1996), p. 23). To give an example: in a banking market where a significant part of the banks is government owned/controlled (cf. France), the profit objective is presumably less important and increased competition will not (to the same extent as in other markets) lead to increased variance of profits.

The reasons bank behavior is interesting for regulators and/or monetary authorities are diverse. Banks are providers of funds and they perform various roles (notably that of intermediary) which smoothen transactions in the economy, make transactions less costly and stimulate economic growth. Also, an increase in the fragility of the banking sector can have disturbing effects on the economy and economic growth. Equally important within the concept of this paper is the role banks play in the transmission of monetary policy. The example of how deposit rate regulation can lead to too many banks has been given by Chiappori, Perez-Castrilo, and Verdier (1995). More generally, the structure of the banking market(s) has consequences for the effectiveness of some of the tools of monetary policy.

VanHoose $(1983,1985,1988)$ and Aftalion and White (1977) analyze the effectiveness of monetary policy under different bank market structures. They do so using extended versions of a portfolio model. Aftalion and White (1977) study a 'pegged discount rate', in what they call "a monetary system typical of many European countries, in which 
the Central Bank carries out monetary policy by pegging the discount rate and then allowing unlimited advances at that rate" (p. 349). VanHoose, in his research, takes a less extreme starting point. He asks whether "monetary policy instruments [are] more or less effective in providing the desired real sector impulses under a competitive banking system as compared to one characterised by imperfect markets" (VanHoose (1983), p. 385). He adds that "[T]his question must be answered before the full monetary policy implications of increased competition in banking can be addressed" (idem). In a general equilibrium framework, the essential difference between 'imperfect local markets' and 'perfect banking markets' is the ability to influence price-setting in the former (reflected by the price-elasticity of supply). VanHoose states that market power in his model "is not a pure monopoly/monopsony as might be the case in some of the European markets referred to by Aftalion and White" (p. 391). Additionally, "it would be a mistake to apply the conclusions of this paper to nationally concentrated, European-type banking systems, just as it would be an error to consider the conclusions of [Aftalion and White's] paper to a U.S.-type system of many geographically separate banking markets" (idem).

VanHoose (1985) introduces some new features. First, there are interactions between the real and the financial sectors of the economy. Second, he "considers the monetary control implications of changes in the competitive structure of banking markets" (p. 299). Basically, the model is subject to the same assumptions as previous models: identical cost structures for banks, a constant reserve ratio, a 'mark-up' (e.g. for the loan rate) c.q. 'mark-down' approach to the security rate, and perfect competition in all markets except for the market for deposits. Importantly, he concludes that changes in bank market structure do not affect monetary control if the central bank targets interest rates. However, if the central targets a monetary aggregate the relationship between monetary control and bank market structure depends on the type of reserve requirement.

Concluding, bank regulation is shown to play an important role in European banking, both theoretically and empirically. There are two ways of incorporating these findings in a study on the competitive dynamics of European banking markets. A first way is to try to explicitly control for the impact of bank regulation and regulatory differences. Secondly, choosing a period of stability (i.e. little or no regulatory changes) can greatly enhance the reliability of SCP analyses.

\subsection{Conclusion}

In this chapter, I have tried to shed a critical light on the use and usefulness of SCP analyses of (European) banking markets. I conclude by recapitulating two issues.

A first issue is the extent to which lessons can be drawn from this critical review in order to improve market power studies. In this respect, it has become clear that the SCP hypothesis in general and the role of market structure in particular merit a more solid theoretical underpinning. Although not always equally relevant in empirical terms, a more careful modelling of market power in European banking can lead to results that 
are more clear cut and easier to interpret. Bank conduct was shown to be a black box, where the same criticism applies. On a different note, the choice of R.O.A. (or a measure with similar characteristics) for an analysis of European banking markets was defended. Also, care has to be taken with the choice of control variables and in estimating a market power model in order to ensure robust and interpretable results. Finally, given timing decisions and regulatory changes the choice of a sample period is far from trivial.

A second issue is a specification of what other types of research may be needed in the future to better explain bank performance. As I have pointed out before, fit and general explanatory power of SCP analyses have for the most part been disappointing. Concommitantly, even though the second half of the 1990s saw an upsurge in the number of bank mergers in most European countries, the number of SCP studies on the banking markets in those countries fell drastically. Instead, research has developed in two directions. First, the theoretical shortcomings - as explained in this chapter - of the SCP model have been adressed in a range of industrial organization models studying different facts of banking market competition. ${ }^{32}$ Although often enriching, these studies rely more heavily on assumptions such as risk neutrality or aversion, absence of cross-subsidization, etc. Also, empirically testing these models is difficult because of a lack of data and the necessity to test reduced forms. I will return to this type of study in chapter 5 . Second, empirical advances have been achieved with many micro-studies into the origins and relative differences of bank performance. Chapters 3, 4, 6 and 7 discuss this type of study in more detail.

${ }^{32}$ For an overview, see Freixas and Rochet (1997). 


\section{Explaining Bank Performance through Efficiency: A Guide through the Theory}

\subsection{Introduction}

In the previous chapter, I surveyed the literature that seeks to relate bank performance to competitive conditions as reflected by overall market concentration and firm-specific market shares. In particular, I focused on Structure-Conduct-Performance studies, since these have been by far the most popular in studies of competitive conditions in (European) banking markets. I emphasized the ad hoc nature of most of the studies in this area, and discussed both theoretical and empirical problems with market power studies.

In addition, the bank competition models reviewed in the previous chapter have only modest explanatory powers. In addition, I explained the ambiguity in the measurement of market structure that puts further doubt on the interpretation of many of the empirical results. Also, I discussed the simultaneity bias that renders the interpretation of a joint test of the SCP hypothesis and the Efficiency hypothesis highly troublesome. Summing up, SCP models can only partly explain performance in European banking. Evidence presented by SCP studies is difficult to interpret since many studies are contradictory. And to the extent that they exist, market power effects are hard to disentangle from other, important explanations of bank performance.

In this chapter, I start from that premise and try to fill the gap. I do so by analyzing an important alternative engine driving bank performance: efficiency. Main objective of this chapter therefore is to establish measures of bank efficiency that help assess market power. Thereby, such measures need to meet two requirements. First, they have to be able to contribute significantly to the explanation of bank performance. Second, if possible they should provide additional and perhaps more accurate information on the existence of market power.

The remainder of this chapter is organized as follows. In section 3.2 , I briefly review alternative explanations for firm performance. Included in this section is a justification for the focus on efficiency. Next, in section 3.3 I introduce a simple production function and show how it can be used to infer economic behavior and performance. Section 3.4 elaborates on this by introducing a cost minimization model as well as a profit maximization model. I explain why these are used to study bank performance instead of the standard production function. In addition, I analyze how the combination of both models can be used to study firm behavior and market power. In section 3.5, I list the most common efficiency concepts in use in the literature and demonstrate how the cost and profit model can be used to measure a particular type of efficiency named X-efficiency. I justify the 
emphasis on this type of efficiency and describe how it is best measured. I conclude in section 3.6.

\subsection{From Market Power to Alternative Explanations for Firm Performance}

The shareholders of a bank are claimants for its profits and it is thereby in their interest to maximize these profits. ${ }^{1}$ They can achieve this by maximizing revenue and by minimizing costs. Also, depending on the market power of the bank in the input- and output-market respectively, they may be able to increase output prices or decrease input prices. Abstracting from speculative motives, shareholders are indifferent to the distribution of profits, receiving a return on their investment in the bank either through an increase in the bank's share price or through dividends received.

Economic theory tells us that in a perfectly competitive situation, profit maximization is equivalent to cost minimization. In practice however, maximization of profits and/or minimization of costs is not necessarily observed. Of course, exogenous factors such as regulation or (economic) shocks can cause suboptimal performance. To the extent that such factors do not have a similar impact on both cost minimization and profit maximization, they can drive a wedge between the two.

Possible other explanations for deviations from profit maximization fall into two categories. The first category is a rallying point for all deviations that can be attributed to incentive problems. These problems cause banks to no longer solely minimize costs and/or maximize profits. The second category harbors all deviations that can be attributed to inefficiency. Inefficiency is defined here as the suboptimal use of inputs given outputs and vice versa.

\subsubsection{Incentive Problems}

Of course the SCP hypothesis, as explained in the previous chapter, falls into the first category. Imperfect competition causes a situation where profits are maximized at an output level where average costs are no longer minimized. Theoretically, a second and related reason why shareholders may abstain from maximizing expected profits and minimizing costs depends on their degree of risk preference. If shareholders are highly risk-averse and not well diversified, they want to ensure a bank performs counter-cyclically and thus make decisions that may be suboptimal for the bank. ${ }^{2}$ Aside from the questionable assumption that shareholders know precisely the correlation between the economic cycle and the banks' performance, the prerequisite that shareholders are not well diversified is impossible to uphold in practice.

\footnotetext{
${ }^{1}$ Here profits are net earnings minus any retained earnings.

${ }^{2}$ See also Tirole (1993), p. 35. The same reasoning, but to a far lesser extent of course holds for risk-neutral shareholders.
} 
Incentive problems that more easily translate to banking practice hinge on the separation of ownership and control and are - ceteris paribus - independent of market structure. ${ }^{3}$ In the absence of complete information, principal-agent theory states that the inability of shareholders to adequately monitor bank management and the resulting managerial discretion may induce nonoptimal behavior, i.e. profits are not maximized and/or costs are not minimized. As long as shareholders can not insure themselves against this possible suboptimal behavior, bank management may show expense-preference behavior or - if it is highly risk-averse - any other strategy that reduces profits. " This means that the asymmetric information between principal and agent that was once used by Diamond (1984) to explain that banks exist because they reduce audit costs for lenders to non-financial firms, now helps explain why banks themselves may also suffer from moral hazard and other incentive problems.

Dewatripoint and Tirole (1994) note that principal-agent problems are of particular importance in banking, where debt is highly dispersed among a bank's deposit holders. The high leverage of banks should negatively affect incentives of management to spend much on perks and reduce managerial slack. Individual deposit holders, however, are too small and freeriding stands in the way of monitoring coalitions. This problem is especially pressing in bad times, when the concave return structure of risk-averse deposit holders should ensure sufficient pressure on a bank's management to avoid excessive risk-taking and stimulate a high level of efficiency.

A vast amount of literature exists on ways to minimize the negative effects of these principal-agent problems. A detailed discussion is beyond the scope of this chapter. Pecuniary and non-pecuniary incentives and yardstick competition are ways to reduce managerial slack while keeping managerial discretion intact. ${ }^{5}$ Discretion itself is affected by for instance external control mechanisms, supervisory institutions, collateralized debt and takeover bids. ${ }^{\text {i }}$ Price and non-price competition, the substitutability of a bank's products and the contestability of its markets may also serve to ensure a bank's optimal performance by putting competitive pressure on its management, provided management compensation is performance-based. ${ }^{7}$ A similar role may be played by signalling devices such as ratings. Finally, it is important to note that although I emphasize incentive prob-

\footnotetext{
${ }^{3}$ This section borrows from Tirole (1993), chapters 0, 1, 6, 7 and 9, from Dewatripoint and Tirole (1994), chapters 2, 5- 8 and 12, and from Freixas and Rochet (1997), chapters 2 and 3.

${ }^{4}$ For an excellent introduction into principal-agent theory, I refer to Arrow (1985). Seminal references for banking are Edwards and Heggestad (1973) and Edwards (1977).

${ }^{5}$ See Tirole (1993), pp. 35-55. In addition, regulators have considered creating deposit insurance schemes conditional on the banks' performance (Dewatripoint and Tirole (1994)p.129). Barnett, Greve, and Park (1994) and Barnett and Hansen (1996) study the same incentive problem.

${ }^{6}$ Sec again Tirole (1993), pp. 35-55, as well as chapters 6 and 8 of Dewatripoint and Tirole (1994).

${ }^{\top}$ For examples, see chapter 3 of Freixas and Rochet (1997).
} 
lems between bank management and debtholders, the same type of problems - if to a lesser extent - also exist for shareholders.

Whether incentive problems are important in European banking is questionable. First, few studies have attempted to empirically test the impact of principal-agent conflicts on the performance of European banks. Translations of the above-described situations where hidden action by or hidden knowledge of bank management results in suboptimal performance into empirical tests are rare. ${ }^{8}$ Second, to the extent that the principal-agent relationship results in moral hazard conflicts, it is only problematic as long as the principal (i.e. the shareholder) can not insure himself against excessive risk-taking by the agent (cf. Tirole (1993), paragraph 2.1). Third, although incentive problems my lead to suboptimal performance of a bank, the extent to which this affects European banking dynamics is unclear. There is little reason to suspect that the incentive problems that can cause a bank to make less profits or above-minimum average costs are significantly different from bank to bank, or from country to country. The separation between ownership and control is highly similar for commercial banks in Europe, even if institutional supervision is not. ${ }^{9}$

Summing up, even if incentive problems can help explain bank performance, empirically testing whether they can explain differences in bank performance is difficult and until now far from conclusive.

\subsubsection{Inefficiency Problems}

An approach that may prove more rewarding is to explain bank performance through inefficiency. The topic was already touched upon in the previous chapter when the efficiency hypothesis was introduced. A bank may produce at lower costs and with a higher profit than other banks if it makes better use of its inputs and transforms them into outputs in the cheapest possible way. In the long rum, every bank has to produce efficiently in order to survive. ${ }^{10}$

Molyneux, Altumbas, and Gardener (1997) underscore the importance of efficiency in European banking and point out that higher efficiency can be expected to "lead to improved financial products and services, a higher volume of funds intermediated, greater and more appropriate innovations, a generally more responsive financial system, and improved risk-taking capabilities if efficiency profit gains are channelled into improved capital adequacy positions" (p. 9). In short, bank efficiency is highly important in explaining and interpreting bank performance. An important example is given by Berger and Humphrey (1992) and Avkiran (1999), who argue that the only way consumers can potentially benefit from large bank mergers is through enhanced efficiency, resulting in lower prices and an increased service level. Likewise, Rose (1995), Altunbas, Molyneux, and

\footnotetext{
${ }^{8}$ See Molyneux, Altunbas, and Gardener (1997), pp. $82-83$ for a short overview.

${ }^{9} \mathrm{Cf}$. chapter 3 of Molyneux, Altunbas, and Gardener (1997), especially table 3.20 where standard deviations for the EU area are small for all banks, and mean ownership (capital/assets) of private and cooperative banks is remarkably similar.

${ }^{10} \mathrm{Cf}$. Hanweck and Rhoades (1984).
} 
Thornton (1997) and Akhavein, Berger, and Humphrey (1997) have examined whether merged banks are more efficient than similar nonmerged banks that are of the same size. Baker and Bresnahan (1985) examine whether stepped-up product differentiation may contribute positively to an increase in efficiency after a merger. Haynes and Thompson (1999) more specifically ask the same question for British building societies. ${ }^{11}$ The importance of questioning whether inefficiency can explain bank performance is underlined by the outcomes of these studies. Only in the last case is there some evidence of efficiency benefits from mergers. In the other studies, there is either no evidence (e.g. Rose (1987)) or even evidence against efficiency benefits from mergers (e.g. Altunbas, Molyneux, and Thornton (1997)).

The renewed attention for efficiency as an explanatory factor in bank performance as well as its potential role in policy-making sufficed for the Economic Research Ltd. (1997) to engage in its own all-encompassing study of market power and efficiency in European banking. The commission hypothesizes that the single market integration program (S.M.P.) "has allowed the (increased) realization of [efficiency gains] in European banking markets" (p.187). Results show that the impact of the S.M.P. on bank efficiency varied across different countries. Importantly, although not concluded by the European Commission itself, this impact is itself not related to the explanatory power of the applied models for different countries. ${ }^{12}$ The results are strong and robust enough however, for the commission to conclude that "there does appear to have been a trend for European banks, on average, to move closer to the EU cost efficiency frontier" (p. 195).

Summing up, efficiency plays an important role in explaining the forces behind European bank performance. Furthermore, it can aid in measuring and interpreting the sources driving bank performance. And it serves as a crucial policy-making tool in reacting to the dynamics of the single market for financial services. In the next sections, I will therefore build an analytical framework that allows for accurate measurement and interpretation of the (relative) efficiency of European banks.

\subsection{From Economic Rationality to Production Functions}

My framework starts with the identification and description of why banks persue efficiency. In order to do so, I must first define bank production and show why and how production is optimized. ${ }^{13}$

\footnotetext{
${ }^{11}$ Zardkoohi, Kolari, and Dahm (1995) do the same for US commercial banks, without the explicit focus on mergers.

${ }^{12}$ To sec why, compare their log-likelihood values and t-ratios on pp. 196-205. More on this topic follows in chapter 6, where I compare efficiency between large, commercial banks in Europe and the US.

${ }^{13}$ This paragraph relies on and refers to Bea (1985), Coelli, Prasada Rao, and Battese (1998) and Molyneux, Altunbas, and Gardener (1997).
} 
I introduce banks as rational economic agents. This concept merits some explanation. To start with, I assume banks act rationally. That is, the bank operates in such a way that it pursues its own goals in what is - ceteris paribus - the best conceivable, optimal way. Of course, this means banks are assumed to know the mechanics of their own production and have the ability and will to use it to reach their goals. Second, banks are agents, interacting with other agents, such as consumers and governments. Therefore in pursuing their goals, banks have to take into account exogenous factors. Finally, banks are economic agents, in that these goals are defined from now on in economic terms. In reference to the previous section, this means that I abstract from any non-pecuniary objectives. ${ }^{1.4}$ Beyond that, banks are assumed to maximize profits and/or minimize costs. ${ }^{15}$

More precisely, a bank tries to be productive and efficient. In order to explain both concepts, I introduce a simple production function:

$$
y=f(x)
$$

where output $y$ is produced using input $x$, all outputs and inputs are homogenous and the production function is twice continuously differentiable. Also, there is no budget constraint..$^{16}$

Figure 3.1 is a graphical depiction of $f$, the production function. It will help to illustrate both productivity and efficiency.

In the example, a bank produces a single output with a single input. The analysis that follows here can easily be generalized to a multi-output, multi-input case though. Always, however, do I consider long-run production functions. The long run is defined by the fact that none of the inputs or outputs are fixed. Also, all inputs and outputs are assumed to infinitely divisible. I start with what is generally coined productivity and then discuss efficiency.

Productivity is defined here as $y / x$, i.e. the number of outputs produced with a single unit of input. For the production function in the graph, $\delta y / \delta x>0$ and from $C$ onwards $\delta^{2} y / \delta^{2} x<0$. Economies of scale are defined as the rate at which output changes as all inputs are varied. Thus, I observe increasing returns to scale from 0 to $C$, constant returns to scale at $C$ and decreasing returns to scale from $C$ onwards. On and below $f$, I find the feasible production set, the set of all possible input-output combinations. In

\footnotetext{
${ }^{14}$ I note that the assumption that banks are rational agents does not mean there is no longer an agency problem, nor does it mean that banks only have pecuniary objectives.

${ }^{15}$ As a sidestep from the argument raised here, it is important to notice that this assumption is highly valid in the long run even in the presence of the incentive problems raised in the previous section. As an example, consider that even the bank manager who pursues ulterior motives such as an increase in his pay check or work force can only continue doing so without being fired as long as his bank makes sufficient profits. In short, profit maximization and cost minimization will no doubt appear in a bank's objective function.

${ }^{16}$ Note that there is of course a feasible production set. A bank can - in principle - be allocated anywhere in this production set.
} 


\section{FIGURE 3.1: Productivity}

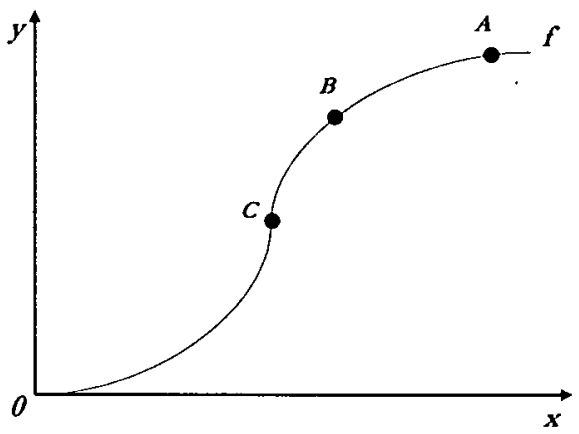

the graph, bank $B$ has the highest (possible) productivity, followed by bank $A$ and $C$. In a multiple-input, multiple-output setting, total factor productivity is the sum of all output-specific productivity (first and second-order partial derivatives). "Economies of scope generate cost savings from delivering multiple goods and services jointly through the same organisation rather than through specialised providers. These potential cost savings are to be differentiated from economies of scale, which refer to lower costs per unit of a single good or service as total output of that good or service rises" (Altunbas, Molyneux, and Thornton (1997), p. 143). In a two-output, single-input setting, economies of scope measure the net cost savings from producing two outputs jointly rather than separately. ${ }^{17}$

Efficiency on the other hand relates to the feasible production set, depicted for a 2output setting in figure 3.2. Generally, efficiency is defined in a similar way as productivity, with one important difference: now, instead of $y$, the actual output, I use $y^{*}$, the maximum output for a given level of input. Therefore, efficiency refers to the difference between observed and optimal input/output mixes. ${ }^{18}$ In figure 3.2, this means I compare relative to the frontier, which defines the maximum output for each input level (or the minimum input level, for input minimization). Efficiency is defined as $(y / x) /\left(y^{*} / x\right)=y / y^{*}$, where $y$ is the vector of outputs $y_{1}$ and $y_{2}$. Thus, bank $B$ is efficient, since it is positioned on the frontier. ${ }^{19}$

The type of efficiency clescribed here is referred to as X-efficiency. It is measures the efficiency that results from the position of a bank within the feasible production set and

\footnotetext{
${ }^{17}$ One way to measure this net effect is by taking cross-derivatives. Although the interpretation is sonewhat more complicated and it has been used less frequently, economies of scale and scope can also be calculated with respect to profits. For an example of the former, see chapter 7 .

${ }^{18}$ See Lovell (1993), p. 4 and also Coelli, Prasada Rao, and Battese (1998).

${ }^{19}$ Note that in this example, the efficiency ranking is invariant to whether I choose output maximization or input minimization. This is coincidental and normally only the case with a constant returns to scale frontier.
} 
FIGURE 3.2: Efficiency

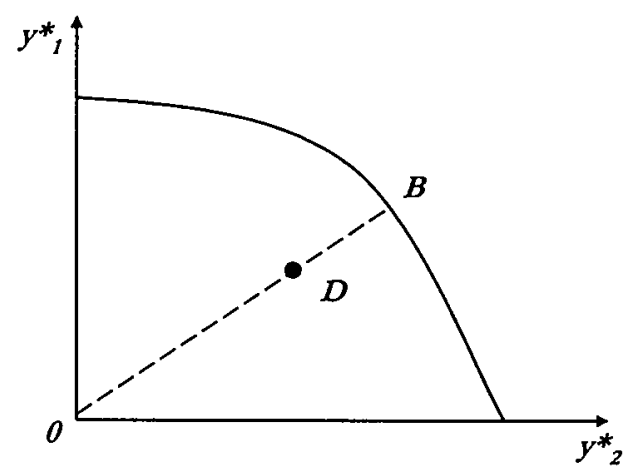

relative to the production frontier. What is not taken into account is the role of prices. In order to do so, I can split up X-efficiency into technical and allocative efficiency. Coelli, Prasada Rao, and Battese (1998) define allocative efficiency as the ability of a firm to use inputs and/or outputs in optimal proportions, given their respective prices and given production technologies. The term allocative efficiency is sometimes also called price efficiency, see Lovell (1993). Of course, for allocative efficiency we need price information. Since output prices are hard (if not impossible) to get for banks, in what follows here when discussing X-efficiency I focus on technical efficiency only.

Recapitulating, economies of scale and scope as productivity measures are closely related to (especially) X-efficiency. Both measure how well a bank combines its inputs to produce its outputs. But whereas the economies of scale and scope are absolute - but comparable - measures, X-efficiency is measured relative to a benchmark. Put differently, the optimal output $y^{*}$ is an efficient and feasible point on the productive frontier, but not necessarily observed in practice. ${ }^{20}$ An important similarity between economies of scale and technical efficiency is that they are both radial measures. ${ }^{21}$ Technical efficiency is measured in figure 3.2 by the ratio of the linear distance between on the one hand 0 and the $D$ and on the other hand 0 and $B .^{22}$

Finally, all efficiency measures derived sofar may change over time. A special case is a symmetric shift (i.e. also a radial measure) of the productive frontier resulting from

\footnotetext{
${ }^{20}$ In the remainder of this chapter and in the chapters that follow I will use the terms 'economies of scale' and 'scale efficiency' interchangeably, in line with Molyneux, Altunbas, and Gardener (1997).

${ }^{21}$ For a comparison of radial and non-radial measures, sec Ferrier, Kerstens, and Vanden Eeckaut (1994).

${ }^{22}$ In the remainder of this thesis, I measure $\mathrm{X}$-efficiency without taking into account allocative efficiency. In line with the literature (cf. Coelli, Prasada Rao, and Battese (1998)) I thereby use technical efficiency and X-efficiency interchangeably.
} 
technological advances making their way into the production process. This is shift is called technical change. ${ }^{23}$

Summing up, I have defined a simple production function and introduced a number of efficiency measures. In the context of the banking industry it is important to note the particular problems arising from the ambiguity of bank's underlying production technology. This ambiguity is one of the major reasons to model efficiency analyses on the basis of cost and/or profit functions. In the next sections, I further elaborate on the use of these efficiency measures to explain (relative) bank performance.

\subsection{From Production Functions to Cost and Profit Functions}

I have explained why efficiency can help explain bank performance. In this section and the next I further refine the type of efficiency that best serves this purpose as well as means to measure this efficiency. I start with a short introduction into bank behavior. Next, I briefly explain the importance of the concept of duality. Then I turn to bank production and examine what way it is best captured. What remains are the formulation of a cost minimization model and a profit maximization model respectively.

\subsubsection{Bank Behavior}

Standard microeconomic theory argues that in a perfect competition setting a bank will be a price-taker that maximizes profits by minimizing costs. ${ }^{2 \cdot 1}$ It increases output up to the point where marginal costs equal marginal revenue and average costs are minimized.

There are a number of reasons why banks may not be price takers and may not operate in a perfectly competitive market. As a first example, in the presence of increasing returns to scale a single bank should theoretically serve the market. ${ }^{25}$ Second, price discrimination can give rise to monopsony powers, for instance through switching costs, search costs and product differentiation. ${ }^{26}$ Third, cross-subsidization may cause spill-over effects from one concentrated banking market to another. ${ }^{27} \mathrm{~A}$ fourth example depends on the existence of regulatory barriers such as the ban on interstate branching in the U.S. following the enactment of the Glass-Steagal act or the existence of interest rate regulation (in the form of maximum rates) in France and Spain in the early 1990s.

\footnotetext{
${ }^{23} \mathrm{Cf}$. Altunbas, Goddard, and Molyneux (1999).

${ }^{24}$ For an elaborate overview and deeper discussion see Freixas and Rochet (1997).

${ }^{25}$ This is the case for instance in the original Diamond model, cf. Diamond (1984), Diamond and Dybvig (1986) and Freixas and Rochet (1997).

${ }^{26}$ Seminal references are Tirole (1993) and Bain (1956), and for banking markets Milgrom and Roberts (1982a), Milgrom and Roberts (1982b) and Freixas and Rochet (1997). Product differentiation in banking has been studied in for instance Berg and Kim (1994) and Berg and Kim (1998). The opposite effect (channel discrimination) has been studied in Barefoot (2000).

${ }^{27}$ See e.g. Ali and Greenbaum (1977), Caprio and Wilson (1997) and Chiappori, PerezCastrilo, and Verdier (1995).
} 
I therefore need an analytical framework that can incorporate and thereby measure behavioral assumptions about banks. Consider that both the bank operating in the perfectly competitive market and the bank that has a natural monopoly maximize outputs, possibly using the same production technology. Hence, they have the same production function. Therefore, I explicitly distinguish between cost minimization and profit maximization. In a perfectly competitive market, for any single bank the two approaches should yield identical results. However, in the case of imperfect competition, the existence of market power (for whatever reason) might lead to a bank that maximizes profits without minimizing costs or vice versa. The combined use of both cost and profit optimization is therefore a good - albeit indirect - way to incorporate bank behavior in response to its competitive environment.

\subsubsection{Duality}

In order to use the production function described in the previous section as well as the efficiency measures described there for a cost minimization model and a profit maximization model, I have to make use of duality. ${ }^{28}$

First, I can use the production function described in the previous section to input demand and output supply equations. In a single-input, single-output model, across inputs I can find the output level that minimizes costs and/or maximizes profits. ${ }^{29}$ Ignoring the difference between given and optimal input and prices for now, profits $(\pi)$ are maximized by taking: $M a x \pi: y-x$. I can find the input demand equations by setting $\delta \pi / \delta x=0 .{ }^{30}$ By substituting the resulting equations back into the profit maximization model (or cost minimization model), I get the primal. In order to follow suit empirically, I would have to estimate the production function and in a system of simultaneous equations estimate the input demand and output supply equations. Such an estimation could then suffer from simultaneous equations bias if one or more inputs are not exogenous. In addition, the resulting efficiency measures would not correct for the possible impact of market power on price-setting. Furthermore, this method requires information on input and output quantities. For banks this is not always straightforward. For example, a loan can be described by its outstanding value or the interest that is earned on it.

With the help of the envelope theorem the derivation of the dual is much easier. For a profit maximization model, Hotelling's Lemma (Bea (1985), p. 227) tells us that the negative of input demand and output supply equations can be derived by taking the first order partial derivatives from a profit function. Likewise, for a cost minimization

\footnotetext{
${ }^{28}$ This subsection relies on Coelli, Prasada Rao, and Battese (1998), Bea (1985) and Kirstner (1981).

${ }^{29}$ Likewise, for every output level, there is a cost-minimizing and/or profit-maximizing input level.

${ }^{30}$ Again, likewise by taking the first derivative with respect to $y$ for the output supply equation. In a multiple-input, multiple-output setting, the principle stays the same, but we solve simultaneously for all inputs and outputs, respectively.
} 
model, Shephard's Lemma states that the first partial derivative of the cost function with respect to each of the input prices defines the conditional input demand functions (i.e. conditional upon the output level, $y$ ). For both models, Young's Theorem states that a second-order partial derivative is invariant to the order of differentiation, and the cross partial derivatives are symmetric (cf. Chiang (1984)). Now, there is no simultaneous equations bias, and I can easily use the resulting cost minimization model and profit maximization model to interpret the role of market dynamics for bank efficiency.

\subsubsection{Bank production}

Before specifying the cost minimzation model and the profit maximization model respectively, I first give a short overview of the inputs and outputs that typically find their way into these models.

The specification of inputs to and outputs of bank production is part of an ongoing debate. On the one hand, the production approach distinguishes labor and physical capital as inputs and numbers of processed documents or transactions as output. In the literature, consensus exists that it is mostly appropriate for bank branches with low autonomy in loan policy (see also Ferrier and Lovell (1990)). On the other hand, the intermediation approach starts from the traditional core function of financial institutions and takes deposits as inputs and defines loans and investments as output. ${ }^{31}$

Both approaches have their disadvantages. In the production approach, output may be better specified as the yield to maturity plus notional amounts. Equivalently, some authors have argued that in the intermediation approach deposits may included as outputs rather than inputs. ${ }^{32}$ However, the main motivation for this seems to be that banks create revenue from deposits. This would suggest including the interest margin, which does not conform with what can be considered an output. Rather, it is a performance measure in itself. Concluding, I consider the inclusion of loans as outputs a reason in itself to include deposits as inputs (hence the term intermediation approach).

Both approaches also fail to incorporate the management of risk, information processing and the solution of agency problems arising due to the differences between loans and deposits and the separation between management and ownership. Potential solutions to these shortcomings may be a different formulation of the constraint under which banks solve their minimization and maximization problems, respectively. An example of the incorporation of risk management is the inclusion of the level of equity in bank production. ${ }^{33}$ In funding loans, equity may be used as an alternative instead of deposits. Clearly, this would have an impact on both costs and profits. Furthermore, Mester (1996) argues that the inclusion of equity in the analysis may account for differing risk attitudes of bank managers, since higher levels of equity reduce the risk of default all else being equal. Fi-

\footnotetext{
31 I refer to Freixas and Rochet (1997), Ferrier and Lovell (1990) and Berger and Humplurey (1997) for an overview of the debatc.

${ }^{32}$ See Molyneux, Altunbas, and Gardener (1997) for a discussion.

${ }^{33}$ See Hughes and Mester (1993), Mester (1991, 1992).
} 
nally, Berger and Mester (1997) mention the larger dependence of huge banks on debt financing as a reason to include equity. I will therefore include equity (or a close proxy for equity as a risk variable) as an additional explanatory control variable in my empirical models.

\subsubsection{Cost minimization}

I now introduce a cost minimization model. The minimization problem is set up as follows ${ }^{3.1}$. Let a cost function $C$ consist of the costs incurred due to buying input quantities $x$ at price $w$. Assuming that banks are price takers in possibly imperfectly competitive input markets, factor prices $w$ are exogenous. All costs are treated as variable costs. Banks minimize their objective function under the restrictions imposed by the transformation function:

$$
\operatorname{Min}_{x}=w^{\prime} x \text { s.t } T(x, y, z)=0
$$

where $w$ and $x$ are vectors, $T(x, y, z)$ is a so-called transformation function and $z$ denotes equity, which is exogenously given. The corresponding Lagrangian function can be formulated as:

$$
L C=w^{\prime} x-\lambda T(\bullet)
$$

Taking first derivatives and solving yields the conditional factor demand equations, or, in terms of Hughes and Mester (1994), the restricted input requirement set:

$$
x_{i}^{*}=x_{i}^{*}(y, w, z)
$$

The minimum cost level is obtained by substituting into the cost function:

$$
T C^{*}=w^{\prime} x_{i}^{*}(y, w, z)=\tilde{c}(y, w, z)
$$

The conditional demand for inputs depends on the amount of output sold at prevailing prices, the given factor prices in input markets and the level of equity in the production period.

The cost minimization model developed here as well as the profit maximization model developed later are purely static. The models represent long-run relationships between costs (or profits) inputs, outputs and prices. I therefore take care when estimating these models in selecting time periods that are marked by (relative) stability.

\footnotetext{
${ }^{34}$ Estimating cost functions in order to determine the efficiency of financial institutions is the traditional approach in the literature. Applications of this concept to European banking data are Altunbas and Chakravarty (1998), Battese, Heshmati, and Hjalmarsson (1998) and Lang and Welzel (1999).
} 
In both this cost minimization model and in the profit maximization model that follows I have to ensure symmetry. Cross partial derivatives of input demand and output supply equations have to be symmetric. In addition, for the cost model with minimum cost $c^{*}$ and input prices $w_{1}, w_{2}:{ }^{35}$

- $c^{*}(y, w) \geq 0$, for $y, w \geq 0$. In the long run, all inputs (and outputs) are flexible, and there are no sunk costs.

- $c^{*}\left(y, w^{a}\right) \geq c^{*}\left(y, w^{b}\right)$, for $w^{a} \geq w^{b}$. The cost function monotonic is in input prices.

- $\mathrm{c}^{*}(y, w)$ is homogenous of degree one in input prices. Thus, if I double all input prices, costs are doubled as well. This property follows from equation 3.1.

- $\delta c^{*}(y, w) / \delta w_{i}$ is homogenous of degree zero in input prices, since taking the first derivative of a function that is homogenous of degree $\lambda$, will provide a function that is homogenous of degree $\lambda-1$.

- If $y=f(x)$ is strictly concave, then $c^{*}(y, w)$ is weakly concave in $w$. Basically, the primal (the production function) and the dual (the cost function) have to have the same returns to scale properties.

Summing up, I have now developed the basic theoretical framework for a cost minimization model. Before I continue with the development of its empirical counterpart, I first develop a similar profit maximization model.

\subsubsection{Profit maximization}

The profit maximization model is derived in much the same way as the above cost minimization model, with some exceptions. Humphrey and Pulley (1997) introduce a standard profit function, under the assumption that banks operate in perfectly competitive input and output markets. Hence, banks choose optimal input and output quantities, dependent on given input and output prices. Since doubts have been raised in the literature concerning the underlying assumption of perfectly competitive output markets, Humphrey and Pulley (1997) develop an alternative profit function. Here, banks are still assumed to face perfectly competitive input markets. However, they are active on imperfect output markets, which offer some scope for price setting. Hence, banks have little opportunity to influence output quantities but instead can negotiate prices and fees in a more flexible manner. The extent to which they can influence prices depends on the given output quantities at the time of decision, the given input prices and other factors influencing their ability to set prices. In addition, the alternative profit function may account for quality differences in output and for scale biases.

${ }^{35}$ Cf. Coelli, Prasada Rao, and Battese (1998), paragraph 3.2.5. 
In this model, banks maximize profits subject to both a technology constraint and the so-called pricing opportunity set. The latter reflects a bank's assessment of its competitive position as well as its assessment of the willingness of customers to pay the prices the bank wishes to charge. The maximization problem then becomes:

$$
\underset{p, x}{\operatorname{Max}} \pi=p^{\prime} y-w^{\prime} x \text { s.t. } T(x, y)=0 \text { and } H(p, y, w, z)=0
$$

Here, $H(\bullet)$ denotes the pricing opportunity set. The Lagrangian system can be written as:

$$
L \pi=p^{\prime} y-w^{\prime} x-\lambda T(\bullet)-\theta H(\bullet)
$$

Solving simultaneously for $p$ and $x$ gives the optimal output prices and input quantities as:

$$
\begin{aligned}
& p^{*}=p^{*}(y, w, z) \\
& x^{*}=x^{*}(y, w, z)
\end{aligned}
$$

Substitution then yields the optimal profit level:

$$
\pi=p^{*}(y, w, z)^{\prime} y-w^{\prime} x^{*}(y, w, z)=\tilde{\pi}(y, w, z)
$$

The appealing feature of this profit function is that it allows for market imperfections on the output side. Additionally, output prices, which are subject to severe measurement problems according to Berger and Mester (1997) and Vennet, Vander (1998), are not required for the empirical analysis.

For this profit model, with optimal profit $\pi^{*}$ and input prices $w_{1}, w_{2}$, properties are similar to those of the cost model ${ }^{36}$ :

- $\pi^{*}(p, w) \geq 0$, for $p, w \geq 0$. In the long run, all inputs (and outputs) are flexible, and there are no sunk costs.

- $\pi^{*}\left(p^{\alpha}, w\right) \geq \pi^{*}\left(p^{b}, w\right)$, for $p^{a} \geq p^{b}$. The profit function is monotonic in output prices.

- $\pi^{*}\left(p, w^{a}\right) \geq \pi^{*}\left(p, w^{b}\right)$, for $w^{a} \leq w^{b}$. The profit function is monotonic in input prices.

- $\pi^{*}(p, w)$ is homogenous of degree one in all prices. Thus, if I double all input prices, profits are doubled as well. This property follows from equation 3.5 .

${ }^{36}$ Coclli, Prasada Rao, and Battese (1998), paragraph 3.2.5. 
- $\delta \pi^{*}(p, w) / \delta p$ and $\delta \pi^{*}(p, w) / \delta w$ are now both homogenous of degree zero in output and input prices, respectively.

- The production function and the profit function also share the same returns to scale properties. So a strictly concave production function requires a profit function that is concave in prices.

I have now introduced a theoretical framework for a cost minimization model and a profit maximization model. In the next section I further develop these models to measure bank efficiency.

\section{$3.5 \mathrm{X}$-Efficiency}

A number of concepts are widely employed in the empirical literature. Scale economies refer to the optimal size of production, that is, it concerns the point on the production curve where productivity is maximized. X-efficiency was defined earlier as a comparison between observed and optimal values of output and input. An efficient frontier is then made up of a continuous series of scale efficient points for different input- and outputmixes.

Berger, Hunter, and Timme (1993) argue that in translog production models scale efficiency refers to that size of a banking firm at which average costs are minimized by moving along production frontier. Scope economies deals with answering the question of whether the joint or the single production of an output bundle is optimal. This kind of inefficiency source is also referred to as product mix economies.

The combination of scale and scope economies concepts is subject to some qualifications. Remember that efficient firms are assumed to operate on the frontier. Indeed, both concepts focus on an optimal production plan in terms of input and output quantities. Consequently, inefficient firms operating above the cost-minimizing frontier can be the result of a suboptimal production size, a suboptimal product mix, or both.

Berger, Hunter, and Timme (1993), in a seminal reference, sum up the major problems associated with measuring economies of scale and scope using translog functions. Measuring economies of scope is particularly problematic given the possible existence of zero outputs. Related, there is often an extrapolation problem: in a sample with universal banks as well as other banks, universal banks are often the only banks truly offering the full range of services. As a result the economies of scope derived from the cost (or profit) function tend to overestimate the true economies of scope present among most banks in the sample. In addition measuring average economies of scope results in scope measures that are highly biased due to the fact that they also include $\mathrm{X}$-(in)efficiency.

The crucial difference between X-efficiency and scale-/scope-efficiency is the perception of the firm's position relative to the best-practice frontier and the assumptions regarding behavior. X-inefficiency indicates the ability of management to convert inputs efficiently 
into outputs given prevailing prices. Beyond formulating a production plan, it also evaluates how well this plan is achieved and is therefore also referred to as managerial efficiency.

Berger, Hunter, and Timme (1993) identify several problems with measuring economies of scale. ${ }^{37}$ First and foremost, research has time and again brought evidence in favor of U-shaped cost curves in banking. Economies of scale increase up to a relatively modest size, sometimes estimated to be as low as USD 100 million or less, after which they tend to increase (albeit slowly). Thus, when using a translog function to measure economies of scale for a sample of small and large banks it is not very well possible to identify the cost curve and find reliable economies of scale for banks in different size classes. A second problem concerns the fact that risk variables are often excluded when measuring economies of scale. Thirdly, Berger, Hunter, and Timme (1993) observe that many studies base their scale measures on observations that are not on or close to the efficient frontier. As a result, these studies cannot separate economies of scale (i.e. the marginal effects of outputs on profits or costs) from X-efficiency (the distance from the efficient frontier). So economies of scale will be biased the further the banks lie from the efficient frontier.

Berger, Hunter, and Timme (1993) and Berger and Humphrey (1991) state that scale and scope inefficiencies (amounting to 5 percent) are less important in the banking industry than X-inefficiencies (20-25 percent). A similar finding is reported in a study carried out for the European Commission by Economic Research Ltd. (1997) for Europe's banking markets. Henceforth, I concentrate on X-efficiency not only because it appears to be quantitatively more important in the banking industry, but also because the conceptual notion is more appealing. In addition, X-efficiency bears the decisive advantage of allowing the firm to react to price changes, see Berger and Mester (1997) and Lovell (1993). It allows for sub-optimal (beneath-frontier) operations and incorporates relative prices into the analysis.

\subsubsection{Parametric Versus Non-Parametric}

A number of techniques exist to measure a production unit's efficiency relative to some kind of 'best-practice-frontier'. A first distinction is between parametric and non-parametric methods. Secondly, different methods exist within each category.

Berger and Humphrey (1997) present an extensive overview and discussion of the pros and cons of both types of methods. They note that the choice of method is important, since efficiency estimates vary significantly in the literature, with respect to the level as well as the ranking of efficiency. ${ }^{38}$ Differences are most pronounced between para-

\footnotetext{
${ }^{37}$ In particular, they discuss the use of translog functions. However, their arguments apply to other flexible forms as well (and to Cobb-Douglas models, with the exception of the first argument).

${ }^{38}$ See also Bauer, Berger, Ferrier, and Humphrey (1998).
} 
metric versus non-parametric methods. The results within each group do not differ that strongly. 39

Non-parametric methods like DEA (Data Envelopment Analysis) and FDH (Free Disposable Hull) have the advantage of refraining from imposing a particular structure on the data a priori. Their main drawback is that inefficiencies are lumped together with random noise due to measurement error, etc.

FDH does not allow to test for the scale properties of the efficient frontier and is therefore less popular among non-parametric approaches. Like FDH, DEA is a deterministic approach that makes use of linear programming to benchmark efficiency. It 'measures' economies of scale with a framework that is linear, and neglects measurement error. The approach makes no assumption, aside from the choice of variables, about the production process. Correlations between inputs and outputs are not taken into account. Although useful for the calculation of Malmquist indices, panel data add relatively little explanatory power to DEA - there is no gain in degrees of freedom. In addition, the necessity of balanced panels can be a problem if there are a lot of missing observations.

Alternatively, parametric methods may be used, which are characterized by the explicit incorporation of random error. The consequent stochastic nature of the data is approached through regression analysis. A best-practice frontier is estimated rather than calculated. Bauer, Berger, Ferrier, and Humphrey (1998) distinguish between SFA (Stochastic Frontier Analysis), TFA (Thick Frontier Analysis) and DFA (Distribution Free Analysis). The three methods differ in the way they separate inefficiencies from white noise. SFA assumes a composite error, consisting of a random noise part and an inefficiency part. TFA estimates a frontier using only the best performing group (say the best quartile) of banks, for which the inefficiency term is assumed to be zero. Then, the remaining error is random. On the other hand, DFA assumes random noise to cancel out over time. For time-averaged data, the only remaining error term is the inefficiency part. Of course, this assumes that core firm inefficiency remains constant over time.

In my view, there are two important arguments in favor of the use of SFA when compared to other parametric methods, since allowing for random noise is important. First, the analysis is based on accounting data, which are expected to be strongly subject to measurement error. Second, the nature of bank production is still subject of debate with respect to the specification of inputs and outputs, implying potential specification error. Within the group of parametric methods, SFA is the best candidate. TFA only allows for an analysis of industry averages, while DFA assumes constancy of core inefficiency over time. For the goal of this thesis, namely benchmarking banks on the basis of X-efficiency, the SFA approach is generally preferred over other paremetric methods. Decisive arguments are its abilities to account for random error, generate point estimates and allow efficiency to vary over time.

\footnotetext{
${ }^{39}$ See Resti (1997) for an example of the combined use of parametric and nonparametric methods, and Coelli and Perelman (1997) for a comparison of both methods.
} 
Concluding, the favorite non-parametric and parametric methods are DEA and SFA respectively. Upon comparing these two approaches more closely, I start with the observation that SFA as a parametric approach is more closely related to the literature on and the estimation of production functions. Its relative dependence on the CRS assumption makes it hard to see from where scale effects stem. They can be real scale effects, but may also be caused by something outside the present functional setup. In addition, there is no information on slacks; through the monotonicity assumption slacks are assumed away. Also, SFA models are estimated with Cobb-Douglas and Translog Production Function specifications, with symmetric substitutability - not necessary a realistic assumption. In both approaches, if an outlier is deep inside the frontier, it does not constitute a problem. However, if the outlier is close to (or, in the case of DEA, on) the frontier, then there is a marked difference: whereas in DEA, ranking and efficiency scores are only partially affected, in SFA the whole frontier may shift. Finally, depending among other things on the number of banks in the analysis, whereas in DEA there is a possibility of efficiency by default, in SFA this same problem can lead to a loss of significance).

As a result of differences in assumptions and setup of the two approaches, there can be marked differences in the interpretation of results. SFA imposes more structure on the shape of the frontier, and consequently may lead to higher technical efficiency scores (and a lower variance in those scores). To the extent that this is the result of the restrictions on the SFA frontiers, this is an advantage of the DEA approach.

However, an important argument in favor of SFA models is something that is extraordinarily important in banking research: EU banking markets have been subject to and influenced by (changes in) exceptionally binding legislations and far-going financial integration. It is widely recognized that these forces have a far-going impact on the performance and efficiency of banks. In the basic form of DEA (as it is used in this paper) these influences cannot be accounted for. There is no random error in DEA. In fact, this is the main reason why SFA scores - also in the models - tend to be higher than DEA scores.

Bauer, Berger, Ferrier, and Humphrey (1998) impose six consistency conditions and examine the extent to which a stochastic frontier (SFA) model, a thick frontier model (TFA), a distribution free model (DFA, where all white noise is inefficiency), and a data envelopment analysis (DEA) meet these consistency conditions. The choice between SFA, TFA, and DFA does not appear to alter efficiency measures significantly.

DEA on the other hand yields a different ranking, lower average efficiencies and appears to be more sensitive to small changes in assumptions, sample size or variables. In a study comparing DEA and SFA, Eisenbeis, Ferrier, and Kwan (1999) find for a standard set of inputs and outputs that SFA scores are closer related to risk-taking behavior, managerial competence and bank stock returns.

Summing up, its advantages in terms of hypothesis testing, fit and the inclusion of measurement error are decisive factors in favor of SFA. It allows for measurement error. This can be important, since measuring bank production is particularly difficult due to 
data availability and the choice of a set of inputs and outputs, which is less obvious than for many other industries. In addition, SFA produces firm-specific efficiency estimates. This allows us to test for differences in efficiency among banks from different countries as well as measure the scale and scope economies of banks that operate close to the frontier. In what follows, I further develop an SFA model.

\subsubsection{Stochastic Frontier Analysis}

Stochastic frontier modelling was introduced more or less simultaneously by Aigner and Schmidt (1977), Schmidt and Lovell (1979), Meeusen and Van Den Broeck (1977) and Battese and Corra (1977). ${ }^{40}$ The method specifies a functional form for a production, profit or cost relation and adds a composite error term. As noted in Bauer, Berger, Ferrier, and Humphrey (1998) and Coelli, Prasada Rao, and Battese (1998), in most applications the composite error term $e$ consists of a random error $\nu$ and an inefficiency term $v$. Usually, the former is drawn from the standard normal distribution and the latter is drawn from a (positive) half-normal distribution. For a cost function inefficiencies would increase costs above best-practice levels, that is $e=\nu+v$. In case of a production or profit function inefficiencies result in lower profits than possible, yielding an error term $e=\nu-v$. Efficiency itself is an average of the estimated $v$ conditional on the entire composite error term $e$.

In this section, I start by briefly discussing the intermediation approach to banking that I employ. Next, I introduce the cost-minimization model and profit-maximization models. Finally, I present the specification of the models to be estimated.

Berger and Humphrey (1997) criticize the assumption of inefficiencies being distributed according to the half-normal distribution since this would impose efficiency. A number of alternative error term distributions have been considered in the literature, partly alleviating the problem. However, Coelli, Prasada Rao, and Battese (1998) point out that there is no sound theoretical foundation to anticipate any kind of error term distribution at all. Although efficiency scores are likely to be sensitive to distributional assumptions according to Battese and Coelli (1995), SFA still has the ability to explicitly rank a single bank. This is due to the fact that the efficiency measure is conditioned on the cost, profit or production residual. Any ambivalence regarding the level of inefficiency is equally valid for all firms in the sample leaving their relative position to each other equal.

\subsubsection{Specification}

In order to construct an empirical model for benchmarking bank efficiency I have to choose a functional form for my empirical models. Basically, I can choose between two

\footnotetext{
${ }^{10}$ See also Färe and Lovell (1978), Greene (1980a), Greene (1980b), Broek, Førsund, Hjalmarsson, and Mecusen (1980), Stevenson (1980), Jondrow, Knox Lovell, Materov, and Schmidt. (1982), and more recently Battese and Coelli (1988).
} 
types of models. The Cobb-Douglas model is the first type. Its main feature is that it is easy to interpret and its coefficients can be nicely used to infer scale properties. On the negative side, it has constant input elasticities and is highly limited shapewise. So-called flexible forms do not suffer from this. Main examples of flexible forms are the translog and the Fourier-Flexible-Form. " ${ }^{41}$ Berger and Mester (1997) have compared the translog to the Fourier Flexible Form. Despite the latter's added flexibility, the difference in results between both methods appears to be negligible. Moreover, Swank (1996) finds supportive evidence for stability of the multiproduct translog model for a comparable data set concerning the Dutch banking industry. The translog combines the ease of interpretation of the Cobb-Douglas model with enough flexibility to incorporate different returns to scale and substitution possibilities. ${ }^{12}$

In a 3-input/3-output setting, the cost frontier function for bank $k$ in period $t$ is therefore represented by:

$$
\begin{aligned}
\ln T C_{k \ell}(y, w, z)= & a_{0}+\sum_{i=1}^{3} a_{i} \ln y_{i k t}+\frac{1}{2} \sum_{i=1}^{3} \sum_{j=1}^{3} a_{i j} \ln y_{i k t} \ln y_{j k t}+ \\
& \sum_{i=1}^{3} b_{i} \ln w_{i k t}+\frac{1}{2} \sum_{i=1}^{3} \sum_{j=1}^{3} b_{i j} \ln w_{i k t} \ln w_{j k t}+c_{0} \ln z_{k t} \\
& +\frac{1}{2} c_{1}\left(\ln z_{k t}\right)^{2}+\sum_{i=1}^{3} \sum_{j=1}^{3} d_{i j} \ln w_{i k t} \ln y_{j k t}+ \\
& \sum_{i=1}^{3} e_{i} \ln w_{i k t} \ln z_{k t}+\sum_{i=1}^{3} f_{i} \ln y_{i k t} \ln z_{k t}+\nu_{k t}+v_{k t}
\end{aligned}
$$

Here, $v$ and $\nu$ are the inefficiency and random error term, respectively. For the profit function, the left-hand side is replaced with a profit measure and the inefficiency term is $-v$.

To measure shifts of the frontier denoted earlier as technical change, I alternatively include a linear and quadratic trend term as well as trend interaction terms. ${ }^{.13}$ The extended

\footnotetext{
${ }^{41}$ See also Judd (1999).

12 Note that this can come at the cost of multicollinearity problems.

${ }^{43}$ Lang (1996) and Altunbas, Goddard, and Molyneux (1999) include such trend terms to measure the rate of technological change. Obviously, these trend terms may capture pure technological change as well as effects of consolidation and deregulation. We only estimate the net effect and are unable to determine the relative contribution of each factor.
} 
cost frontier takes the form: ${ }^{1-1}$

$$
\begin{aligned}
\ln T C_{k t}(y, w, z)= & \text { [equation 3.10] }+g_{o} t+\frac{1}{2} g_{1}(t)^{2}+\sum_{i=1}^{3} d_{i} \ln w_{i k t} t \\
& +\sum_{i=1}^{3} h_{i} \ln y_{i k t} t+c_{2} \ln z_{k t} t
\end{aligned}
$$

In practice, I can measure the same shifts with year dummies or by estimating a fixed effects panel model. In my empirical applications, I report only the above specification (unless there is a marked difference with the other approaches). As pointed out by Bea (1985), duality requires a number of restrictions to be imposed a priori in order to estimate indirect cost and profit functions. Following Lang and Welzel (1999), the required symmetry and linear homogeneity in input prices is ensured by imposing the following restrictions, respectively:

$$
\begin{gathered}
a_{i j}=a_{j i} \forall_{i, j}, b_{i j} \doteq b_{j i} \forall_{i, j}, \sum_{i=1}^{3} b_{i}=1, \sum_{j=1}^{3} b_{i j}=0 \forall_{i}, \\
\sum_{i=1}^{3} b_{i j}=0 \forall_{j}, \sum_{i=1}^{3} e_{i}=0, \sum_{i=1}^{3} d_{i}=0
\end{gathered}
$$

In the empirical estimation, linear homogeneity in input prices is imposed by normalizing the dependent variable (PROFIT) and all factor price variables $(w)$ before taking logarithms. ${ }^{45}$ Each of the variables is included as a ratio relative to one of the factor price variables. Here, the price of labor has been chosen. Note that this imposes homogeneity of degree one in factor prices only. To impose constant returns to scale, normalization of the output variables would be required too. ${ }^{.16}$

Empirically, this implies only two coefficients $\left(b_{i}\right)$ for the input factor price variables are obtained while the third one can be inferred from the imposed restriction. The random error term $\nu_{k t}$ is assumed i.i.d. with $\nu_{k l} \sim N\left(0, \sigma_{\nu}^{2}\right)$ and independent of the explanatory variables, see Aigner and Schmidt (1977) and Coelli (1996b). The inefficiency term $v_{k t}$ is

4. The alternative profit function again is similar except for the before-mentioned adaptations.

${ }^{45}$ See Coelli, Prasada Rao, and Battese (1998). A caveat is in place here. In the model, I allow for the possibility of market power in output markets (in fact, a Bertrand competition, where banks cannot choose quantities but they can set prices). An important assumption for the above properties to hold for the profit function where input prices are included and output prices estimated is then that any increase in input prices is completely passed through to output prices. This is necessary for the model to be homogenous of degree 1 in all prices.

${ }^{46}$ Ideally, I would also like to estimate the profit and cost models as a system. Unfortunately, deriving the maximum likelihood is so cumbersome it has as yet not been done succesfully. 
i.i.d. with $v_{k} \sim\left|N\left(\mu, \sigma_{v}^{2}\right)\right|$ and it is independent of $\nu_{k l}$. It is drawn from a non-negative distribution truncated at $\mu$ instead of zero. Automatically truncating at zero would induce efficiency, as most banks are placed close to the efficient frontier. For the cost model, let $\varepsilon_{k t}=v_{k t}+\nu_{k t}$. A cost efficiency estimate of bank $k$ at time $t$ is given by the mean of the conditional distribution of $v_{k l}$ given $\varepsilon_{k t}$ and is defined as: ${ }^{17}$

$$
\text { Cost } \mathrm{EFF}_{k t}=E\left[\exp \left(v_{k t}\right) \mid \varepsilon_{k t}\right]
$$

This measure takes on a value between 1 (fully efficient) and $\infty$ and indicates how close a bank's costs conditional on its output, input prices and equity level are to the cost a fully efficient bank would incur under the same conditions. Unless mentioned otherwise, I use $1 /$ Cost $E F F_{k t .}$. This way I obtain a cost efficiency measure between 0 and 1( fully efficient), comparable to the profit efficiency measure. Namely, for the profit model, $\varepsilon_{k t}=\nu_{k t}-v_{k t}$. Firm specific profit efficiency estimate is then given by the mean of the conditional distribution of $v_{k t}$ given $\varepsilon_{k t}$ and is defined as:

$$
\text { Profit } \mathrm{EFF}_{k t}=E\left[\exp \left(-v_{k t}\right) \mid \varepsilon_{k t}\right]
$$

which takes on a value between 0 and 1 , where 1 indicates a fully efficient bank.

Next, I show how to optimize the profit and cost model in order to estimate these cost and profit efficiencies.

\subsubsection{Optimization}

I can estimate both models in three steps. First I estimate a standard OLS model. Following the parameterization outlined in Coelli (1996b), the terms $\sigma_{v}^{2}$ and $\sigma_{\nu}^{2}$ are replaced by $\sigma^{2}=\sigma_{v}^{2}+\sigma_{\nu}^{2}$ and $\gamma=\sigma_{v}^{2} /\left(\sigma_{v}^{2}+\sigma_{\nu}^{2}\right)$. The parameter $\gamma$ represents the share of inefficiency in the overall residual variance and ranges between 0 and 1 . A value of 0 can be seen as evidence in favor of a standard OLS estimation, whereas a value of 1 suggests the existence of a deterministic frontier. ${ }^{18}$ In the former case, no inefficiency exists.

I take the OLS coefficients to maximize the likelihood function for $\gamma$. These results are needed to update the values for $a_{0}$ (the intercept) and $\sigma^{2}$. These values are biased since I did not yet use the composite error term of the frontier model in the OLS estimation. Thus, the OLS value for the intercept is biased upwards (downwards) for the profit model (cost model). ${ }^{.9}$ As a third and final step, I maximize the ML function for the whole model to arrive at the firm-specific estimates of profit efficiency, namely cost efficiency.

\footnotetext{
${ }^{17}$ In line with the literature, I use the term cost efficiency to refer to X-efficiency estimated with a cost model. Likewise, profit efficiency refers to X-cfficiency estimated with a profit model.

${ }^{48}$ I note that this is not the same as a DEA model, because of restrictions on the shape of the frontier and the distribution of the inefficiency term.

${ }^{49}$ The updated value for $a_{0}$ becomes $a_{0}($ ols $)+\left(2 \gamma \sigma_{s}^{2} / \pi\right)^{1 / 2}$.
} 
In estimating the stochastic frontier models, I take the following steps. First, I check the skew of the residuals of the OLS estimation. Waldman (1982) has shown that in case of a negative skew for a profit frontier the maximum likelihood estimator is OLS. Likewise, for a cost frontier a positive skew means the MLE stops at the OLS values and since $\sigma_{\nu}^{2}=\sigma_{v}^{2}=0$, no cost efficiency can be estimated.

The second step involves specifying the truncation of the inefficiency term. Truncating at zero implies that a high average efficiency is induced without any prior reason to do so. I truncate at $\mu$, which results from the MLE and can be both higher or lower than zero.

Thirdly, I then choose an optimization algorithm..$^{50}$ As noted in the previous section, it is not likely that the function reaches a global optimum with either the translog model or the Fourier Flexible Form model. In addition, the (modified) Newton algorithms used to maximize the log likelihood may result in an optimum that is globally optimal, but I cannot be sure they will. ${ }^{51}$ Standard Newton methods suffer from the fact that with the quadratic approximation used to optimize the likelihood they assume the function to optimize to always be globally optimal. Put differently, in the optimization process the Hessian matrix with second-order derivatives is never updated. If the Hessian is positive definite this is not a serious problem, but I cannot be sure it is. I therefore use a quasiNewton method developed by Broyden, Fletcher, Goldfarb and Shanno (BFGS) ${ }^{52}$ In doing so, I ensure that the Hessian is replaced with an approximation that is always positive semi-definite and updated at each iteration in the maximization process.

Important as a next step is scaling the data. Differences in scale between different variables can significantly hamper the optimization procedure. An often used solution is to express all variables in logs. In the presence of heteroscedasticity, the least squares estimator is unbiased, consistent and asymptotically normally distributed, but no longer efficient. To avoid heteroscedasticity problems, I therefore use weighted least squares where weights are based on the log of total assets (unless specified otherwise).

The fifth step involves choosing starting values. I use the OLS values and see whether varying them slightly significantly changes the fit and efficiency estimates. If is not the case, I continue to us the OLS values with an intercept that is updated after the maximum likelihood for $\gamma$ is optimized.

Finally, I have to set the convergence criteria. In doing so, I have to balance function convergence, parameter convergence and gradient convergence. In estimating a frontier model I care most about function convergence. I am less interested in individual coefficients, since my main interest is in the overall fit and the concomitant efficiency measures. Every time I maximize the likelihood, I choose different values for each of the convergence criteria and check whether and to what extent estimation results are affected. In doing

\footnotetext{
${ }^{\text {51) }}$ See also Judd (1999).

${ }^{51} \mathrm{Cf}$. chapter 4 of Judd (1999).

${ }^{52} \mathrm{Idem}$.
} 
so, I examine the likelihood value, the number of iterations, and the model coefficients and check the range over which results are robust at modest convergence rules.

\subsubsection{Maximum Likelihood Estimator}

What remains is the construction of a maximum likelihood estimator. I follow Stevenson (1980) and Battese and Coelli (1993) and start with the density functions that together compose the error term $\varepsilon .{ }^{53}$ I focus again on the cost frontier model, where $\varepsilon=\nu-v$. Abstracting from subscripts $k$ and $t$, the density function is that of a standard normal random variable. The density function is positively truncated at $\mu$ :

$$
\begin{aligned}
\phi(\nu) & =\frac{\exp \left[-\left(\nu / 2 \sigma_{v}\right)^{2}\right]}{\sqrt{2 \pi} \cdot \sigma_{v}},-\infty<\nu<\infty \\
\phi(v) & =\frac{\exp \left[-(v-\mu)^{2} / 2 \sigma_{v}^{2}\right]}{\left[1-F^{*} \cdot\left(\mu / \sigma_{v}\right)\right] \cdot \sqrt{2 \pi} \cdot \sigma_{v}}, v \geq 0
\end{aligned}
$$

Where $F^{*}$ is the cumulative distribution function for a standard normal random variable. Given that $\nu$ and $v$ are independently distributed, the joint density function for $\nu$ and $v$ is the product of the individual density functions: ${ }^{5.1}$

$$
\phi(\varepsilon)=\int_{0}^{\infty} \frac{1}{q_{\varepsilon}} \times \exp \left[-\frac{1}{2}\left(\left(\frac{(\varepsilon-v)}{\sigma_{v}}\right)^{2}+\left(\frac{(v-\mu}{\sigma_{v}}\right)^{2}\right)\right] d v
$$

Where $q_{\varepsilon}=\left(\left(1-F^{*}(\mu / \sigma)\right) \cdot 2 \pi \cdot \sigma_{\nu} \cdot \sigma_{v}\right.$. Let $\sigma^{2}=\sigma_{v}^{2}+\sigma_{\nu}^{2}$ and let $\lambda=\sigma_{u} / \sigma_{v}$. The standard normal distribution is denoted by $f *$, evaluated at $((\varepsilon-\mu) / \sigma)$. Following Jondrow, Knox Lovell, Materov, and Schmidt (1982), the conditional expectation of $v$ dependent on $\varepsilon$ is the ratio of the joint density function of $\varepsilon$ and $v$ to the density function of $\varepsilon$, expressed as:

$$
E[(-u \mid \varepsilon)]=\left(\frac{\sigma_{v} \sigma_{v}}{\sigma}\right)\left[\left[f^{*}\left(\frac{\varepsilon \lambda}{\sigma}\right) / F^{*}\left(-\frac{\varepsilon \lambda}{\omega}\right)\right]-\frac{\varepsilon \lambda}{\sigma}\right]
$$

To find the logged likelihood expression for the cost function, I compute the integral $\phi(\varepsilon)$ :

$$
\phi(\varepsilon)=\left(\frac{1}{\sigma}\right) f^{*}\left(\frac{\varepsilon-\mu}{\sigma}\right)\left[1-F^{*}\left(-\frac{\mu}{\sigma \lambda}-\frac{\varepsilon \lambda}{\sigma}\right)\right] \times\left[1-F^{*}\left(-\frac{\mu}{\sigma_{v}}\right)\right]^{-1}
$$

\footnotetext{
${ }^{53}$ See also Jondrow, Knox Lovell, Materov, and Schmidt (1982) and Aigner and Schmidt (1977).

${ }^{54}$ Weinstein (1964) first derived the distribution function of the sum of a symmetric standard normal variable and a truncated normal variable. Stevenson (1980)derived the density function.
} 
Let $a=1 /\left(1-F^{*}\left(-\mu / \sigma_{u}\right)\right)$. Mean and variance of $\varepsilon$ are given by Stevenson (1980):

$$
\begin{aligned}
& E(\varepsilon)=\frac{\mu \alpha}{2}+\frac{\sigma_{u} a}{\sqrt{2 \pi}} \exp \left[-\frac{1}{2}\left(\frac{\mu}{\sigma_{u}}\right)^{2}\right] \\
& V(\varepsilon)=\mu^{2} \frac{a}{2}\left(1-\frac{a}{2}\right)+\sigma_{u}^{2} \frac{a}{2}\left(\frac{\pi-2}{\pi}\right)+\sigma_{v}^{2}
\end{aligned}
$$

Where $E(\varepsilon)=E(v)$ and $V(\varepsilon)=V(v)+V(\nu)$. The logged likelihood cost function can then be expressed as: $:^{55}$

$$
\begin{aligned}
\ln T C= & \ln \left(Y \mid \beta, \lambda, \sigma^{2}, \mu\right)= \\
& -\frac{n}{2} \ln \sigma^{2}-\frac{n}{2} \ln 2 \pi-\frac{1}{2 \sigma^{2}} \sum_{k=1}^{K}\left(\left(Y_{k}-\beta^{\prime} X_{k}\right)-\mu\right)^{2} \\
& +\sum_{k=1}^{K} \ln \left[1-F^{*}\left(\frac{1}{\sigma}\left(-\frac{\mu}{\lambda}\right)-\left(Y_{k}-\beta^{\prime} X_{k}\right) \lambda\right)-n \ln \left[1-F^{*}\left(-\frac{\mu}{\sigma}\left(\sigma_{u}\right)\right)\right]\right]
\end{aligned}
$$

Arriving at the Maximum Likelihood Estimators [MLEs] in the cost function is now straightforward, using partial derivatives of the above expression and a minimization algorithm.

\subsection{Conclusion}

In this chapter, I explored the possibilities for efficiency measures as additional explanatory forces for European banking. Starting broadly, I introduced a number of possible alternative theories that may explain why market power studies alone do not suffice. Next, I introduced a basic production function and used it to highlight several important efficiency concepts. Including some behavioral assumptions led to the development of a cost and a profit model, respectively. Finally, I explained my focus on X-efficiency and described how the cost and profit model can be used to measure X-efficiency.

Concluding, I have in a very straightforward way developed a framework for benchmarking and interpreting bank efficiency. In chapters 4, 6 and 7 I will apply this framework to a number of problems. In doing so, I tackle several remaining methodological issues dependent on the problems at hand. In chapter 4, I further develop and interpret the relation between cost and profit efficiency. In addition, I reconsider variable choices for both a cost and a profit model when the sample of banks is quite heterogeneous. I also come back to the robustness of efficiency estimations.

Chapter 6 requires me to further elaborate on the importance of the fit of efficiency models. Also, I turn more explicitly to the role of efficiency measures in explaining bank

\footnotetext{
${ }^{55}$ Stevenson (1980) notes that $\sigma_{u}$ can be written as $\sigma \sqrt{\left(\lambda^{-2}+1\right)}$.
} 
performance and I consider the impact of environmental variables. Finally, in chapter 7 I dedicate specific attention to the optimization routine and its impact on the robustness of estimations. I further discuss the elementary question how to decide which banks to benchmark against a single stochastic frontier. 


\section{Bank Size, Specialization and Efficiency in the Netherlands: 1992-1998}

\subsection{Introduction}

The 1990s have been witness to a series of related yet separately distinguishable global trends in the provision of financial services. These trends include disintermediation, stepped-up competition, internationalization, and deregulation. ${ }^{1}$ In the European Union, the liberalization of the market for financial institutions [FIs] is asssumed to have led to an increase in competition in this period. ${ }^{2}$ After the First Banking Coordination Directive of 1977, the EU White Paper of 1985 and the Second Banking Coordination Directive of 1988 , the single market for financial services was established on January 1,1993 . In some EU member countries, this has also led to a considerable consolidation process. As (international) competition increases at a rapid pace, both from banks and non-bank financial institutions, cost efficiency becomes a prerequisite for survival (Allen and Rai (1996) and Berger, Hunter, and Timme (1993)). At the same time, in the battle over increasing market share in these consolidating markets, profitability is the measure of success of individual firms' survival strategies.

Developments in the Dutch banking market have preceded those in other EU countries. The liberalization and consolidation trends currently reshaping many banking markets have already taken place in the Netherlands at the beginning of the 1990s. In the Dutch banking market, concentration in the period 1989-1992 doubled to approximately $80 \%$ $\left[C_{3}\right.$ ratio] as a result of a series of mega-mergers. Also, many foreign banks operate in the Netherlands. The Netherlands therefore serve as an excellent example to study relative bank efficiency in a liberalized and consolidated market.

In this chapter, I use stochastic frontier efficiency analysis to get firm-specific efficiency estimates for a sample of banks operating on the Dutch banking market in the period 1992-1998. During this period no new major institutional changes occurred in the Dutch banking market. First, I analyze whether average cost efficiency and average profit efficiency have shown an increasing or decreasing trend between 1992 and 1998. Second, I investigate whether the Dutch financial landscape after the consolidation and deregulation wave of the early nineties has become a level playing field. To this purpose I test for the equality of cost and profit efficiency between different types of FIs and between FIs of different size.

I use the stochastic cost and profit frontier models developed in the previous chapter. Empirically, the SFA methodology allows for an identification and quantification of

\footnotetext{
${ }^{1}$ For an overview, see Berger (1998).

"In this paper the terms "financial institutions" and "banks" are used intermittently.
} 
the sources of inefficiency. It yields individual firm performance measures benchmarked against a best-practice frontier. I use these measures to test for significant differences in efficiency between large general banks, small general banks, and specialized banks. I find that all banks appear to perform rather similarly in terms of cost efficiency. However, in terms of profit efficiency large banks and specialized banks clearly outperform small, general banks.

The remainder of this chapter is organized as follows. In section 4.2, I introduce the Dutch banking market, with emphasis on the causes and consequences of consolidation and liberalization trends. Also, I present the data set. Section 4.3 contains the estimation results. In section 4.3.1, I estimate and compare different versions of cost and profit functions. I use the preferred models to compute individual and average efficiency scores in section 4.3.2. In this section I also test for the existence of time trends in cost and profit efficiency. In section 4.3.3, I test for the equality of cost and profit efficiency between different types of FIs. I conclude in section 4.4 .

\subsection{The Dutch Banking Market}

The Dutch banking market has long been a forerunner in the EU with respect to both liberalization and consolidation. ${ }^{3}$ De Leeuw (1996) argues that the "Wet Toezicht Kredietwezen' of 1978 had already led to significant changes in the Dutch banking market." The new law spurred desegregation and increased competition between banks, non-bank financial institutions and insurance companies, which could now more easily apply for a full banking license. Entry into the market traditionally reserved for banks increased and a merger wave followed. Overall, market concentration increased. The next revision of the Wet Toezicht Kredietwezen in 1992 continued this liberalization trend and brought Dutch legislation in line with EU directives. This ongoing deregulation and liberalization of the Dutch market for financial services was expected to increase competition, not only internally but also from abroad. The presence of an increasing number of foreign banks (notably Japanese and German) in the Dutch banking market is witness of this development. Nevertheless, competition in the Dutch banking market is in many ways still limited by the Dutch borders, making it a market in its own right [see Huizinga (1998)]. An example in case is given by Fase (1997), who finds that cross-border substitutability between domestic and foreign deposits is almost non-existent. ${ }^{5}$ The Netherlands is thus

\footnotetext{
${ }^{3}$ For comparative European efficiency studies, see Bikker (1997), Molyneux, Altunbas, and Gardener (1997), Altunbas, Molyneux, and Thornton (1997) and Allen and Rai (1996). Altunbas, Goddard, and Molyneux (1999) try to separate scale and scope economies as well as $\mathrm{X}$-efficiency from what is called 'pure technical change'. The latter is defined as the efficiency change that is solely attributable to technological progress.

$4=$ Law on the Supervision of Credit Institutions. See, De Leeuw (1996), ch. 4.

${ }^{5}$ Fase (1997) finds a substitution elasticity of 0.22 (SD $=0.07$ ) for the period 1984-1994 (with M2 as a denominator for the share of cross-border deposits).
} 
faced with a banking market that is open and relatively deregulated, but at the same time still limited in terms of geographic scope of competition. ${ }^{6}$

TABLE 4.1: Types of Banks

\begin{tabular}{llll}
\hline Type & & Frequency & $\%$ \\
\hline General & Commercial Bank & 32 & 69.6 \\
& Cooperative Bank & 2 & 4.3 \\
Specialized & Investment Bank/Securitics House & 5 & 10.9 \\
& Real Estatc / Mortgage Bank & 4 & 8.7 \\
& Credit Institutions & 3 & 6.5 \\
& Total & 46 & 100 \\
\hline
\end{tabular}

In anticipation of increasing European competition, two mergers around 1990 created Dutch financial giants ABN AMRO and ING. ${ }^{7}$ The merger leading to ING Group was the first case of so-called 'Bancassurance': the combination of a universal bank and an insurance company [Nationale Nederlanden]. In 1990, the Fortis Conglomerate was set up in the Netherlands and Belgium as a much looser form of the same principle. As a consequence of these developments, the market concentration rate $\left[C_{3}\right.$ ratio] jumped from slightly above $40 \%$ to more than $80 \%$ in a period of three years and is currently the highest in the European Union. The number of banks is relatively stable, although the big players in the market have all indicated their desire to further expand. The reason behind a new merger trend would be the wish to become a European and/or global player. Consequently, future merger candidates might have to be found across the border.

Another noteworthy feature of the Dutch banking market is the rapid decrease in the number of branches held by the merged banks in the years immediately following their mergers. The large banks used the good economic climate to eliminate most of the overlap in branch networks and to restructure operations in a period of three years. ${ }^{8}$ At the same time, other banks in the market reacted to the new market situation. They were forced to reconsider their strategic options and possibly restructure as well. The literature on

\footnotetext{
${ }^{6}$ Moverover, both the new firms entering the market and the competition from non-bank financial institutions that follow the liberalization trend focus on the supply of specialized financial products. The traditional intermediary function that still makes up the bulk of the general banks (commercial banks and cooperative banks) does not face the same competitive threat.

${ }^{7}$ The ABN AMRO merger took place in 1990. ING Group was formed in 1989 through a merger of NMB and Postbank with Dutch insurance company Internationale Nederlanden. In addition, in 1991 Bank Mees en Hope and Pierson merged to form MeesPierson (effective in 1992).

${ }^{8}$ The total number of branches went from 5718 (end of 1987) to 7518 (end of 1993) and back to 6635 (end of 1996). Sources: Molyneux, Altunbas, and Gardener (1997), p. 66 and Liso, Balaguer, and Soler (1999), p. 114.
} 
bank mergers finds these effects of mergers take a period of approximately 4 years to fully materialize. ${ }^{9}$

TABLE 4.2: Frequency per Year

\begin{tabular}{lllllllll}
\hline Year & 1992 & 1993 & 1994 & 1995 & 1996 & 1997 & 1998 & Total \\
\hline Frequency & 21 & 23 & 33 & 34 & 35 & 30 & 34 & 210 \\
Percentage & 10 & 11 & 16 & 16 & 17 & 14 & 16 & 100 \\
\hline
\end{tabular}

The sample period runs from 1992 to 1998 , starting directly after the consolidation phase in the Netherlands and ending before a new consolidation wave announced itself. During that period, the market for FIs in the Netherlands is more or less stable and consists of approximately 80 firms with a full banking license.

I use the IBCA data provided through BankScope. Taking care of overlap due to holding companies and eliminating non-bank FIs, I are left with approximately 60 firms. ${ }^{10}$ For every year, I include only those firms for which all variables are available. This leaves us with a non-balanced panel with 46 banks, 7 periods and 210 observations (112 missing), with sizes ranging from 432 billion Euros for ABN AMRO Holding to 22 million Euros for Finansbank Holland. ${ }^{11}$ Of those 46 FIs, 13 are owned by foreign companies. Three large conglomerates form a distinct group in terms of size: ABN AMRO Holding, ING Group and Rabobank Group. In table 4.1, the typology of the 46 banks is presented; 34 are general banks, two of which are cooperative banks. Twelve institutions have a specialized nature.

As can be seen in table 4.2 , the total number of banks included per year in the data set varies from 21 to 35 . In table 4.3 , I give an overview of all banks and the number of years they have been included. I note that this is mostly the result of data availability.

In table 4.4, I present a few summary statistics for the variables involved. All quantity variables are in thousands of Euros and corrected for inflation. The explanatory variables are profit before tax $(P B T)$ and total cost $(T C)$. The former is recorded in the banks profit and loss account, whereas the latter is the sum of interest expenses, personnel expenses and other operating expenses. I identify three outputs. Loans $\left(y_{1}\right)$ is the total stock of all loans supplied by a bank. Investments $\left(y_{2}\right)$ is the sum of total securities, equity

${ }^{9}$ See Akhavein, Berger, and Humphrey (1997), Shaffer (1993) and Altunbas, Molyneux, and Thornton (1997) for analyses of big bank mergers. The effects of bank mergers for consumers are studied by Avkiran (1999) and Berger and Humphrey (1992). Vennet, Vander (1998) tries to predict mergers.

${ }^{10} \mathrm{~A}$ good example is ABN AMRO Lease Holding: although it has a banking license, I do not consider it a real 'bank' and hence it is removed from our sample data set.

${ }^{11}$ ABNAMRO figures for 1998, Finansbank Holland figures for 1994. Inflation adjusted. In order to check for selection bias, I compare my sample with the original data set. With respect to size distribution and profitability (two important indicators in the light of this study), there are no important difference between the sample and the original data set. Missing observations appear largely the result of data problems that occur at all banks alike. 
investments and other investments. The third output is deposits held with other banks $\left(y_{3}\right)$. As explained in section ?? and in line with Hughes and Mester (1993), I include equity $(z)$ as a control variable.

TABLE 4.3: Banks Included

\begin{tabular}{llllll}
\hline N & F & NAME & N & F & NAME \\
\hline 1 & 7 & ABN Amro Holding & 24 & 5 & GWK Bank \\
2 & 5 & Achmea Hypotheeklank & 25 & 4 & Hollandse Koopmans Bank \\
3 & 4 & Asahi Bank (Nederland) & 26 & 6 & Indonesische Overzeese Bank \\
4 & 3 & Bank Labouchere NV & 27 & 6 & ING Group \\
5 & 6 & Bank NL Gemeenten & 28 & 6 & Kas-Associatic \\
6 & 7 & Bank of Tokyo - Mitsubishi & 29 & 1 & KBC Bank Nederland \\
7 & 7 & Banque Artesia Nederland & 30 & 7 & Kempen en Co \\
8 & 4 & Banque de Suez Nederland & 31 & 5 & MeesPierson \\
9 & 7 & CenE Bankiers & 32 & 1 & Bank v/d Bouwnijverheid \\
10 & 3 & CITCO Bank & 33 & 7 & Nationale Investeringsbank \\
11 & 3 & Commerzbank & 34 & 1 & Waterschapsbank \\
12 & 4 & Cooperaticve Voorschotbank & 35 & 3 & Nedship Bank \\
13 & 7 & Dai-Ichi Kangyo Bank & 36 & 5 & Nomura Bank \\
14 & 7 & Delta Lloyd Bank & 37 & 4 & Rabobank Group \\
15 & 6 & Denir-Halk Bank & 38 & 3 & Robeco Effectenbank \\
16 & 6 & Deutsche Bank de Bary & 39 & 3 & SNS Reaal Groep \\
17 & 2 & Effectenbank Stroeve & 40 & 2 & Spaar en Voorschotbank \\
18 & 4 & F. van Lanschot Bankiers & 41 & 1 & Staal Bank \\
19 & 7 & FGH Bank NV & 42 & 5 & Tokai Bank Nederland \\
20 & 4 & Finansbank (Holland) & 43 & 1 & Triodos Bank \\
21 & 7 & Fortis Bank Nederland & 44 & 5 & United Garanti Bank Int. \\
22 & 7 & Friesland Bank & 45 & 2 & Van der Hoop Effektenbank \\
23 & 6 & Generale Bank Nederland & 46 & 4 & Westland/Utrecht Hyp. bank \\
\hline & & & & &
\end{tabular}

Finally, I identify three input prices. The price of financial capital, expressed in anmual percentages is constructed as: [Interest Expense/[Customer \& Short Term Funding + Other Funding] ]*100. Next, I compute the price of labor. Unfortunately, information about the number of people employed by banks is fragmentary. Therefore, I estimate the number of employees as follows. I assume a constant relationship between number of employees and fixed assets. For all banks in the Netherlands for which I have information about the number of employees, I regress the logarithm of the number of employees on the logarithm of fixed assets. ${ }^{12}$ This result is used to estimate the number of employees

${ }^{12}$ The result is: $\ln$ Employees $=3.215(0.104)+0.899(0.031) * \ln$ Fixed Assets, with an $\bar{R}$ of 0.885 . Standard errors are in parentheses. 
for all banks. The proxy for the price of labor is therefore composed as follows: Personnel Expenses/Estimated number of Employees.

TABLE 4.4: Summary Statistics

\begin{tabular}{lllllll}
\hline & & Min. & Max. & Mean & SD & Skew \\
\hline PBT & Profit Before Tax & 108 & 3504100 & 160591 & 540438 & 4.24 \\
$T C$ & Total Cost & 4889 & 33659600 & 1586822 & 5110147 & 4.02 \\
$y_{1}$ & Loans & 21443 & 221401700 & 11781323 & 35907411 & 3.95 \\
$y_{2}$ & Investnents & 520 & 141876600 & 5100788 & 19388943 & 4.93 \\
$y_{3}$ & Deposits with Banks & 3300 & 64700986 & 3466024 & 11850548 & 4.47 \\
$z$ & Equity & 7893 & 29077300 & 1099080 & 3706414 & 4.68 \\
$w_{1}$ & Price of Financial Capital & 0 & 11.97 & 5.45 & 2.05 & 0.39 \\
$w_{2}$ & Price of Labor & 0.02 & 337351 & 5164 & 34085 & 9.05 \\
$w_{3}$ & Price of Physical Capital & 18 & 1542 & 182 & 245 & 3.20 \\
\hline
\end{tabular}

SKEW $=$ Skewness, SD $=$ Standard Deviation

The price of physical capital $\left(w_{3}\right)$ is: [Other Operating Expense/Fixed Assets] ${ }^{*} 100$. Before estimation PBT, TC, $w_{1}$ and $w_{2}$ are divided by $w_{3}$, the price of physical capital to impose linear homogeneity in input prices, as explained in section ??.

\subsection{Estimation Results}

I now turn to the empirical analysis. In section 4.3.1, I first estimate the different model versions and compare the results. I note that in this chapter, I use a cost efficiency measure that lies between 1 (fully efficient) and $\infty$ (cf. chapter 3 ). I choose one model as the preferred model and interpret it. In section 4.3.2, I use the preferred models to compute individual and cross-section efficiency scores. I then investigate whether the consolidation and liberalization wave in the early 1990s leads to trendlike changes in estimated mean cost and profit efficiency over the period 1992-1998. In section 4.3.3, I take the efficiency scores for individiual FIs from the preferred models. I use these results to analyze differences in efficiency between large and small banks and between general and specialized banks.

\subsubsection{Estimated Cost and Profit Frontiers}

The detailed estimation results for versions $a, b$ and $c$ of the cost and profit models respectively are presented in table 4.6 and table $4.7 .^{13}$

\footnotetext{
${ }^{13}$ I start by estimating model a. The resulting maximum likelihood estimators are used as starting values for the grid search in the estimation of model $b$. For the additional variables of model $b$, I use starting values 0 . For $\sigma^{2}, \gamma$ and $\mu \mathrm{I}$ use the grid values of model a. The same procedure is used when I estimate model $\mathrm{c}$ (with the values from model b). This procedure ensures that I have a smooth grid search and run less risk of the grid stopping at a local
} 
FIGURE 4.1: Distribution Bank Specific Cost Efficiency Scores (Model 1c)

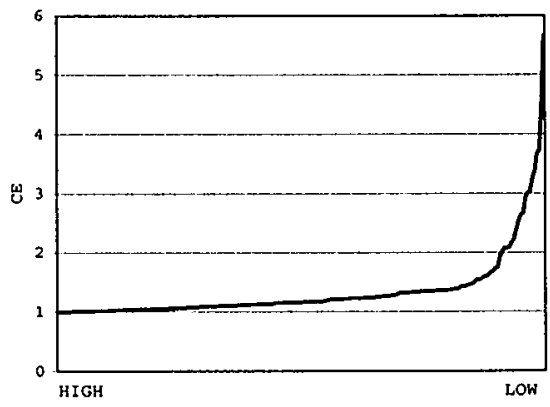

In table 4.6 and table 4.7 I also present 1-sided Log Likelihood Ratio (L.L.R.) tests of the standard response function [OLS] versus the full frontier model. ${ }^{1 / 4}$ The L.L.R. test results show that I can reject the restrictions imposed by OLS. Consequently I use the specification including a stochastic inefficiency term for all models.

FIGURE 4.2: Distribution Bank Specific Profit Efficiency Scores (Model 2b)

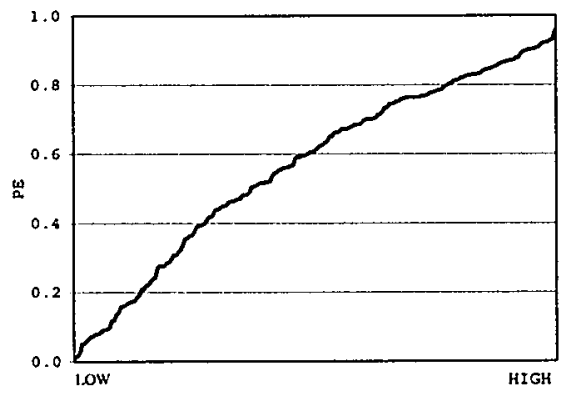

With respect to the estimated cost function in table 4.6, I note that $\gamma$, the share of inefficiency in the overall residual variance, is insignificantly different from 1 , which indicates a deterministic frontier. Also, for the cost model $\mu$ is significantly negative with a value of -0.66 for the model $1 c$. This means that the top of the half normal distribution

maximum. The maximum number of interations for the grid has been set at 10,000. To save space, the coefficient estimates for the interaction terms (except those including the time trend) have been left out. They are available upon request.

${ }^{14}$ See Kodde and Palm (1986). The null hypothesis in this test is $\gamma=0$ versus the alternative that $\gamma>0$. 
of the inefficiency term $u$ lies close to 1 , as is evident from figure 4.1. Hence most of the FIs are relatively cost efficient and average cost efficiency is high.

The profit efficiency results in table 4.7 show that again $\gamma$ is insignificantly different from 1 so that the efficient frontier is deterministic. The estimated value of $\mu$ is significantly negative but with a reported value of approximately -4 . This is a much larger value than was the case for the cost efficiency estimate. The impact of a different value of $\mu$ can be easily seen from a comparison of figures 4.1 and 4.2. These figures display the distribution of cost and profit efficiency scores respectively. In the case of cost efficiency, the relatively small value of $\mu$ indicates that the peak of the density function of inefficiency terms $(u)$ is close to zero. As a result, most individual efficiency scores are close to the full efficiency value of 1 . In figure 4.1 , this is reflected by the very flat path of the efficiency scores on the left side. The large negative $\mu$ for profit efficiency on the other hand implies that the peak of the density function of inefficiency terms is far away from zero. Consequently, most individual FIs are in the tail of the density, leading to wider dispersion of profit efficiency than of cost efficiency.

TABLE 4.5: Likelihood Ratio Test

\begin{tabular}{llllll}
\hline Model 1 & Restrictions & Test Statistic & Model 2 & Restrictions & Test Statistic \\
\hline LRTa,c & 8 & $42.68^{*}$ & LRTa,c & 8 & $12.67^{*}$ \\
LRTb,c & 6 & $15.23^{* *}$ & LRTb,c & 6 & 7.17 \\
LRTa,b & 2 & $27.44^{*}$ & LRTa,b & 2 & $5.51^{* *}$ \\
\hline \multicolumn{5}{c}{${ }^{* *}=$ significant at $1 \%,{ }^{*}=$ significant at $5 \%$} \\
\end{tabular}

Table 4.5 reports likelihood ratio tests for all models. The only case in which the null hypothesis is not rejected is for the test of model $2 \mathrm{~b}$ against model $2 \mathrm{c}$. In the remainder of this paper I therefore choose for models $1 \mathrm{c}$ and $2 \mathrm{~b}$, except when explicitly mentioned otherwise.

Interpretation of the regression coefficients requires much caution, due to the presence of a large number of nonlinear interaction terms. The marginal effect of an increase in the loan variable $\left(\ln \left(y_{1}\right)\right)$ on the respective dependent variables total costs (TC) or before tax profits (BTP) for instance is not measured by the magnitude of the coefficient on $\ln \left(y_{1}\right)$ alone, but by the combination of all coefficients on explanatory variables that include $\ln \left(y_{1}\right)$. Also note that coefficients are not elasticities as the left hand variables are in absolute numbers, not logarithms. With these caveats in mind, the following holds for the direct effects, excluding interaction terms. For cost model $1 \mathrm{c}$, all coefficients on the output variables carry a positive sign, although it is insignificant for $\ln \left(y_{1}\right)$, the loans variable. High equity holdings are significantly negatively correlated with total costs. The effect of input prices is diverse; it is high and significantly positive (2.08) for the price of financial capital $\left(w_{1}\right)$, low and significantly negative $(-0.31)$ for the price of labor $\left(w_{2}\right)$, and positive $(-2.08+0.31+1=0.77)$ for the price of physical capital $\left(w_{3}\right)$. The negative coefficient on $w_{2}$ suggests that total costs decrease with higher wages. The positive coefficient on the linear trend term $T$ suggests a shifting cost curve through time with higher costs (on 
the frontier) in later years. The negative squared trend coefficient offsets the linear trend effect as time goes on.

TABLE 4.6: Estimation Results under Cost Minimization (Model 1)

\begin{tabular}{|c|c|c|c|c|c|c|}
\hline MODEL & 1a & & $1 \mathrm{~b}$ & & $1 \mathrm{c}$ & \\
\hline & $\mathrm{B}$ & $\mathrm{t}$ & B & $\mathrm{t}$ & B & $\mathrm{t}$ \\
\hline INTERCEPT & 3.61 & 3.80 & 4.49 & 5.63 & 5.10 & 6.44 \\
\hline LNY1 & 0.53 & 1.25 & 0.39 & 1.14 & 0.10 & 0.28 \\
\hline LNY2 & 0.72 & 4.02 & 1.01 & 7.44 & 0.70 & 4.49 \\
\hline LNY3 & 0.28 & 1.55 & -0.05 & -0.30 & 0.65 & 3.50 \\
\hline $\mathrm{LNZ1}$ & -1.57 & -2.77 & -1.47 & -3.18 & -1.73 & -3.40 \\
\hline LNW13 & 1.70 & 11.76 & 2.01 & 17.73 & 2.08 & 14.14 \\
\hline LNW23 & -0.33 & -4.68 & -0.37 & -5.49 & -0.31 & -4.50 \\
\hline $\mathrm{T}$ & & & 0.12 & 3.86 & 0.37 & 4.64 \\
\hline $\mathrm{T}^{2}$ & & & -0.01 & -3.60 & -0.01 & -1.79 \\
\hline TlnY1 & & & & & -0.03 & -2.01 \\
\hline$T \ln Y 2$ & & & & & 0.01 & 1.30 \\
\hline $\mathrm{Tln} Y 3$ & & & & & -0.01 & -0.98 \\
\hline$T \ln W 13$ & & & & & -0.01 & -0.88 \\
\hline TlnW23 & & & & & 0.00 & 0.31 \\
\hline$T \ln Z_{1}$ & & & & & 0.00 & 0.12 \\
\hline$\sigma^{2}$ & 0.60 & 5.17 & 0.54 & 10.01 & 0.27 & 8.99 \\
\hline$\gamma$ & 1.00 & 763 & 1.00 & 3615108 & 1.00 & 81267 \\
\hline$\mu$ & -1.54 & -5.82 & -1.47 & -7.71 & -0.66 & -5.45 \\
\hline$\eta$ (restricted) & 0 & & 0 & & 0 & \\
\hline LL Function & 49.87 & & 63.59 & & 71.20 & \\
\hline LLR 1-sided & $103.40^{* *}$ & & $127.72^{* *}$ & & $124.97^{* *}$ & \\
\hline Iterations & 47 & & 50 & & 57 & \\
\hline
\end{tabular}

For the profit model $2 \mathrm{~b}$, the coefficients on both total loans $\left(y_{1}\right)$ and deposits with banks $\left(y_{3}\right)$ are negative and significant. The coefficient on $y_{2}$ on the other hand is not significantly different from zero. Overall, increasing the size of production leads to lower or at best equal profits, implying diseconomies of scale (again excluding the interaction effects). The coefficient on equity is positive and significant. Remember that the effect of equity in the cost estimation was significantly negative. The coefficient on the price of financial capital $\left(w_{1}\right)$ is significantly positive $(0.83)$. The coefficients on the prices of personnel $\left(w_{2}\right)$ and physical capital $\left(w_{3}\right)$ are small, viz. 0.24 and $-0.07(-0.83-0.24+1)$ and insignificant. Finally, the coefficients on the linear and squared trend terms are small and insignificant. This implies a stable efficient profit frontier over time. 
TABLE 4.7: Estimation Results under Profit Maximization (Model 2)

\begin{tabular}{|c|c|c|c|c|c|c|}
\hline MODEL & $2 a$ & & $2 b$ & & $2 c$ & \\
\hline & $\mathrm{B}$ & $\mathrm{t}$ & B & $t$ & B & $\mathrm{t}$ \\
\hline INTERCEPT & 5.42 & 4.96 & 5.42 & 4.96 & 6.25 & 5.87 \\
\hline LNY1 & -2.04 & -2.77 & -2.04 & -2.77 & -0.71 & -1.00 \\
\hline LNY2 & -0.16 & -0.27 & -0.16 & -0.27 & 0.40 & 0.67 \\
\hline LNY3 & -1.63 & -2.35 & -1.63 & -2.35 & -0.33 & -0.44 \\
\hline LNZ1 & 3.93 & 3.78 & 3.93 & 3.78 & 0.14 & 0.15 \\
\hline LNW13 & 0.83 & 2.38 & 0.83 & 2.38 & 1.17 & 2.30 \\
\hline LNW23 & 0.24 & 1.14 & 0.24 & 1.14 & -0.14 & -0.47 \\
\hline $\mathrm{T}$ & & & 0.01 & 0.08 & 0.50 & 1.51 \\
\hline $\mathrm{T}^{2}$ & & & 0.01 & 0.45 & 0.00 & 0.23 \\
\hline$T \ln Y 1$ & & & & & 0.00 & -0.07 \\
\hline$T \ln Y 2$ & & & & & 0.01 & 0.47 \\
\hline$T \ln Y 3$ & & & & & 0.02 & 0.76 \\
\hline$T \ln W 13$ & & & & & 0.00 & -0.09 \\
\hline$T \ln W 23$ & & & & & 0.02 & 1.49 \\
\hline$T \ln Z 1$ & & & & & -0.07 & -0.80 \\
\hline$\sigma^{2}$ & 5.15 & 4.18 & 4.95 & 4.05 & 4.32 & 3.96 \\
\hline$\gamma$ & 1.00 & 332 & 1.00 & 245 & 0.99 & 219 \\
\hline$\mu$ & -4.53 & -3.63 & -4.44 & -3.79 & -4.14 & -3.08 \\
\hline$\eta$ (restricted) & 0 & & 0 & & 0 & \\
\hline LL Function & -197.24 & & -194.49 & & -190.90 & \\
\hline LLR 1-sided & $65.17^{* *}$ & & $63.28^{* *}$ & & $56.25^{* *}$ & \\
\hline Iterations & 42 & & 44 & & 46 & \\
\hline
\end{tabular}

\subsubsection{Efficiency Scores}

Next, I turn to the efficiency scores that result from model $1 \mathrm{c}$ and model $2 \mathrm{~b}$. Remember that profit efficiency scores are in a range from 0 to 1 , where 1 indicates a bank is efficient and operates on the frontier. For cost efficiency, scores lie range from 1 to $\infty$, where an efficient bank again has a score of 1 . In table 4.8, I report a few summary statistics on cost and profit efficiency scores.

Table 4.8 shows that individual cost efficiencies vary from a high of 1.003 to a low of 5.658. Moreover, the mean cost efficiency of 1.35 suggests that most FIs have an efficiency score close to 1 .

This is consistent with the graphical evidence in figure 4.3. On the other hand, the distribution of individual profit efficiency scores is much flatter. This follows from the fact that mean profit efficiency is almost halfway the lowest efficiency score of 0.012 and the highest efficiency score of 0.956 . In addition, figure 4.3 provides graphical evidence on the relation between cost and profit efficiency scores for individual FIs. The scatter plot suggests a weak correlation between both scores. This is confirmed by the bilateral 
correlation coefficient between these two scores, which equals -0.114 . It provides evidence in support of the claim that both cost and profit efficiency need to be investigated. The larger spread in profit efficiency suggests that it is more susceptible to differences in market share, strategic positioning, and other 'market' circumstances.

TABLE 4.8: Summary Statistics Cost Efficiency and Profit Efficiency

\begin{tabular}{lrrrrrr}
\hline & $\mathrm{N}$ & Min. & Max. & Mean & SD & Skewness \\
\hline Cost Efficiency & 210 & 1.003 & 5.658 & 1.35 & 0.60 & 3.92 \\
Profit Efficiency & 210 & 0.012 & 0.956 & 0.56 & 0.26 & -0.50 \\
\hline
\end{tabular}

I now investigate whether in the period after the consolidation in the Dutch banking market in the period 1989-1991 cost and profit efficiency followed a steady trend. To this purpose I compute the time paths of annual average cost and profit efficiency for the period 1992-1998 on the basis of the estimation results. Figure 4.4 reports mean cost efficiency for the years 1992-1998, both unweighted and weighted by total assets. Figure 4.5 does the same for mean profit efficiency.

FIGURE 4.3: Scatter Plot of Cost Efficiency and Profit Efficiency

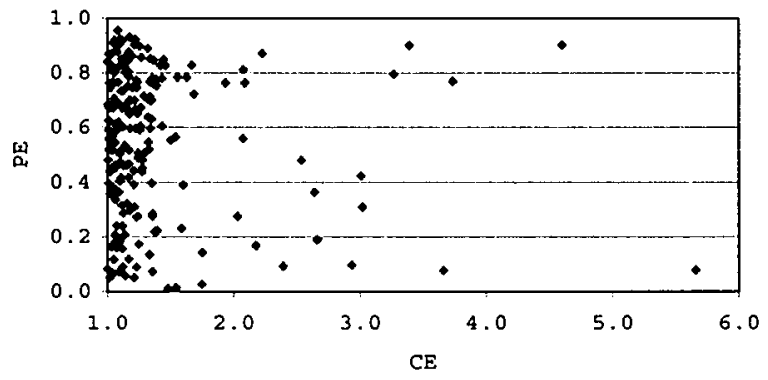

From figure 4.4, it appears that the drawn line representing weighted mean cost efficiency lies below the dotted line for unweighted mean cost efficiency in every year. This is especially the case in 1992 and after 1995. In addition, the figure shows that weighted mean cost efficiency is relatively variable over time. In the years 1992 and 1996-1997 weighted mean cost efficiency is substantially higher than in the period 1993-1995. The evidence suggests that on average larger firms are more cost efficient than smaller firms. Only in the period 1993-1995 do the larger firms seem to lose their competitive edge on the cost efficiency side. I hypothesize that this temporary effect could be due to the necessary adjustment of especially large FIs to both the merger wave in the early nineties and the European liberalization process. Note that the impact of a number of impor- 
FIGURE 4.4: Cost Efficiency Trend

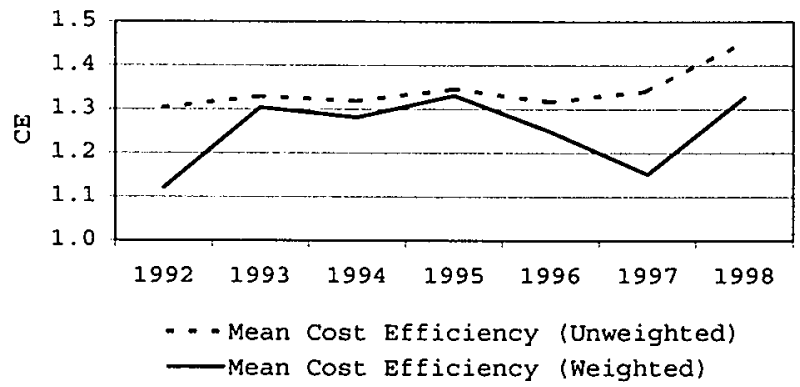

tant mergers may not be confined to the FIs directly involved but also on other market participants because of the resulting change in general market conditions. ${ }^{15}$

FIGURE 4.5: Profit Efficiency Trend

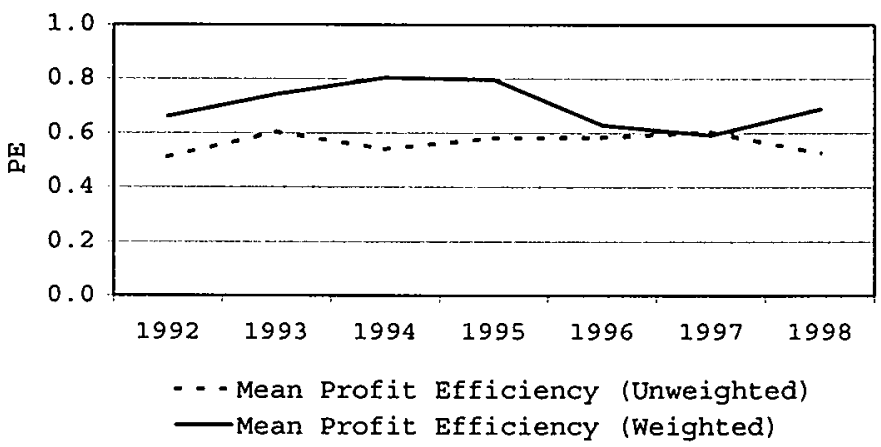

In figure 4.5 unweighted mean profit efficiency is stable at a level around 0.6. As with cost efficiency, the drawn line representing weighted profit efficiency is closer to the full efficiency level - now higher - than the dotted line which indicates unweighted profit efficiency. Again, larger banks are more profit efficient. However, the difference becomes negligible in 1996 and 1997 . To what extent the widening of the gap in 1998 is permanent cannot be judged on the basis of the data. Clearly, the European integration and liberalization process and the consequent expected increase in competition hardly affected mean profit efficiency in the first half of the nineties. Also, as is apparent from figure 4.3, there is not a strong relation between cost and profit efficiency.

${ }^{15}$ I refer to Akhavein, Berger, and Humphrey (1997) and Altunbas, Molyneux, and Thornton (1997) for an analysis of the effect of individual cases of consolidation on the entire industry. 
The observed decrease in profit efficiency for especially the larger FIs in the sample in 1996-1997 may be a lagged response to the change in European market conditions. Certainly, larger general banks operating internationally might be expected to be affected more than smaller general banks, operating only within the Netherlands. On the other hand, small domestic specialized FIs might feel the pressure of increased competition from abroad too, due to the fact that market entry is probably easier in specialized market segments than in the retail market that small general banks operate in normally.

In summary, I conclude that firm-to-firm profit efficiency varies more than cost efficiency. Secondly, in both models average performance remains stable over time, suggesting little overall impact of consolidation and deregulation on industry efficiency. Thirdly, whereas many banks have a relatively high cost efficiency, profit efficiency for many banks is relatively low. This is in line with Berger, Hancock, and Humphrey (1993) and Akhavein, Berger, and Humphrey (1997), who show that the inefficiencies arising from the output side appear to be of larger magnitude than those appearing on the input side. Finally, when comparing all observations, there is no clear correlation between profit efficiency and cost efficiency.

\subsubsection{Testing Equality of Efficiency}

In this section, I analyze differences in cost and profit efficiency across individual banks in more detail. To this purpose, I first distinguish between large and small banks. The large banks in the sample are ABN AMRO, ING, and Rabobank, all three of which have a balance sheet size exceeding 80 billion Dutch guilders. Note that these three banks account for around 85 percent of the Dutch deposit and loan markets. Of the total number of available bank-year observations (210), 17 are for the three large banks, while the remaining 193 correspond to observations for the other banks. ${ }^{16}$ In the group of small banks both general banks and specialised institutions are included. Before I discuss the results, I would like to make the caveat that the number of observations in the tests is generally quite low.

In table 4.9, I report independent sample t-tests for the null hypothesis of equality in mean cost and profit efficiency, respectively, for large versus small banks. ${ }^{17}$ I report two t-test statistics. In the first test (test 1) I assume equal sample variances, while in the

\footnotetext{
${ }^{16}$ Note that in 1992 ING Group is missing in BankScope.

${ }^{17}$ Alternatively, I could choose a nonparametric test like a Mann-Whitney U test. Or I could use a likelihood ratio test. For ease of interpretation, I use a simple t-test instead. Results do not differ qualitatively if tested in either of the above suggested ways.
} 
second (test 2) I release this assumption. In addition, I report an $\mathrm{F}$-test $\left(\mathrm{F}^{*}\right)$ on the null hypothesis that the sample variances are indeed equal. ${ }^{18}$

TABLE 4.9: Independent Samples Large Vs Small Banks

\begin{tabular}{lllllllllll}
\hline CE & $\mathrm{N}$ & Mean & SD & & PE & N & Mean & SD & \\
\hline Large & 17 & 1.248 & 0.227 & & & Large & 17 & 0.690 & 0.164 & \\
Small & 193 & 1.357 & 0.541 & & & Small & 193 & 0.564 & 0.254 & \\
\hline Test & $\mathrm{F}^{*}$ & Sig. & $\mathrm{t}$ & Sig.** $^{* *}$ & Test & $\mathrm{F}^{*}$ & Sig. & $\mathrm{t}$ & Sig.** \\
\hline test 1 & 1.594 & 0.208 & -0.819 & 0.414 & test 1 & 5.621 & 0.019 & 2.009 & 0.046 \\
test 2 & & & -1.608 & 0.117 & test 2 & & & 2.882 & 0.008 \\
\hline
\end{tabular}

test. $1(2)=$ Equal variances (not) assumed, ${ }^{*}=$ Levene's test for equality of variances.

$$
* *=2 \text {-tailed. }
$$

The results in table 4.9 show that mean cost efficiency is marginally higher - closer to unity - for large banks than for small banks. However, the two t-tests show that this difference is statistically insignificant. Since the F-test on equal variances is not rejected at conventional significance levels, I prefer test 1 . In the case of profit efficiency, the conclusions are quite different. First, the difference in mean profit efficiency between large and small banks is considerably more pronounced than was the case for mean cost efficiency. Second, the assumption on equal variances is strongly rejected, so that t-test 2 is more appropriate. Both t-test 1 and 2 give the same message, though. According to the results, large banks are significantly more profit efficient than small banks. Overall, the results suggest that large banks are unable to exploit their size advantage on the cost side, while they do have better performance on the profit side. A possible explanation is the presence of more opportunities of scale economies on the output side than on the input side. Alternatively, the dominance of the big three on the Dutch market may allow them to reap gains from price leadership and a lack of effective competition.

\footnotetext{
${ }^{18}$ Here, I opt for Levene's robustness test since it is less dependent on the assumption of normality than most tests. In short: $s_{\bar{x}_{1}-\bar{x}_{2}}=\sqrt{\frac{s_{1}^{2}}{n_{1}}+\frac{s_{2}^{2}}{n_{2}}}$, where - if population variances are not equal - degrees of freedom are: $d f=\frac{\left(\frac{s_{1}^{2}}{n_{1}}+\frac{s_{2}^{2}}{n_{2}}\right)^{2}}{\left(\frac{\frac{s_{1}^{2}}{n_{1}}}{n_{1}-1}+\frac{\frac{s_{2}^{2}}{n_{2}}}{n_{2}-1}\right)}$
} 
TABLE 4.10: Independent Samples Test Large and Small General Banks

\begin{tabular}{|c|c|c|c|c|c|c|c|c|c|}
\hline $\mathrm{CE}$ & $\mathrm{N}$ & Mean & SD & & $\mathrm{PE}$ & $\mathrm{N}$ & Mean & SD & \\
\hline Large & 17 & 1.277 & 0.458 & & Large & 17 & 0.690 & 0.164 & \\
\hline Small Gen. & 146 & 1.380 & 0.666 & & Small Gen. & 146 & 0.530 & 0.255 & \\
\hline Test & $F^{*}$ & Sig. & $t$ & Sig. ${ }^{* *}$ & Test & $F^{*}$ & Sig. & $t$ & Sig.** \\
\hline test 1 & 1.348 & 0.247 & 0.618 & 0.537 & test 1 & 5.289 & 0.023 & -2.520 & 0.013 \\
\hline test 2 & & & 0.828 & 0.415 & test. 2 & & & -3.554 & 0.001 \\
\hline
\end{tabular}

test $1(2)=$ Equal variances (not) assumed, ${ }^{*}=$ Levene's test for equality of variances.

$$
* *=2 \text {-tailed. }
$$

Potentially, the joint presence of general and specialized banks in the group of small banks may have an impact on the conclusions from table 4.9. Therefore, I now repeat the analysis for general banks only, excluding specialized institutions. In table 4.10, I test for the equality of mean cost and profit efficiency respectively between large general banks and small general banks. Due to the exclusion of specialized banks the number of bank-year observations in the group of small banks falls from 193 to 146.

The test results are qualitatively similar to those in table 4.9 . I confirm the absence of a significant difference in mean cost efficiency between large and small general banks, and the presence of a significant difference in mean profit efficiency. Large general banks perform better than small ones in terms of profit efficiency.

TABLE 4.11: Independent Samples Tests Small General and Specialized Banks

\begin{tabular}{|c|c|c|c|c|c|c|c|c|c|}
\hline $\mathrm{CE}$ & $\mathrm{N}$ & Mean & SD & & $\mathrm{PE}$ & $\mathrm{N}$ & Mean & SD & \\
\hline Specialized & 47 & 1.297 & 0.407 & & Specialized & 47 & 0.669 & 0.220 & \\
\hline Small Gen. & 146 & 1.380 & 0.666 & & Small Gen. & 146 & 0.530 & 0.255 & \\
\hline Test & $\mathrm{F}^{*}$ & Sig. & t & Sig.** & Test & $\mathrm{F}^{*}$ & Sig. & t & Sig.** \\
\hline test 1 & 2.990 & 0.085 & 0.805 & 0.422 & test 1 & 1.981 & 0.161 & -3.356 & 0.001 \\
\hline test 2 & & & 1.022 & 0.309 & test 2 & & & -3.618 & 0.000 \\
\hline
\end{tabular}
2-tailed.

In table 4.11, I subsequently partition the total group of small banks into general and specialized institutions. Again, I test for equal mean cost and profit efficiency. As before, no significant differences in mean cost efficiency are found. Note that the $F$ test on equal variances here is rejected at the 10 percent level. This result makes a choice between the two t-tests somewhat difficult. However, since the t-tests give the same outcome, it has no impact on the conclusion. Turning to the results for mean profit efficiency, one clearly sees it to be significantly higher for specialized institutions than for small general banks. Again, I reject the assumption of equal variances at the 10 percent level. The two t-tests unambiguously point to the same conclusion.

Finally, table 4.12 compares mean cost and profit efficiency for large general banks on the one hand and small specialised institutions on the other. Even more so than in the 
previous tables, the number of observations is small. Consequently, caution is in order in interpreting the results. Given this caveat, the table suggests that neither mean cost efficiency nor mean profit efficiency differ significantly between large general banks and small specialized institutions.

TABLE 4.12: Independent Samples Tests Large General and Small Specialized Banks

\begin{tabular}{|c|c|c|c|c|c|c|c|c|c|}
\hline $\mathrm{CE}$ & $\mathrm{N}$ & Mcan & SD & & $\mathrm{PE}$ & $\mathrm{N}$ & Mean & $\mathrm{SD}$ & \\
\hline Large Gen. & 17 & 1.277 & 0.458 & & Large Gen. & 17 & 0.712 & 0.178 & \\
\hline Small Spec. & 47 & 1.297 & 0.407 & & Small Spec. & 47 & 0.674 & 0.224 & \\
\hline Test & $\mathrm{F}^{*}$ & Sig. & $t$ & Sig.** & Test & $\mathrm{F}^{*}$ & Sig. & $\mathrm{t}$ & Sig.** \\
\hline test 1 & 0.016 & 0.899 & -0.167 & 0.868 & test 1 & 1.833 & 0.181 & 0.628 & 0.533 \\
\hline test 2 & & & -0.158 & 0.876 & test 2 & & & 0.700 & 0.489 \\
\hline
\end{tabular}

test $1(2)=$ Equal variances (not) assumed, ${ }^{*}=$ Levene's test for equality of variances. ${ }^{* *}=$ 2-tailed.

Overall, two conclusions emerge. First, differences in mean cost efficiency between different groups of FIs in the Netherlands are small. Neither specialization nor size offer a systematic comparative advantage on the cost side. Second, significant differences do exist in terms of mean profit efficiency. Both size due to market power or scale economies and specialization in a niche market lead to higher than average profit efficiency. Small general banks are the losers on average. As a corollary, I conclude that the exclusive focus on cost efficiency and the neglect of profit efficiency that is quite common in the literature is inappropriate and may lead to incorrect inferences.

\subsection{Conclusion}

In this chapter, I investigate cost and profit efficiency in the Dutch banking industry between 1992 and 1998. Prior to this period both a consolidation wave and a major deregulation took place. The period itself is characterized by the absence of major institutional changes. For the analysis I use both a stochastic frontier cost and profit model. I estimate a translog functional form, also including linear and quadratic trend terms. Inefficiency is modelled as a truncated normal distribution. The results show that both the cost and profit frontiers are deterministic. In summary, I conclude that firm to firm profit efficiency varies more than cost efficiency. Secondly, whereas many banks have a relatively high cost efficiency, profit efficiency for many banks is relatively low. This is in line with Berger, Hancock, and Humphrey (1993) and Akhavein, Berger, and Humphrey (1997), who show that the inefficiencies arising from the output side appear to be of larger magnitude than those appearing on the input side. Thirdly, when comparing all observations, there is no clear correlation between profit efficiency and cost efficiency. As mentioned, market conditions may explain this result. ${ }^{19}$

\footnotetext{
${ }^{19}$ See also chapter 7 .
} 
I then focus on two issues. First, I analyze whether average cost and profit efficiency in the period 1992-1998 display a significant time trend. Such a trend might be the result of a gradual impact of the preceding consolidation and deregulation as suggested by the literature. In both models average performance remains stable over time, suggesting little overall impact of consolidation and deregulation on industry efficiency.

Second, I distinguish between FIs of different type and size and test for systematic differences in cost and profit efficiency between these groups. I find that whereas all banks appear to perform rather similarly in terms of cost efficiency, in terms of profit efficiency large general banks and specialized banks clearly outperform small, general banks. Large banks appear to benefit from sheer size and perhaps market power, whereas specialized banks continue to operate safely and efficiently in what might be termed a niche market. 



\section{5}

\section{Market Power in the Dutch Banking Market: Empirical Evidence 1992-1998}

\subsection{Introduction}

I now return to market power models. As I explained in chapter 2, Structure-ConductPerformance $[\mathrm{SCP}]$ models are a widely used method to assess competitive conditions in banking markets. The SCP hypothesis explains the performance of firms by the structure of the market and is based on the premise that a more concentrated market indicates higher market power and consequently better performance. ${ }^{1}$ However, a sound theoretical framework for the SCP models tested is generally lacking. Also, empirical tests of this hypothesis tend to be inconclusive and have insignificant results. ${ }^{2}$

In this chapter I try to improve upon the traditional SCP model. I try to find a more solid theoretical underpinning for a market power study. In addition, I attempt to establish a better way of testing the SCP hypothesis and the Efficiency hypothesis against each other.

In doing so, I examine competitive conditions in the Dutch banking market over the period 1992-1998. The Netherlands has the highest banking market concentration in the European Union, with the market share of the three largest banks summing to roughly $80 \%{ }^{3}$ As such, it provides a good case for testing whether market power is a driving force behind bank performance.

Section 5.2 discusses some of the key features of the Dutch banking market. I summarize - in sofar as available - the conclusions of other market power studies of the Dutch banking market.

In section 5.3 I introduce a version of the traditional SCP model that is similar to the models described in an overview of SCP studies for European banking markets by Molyneux, Altunbas, and Gardener (1997). First, I describe the data to be used in this and the next section. Upon shortly describing the model, I return to some of the flaws of SCP studies.

Then I introduce a simple Cournot model in section 5.4 and show how it can also provide a test for the existence of market power. In doing so, I emphasize how it solves some of the problems associated with SCP models. Next, I discuss the Efficiency hypothesis in section 5.5. I focus on the identification problem that exists when the SCP hypothesis is tested against an alternative hypothesis, the Efficiency hypothesis. I propose an alternative test of the Efficiency hypothesis. I conclude in section 5.6.

\footnotetext{
${ }^{1}$ For an introduction see Molyneux, Altunbas, and Gardener (1997), chapter 4.

${ }^{2}$ See chapter 2 and Molyneux, Altunbas, and Gardener (1997), chapter 4 and appendix I.

${ }^{3}$ Measured by deposits or balance sheet total. See also table 5.1.
} 


\subsection{The Dutch Banking Market}

As described in the previous chapter, the Dutch banking market is dominated by three large banks (ABN AMRO, ING, Rabobank), who together share roughly $80 \%$ of the Dutch banking market. Molyneux (2000), in an overview of financial restructuring in the European Union, cites deregulation and technological change as "lowering entry barriers and making markets more contestable" [p. 1]. This supports his claim that "there is little evidence to suggest that market structure and bank size strongly influence performance" [p. 2]. Combined, these statements raise two important questions. First, to what extent is there indeed such a thing as a Dutch banking market? Second, to what extent has the literature on SCP models been using the wrong measurements of market power?

\subsubsection{Market Definition}

To be sure, the answer to the second question depends on the answer to the first question. If it turns out market power studies have been using the wrong market definitions, then their results will always be biased.

In general, the observation in the literature that deregulation and technological change have led to more contestable banking markets lacks convincing empirical support. Crossborder mergers are rare and difficult to realize (cf. ING and ABN AMRO's battle over Banque Bruxelles Lambert). The mergers that have taken place sofar still have to prove they are a success. Also, revenue from internet banking is still very small as is the number of customers. With well-established national branch networks by leading banks, entry barriers for foreign commercial banks seeking to enter into private banking are still significant.

For the European Union as a whole on the other hand, Molyneux (2000)finds that "[T]he only systems where foreign banks are strongly involved in domestic banking activities are Belgium, the Netherlands and Portugal" [p. 4]. His findings also point out that only in Germany, Italy, and Spain there is an increase in the number of branches in the 1990s. In Italy and Spain this is the result of a removal of branching and territorial restrictions, whereas in Germany "the increase in branch numbers has mainly been a reflection of expansion of the savings bank sector reflecting increased non-price competition" [p. 5]. In the Netherlands, the number of branches is very stable, after an initial decline following the creation of ABN AMRO and ING Group respectively: 7,518 in 1992 compared to 7,219 in 1996. In short, whereas there has been an increase in the involvement of foreign banks in the Netherlands, this has not led to an increase in the total number of branches.

That is not to say there is no increase in competition to be expected anywhere; the mere increase in size that often results from a merger gives banks leverage effects that make it easier to compete in investment banking or invest in ICT projects with high fixed costs. 
It is important to take note of the fact that most of the increases in competition that result from the deregulation and technological trends that are emphasized by Molyneux (2000) (and others, including myself) are in areas where there is at present little concern over market power. It is in the domains of consumer loans, deposits, mortgages and other products for which switching costs and search costs are (relatively) high where I should be concerned over market power and the impact its abuse has on consumers. ${ }^{-1}$

For the Netherlands, Fase (1997) finds that cross-border substitutability between domestic and foreign deposits is almost non-existent. He estimates cross-border substitutability for the period 1984-1994 and, using $M_{2}$ as a denominator for the share of cross-border deposits find a substitution elasticity of 0.22 (and standard error of 0.07 ).

Hassan, Lozano-Vivas, and Pastor (2000) examine bank cross-border performance in Europe. Their findings confirm what becomes apparent from most banks' annual reports: bank performance is still predominantly 'national', with only modest revenue and profits from cross-border activities.

Huizinga (1998) describes the entry of foreign banks in the Dutch banking market. At the end of the 1980s and the beginning of the 1990s, a number of foreign banks entered the market or significantly expanded their presence on the Dutch banking market. For some (mostly German) banks, their presence on the Dutch banking market was clearly an attempt to get a foothold in the market. Other banks (mostly Asian and American) merely started branches that have a banking license but are aimed at servicing existing clients abroad. The presence of both groups of foreign banks on the Dutch banking market has increased during the $1990 \mathrm{~s}$, but in total is still marginal. Included in the analysis in this chapter are only those banks that try to compete with other banks in a broad range of services. This group consists of commercial banks with a banking license that offer loans and deposits to both commercial and private clients. ${ }^{5}$

Excluded from my analysis here is the branching network of banks. Research indicates that this may be an important factor in creating market power. ${ }^{\circ}$ Accurate data on branching networks are not available in IBCA/BankScope. However, in accordance with the analysis in the previous chapter, I distinguish between the three large banks, a group of small general banks and a group of specialized banks. I include dummies for the latter two groups. The three large banks are the only banks that have established truly national branching networks. The small(er) general banks have regional networks that

\footnotetext{
${ }^{4}$ As a sidestep from the discussion, consider the following: a bank with a relatively large foreign revenuc can benefit from a dominant position on its home market in two ways. First, its market power may allow it to increase prices, thus increasing domestic revenue and directly increasing profits. Sccond, it may use its domestic monopoly rents to help finance its foreign expansion and thus indirectly support profits. It seems that the latter plan is frequently used by European banks venturing into investment banking.

${ }^{5}$ This was checked through a telephone survey.

'See also chapter 7 .
} 
FIGURE 5.1: Structure Dutch Deposit Market

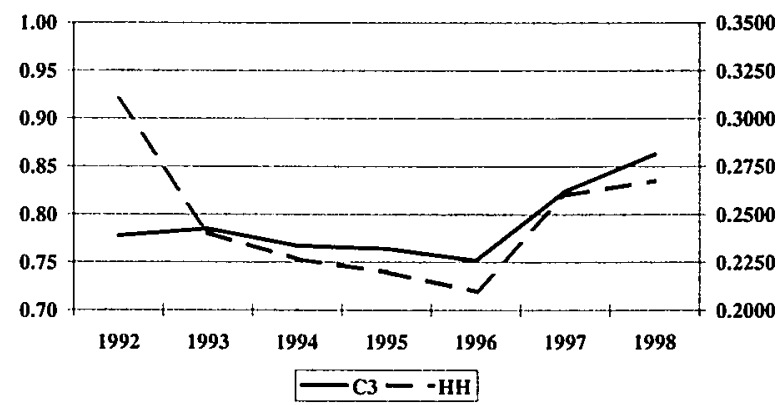

are occasionally quite extensive (e.g. SNS bank). The specialized banks have very small networks.

Summing up, I consider the Dutch retail banking market, in particular the market for deposits, as still confined to a large extent by its national borders.

\subsubsection{Market Power}

In order to answer the second question, I first describe some characteristics and developments of the structure of the Dutch banking market. Next, I briefly summarize some empirical evidence with respect to the (non-)existence of market power in the Dutch banking market.

In the beginning of the 1990s, the Dutch banking market experienced a rapid consolidation phase as a result of a series of mega-mergers that created ABN AMRO and ING. ${ }^{7}$ In 1990, the Fortis Conglomerate was set up in the Netherlands and Belgium as a much looser form of the same principle. As a consequence, the Netherlands currently has the highest market concentration of all EU countries, with the market share of the three largest banks in the market for deposits summing to more than $85 \%$ in 1998 (see figure 5.1).

As can be seen from table 5.1, the number of banks included increases slightly before decreasing again. This is the combined effect of several things. First, for later years data availability increases and thereby it becomes possible to include more banks for which I have good data. Second, as observed by De Leeuw (1996), next to an influx of foreign banks there was also an increase in the demand for banking licenses as more financial

\footnotetext{
${ }^{7}$ The ABN AMRO merger took place in 1990. ING Group was formed in 1989 through a merger of NMB and Postbank with Dutch insurance company Internationale Nederlanden. In 1991, Bank Mees en Hope and Pierson merged to form MeesPierson (effective in 1992). Summing up, 1993 is the first full year after the three mega-mergers took place.
} 
institutions started roaming in the field of commercial banks. To the extent that these institutions effectively started supplying loans and demanding deposits, this is reflected in the data. Finally, there is the net effect of entry and exit. Important to note is that for all years, market coverage is over $95 \%$.

The $C_{3}$ ratio remains relatively stable over the entire period, but expands slightly in 1997/1998, amongst other through growth of ABN AMRO and ING Group. The Hirschman-Herfindahl index mostly follows this trend, but - as can be seen in table 5.1 and figure 5.1 more prominently captures the entry of small foreign players through a marked decrease in 1993. Finally, market share $M S$ follows the same trends. As becomes clear from table 5.1, small players are very small indeed on the Dutch banking market, with market shares of $0.006 \%$ in $1998 .^{8}$

TABLE 5.1: Structure Dutch Deposit Market

\begin{tabular}{|c|c|c|c|c|c|c|}
\hline Year & $\mathrm{N}$ & $\overline{\mathrm{C}_{3}}$ & $\mathrm{HH}$ & $\begin{array}{l}\text { MS } \\
\text { Mean (SD) }\end{array}$ & Minimum & Maximum \\
\hline 1992 & 42 & 0.7777 & 0.3098 & $0.0244(0.0845)$ & 0.00012 & 0.4955 \\
\hline 1993 & 49 & 0.7850 & 0.2401 & $0.0212(0.0690)$ & 0.00009 & 0.4066 \\
\hline 1994 & 56 & 0.7674 & 0.2265 & $0.0187(0.0632)$ & 0.00003 & 0.3892 \\
\hline 1995 & 63 & 0.7639 & 0.2199 & $0.0169(0.0597)$ & 0.00007 & 0.3767 \\
\hline 1996 & 62 & 0.7520 & 0.2097 & $0.0176(0.0591)$ & 0.00008 & 0.3558 \\
\hline 1997 & 54 & 0.8244 & 0.2600 & $0.0194(0.0694)$ & 0.00006 & 0.4174 \\
\hline 1998 & 47 & 0.8625 & 0.2675 & $0.0220(0.0747)$ & 0.00006 & 0.3901 \\
\hline
\end{tabular}

Haaf (2000) uses a Lorenz curve to describe the "size inequality of the banks in the Dutch banking sector" [p. 32]. As can be seen from figure 5.2, 75\% of the banks in the Netherlands account for only $10 \%$ of deposits. Interesting in this respect is the big difference between the largest small banks and the top three banks in the Netherlands. In light of the arguments raised in the previous chapter this highly skewed size distribution is hard to capture by many market structure variables used in traditional SCP models.

Although the numbers described so far suggest otherwise, there is little evidence in the literature to suggest that there is indeed market power in the Dutch banking market.

Canals (1994) and Molyneux, Altunbas, and Gardener (1997) include a descriptive analysis of European banking markets. Interestingly, although he does not include the Netherlands, Canals (1994) hints at possible signs of market power in banking markets (Germany, Italy) less concentrated than the Netherlands. Molyneux, Altunbas, and Gar-

\footnotetext{
${ }^{8}$ Note that both $C_{3}, H H$ and $M S$ do not change much when based on a different variable such as total assets or loans.

${ }^{9} \mathrm{Her}$ analysis is based on total assets, but the main conclusions stay the same.
} 
dener (1997) also cite a range of European SCP studies, but find that the results are far from conclusive. Importantly though, in many cases evidence of market power disappears when the SCP hypothesis is tested against the Efficiency hypothesis. Molyneux and Forbes (1995) and Altunbas and Molyneux (1994) confirm this in an empirical analysis of European banking markets. However, Molyneux and Thornton (1992) already suggested that the link between market share and profitability is a lot stronger than the link between market structure and profitability. This idea is especially interesting given the observation in Molyneux, Altunbas, and Gardener (1997) that scale economies are very small in European banking.

FIGURE 5.2: Lorenz Curve Dutch Deposit Market (1992)

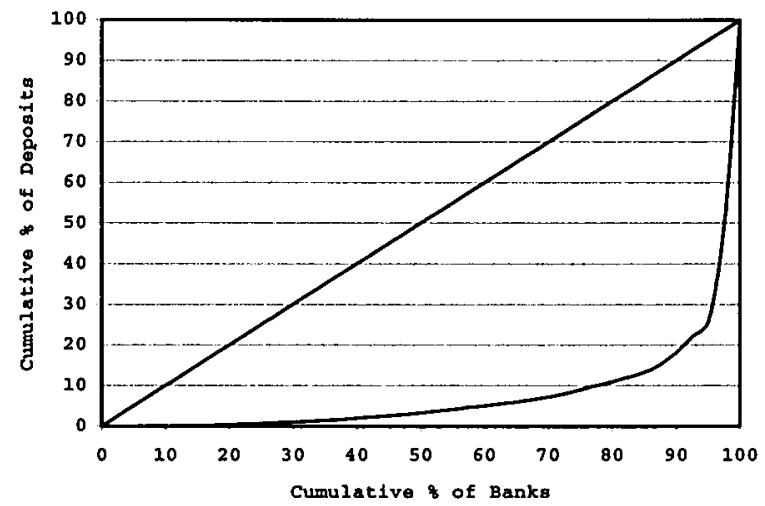

Goldberg and Rai (1996) and Economic Research Ltd. (1997) also use the SCP model and find similar results. Using a different setup however, Vennet, Vander (1994) and Vennet, Vander (1996) analyze the impact of concentration, mergers, efficiency and entry barriers on European bank profitability. In line with the above, evidence of a significant impact from a decrease in entry barriers is absent. Mergers however, do seem to have some influence on bank profitability. In a more direct test of market power, Bikker and Groeneveld (1998) test the Ross-Panzar H-statistic and also find evidence of (limited) market power.

Concluding, evidence of market power is mixed, but it does appear to depend on the method in which market power is tested. In addition, inclusion of the Efficiency hypothesis alters results rather drastically. In the next two sections, I tackle both issues. 


\subsection{The SCP Model}

\subsubsection{Model Setup}

As explained in chapter 2, SCP models are loosely based on Chamberlin's oligopoly theory (Chamberlin (1933)) and seek to explain firm performance through market structure conditions, such as number and size distribution of firms and entry condition in the market. The hypothesis that structure determines performance relies on the assumption that firm conduct is the direct result of market structure.

Rationales for testing the SCP hypothesis on banks include the stability, efficiency and competitiveness of banking markets and are usually based on concerns about the effects of bank consolidation on consumers (Molyneux, Altunbas, and Gardener (1997) and Economic Research Ltd. (1997)). Especially in Europe's highly concentrated banking markets, banks might be able to reap oligopoly profits on their home markets - perhaps to cross-subisidize their international competitive efforts (see also Cecchini (1988) and Price Waterhouse (1988)).

The basic SCP model can be formulated as follows (where $t$ is time): ${ }^{10}$

$$
P_{t}=f\left(M_{t}, D_{t}, C_{t}\right)
$$

where $P$ is a performance measure, $M$ a (set of) market structure variable(s), $D$ a (set of) demand variable(s) and $C$ a set of firm/product-specific control variables such as cost variables.

\subsubsection{Variables}

I use the IBCA data provided through BankScope. Taking care of overlap due to holding companies and eliminating non-bank financial intermediaries (e.g. ABN AMRO Lease Holding), I am left with approximately 60 banks. For every year, I include only those firms for which all variables are available. This leaves me with an unbalanced panel of 7 years. Important to note is that coverage of the market is never below $95 \%$.

For performance measurement and market structure measures there is a wide range of variables used in the literature. No agreement exists as to which measures are superior. ${ }^{11}$ Performance measures range from purely financial measures such as profits, return on equity [R.O.E.], and return on assets [R.O.A.] to more eclectic measures such as market share stability, expenses and the number of bank employees (see also chapter 2). Most SCP studies use either R.O.E. or R.O.A.. I will do the same, and opt for R.O.A. since it is invariant to (changes in) market capitalization.

\footnotetext{
${ }^{10}$ See Molyneux, Altunbas, and Gardener (1997), p. 97. A seminal reference is Rhoades (1977).

${ }^{11}$ See chapter 2, Molyneux, Altunbas, and Gardener (1997)(chapter 4 and appendix I), Gilbert (1984), Heggestad (1979) and Berger (1995) for overviews of SCP studies of banking markets.
} 
TABLE 5.2: Descriptives Full Sample

\begin{tabular}{lrrrrrrr}
\hline Variable & \multicolumn{1}{c}{ Mean } & Std.Dev. & Skew. $^{\alpha}$ & Kurt. $^{\beta}$ & Min. & Max. & N \\
\hline PFR & 0.9305 & 0.1427 & -1.44 & 8.05 & 0.2 & 1.3704 & 351 \\
R.O.A. & 0.0062 & 0.0079 & 4.54 & 33.36 & -0.0097 & 0.0811 & 351 \\
MS & 0.0198 & 0.0675 & 4.62 & 24.99 & 0.00003 & 0.4955 & 351 \\
C $_{3}$ & 0.7884 & 0.0359 & 1.03 & 2.71 & 0.752 & 0.8625 & 351 \\
HH & 0.244405 & 0.030772 & 0.85 & 2.77 & 0.209724 & 0.309753 & 351 \\
RISK & 0.502455 & 0.248834 & 0.05 & 2.33 & 0.001109 & 0.983561 & 351 \\
LIQUIDITY & 0.3264 & 0.2201 & 0.46 & 2.43 & 0.0007 & 0.8799 & 351 \\
COST & 0.685 & 0.2188 & -0.41 & 3.30 & 0.0607 & 1.4 & 351 \\
MARKET & 0.57094 & 0.120364 & 0.16 & 2.64 & 0.358904 & 0.790087 & 351 \\
\hline \multicolumn{7}{c}{$\alpha .=$ skcwness, $\beta=$ kurtosis } \\
\end{tabular}

For the Cournot model introduced in the next section, I use the same set of variables, with two exceptions. Instead of R.O.A. I use a markup which is derived from a Cournot model. It consists of total revenue minus variable costs as a ratio over total revenue, which is in turn equal to profits (P) plus fixed costs (F) over revenue (R). It is included in table 5.2 as PFR. Also, in this Cournot model I use a market share variable $M S$, based on total deposits. In order to assess the robustness of the analyses, I also estimated nested versions of both the SCP and the Cournot model. The estimations reported in table 5.6 includes both market share and market structure variables. Other combinations, however, did not qualitatively change the conclusions in this chapter and are therefore not reported.

For the SCP model introduced here, I use two market structure variables. Structure variables used in the literature include a Hirschman-Herfindahl index, a $C_{3}$ - or $C_{5}-$ ratio, and the total number of banks. Given the market structure of the Dutch banking market, choosing $C_{3}$ - the sum of the percentage market share of the three largest banks - seems a logical choice. As I argued in chapter 2, this is rather arbitrary. For the sake of comparison I therefore alternate $C_{3}$ with $H H$, the Hirschman-Herfindahl index. Both variables are based on total deposits, as is most common in the literature.

Likewise, I include the most popular control variables (see Molyneux, Altunbas, and Gardener (1997), ch. 4 and appendix 1). I. purposely restrict the number of control variables included to avoid high correlation between different control variables which would render the interpretation of the model overly complicated. However, the variables included here cover everything for which SCP models attempt to control. In addition, for the set of control variables here I checked - for each of the estimation results following in this and the next two sections - whether including respectively excluding them altered sign or significance of the other variables. The set of variables as described below is highly robust and the explanatory variables as such are not highly correlated. For comparison purposes, I report the same set of control variables for all estimations, even if for some specifications control variables are highly insignificant. 
Firm-specific control variables $C$ are as wide ranging as cost/income ratios, capital ratios, typology dummies and firm size. Differences in risk attitude are usually controlled for using either loans over assets or equity over assets. The former is expected to have a positive sign, the latter a negative sign. I include a variable $R I S K$ that is defined as total net loans as a percentage of total assets. I expect it to carry a positive sign, reflecting a higher return to a more risky position. ${ }^{12}$ I also include $L I Q U I D I T Y$, liquid assets as a percentage of total assets. It is expected to have a negative coefficient, as banks trade off liquidity for profitability. Finally, I include COST, the ratio of total operating expenses over total operating income. Of course, it is expected to have a negative coefficient.

Generally, in SCP studies demand variables control for market changes and include such variables as total demand and GNP. I use the sum of demand deposits as a proxy for total demand. ${ }^{13}$ Market size is therefore measured by $M A R K E T$, total deposits in billions of guilders, measured in constant prices. It is expected to carry a negative sign if there is potential competition from both existing competitors and possible entrants. On the other hand, if the market is less contestable, an increase in its size leads to a positive expected effect on performance.

\subsubsection{Results}

I estimate the traditional SCP model both with and without a lag. ${ }^{1 \cdot 4}$ I note that accounting practices themselves already lead to a lag; bank profit is a flow variable, whereas the independent variables, including market structure (and market share) are stock variables that change little from year to year. Thus, there is already somewhat of a lag in the latter model. Both specifications were estimated as OLS models and Fixed Effect models, with time-varying fixed effects. As noted in the previous chapter, the period 1992-1998 is relatively stable, and relatively short. It is therefore not surprising that none of the fixed effects differed significantly from the intercept in the OLS model. In addition, coefficients for all variables were highly similar. I focus therefore on the OLS specifications.

${ }^{12}$ The opposite is the case in the so-called 'quiet life hypothesis', that assumes banks trade off (some of) their monopoly rents against a lower risk [Molyneux, Altunbas, and Gardener (1997), pp. 117/118].

${ }^{13}$ I have also estimated the SCP-models with GNP, but this variable was never significant and those results are not reported here.

${ }^{14}$ Since they do not differ significantly from the non-lagged specifications, estimations with lags are not reported in this and the following sections. To minimize possible problems with heteroskedasticity, all models in this chapter are estimated using weighted least squares with total assets as weights. 
TABLE 5.3: SCP Model with $\mathrm{C}_{3}$ Concentration Ratio

\begin{tabular}{lcll}
\hline $\mathrm{R}^{2}$ adj. & 0.28696 & Obs. & 351 \\
\hline Variable & Coeff. & (SE) & \\
\hline INTERCEPT & 0.01644 & $(0.00262)$ & $* * *$ \\
$\mathrm{C}_{3}$ & -0.00811 & $(0.00352)$ & $* *$ \\
RISK & -0.00691 & $(0.00113)$ & $* * *$ \\
LIQUIDITY & -0.00930 & $(0.00096)$ & $* * *$ \\
COST & 0.00034 & $(0.00068)$ & \\
MARKET & 0.00153 & $(0.00120)$ \\
\hline$* /^{* *} / /^{* * *}=$ significant at $10 / 5 / 1 \%$ level.
\end{tabular}

Table 5.3 contains estimation results for the traditional SCP model with $C_{3}$ as a market structure variable, estimated both without and with a lag. There are no singificant differences between both specifications. Contrary to expectations, the concentration ratio $C_{3}$ carries a negative sign. $R I S K$ also carries an unexpected, negative sign. As explained above it is composed of the ratio of net loans over total assets. ${ }^{15}$ Although quite common in the literature as a risk measure, it apparently fails to capture the effects of increases in risk-taking on profits. LIQUIDITY is negative and significant, indicating that banks pay for higher liquidity by lower profits. Finally, COST and MARKET are both positive but insignificant. For COST this is in line with much of the empirical literature that tends to find weak links between bank performance and cost ratios. ${ }^{16}$ The variable MARKET is perhaps handicapped by the fact that in a static setting it is expected to capture a dynamic effect. Additional estimations (results not included here) for this model specified in growth terms did not change its sign or significance however. ${ }^{17}$

TABLE 5.4: SCP Model with HH Concentration Variable

\begin{tabular}{llll}
\hline $\mathrm{R}^{2}$ adj. & 0.28843 & Obs. & 351 \\
\hline Variable & Coeff. & (SE) & \\
\hline INTERCEPT & 0.01290 & $(0.001578)$ & $* * *$ \\
HH & -0.00672 & $(0.003102)$ & $* *$ \\
RISK & -0.00698 & $(0.001132)$ & $* * *$ \\
LIQUIDITY & -0.00938 & $(0.000960)$ & $* * *$ \\
COST & 0.00030 & $(0.000678)$ & \\
MARKET & -0.00045 & $(0.000773)$ & \\
\hline${ }^{* * *} /^{* * *}=$ significant at & $10 / 5 / 1 \%$ level.
\end{tabular}

In table 5.4, the model with the Hirschman-Herfindahl index $(H H)$ as a market structure variable tells the same story. Main difference between both specifications of the

\footnotetext{
${ }^{15}$ Correlation with $L I Q U I D I T Y$, which is also a ratio over total assets is very low.

${ }^{16}$ Note that this is different from the link between efficiency and performance.

${ }^{17}$ It also did not change the rest of the conclusions.
} 
model is the negative sign for the control variable $M A R K E T$. However, the variable is still insignificant. For both specifications, overall fit of the model is good considering the small number of control variables and what is practice in the literature. As is also common in market power studies of the Dutch banking market, no evidence of market power is found.

\subsection{The Cournot Model}

As was elaborately described in chapter 2, the SCP model tested above is subject to critique. For example, the market structure measures used seem to assume that all banks benefit equally from a high market concentration. This idea runs counter to much of the theoretical literature that identifies strategic group behavior and more elegantly translates asymmetric market structures into performance differences. In this section, I develop a market power model that is based on a dynamic Cournot model by Cowling (1976), Cowling and Waterson (1976) and Stigler (1964). The model by Cowling describes a relationship between industry performance and market concentration, both over time (intra-industry) and between industries (inter-industry). I modify his model slightly to get a relationship between firm performance and market share. This modification will make it casier to accommodate asymmetric market structures, differences in cost structures and collusive behavior.

\subsubsection{Model Setup}

The model derived here is based on a straightforward extension of a Cournot oligopoly model. I first develop the case with profit maximization by collusive Cournot oligopolists. Next, I show how equilibrium conditions from this model can also be used to test more extreme models, namely perfect competition and myopic oligopoly behavior (the classic Cournot model).

I start by defining profit $\Pi_{i}$, output $X_{i}$, price $p$, firm-specific variable cost $c_{i}$ and firmspecific fixed cost $F_{i}$. Firm $i$ then maximizes:

$$
\begin{aligned}
\Pi_{i} & =p X_{i}-c_{i}\left(X_{i}\right)-F_{i} \\
\text { s.t. } \quad p & =f\left(\sum_{i=1}^{N} X_{i}\right)=f(X)
\end{aligned}
$$

where $f(\bullet)$ is the inverse market demand and $N$ the number of firms. Profit is maximized if:

$$
\frac{d \Pi_{i}}{d X_{i}}=p+X_{i} f^{\prime}(X) \frac{d X}{d X_{i}}-c_{i}^{\prime}\left(X_{i}\right)=0
$$


where

$$
\frac{d X}{d X_{i}}=1+\frac{d \sum_{j \neq i} X_{j}}{d X_{i}}=1+\lambda_{i}
$$

and $\lambda_{i}$ is known as the conjectural variation of firm $i$ 's output. ${ }^{18}$ Multiplying by $X_{i}$ gives:

$$
p X_{i}-c_{i}^{\prime}\left(X_{i}\right) X_{i}=-\left(X_{i}\right)^{2} f^{\prime}(X)\left(1+\lambda_{i}\right)
$$

Dividing both sides by $p X_{i}$ gives:

$$
\begin{aligned}
\frac{p X_{i}-c_{i}^{\prime}\left(X_{i}\right) X_{i}}{p X_{i}} & =-\frac{\left(X_{i}\right)^{2} \cdot f^{\prime}(X) \cdot\left(1+\lambda_{i}\right)}{p X_{i}} \\
& =-\left(\frac{X_{i}}{X}\right) \frac{f^{\prime}(X) X}{p}\left(1+\lambda_{i}\right)
\end{aligned}
$$

Marginal costs, $c_{i}^{\prime}\left(X_{i}\right)$, are constant but can differ from bank to bank. Revenue is denoted by $p X_{i}$. The left-hand side of the above equation therefore contains the ratio of profit $\left[\Pi_{i}\right]$ plus firm-specific fixed costs $\left[F_{i}\right]$ to revenue $\left[R_{i}\right]$. The right-hand side of the above formula can be broken down in three parts. First, $\left(\frac{X_{i}}{X}\right)$ is firm $i$ 's market share, with $0 \leq M S \leq 1$. Second, $\frac{f^{\prime}(X) X^{2}}{p X}$ is the inverse of the market price elasticity of demand, $\frac{1}{\eta_{D}}$. Since the main prices for banks in the context of this analysis are interest rates I will refer to $\eta_{D}$ as the interest elasticity of demand. Finally, $1+\lambda_{i}$ measures firm $i$ 's expectations about the reactions of its rivals $d X / d X_{i}$, with $-1 \leq \lambda_{i} \leq 1$. A Cournot oligopoly implies a value of 1 for $\left(1+\lambda_{i}\right)$, i.e. $\lambda_{i}=0$. On the other hand a value of $\lambda_{i}=-1$ implies perfect competition. For the collusive oligopolist $\lambda_{i}>0$. Simplifying further gives: ${ }^{19}$

$$
\frac{\Pi_{i}+F_{i}}{R_{i}}=\left(-\frac{1}{\eta_{D}}\right) *\left(M S_{i}\right) *\left(1+\lambda_{i}\right)
$$

There are two problems associated with using this equilibrium condition as a basis for estimating an SCP model. First, I do not have a precise measurement of $\eta_{D}$, the interest elasticity of demand. Secondly, I do not have a measure for the conjectural variation $\lambda_{i}$.

To solve these two problems I have to make two additional assumptions. The first is that $\eta_{D}$, the price elasticity of demand is constant. If not, then the interpretation of a coefficient for $M S_{i}$ - in the absence of a proxy for $\eta_{D}$ - could be biased by changes

${ }^{18} \mathrm{~A}$ high $\lambda_{i}$ means a firm has a high awareness of its interdependence with other firms.

${ }^{19}$ Cowling and Waterson (1976) sums over $N$ firms to find:

$$
\frac{\Pi+F}{R}=-\frac{H}{\eta_{D}}(1+\mu)
$$

where $H=\sum\left(X_{i} / X\right)^{2}$, i.e. the Hirschman-Herfindahl index, and $0 \leq H \leq 1$. Profits, fixed costs and returns are now summed for the whole industry, and $\mu=\left(\sum \lambda_{i} X_{i}^{2}\right) /\left(\sum X_{i}^{2}\right)$. 
in the interest elasticity of demand over time. In the context of this paper, the above assumption requires a relatively constant interest elasticity of $M_{2} \cdot{ }^{20}$ A clear advantage here is the relatively short sample period of 7 years, during which no major crisis has occured that would have changed the interest elasticity of demand. In addition, the assumption of a constant interest elasticity of demand is supported by empirical research for the Netherlands. ${ }^{21}$

The second asumption concerns the individual firm's conjectural variation $\lambda_{i}$, the extent to which it expects other firms to react to a change in output. Here, I have two options. As a first option, if I can assume $\lambda_{i}$ is constant and equal across firms it drops out of the above equation and I am left with a straightforward performance-market share relationship. The time period considered here is again an argument in favor of this assumption; as reported before, in the period 1992-1998 the number of competitors in the Dutch banking market is relatively stable and relative sizes vary very little over time. Not surprisingly, this is also the equilibrium condition for the myopic Cournot oligopolist, who is ignorant of the impact of his actions on his competitors and therefore not prone to collusive behavior.

The second option is that, under the presumption of collusive behavior, I formalize the relationship between $\lambda_{i}$ and $M S_{i}$. Following Stigler (1964), I can show that an increase in market share $M S_{i}$ is expected to increase awareness $\lambda_{i}$ and thereby lead to more collusive behavior [for proof, see the appendix]. Although this still leaves me without a direct measure of $\lambda_{i}$, it does allow me to capture its impact through $M S_{i}$. After all, the collusive oligopolist realizes a more than proportionate increase in performance as a result of an increase in market share. Alternatively, the penalty for not behaving collusively increases with market size.

Summing up and taking $\eta_{D}$ to be constant and $\lambda_{i}$ closely linked with $M S_{i}$, I have now developed a basic relationship between performance and structure that is consistent with a dynamic Cournot equilibrium. ${ }^{22}$ The basic equation (without control variables) is then:

$$
\ln \left(\left(\Pi_{i, t}+F_{i, t}\right) / R_{i, \ell}\right)=\beta_{0, t}+\beta_{1} \ln \left(\left(1+\lambda_{i, t}\right) * M S_{i, t}\right)+\varepsilon
$$

The model now amounts to interpreting the combined impact of $\lambda_{i, t}$ and $M S_{i, t}$ on performance. In two extreme cases, interpretation of the coefficient $\beta_{1}$ is straightforward. The Cournot oligopoly prediction is $\hat{\beta}_{1}=1$, since $\lambda_{i, t}=0$ and impact of $M S_{i, t}$ is exactly proportional. If collusive behavior exists, $\lambda_{i, t}>0$ and the impact of market share is more

\footnotetext{
${ }^{20}$ I consider this the most appropriate monetary aggregate in the light of this paper since it includes deposits.

${ }^{21}$ See for instance Fase and Winder (1993), who analyze the demand for money for the Netherlands in 1970-1988 and consider "the residual variation, which reflects the noise rather than the degree of misspecification, as a measure of stability" (p. 486). For M2 money demand equations they find the Netherlands has the smallest standard error residual (0.12) of all EC countries.

${ }^{22}$ As explained, for the collusive oligopoly I assume a $\lambda_{i}$ that is not constant but unmeasurable - except through $M S_{i}$.
} 
than proportional, the prediction for $\hat{\beta}_{1}>1$. Finally, in case of perfect competition an increase in market share has no impact on performance and since $\lambda_{i, t}=-1$, this means $\hat{\beta}_{1}=0$.

The model I estimate therefore becomes:

$$
\ln \left(\left(\Pi_{i, t}+F_{i, t}\right) / R_{i, t}\right)=\beta_{0 t}+\beta_{1} \ln \left(M S_{i, \ell}\right)+\varepsilon
$$

Therefore, in interpretating the coefficient $\hat{\beta}_{1}$, I will focus on its sign and significance rather than its magnitude.

Finally, as argued by Cowling (1976), firms could need time to adjust to the new competitive situation and the impact of an increase in market share on performance may therefore involve a lag. I therefore again include a specification with an additional one-year lag:

$$
\ln \left(\left(\Pi_{i, t}+F_{i, t}\right) / R_{i, t}\right)=\beta_{0 t}+\beta_{1} \ln \left(M S_{i, t-1}\right)+\varepsilon
$$

Of course, this Cournot model does not measure exactly the same relationship as the SCP model. Whereas the latter concentrates on the impact of market structure, the former focuses on individual banks' market share. However, in doing so it more accurately captures asymmetric market structures, differences in cost structures and collusive behavior.

\subsubsection{Variables}

A generally accepted feature in SCP analyses is the inclusion of a number of firm specific variables, to reflect differences between firms (as opposed to differences between markets and/or a market over time). ${ }^{23}$ Examples include liquidity ratios, income/cost ratios, size measures etc. Given that a priori there are often no expectations with respect to these variables, they are indeed control variables in the true sense of the word.

Once again, I will refrain from using too many control variables for two related reasons. First, I wish to avoid estimation problems associated with these control variables. They are either balance sheet items or profit/loss account items, and therefore by their very nature tend to be correlated - also with market structure variables. ${ }^{24}$ Hence, whereas they improve the fit of an SCP estimation, they blur the impact of market share on profitability.

Second, the relationship described in equation 5.8 (and equation 5.9) is an equilibrium condition. Randomly adding control variables without knowing their impact on the model

\footnotetext{
${ }^{23}$ Remember that whereas the prime explanatory variable in tradional SCP analyses is often a market structure variable, the explanatory variable here is market share. Thus, to some extent differences between firms are already accounted for.

${ }^{2 \cdot t}$ This especially holds for any size measures such as total assets, total deposits, etc.
} 
and model assumptions that led to this equilibrium condition can lead to biasing tests of the SCP hypothesis. I therefore estimate a fixed effects model and include a limited number of control variables.

The performance indicator $P F R$ as prescribed by the model is constructed as follows: [(Profit before tax+ Personnel Expenses + Other Operating Expenses)/(Total Operating Income)]. For the sake of comparison, the control variables are identical to those used for the SCP model. Likewise, the market share variable $M S$ is based on deposits, just as was the case for the market structure variables in the SCP model.

\section{4 .3 Results}

As can be seen from table 5.5, the fit is similar to that of the SCP model. Again, estimating a fixed effects model does not change results. Also, there does not appear to be a difference between the specification with and without a lag. The coefficient $\hat{\beta}_{1}$ for market share variable $M S$, although not very large, is highly significant. Since I find that $0<\hat{\beta}_{1}<1$, there is cautious evidence of the existence of market power.

TABLE 5.5: The Cournot Model

\begin{tabular}{llll}
\hline $\mathrm{R}^{2}$ adj. & 0.28357 & Obs. & 351 \\
\hline Variable & Coeff. & (SE) & \\
\hline INTERCEPT & -0.06833 & $(0.01637)$ & $* * *$ \\
MS & 0.00622 & $(0.00237)$ & $* * *$ \\
RISK & -0.01250 & $(0.01257)$ & \\
LIQUIDITY & -0.03900 & $(0.00499)$ & $* * *$ \\
COST & -0.01592 & $(0.00974)$ & \\
MARKET & 0.08341 & $(0.01358)$ & $* * *$ \\
\hline$* /^{* *} /^{* * *}=$ significant at & $10 / 5 / 1 \%$ level.
\end{tabular}

The coefficient for the control variable $R I S K$ again carries the wrong sign, but it is insignificant here. Although the coefficient for variable COST now carries the expected positive sign it is insignificant as well. LIQUIDITY is negative and significant. $M A R K E T$ is positive and significant, confirming the observation earlier in this chapter that the Dutch banking market is not highly contestable.

Concluding, the Cournot model appears to be provide rather different evidence than the traditional SCP model. From this model I cannot reject the hypothesis that there is (some) market power in the Dutch banking market.

\subsection{The Efficiency Hypothesis}

As mentioned in chapter 2, the Efficiency hypothesis is considered to be an important alternative explanation of market performance in SCP studies. In this section, I critically 
review the way the SCP hypothesis and the Efficiency hypothesis are tested against each other. In addition, I provide an alternative test of the Efficiency hypothesis.

\subsubsection{Model Setup}

Closely related to the SCP hypothesis is the Efficiency hypothesis, which attributes differences in performance to differences in efficiency (Goldberg and Rai (1996), Smirlock (1985)). According to the Efficiency hypothesis, both high market share and good performance result from high efficiency. Tests aimed at setting off both hypotheses against each other tend to suffer from identification problems, since the same market structure variable behaves similarly for both cases.

Thus, whereas according to the traditional SCP hypothesis a high market concentration is an explanatory variable for above average performance, within the Efficiency hypothesis it is seen as, at most, the result of a higher efficiency. Testing one hypothesis against the other therefore generally involves including both market shares and a market structure variable in the estimated equations. The premise is that if the Efficiency hypothesis holds, once individual banks' market share is controlled for, overall market concentration does not explain profits (cf. Demsetz (1973)).

TABLE 5.6: SCP-Model with Traditional Efficiency Hypothesis

\begin{tabular}{|c|c|c|c|c|c|c|c|}
\hline $\mathrm{C}_{3}$ & & & & $\mathrm{HH}$ & & & \\
\hline $\mathrm{R}^{2} \mathrm{adj}$. & 0.31935 & Obs. & 201 & $\mathrm{R}^{2} \mathrm{adj}$. & 0.31696 & Obs. & 201 \\
\hline Variable & Coeff. & (SE) & & Variable & Coeff. & (SE) & \\
\hline INTERCEPT & 0.01668 & $(0.00346)$ & $* * *$ & INTERCEPT & 0.01311 & $(0.00217)$ & $* * *$ \\
\hline $\mathrm{C}_{3}$ & -0.00792 & $(0.00457)$ & & $\mathrm{HH}$ & -0.00639 & $(0.00421)$ & \\
\hline MS & -0.00103 & $(0.00087)$ & & MS & -0.00101 & $(0.00088)$ & \\
\hline RISK & -0.00730 & $(0.00167)$ & & RISK & -0.00729 & $(0.00167)$ & \\
\hline LIQUIDITY & -0.00951 & $(0.00123)$ & $* * *$ & LIQUIDITY & -0.00956 & $(0.00123)$ & $* * *$ \\
\hline COST & 0.00053 & $(0.00099)$ & & $\cos T$ & 0.00051 & $(0.00100)$ & \\
\hline MARKET & 0.00149 & $(0.00161)$ & & MARKET & -0.00043 & $(0.00100)$ & \\
\hline
\end{tabular}

There are several problems with this method. First, there is no concensus with respect to the market structure variable. More fundamentally, whereas the importance of the Efficiency hypothesis itself in SCP studies is beyond doubt, identification problems are predominant in tests of both hypothesis at the same time. Most importantly, the variable market share at once proxies for market power - as does the market structure variable - and for efficiency. The market structure variable is an aggregate measure that only changes over time. The market share variable, however, differs from firm to firm and over time. The identification problems resulting form using both types of variables are 
demonstrated in table 5.6, where neither market concentration $\left(C_{3}\right.$ and $H H$ respectively) nor market share $(M S)$ are significant. In addition, both carry a negative sign. ${ }^{25}$

Berger and Hannan (1993) and Molyneux (2000) recognize this problem and try to solve it by including an efficiency measure directly into the SCP model. Berger and Hannan (1993) include both an X-efficiency measure and a scale efficiency measure and find that it alters the results of his SCP model for a sample of U.S. banks, albeit not with much significance. Berger also finds that whereas market structure does not significantly impact performance, X-efficiency and market share do. Molyneux (2000) in his review agrees and cites as a conclusion that neither scale efficiency nor any of the market power hypotheses (market structure and market share) contribute to explaining bank performance in any important way. Not surprisingly, the overall conclusion appears to be that X-efficiency is left as the sole important factor. ${ }^{20}$

Although recognized here as well as an important explanatory power in banking, this conclusion is perhaps too easy. It is important to remember that the Efficiency hypothesis assumes that (a high) market share results from (a high) efficiency. In the empirical models by Berger and Hannan (1993) and Molyneux (2000) however, both market share and efficiency are included as explanatory variables for bank profit. Clearly, this is not a clean test of the Efficiency hypothesis.

I therefore suggest a more appropriate test including firm-specific efficiency measures. ${ }^{27}$ In order to do so, I take a two-step procedure. First, I regress $M S_{i, \ell}$ on an efficiency measure. From the previous chapter, I have available both a profit efficiency measure $(P E)$ and a cost efficiency measure $(C E)$. Using profit efficiency does not really solve the problem, since - to the extent that a bank with market power can maximize profits without minimizing costs - it basically captures the same effect as $M S$. I therefore use cost efficiency:

$$
\ln M S_{i, t}=\gamma_{0 t}+\gamma_{1} \ln C E_{i t}+\varepsilon
$$

I then estimate equation 5.9 , but replace $M S_{i, t}$ with $M S(C E)_{i, t}$ - the residuals of the above equation. The Cournot equation then reads:

$$
\ln \left(\left(\Pi_{i, \ell}+F_{i, t}\right) / R_{i, \ell}\right)=\beta_{0 t}+\beta_{1}\left(M S(C E)_{i, t}\right)+\beta_{2} \ln C E_{i t}+\varepsilon
$$

Now, I effectively control for the Efficiency hypothesis. I can compare both hypotheses by comparing the results from estimating equation 5.9 with those of estimating equation 5.12 . If the market power hypothesis holds, $\beta_{1}$ is significant and positive in both specifications.

\footnotetext{
${ }^{25}$ In the next sections, I use 201 observations on bank efficiency from chapter 3 of this thesis. In order to get comparable results, the same observations are used here.

${ }^{26}$ See also Ashton (1999), Burdisso and D'Amato (2000) and Polius and Samuel (2001) for similar results.

${ }^{27}$ The modification I suggest is explained for the Cournot model and therefore in loglinear form. I have also applied it (without taking logarithms) to the traditional SCP model.
} 
On the other, if $\beta_{1}$ is positive and significant when estimating equation 5.9 , but zero or positive and significant when estimating equation 5.12 , this is evidence in favor of the Efficiency hypothesis.

\subsubsection{Variables}

As evidenced by the discussion in chapters 3 and $4, \mathrm{X}$-efficiency is generally found to dominate scale efficiency in banking. The cost efficiency $[C E]$ measure I have developed in chapter 3 and estimated in chapter 4 indicates how close a bank's costs, conditional upon its output, input prices and equity level, are to the costs a fully efficient bank would incur under the same conditions. As such, I consider it the best efficiency measure to use in my two step approach. In the first step, I regress the logarithm of a bank's market share on its cost efficiency estimate from the previous chapter [this regression is not reported here]. In the second step, both the $C E$ estimate and the residual from the first step regression are included in the standard SCP and Cournot equations. Matching these efficiency results with the sample data used so far results in a further decrease of the number of observations to 201 (market coverage is still very high and the decrease is proportional per year).

\subsubsection{Results}

Table 5.7 contains the estimation results for the SCP model with the modified test for the Efficiency hypothesis. ${ }^{28}$ Signs are similar to those in the results reported in section 5.3 .

TABLE 5.7: SCP-Model with Modified Efficiency Hypothesis

\begin{tabular}{|c|c|c|c|c|c|c|c|}
\hline $\mathrm{C}_{3}$ & & & & $\mathrm{HH}$ & & & \\
\hline $\mathrm{R}^{2}$ adj. & 0.31583 & Obs. & 201 & $\mathrm{R}^{2}$ adj. & 0.31358 & Obs. & 201 \\
\hline Variable & Coeff. & (SE) & & Variable & Coeff. & (SE) & \\
\hline INTERCEPT & 0.01669 & $(0.00372)$ & $* * *$ & INTERCEPT & 0.01289 & $(0.00233)$ & $* * *$ \\
\hline $\mathrm{C}_{3}$ & -0.00795 & $(0.00467)$ & & $\mathrm{HH}$ & -0.00635 & $(0.00422)$ & \\
\hline MS (CE) & -0.00103 & $(0.00088)$ & & MS (CE) & -0.00099 & $(0.00088)$ & \\
\hline $\mathrm{CE}$ & $-3.8 \mathrm{E}-06$ & $(0.00027)$ & & $\mathrm{CE}$ & $6.5 \mathrm{E}-05$ & $(0.00027)$ & \\
\hline RISK & -0.00731 & $(0.00171)$ & $* * *$ & RISK & -0.00721 & $(0.00171)$ & $* * *$ \\
\hline LIQUIDITY & -0.00953 & $(0.00129)$ & $* * *$ & LIQUIDITY & -0.00948 & $(0.00129)$ & $* * *$ \\
\hline COST & 0.00053 & $(0.00100)$ & & COST & 0.00052 & $(0.00129)$ & \\
\hline MARKET & 0.00150 & $(0.00161)$ & & MARKET & -0.00038 & $(0.00102)$ & \\
\hline
\end{tabular}

${ }^{28}$ Again, a Fixed Effects specification was first estimated, but it did not differ from the OLS specification reported here. 
Results of the specification with $C_{3}$ as a market structure variable and $H H$ as a market structure variable differ very little. This once again confirms the observation in chapter 2 that empirically there does not appear to be a dominant market structure variable. Contradictory to expectation, the market share variable $M S$ is positive but insignificant as are the market structure variables.

Testing the Efficiency hypothesis with the Cournot model shows somewhat different results. In the static model, the coefficient for $M S(C E)$, which is orthogonal to efficiency, is positive and significant. Although somewhat larger in magnitude the coefficient for cost efficiency is marginally insignificant. This would seem to be evidence in favor of the existence of market power.

TABLE 5.8: Cournot-model with Efficiency Hypothesis

\begin{tabular}{llll}
\hline Static & & & \\
\hline $\mathrm{R}^{2}$ adj. & 0.34772 & Obs. & 201 \\
\hline Variable & Coeff. & $(\mathrm{SE})$ & \\
\hline INTERCEPT & -0.09372 & $(0.02803)$ & $* * *$ \\
MS (CE) & 0.00716 & $(0.00299)$ & $* *$ \\
CE & 0.01960 & $(0.01534)$ & \\
RISK & 0.02114 & $(0.02094)$ & \\
LIQUIDITY & -0.04114 & $(0.00620)$ & $* * *$ \\
COST & -0.00354 & $(0.01294)$ & \\
MARKET & 0.07764 & $(0.01657)$ & $* * *$ \\
\hline$* / * * / * * *$ & significant at & $10 / 5 / 1 \%$ level.
\end{tabular}

Taken as such, these results confirm the results from the Cournot model estimated before and suggest that there is evidence of some market power on the Dutch banking market.

\subsection{Conclusion}

In this chapter, I compare the traditional SCP model with a simple Cournot-model. I demonstrate how the latter can be used to test for the existence of market power, overcoming some of the problems persistently hampering traditional SCP analyses. I extend the model to be able to set off the SCP hypothesis against the Efficiency hypothesis.

Based on the results from the SCP model, it would appear that for the Dutch banking market over the period 1992-1998 I can reject the SCP hypothesis. On the other hand, results from the Cournot model suggest the existence of some market power. In addition, there is some evidence in favor of the Efficiency hypothesis as well.

Theoretically speaking the Cournot model provides a better test for the existence of market power than the SCP model. Likewise, explicitly correcting for and including 
efficiency allows for a more correct test of the Efficiency hypothesis. Empirical results, however, provide mixed evidence.

\subsection{Appendix: The Stigler Approach}

In this appendix I show that, under the presumption that collusive behavior de facto exists, the extent to which banks will engage in collusive behavior is directly and positively related to their market share. An increase in market share $\left(M S_{i}\right)$ leads to an increase in awareness $\left(\lambda_{i}\right)$, and thereby to collusive behavior. ${ }^{29}$

To prove this, I start with Stigler's rule that the (pricing) behavior of firms must be inferred from the way their customers react. The assumption then is that "[T]here is no competitive price-cutting if there are no shifts of buyers among sellers" (Stigler (1964), p. 48). Thus, the higher the loyalty of customers, the less likely a bank is to behave collusively. Intuitively, the higher customer loyalty is, the less a bank has to gain by cutting prices: it does not have to do it to keep its old customers and it does not expect to gain a lot of new customers. In terms of the dynamic Cournot model, the lower the conjectural variation $\lambda_{i}$, the more likely the bank is to engage in collusive behavior.

In line with Stigler (1964), a bank targets three groups of customers. First, it wants its share of the growth of new customers $\left[C_{n}\right]$. Second, it wants to retain as many of its old customers as possible $\left[C_{r}\right]$. Third, it wants growth through the other banks' old customers $\left[C_{o}\right]$.

Let $N_{n}=$ number of new customers, and $N_{o}=$ the total number of old buyers in the market. ${ }^{30}$ Also, let $n_{o}^{i}=$ the number of old customers for bank $i$. The probability of repeat purchases is denoted $p$, and $M S_{i}$ is bank $i$ 's market share. ${ }^{31}$ The expected number of customers for each group is given by:

$$
\begin{aligned}
& E\left(C_{n}^{i}\right)=M S_{i} * N_{n} \\
& E\left(C_{r}^{i}\right)=p * M S_{i} * N_{o} \\
& E\left(C_{o}^{i}\right)=(1-p) * M S_{i} *\left(N_{o}-n_{o}^{i}\right)
\end{aligned}
$$

For each group the cost of cheating (i.e. not behaving collusively) is given by the variance of the expected number of customers. The higher this variance, the more likely a bank is

${ }^{29}$ On a market level, the notion that concentration "facilitates collusion between firms and increases industry-wide profits" (Tirole (1993), p. 222) is widely accepted [sec also Bain (1951) and Bain (1956).

${ }^{30}$ Where $\sum_{i=1}^{N} X_{i}=X=f\left(N_{o}\right)$.

${ }^{31}$ Where $M S_{i}=X_{i} / \sum_{i=1}^{N} X$. 
to show collusive behavior. For each set of customers, variances are given by: ${ }^{32}$

$$
\begin{aligned}
\operatorname{var}\left(C_{n}^{i}\right) & =\left[N_{n} * M S_{i} *\left(1-M S_{i}\right)\right] \\
\operatorname{var}\left(C_{r}^{i}\right) & =\left[N_{o} * p * M S_{i} *\left(1-p * M S_{i}\right)\right] \\
\operatorname{var}\left(C_{o}^{i}\right) & =\left[\left(N_{o}-n_{o}^{i}\right)\left\{\left((1-p) M S_{i}\right)\left(1-(1-p) M S_{i}\right)\right\}\right]
\end{aligned}
$$

As explained, an increase in market share $\left(M S_{i}\right)$ leads to more collusive behavior if $\frac{d v a r(\bullet)}{d M I S_{i}}>0$. This requires:

$$
\begin{aligned}
\frac{d \operatorname{var}\left(C_{n}^{i}\right)}{d M S_{i}} & =N_{n}-2 N_{n} M S_{i}>0 \\
\frac{d \operatorname{var}\left(C_{r}^{i}\right)}{d M S_{i}} & =p N_{o}-2 M S_{i} p^{2} N_{o}>0 \\
\frac{\operatorname{var}\left(C_{o}^{i}\right)}{d M S_{i}} & =\left((1-p)\left(N_{o}-n_{o}^{i}\right)\right)-2\left((1-p)\left(N_{o}-n_{o}^{i}\right)\right) M S_{i}>0
\end{aligned}
$$

Equations 5.13 and 5.15 hold iff $M S_{i}<0.5$. As can be seen in table 5.2, the maximum market share held by a bank in the Dutch banking market over the period 1991-1998 is 0.45 , so this is the case. Equation 5.14 holds iff $p>2 p^{2} * M S_{i}$. Since $M S_{i}<0.5$, this condition is also satisfied.

Since $C_{n}^{i}, C_{r}^{i}$ and $C_{o}^{i}$ are disjoint subsets of the whole customer population (i.e. there is no overlap), I can simply add up their variances, which under the above mentioned conditions are larger than zero. Summing up therefore, an increase in market share $M S_{i}$ leads to an increase in awareness $\lambda_{i}$ and thereby to more collusive behavior.

${ }^{32} \mathrm{~A}$ bank expects a consumer to become either customer (with expectations dependent on its current market share) or not. Thus, for the binomial mean $\mu=n * \pi$, variance is $n * \pi(1-\pi)$. 

6

\section{Large Bank Efficiency in Europe and the United States}

\subsection{Introduction}

Deregulation of the banking industry in Europe and the United States in the 1980s and 1990s stimulated an unprecedented merger and consolidation wave (see Berger, Demsetz, and Strahan (1998)). ${ }^{\prime}$ However, most mergers have been limited to continental borders, rather than crossing over the Atlantic Ocean (Berger and Humphrey (1997)). In view of recent changes in European and U.S. banking laws, the next merger wave can be expected to involve an international consolidation. ${ }^{2}$ Over the past half-century financial systems in Europe and the U.S. have become increasingly integrated by virtue of the international flow of money and capital in securities markets. In the near future the process of integration may be completed by increasing structural overlap among financial institutions via cross-Atlantic consolidation.

The prospect of joint European-U.S. consolidation of financial services raises numerous questions. Will such inter-continental mega-mergers result in public gains in terms of the quality and prices of financial services? What are the driving forces motivating large banks in Europe and the U.S. to merge? In this regard, is it possible that megainstitutions combining geographically-dispersed operations are more efficient in terms of costs and profits than otherwise? If increasing returns to scale are available to large banking institutions, an economic rationale for cross-Atlantic mergers would exist. Moreover, efficiency differences between large banks in Europe and the U.S. would imply that there is an opportunity to enhance efficiency via cross-Atlantic mergers. ${ }^{3}$ Of course, aside

\footnotetext{
${ }^{1}$ This rescarch was supported by an NWO grant.

'In the European Union, recent legal reforms are the Second Banking Coordination Directive of 1988 and the establishment of the single market for financial services in 1993. In the U.S. the Riegle-Neal Interstate Banking and Branching Act of 1994 and the Financial Services Modernization Act of 1999 have expanded geographic and financial services powers of banking institutions.

${ }^{3}$ The literature on the performance benefits of bank mergers is mixed (sce Berger and Humphrey (1992) and Rhoades (1994). However, a recent study by Rhoades (1998) examined case studies of nine large U.S. bank mergers and found that cost efficiency improved in each case. Seven of the bank merger cases exhibited increased profitability relative to their pecrs. In most cases the acquiring (acquired) bank was more (less) efficient than its peer group. Thus, while not all mergers yielded increased performance, most large bank combinations provided economic benefits relative to peer banks. Also, Siems (1996) has reported evidence that shareholder wealth significantly increased in response to megamergers of U.S. banks in 1995. The author inferred that the results tended to support in part the synergy hypothesis, whereby acquiring banks reap economies of scale and scope via cutting costs of redundancies and duplication of operations.
} 
from cost and profit considerations, cross-Atlantic consolidation of large banks could be motivated by a variety of other factors, including market power and management incentives (e.g., see Milbourn, Boot, and Thakor (1999)). In this chapter I take the very first step towards answers to these questions. This chapter seeks to examine whether there is a level playing field by conducting stochastic frontier cost and profit analyses to estimate economies of scale as well as X-efficiency for multi-billion dollar European and U.S. banks in the period 1995-1999. In doing so, I focus on the comparison between the two continents.

Based on separate analyses of large European and U.S. banks, I find that cost and profit functions for banks in both regions are strikingly similar with decreasing (increasing) cost (profit) returns to scale. Consequently, large banks in Europe and the U.S. can increase profit efficiency via output expansion, especially in the nontraditional areas of investments and off-balance sheet activities. Based on these cost and profit models, X-efficiency scores revealed that on average European banks have greater (lower) cost (profit) efficiencies compared to U.S. banks, and the dispersion of both profit and cost efficiency scores is considerably smaller for U.S. banks than for European banks.

Further analyses evaluate the reasonableness of estimating a combined cost or profit frontier for European and U.S. banks. A necessary condition for comparable-shaped frontiers is for economies of scale to be similar for efficient banks in Europe and the U.S. I therefore test for differences in economies of scale by moving progressively closer to the frontier in an effort to evaluate the appropriateness of estimating a single frontier for both regions. In brief, I find that, while a single cost frontier exists, separate profit frontiers are implied. This result, although new in the literature, is not surprising given the fact that market conditions are markedly different. Upon continuing, I find that banks in the U.S. tend to exhibit higher average profit efficiency than banks in Europe. U.S. banks are also more profit efficient than banks in most individual European countries. And country specific dummies for European countries in addition to independent sample tests on efficiency scores suggest important differences among European countries as well. I conclude that, based on profit model evidence of both increasing returns to scale and differences in efficiency, the empirical results tend to support the notion that efficiency differences persist internationally, despite ongoing globalization.

Section 6.2 overviews related literature on the efficiency of European and U.S. banks. Section 6.3 describes the methodology, and section 6.5 reports the empirical results. The final section contains the conclusions.

\subsection{Literature}

A large body of literature that spans a half-century exists on banking efficiency in the U.S. (e.g., see surveys in Berger and Humphrey (1997); Berger, Demsetz, and Strahan (1998); and Berger and Mester (1999)). Likewise, a more recent but growing literature on European banking efficiency is developing (e.g., see Molyneux, Altunbas, and Gardener 
(1997); Sheldon (1999); Altunbas, Gardener, Molyneux, and Moore (2001)). ${ }^{4}$ Studies prior to the 1980s tended to report U-shaped cost curves with economies of scale exhausted at $\$ 100-\$ 500$ million in total assets for the most part. Results for economies of scope (i.e., joint production of outputs) were mixed, with most authors concluding that banks do not gain efficiencies from providing multiple financial services to the public. Altering the path of efficiency research, Berger and Humphrey (1991) showed that U.S. banks could improve their cost efficiency more by reducing frontier inefficiencies than by reaching some optimal level of scale and scope economies to minimize average costs. Subsequent research further investigated this issue using both parametric and non-parametric frontier estimation methods (e.g., see Lovell (1993)). Moreover, recent research has expanded the analyses to consider both cost and profit efficiency (e.g., see Berger and Mester (1997); Berger and Humphrey (1997); and others), as well as risk variables (e.g., see Berg, Førsund, and Jansen (1992); McAllister and McManus (1993); Mester (1996); Berger and DeYoung (1997); and others). In general, studies have confirmed Berger and Humphrey's result that cost and profit frontier inefficiencies outweigh output inefficiencies associated with scale and scope economies by a considerable margin.

A major gap in early bank efficiency literature was the scant evidence on large banks. This shortfall was substantial, due to the pivotal role of large institutions in shaping the structure of the banking industry. If large bank size is closely related to the efficient production of financial services, the implication is that the post-deregulatory consolidation movement will result in a highly concentrated banking industry dominated by a relatively small number of institutions. Conversely, if inefficiencies occur as banks expand output beyond some size threshold, it is likely that the organizational structure of the industry would be less concentrated with a larger number of banks offering services to the public. Without research on large bank cost and profit efficiencies, no inferences about deregulation and related policy implications to banking industry structure could be made.

In the 1980s and 1990s numerous studies on large U.S. banks were published to overcome this shortfall in the literature. ${ }^{5}$ Summarizing this literature, scale economies were found for banks between $\$ 1$ billion and $\$ 15$ billion in assets with diseconomies thereafter. The existence of scope economies was more elusive with most studies reporting insignificant results. One exception is that, upon resolving some econometric problems plaguing previous work in this area, Pulley and Humphrey (1993) reported significant scope economies in the joint production of two types of deposit services and three credit areas.

\footnotetext{
${ }^{4}$ See also table 6.1 .

${ }^{5}$ See studies by Hunter and Timme (1986), Shaffer and David (1986), Kolari and Zardkoohi (1987), Charnes et al. (1990), Noulas, Ray, and Miller (1990), Hunter, Timme, and Yang (1990), Elyasiani and Mehdian (1990), Evanoff and Israilevich (1990), Berger et al. (1993), Saunders and Walters (1994), Hunter (1995), Jagtiani, Nathan, and Sick (1995), Jagtiani and Khanthavit (1996), Miller and Noulas (1996), Mitchell and Onvural (1996), Rhoades (1998), and Rogers (1998).
} 


\section{TABLE 6.1: Synopses of European Bank Efficiency Studies}

Altunbas and Molyneux (1996) reported economies of scale and scope estimates for banks in France, Germany, Italy, and Spain but the significance of any relationship with bank size was inconclusive.

Molyneux et al. (1997) found economies of scale and scope at the plant (or branch) level in France, Germany, Italy but not in Spain. Cost savings were gained from the increased average size of bank branches rather than from the size of the banking firm. Economic Research Europe (1997) estimated X-efficiency for individual banking markets and for the E.U. as a whole. They found that banks' X-efficiency estimates varied widely among European countries.

Altunbas and Chakravarty (1998) examined the relationship between bank efficiency and bank market structures in 15 European countries. Based on both country- and Europewide evidence, they find that efficiency differs significantly among various kinds of banks. Altunbas et al. (1999) found for a sample of 3,779 European banks over the period 1989-1996, that total technical change was about $2.8 \%$ in 1989 compared to $3.6 \%$ in 1996 . Large banks appeared to have greater technical gains than small banks in this period. Bikker (1999) reported stochastic cost frontier estimates for banking markets in Belgium, France, Germany, Italy, Luxembourg, Netherlands, Spain, Switzerland and the U.K in 1989-1997. Based on 3,085 sample banks of all types (commercial, cooperative, etc.), he found that country-specific results substantially differed from Europe-wide results for banking institutions.

Hasan et al. (2000) conducted cross-country comparisons of 612 banks from 10 European countries in 1993. Controlling for environmental factors, they simulated the efficiency of an average bank operating in another country and found that banks from efficient countrics do well in other countries, whereas banks from inefficient countries have a hard time operating across the border.

Molyneux et al. (1997) reported results from stochastic cost frontier analyses for Germany, Italy, the U.K., Scandinavia, Spain, Portugal and Ireland. Some of their results include: specialist banks in Germany are found to be less efficient than universal banks (see also Lang and Welzel 1997 for further cost frontier analyses of German banks); low efficiency scorcs among U.K. banks.

Pastor, Pérez and Quesada (1994) compared Spanish banks to those in 7 other countries (6 European countries and the U.S.) using data envelopment analysis (DEA). They found that U.S. and Spanish banks were the most efficient.

Soares de Pinho (1994) and Mendes and Rebelo (1997) report cvidence that nationalized banks in Portugal are less efficient than other banks and that universal banks are more efficient than agricultural banks, respectively.

Resti (1997) reported a significant regional difference in the efficiency of northern versus southern Italian banks.

Lucey (1995) finds that technical rather than allocative efficiency determined total X-efficiency of Irish banks.

Battese et al. (1998) found for Swedish banks overall efficiency in the use of labor of about 12 percent. However, differences in the types of banks, number of branches and total inventories affected the results on labor inefficiencies, with no clear pattern over time. 
According to Berger, Hunter, and Timme (1993) and Berger and Humphrey (1991), the significance of scale and scope inefficiencies (amounting to 5 percent) is less important in the banking industry than X-inefficiencies (20-25 percent).Berger and DeYoung (1997) also find that frontier inefficiencies are far greater than scale and scope inefficiencies. ${ }^{6}$

To my knowledge no European studies have focused on large bank efficiency per se; instead, banks of different sizes are comparatively examined. ${ }^{7}$ Only a few studies have been published on the subject of large bank efficiency outside the U.S.. Allen and Rai (1996) estimated a global cost function for 194 banks in 15 countries (including the U.S.). Banks were divided by asset size into two groups (i.e., small versus large banks below and above the median asset size of a country's banks, respectively) and by regulatory environment (i.e., countries with functionally integrated or universal banking versus those with functionally separated banking). Since the median bank asset size in most countries exceeded 40 billion U.S. dollars, most banks in the study can be considered large banks. They found that universal banking countries were more efficient than non-universal banking countries, which implies that banks offering a variety of financial services (e.g., loans, deposits, insurance, securities investment, real estate, etc.) are more competitive than banks offering selected financial services. Also, France, Italy, the U.K., and the U.S. had the most inefficient banking institutions.

Another study by Saunders and Walter (1994) measured scale and scope economies for 133 of the largest 200 banks in the world at year-end 1988. Based on a translog cost model, they found that, while banks with loans less than $\$ 10$ billion and more than $\$ 25$ billion exhibited scale diseconomies, banks in the middle range had scale efficiencies. Also, scope diseconomies between fee-earning and interest-earning financial services existed. Given that their sample banks typically operated in multiple countries, they concluded that international expansion may well offer economies of scale opportunities for many financial institutions. They also concluded that it was too early in the 1980s to make clear inferences about potential scope economies, which they believed might materialize after some initial fixed costs of expanding beyond traditional commercial banking activities had been incurred.

The aforementioned large bank studies are unique from other European work in that consolidated data are employed in the analyses. By consolidating the data from the entire organization, they provide insight into bank efficiency at the firm level, rather than at divisional or branch levels. There have been other efficiency studies of European banking

${ }^{6}$ See also Berger and Humphrey (1997) and Molyneux, Altunbas, and Gardener (1997).

${ }^{7}$ For example; see studies by Berg, Forsund, and Jansen (1992); Fecher and Pestiau (1993); Berg, Førsund, Hjalmarsson, and Suominen (1993); Pastor, Pérez, and Quesada (1997); Vennet, Vander (1994); Altunbas and Molyneux (1996b); Ruthenberg and Ellias (1996); Soares de Pinho (1994); Molyneux, Altunbas, and Gardener (1997); Economic Research Ltd. (1997); Mendes and Rebelo (1997); Pastor, Pére\%, and Quesada (1997); Resti (1997); Altunbas and Chakravarty (1998); Dietsch, Ferrier, and Weill (1998); Battese, Heshmati, and Hjalmarsson (1998); Altunbas, Goddard, and Molyneux (1999); Bikker (1997); Sheldon (1999); Vennet, Vander (1999); Berger, DeYoung, Genay, and Udell (2000); Hassan, Lozano-Vivas, and Pastor (2000). 
that provide some large bank results, but they typically employ unconsolidated data. For example, Berger, DeYoung, Genay, and Udell (2000) reported efficiency results for European banks with assets exceeding $\$ 100$ million; however, they are careful to observe that their results are only relevant for subsidiaries of banking organizations due to the use of unconsolidated data. In this regard, they noted that transfer pricing can shift profits from one affiliate to another and affect efficiency estimates for subsidiaries. While they did not believe that this potential bias was significant in their study, it is not possible to determine the extent to which transfer pricing, shared inputs, and other intra-organizational arrangements might impact efficiency assessments. The authors estimated separate cost and profit functions for 2,123 commercial banks (i.e., other types of banks are excluded) with data available for the period 1993-1998 in France, Germany, Spain, U.K., and the U.S. Comparative analyses revealed that domestic banks on average had higher cost and profit efficiency than foreign banks in these countries. However, when the results were disaggregated on a country-by-country basis, they found that foreign banks from some countries were equal to or more efficient than domestic banks. Interestingly, U.S. banks overseas tended to be more efficient than domestic banks in their respective countries. They inferred that, since there is not necessarily a home field advantage, additional global consolidation is likely in the future. Relevant to this work, they recommended that future empirical work in this area should expand the analyses to a substantial number of countries.

A study by Sheldon (1999) used unconsolidated data for 1,783 commercial and savings banks in the EU, Norway, and Switzerland for the period 1993-1997. Data envelopment analysis (DEA) was employed to examine cost and profit efficiency. Sheldon found that large banks, specialized banks, and retail banks are more cost and profit efficient than small banks, diversified banks, and wholesale banks, respectively. Average frontier efficiency was fairly low, at about 45 percent for costs and 65 percent for profit. Banks in Denmark, France, Luxembourg, and Sweden had the highest average efficiency, and banks in Greece, Italy, Portugal, Spain, and U.K. had the lowest average efficiency. Furthermore, estimates of economies of scale in costs and profits indicated that most banks in their sample were sub-optimal in size, with optimal scales in the range of 0.5 to 1.5 billion U.S. dollars. Decreasing cost and profit returns to scale were reported for most multi-billion dollar banks. These and other results led Sheldon to conclude that inefficient operations, rather than unexploited economies of scale, explain cost and profit differences across European banks. The author inferred that diseconomies of large scale with respect to both costs and profits prohibit a high degree of industry concentration in the European banking market.

In view of previous literature, the present study contributes new empirical evidence on large bank efficiency. Comparative analyses of European and U.S. large banks provide perspective in understanding similarities and differences between institutions located in these two regions of the world. Unlike previous European bank studies, I employ consolidated data for independent banks, as opposed to all entities contained within the 
organization. While some studies do use consolidated data, they do not exclude banking entities for which the organization does not have a controlling interest (e.g., at least 25 percent ownership of common stock). ${ }^{8}$ Instead, they include banks that are under controlling interest by others as separate entities. Consequently, these studies suffer from double counting and tend to include banks that are not independent organizations. To a significant extent, this also runs counter to the profit-maximization and/or cost-minimization assumptions behind the efficiency measures employed, where banks are assumed to choose the input/output mix that is most efficient. Finally, I extend prior work by Allen and Rai (1996)and Saunders and Walter (1994) by collecting larger samples of multi-billion dollar banks and updating analyses to the last half of the 1990s. I next turn to further details of the methodology.

\subsection{Methodology}

In this chapter, I again employ the stochastic frontier models developed in chapter 3 that allow me to measure scale and scope efficiency as well as X-efficiency. The data used here are extensive and collected from different sources. Therefore, I pay special attention to the robustness of the frontier estimations. First, I discuss the optimization techniques used in estimating these frontiers. Then, I explain how I test whether U.S. and European data can used to estimate a single frontier.

\subsubsection{Optimization}

The profit and cost models are developed in three steps. ${ }^{9}$ First, the translog cost and profit models are estimated using OLS. Second, I apply the usual reparameterization, replacing $\sigma_{v}^{2}$ and $\sigma_{\omega}^{2}$ with $\sigma^{2}=\sigma_{\omega}^{2}+\sigma_{v}^{2}$ and $\gamma=\sigma_{v}^{2} /\left(\sigma_{v}^{2}+\sigma_{\omega}^{2}\right){ }^{10}$ I then use the OLS coefficients to maximize the likelihood function for $\gamma$. These results are needed to update the values for

\footnotetext{
${ }^{8}$ We develop independent bank accounting statements for European banks by excluding entities in the organization that are not controlled by the bank. However, BankScope has ownership data for only the last year of our sample period in 1999; moreover, as noted by the publisher of BankScope, or Burcau van Dijk, ownership data are incomplete and dependent upon availability. National accounting standards require majority ownership to be published in some countries, whereas for others this information is provided on a voluntary basis. With the kind assistance of Mark Wessels and Patrick Oosterling of Bureau van Dijk, we were able to inanually retrieve updated ownership and control data from the 1995-2000 issues of BankScope. Gaps in these reports were filled by gathering further data from Dunn and Bradsheet Linkages, Reuter's News, and banks' annual reports. In this way we constructed a complete set of large, independent commercial banks for each of the years included in our sample.

${ }^{9}$ See chapter 3 and Coelli (1998) for further discussion and references.

${ }^{10}$ The parameter $\gamma$ represents the share of inefficiency in the overall residual variance and ranges between 0 and 1 . A value of 1 for $\gamma$ suggests the existence of a deterministic frontier, whereas a value of 0 represents evidence in favor of a standard OLS estimation. Note that a deterministic frontier is by no means necessarily identical to a DEA model, given the latter's
} 
$a_{0}$ (the intercept) and $\sigma^{2} .{ }^{11}$ Third, and last, I maximize the likelihood function for the whole model to arrive at firm-specific estimates of $P E$ and $C E$, respectively.

To estimate the stochastic frontier models, I begin by checking for skewness in the residuals of the OLS estimation. Waldman (1982) has shown that, in the case of a negatively skewed profit frontier, the maximum likelihood estimator is OLS. For a cost frontier positive skewness means the MLE stops at the OLS values and, since $\sigma_{v}^{2}=0$, no cost efficiency can be estimated. Fortunately, this problem did not arise in the analyses.

Next, truncation of the inefficiency term needs to be considered. Truncating at zero implies that a high average efficiency is induced without any prior to do so. I truncate at $\mu$ based on results from the MLE.

With respect to selecting an optimization algorithm, it is well known that a global optimum likely cannot be reached with either the translog model or the Fourier Flexible Form model. Also, Newton algorithms used to maximize the log likelihood may not result in a global optimum (e.g., see Judd (1999)). More specifically, they suffer from the fact that the Hessian matrix with second-order derivatives is not updated. If the Hessian is positive definite, this may not be a serious problem. I therefore use a quasi-Newton method developed by Broyden, Fletcher, Goldfarb and Shanno (see Judd (1999), p. 114). In doing so, I ensure that the Hessian matrix is replaced with an approximation that is positive semi-definite and updated at each iteration in the maximization process.

It is noteworthy that differences in scale among various variables can hamper the optimization procedure. Dependent variables and outputs are therefore expressed in thousands of U.S. dollars and log transformed.

To choose starting values I used the OLS values and checked whether varying them slightly changed the fit and efficiency estimates significantly. Since this was not the case, I used the OLS values with an intercept that is updated after the maximum likelihood for is optimized.

Finally, I selected the convergence criteria. In doing so, I need to balance function convergence, parameter convergence, and gradient convergence. In estimating a frontier model function convergence is dominant, as the main interest is in the overall fit and associated efficiency measures. Even so, I chose different values for each of the convergence criteria to examine the extent to which the estimation results were affected (i.e., the likelihood value, number of iterations, values for $\sigma_{v}^{2}$ and $\sigma_{\omega}^{2}$, and model coefficients). For each of the estimations reported here, the range over which results are robust is considerable. This justifies using relatively modest convergence rules. ${ }^{12}$

restrictions on the shape of the fronticr and the distribution of the inefficiency. Sec Coelli (1996a) for further discussion.

"The resulting values are biased as I have not yet utilized the composite error term of the frontier model in the OLS estimation. The updated value for $\hat{a}_{0}$ becomes $\hat{a}_{0}(o / s)+\sqrt{2 \gamma \sigma^{2} / \pi}$.

${ }^{12}$ I set each of the three criteria at 0.00001 and vary them one-by-one from 0.1 to $10^{-11}$ to see whether the results are robust. The likelihood value, model coefficients, and efficiency measurements do not change significantly, the number of iterations does change. 


\subsubsection{Profit and Cost Frontiers in Europe and the U.S.}

As discussed earlier, in order to evaluate whether a single profit frontier and a single cost frontier for Europe and the U.S. can be estimated, it is necessary to determine the shape of the individual frontiers. I should only estimate a joint frontier if estimated European and U.S. frontiers are similar in shape. Characteristics of cost and (to a lesser extent) profit functions are often expressed in terms of economies of scale and scope measures. Because estimating economies of scope can be problematic, I rely on scale economies in tests for joint cost and profit frontiers respectively. ${ }^{13}$ Output-specific economies of scale are calculated by taking the derivative of the profit (or cost) model with respect to an output. For example, based on equation (3.10), scale economies for output $y_{1}$ can be estimated as:

$$
\begin{aligned}
\frac{\delta \ln T C}{\delta \ln y_{1}}= & a_{1}+a_{11} * \ln y_{11}+a_{12} * \ln y_{2}+a_{13} * \ln y_{3}+d_{11} * \ln w_{1} \\
& +d_{21} * \ln w_{2}+d_{31} * \ln w_{3}+f_{1} * \ln z
\end{aligned}
$$

For the cost function a value larger (smaller) than one indicates decreasing (increasing) returns to scale, and unity indicates constant returns to scale. For the profit function, scale estimates are oppositely interpreted. Overall economies of scale are simply the sum of output-specific economies of scale. I use these economies of scale, measured at the frontier, as an indicator of the shape of the frontier.

Berger, Hunter, and Timme (1993) identified four aspects of measuring economies of scale that are relevant to the analyses. First and foremost, research has confirmed that banks have U-shaped cost curves. Economies of scale increase up to a relatively modest size, often estimated in the range of $\$ 100-\$ 500$ million, after which they tend to decrease (albeit slowly). Since the large banks in the samples normally operate well beyond the minimum average cost point, I need only match one segment of the cost curve, rather than the entire curve. Second, risk variables are often excluded when measuring economies of scale. Following Mester (1996) and Berger and Mester (1997), I attempt to overcome this problem by including an equity/total assets ratio that enters scale measures via interaction terms.

Third, many studies base their scale measures on observations that do not lie on or close to the efficient frontier. As such, economies of scale (i.e. the marginal effects of outputs on profits or costs) cannot be separated from X-efficiency (i.e., the distance from the efficient frontier). In this case economies of scale will be biased to the extent that banks

\footnotetext{
${ }^{13}$ One problem with scope estimation is the possible existence of zero outputs. Another problem is that there is often an extrapolation problem; given a sample containing both universal banks and other banks, only the former banks typically offer the full range of financial services. Consequently, the economies of scope derived from the cost (or profit) function tend to overestimate the true economies of scope among most sample banks. A further problem is that measuring average cconomies of scope results in values that are biased due to the inclusion of $\mathrm{X}$-(in)efficiencies.
} 
do not lie on or close to the efficient frontier. Unlike DEA, in which actual observations make up the edges of the frontier, the frontier is estimated in SFA. For this reason even the most efficient bank is rarely 100 percent efficient and, in turn, identifying the banks that are most important in shaping the frontier is not possible. This problem is worsened by the fact that the distribution of efficiency measures, when truncated towards the frontier, is generally highly skewed, with the majority of banks lying close to the frontier. For these reasons choosing a set of efficient banks is an arbitrary decision. Interestingly, I do not need a single cut-off point beyond which I have a number of efficient banks; instead, the solution to this problem derives from the fact that, if for example the cost frontiers in Europe and the U.S. have the same shape, I should expect to see a decrease in the difference in economies of scale as I get closer to the frontier. By measuring cost and profit efficiencies as I gradually move closer to the frontier, I decrease the bias from $\mathrm{X}$-efficiency but simultaneously decrease the number of observations in the independent sample tests. I therefore start with the $50^{\text {th }}$ percentile as a cut-off point and end with the $90^{t / 2}$ percentile, which still provides sufficient observations to obtain reliable estimates. The $90^{\text {th }}$ percentile results will be used in the rest of the analysis. At each increment I test the significance of the difference in average economies of scale for European and U.S. banks, both with and without correction for the difference in variance. If the frontiers do have the same shape, this significance should decrease as attention is narrowed to the most. X-efficient banks.

Fourth, the most reliable measure of economies of scale is an overall estimate, defined as the sum of output-specific economies of scale. The sum of the partial derivatives of each output is less dependent on changes and differences in the output mix. Therefore, although I report output-specific economies of scale when I discuss the individual results for Europe and the U.S., only overall economies of scale are used to evaluate the shape of the frontiers.

\subsection{Data}

\subsubsection{Sample Data}

Data on European banks are collected from IBCA reports found in BankScope. For U.S. banks data are gathered from the Call Reports for Income and Condition provided by the Federal Reserve System. Data for both samples are pooled for the period 1995 to 1999. The beginning year 1995 was chosen due to the advent of interstate banking in the U.S. in 1995 as well as a single market for financial services in the European Union in 1993. Because the Financial Modernization Act was effective in 2000 and fundamentally altered the organizational structure of U.S. banks to include greater securities and insurance powers, I ended the analyses in 1999. During the sample period, few regulatory 
changes occurred in European and U.S. banking markets. It should also be mentioned that economic conditions were stable in both regions during this period. ${ }^{1+4}$

Since I comparatively examine both cost and profit efficiency, sample banks must be profit maximizing. Also, in order to test for one cost frontier and one profit frontier for all banks, it is necessary to include banks with similar output mixes. In this respect I exclude brokerage firms with a banking license due to their large securities activities and relatively small commercial lending services. Likewise, while general banks and bank holding companies are included in the analyses, cooperative banks, credit unions, mutual banks and credit card banks are excluded. ${ }^{15}$

To ensure that variables are computed similarly across countries and over time, all values are expressed in 1995 U.S. dollars. ${ }^{16}$ The dollar exchange rate in the sample period was relatively stable for the 17 European countries with banks in the analyses. For European banks a purchasing power parity (PPP) correction is computed. Given a nominal variable $V$ (for a European bank) and nominal exchange rate $S, I$ calculate:

$$
q_{t}=\frac{V_{t}}{S_{p p p, t}}=V_{t} \bullet \frac{P_{t}}{\left[S_{t=0} \bullet P_{t}^{*}\right]}=\frac{V_{t}}{S_{t}} \bullet \frac{\left[S_{t} \bullet\left(P_{t} / P_{t}^{*}\right)\right]}{S_{t=0}}
$$

where $q_{t}$ is the nominal dollar equivalent in current prices using the PPP exchange rate. $P_{t}$ is the U.S. CPI in year $t, P_{t}^{*}$ is the CPI of a European country, and $S_{t=0}$ is the dollar exchange rate in 1995. CPI and exchange rate series were taken from EIU Country Data. As a final step, all European and U.S. data are expressed in 1995 dollars using the U.S. CPI.

Previous research has demonstrated that scale economies are not present beyond $\$ 500$ million in total assets. I therefore set a bank asset size cut-off point of $\$ 1$ billion U.S. dollars after the PPP adjustment above. Although this restriction substantially reduces the sample size, multi-billion dollar banks represent the dominant share of the banking assets in Europe and the U.S. due to concentration of resources among larger banks.

Only independent banks and bank holding companies (BHCs) that are not owned or controlled by other firms are included in the sample. In this regard, the models presume banks have some degree of freedom to choose their inputs and set output prices, which would not be entirely true of component subsidiaries within the organization. Also, and as cited earlier, Berger, DeYoung, Genay, and Udell (2000) have noted that transfer pricing and other intra-organizational funds flows could affect efficiency estimates. I therefore

\footnotetext{
${ }^{14}$ An exception is the Asian crisis in 1997. Since I do not estimate a panel data model and given the fact that this crisis affected all of the countries involved in our study, I do not cxpect this crisis to significantly affect the comparative results.

${ }^{15}$ In the U.S. the Comptroller of the Currency defines credit card banks as those banks with credit card loans totaling 6.5 percent or more of total assets. I exclude banks that exceeded this threshold from the analyses.

${ }^{16} \mathrm{As}$ a robustness check, I also used German marks as a reference currency with no change in results.
} 
use consolidated statements and set limits on the maximum ownership and control by outside parties. With respect to ownership, U.S. law requires banks that are 25 percent or more owned by a single shareholder to be included in a BHC. For U.S. bank data I applied this legal criterion to the construction of the sample banking organizations. In Europe, under the First Banking Coordination Directive of 1977, similar rules allow us to apply the same criterion to European banks. ${ }^{17}$ Due to numerous mergers and takeovers in Europe and the U.S. during the sample period, ownership thresholds are checked for all large banks in each year of the sample period. ${ }^{18}$

I also exclude all observations with variable values missing and values less than or equal to zero. A negative or zero value for a variable implies that the respective bank's production function is quite different from other sample banks. Moreover, if such observations were included in the analyses, an arbitrary transformation would be required due to the fact that zero and negative values are disallowed in the translog model. For the combined data set only 10 observations were dropped for this reason.

Lastly, outliers are considered by estimating the models with all observations and then checking for outliers in the efficiency scores. As found in other studies, outliers tend to have higher scores than other sample banks. If outliers in the independent variables are consistent with outliers in the dependent variable, I omit the observations as long as skewness is not substantially altered. I then re-estimate the models and report the results with all observations (with outliers omitted) if the coefficients have not changed (have changed) significantly. I correct for heteroscedasticity

\subsubsection{Variables}

Consistent with most SFA studies, bank outputs are defined as follows: loans $\left(y_{1}\right)$, investments $\left(y_{2}\right)$, and off-balance sheet activities $\left(y_{3}\right)$. Loans aggregate commercial and industrial, real estate, consumer, agriculture, and other outstanding credit. Investments include securities, equity investments, and all other investments reported on the balance sheet. Off-balance sheet activities are credit items and other guarantees, loan commitments, derivative securities, and other loan and securities exposures not reflected on the balance sheet. Of course, these activities are particularly important among large banks.

${ }^{17}$ The First Banking Directive of 1977 (and further requirements set forth in 1983) state that: 25 percent ownership of a bank's shares constitutes official participation; 50 percent ownership) requires that proportional consolidation take place; and ownership below 50 percent is left to the discretion of member states concerning the consolidation procedure, with most member states requiring proportional consolidation for ownership between 25 percent and 50 percent.

${ }^{18}$ Occasionally, there are (literally) border cases. Some banks have headquarters in more than one country. A prime example is Fortis Group. In such cases, a bank is assigned proportionally to a country. Fortunately, proportions can be taken directly from the bank's own annual reports. 
TABLE 6.2: Descriptives

\begin{tabular}{|c|c|c|c|c|c|c|}
\hline \multicolumn{7}{|l|}{ European Banks* } \\
\hline Variable & Mean & Std.Dev. & Skew. ${ }^{a}$ & Min. & Max. & $\mathrm{N}$ \\
\hline TC (total cost) & 4791070 & 8124660 & 2.27 & 16358.6 & 49246900 & 519 \\
\hline PBT (profit before taxes) & 831208 & 1443620 & 2.66 & 655.76 & 9177220 & 519 \\
\hline$y_{1}$ (loans) & 32366000 & 56840900 & 2.53 & 13382.7 & $3.43 \mathrm{E}+08$ & 519 \\
\hline $\mathrm{y}_{2}$ (investments) & 12396900 & 26578300 & 3.31 & 116.78 & $1.91 \mathrm{E}+08$ & 519 \\
\hline$y_{3}$ (off-balance sheet) & 19342800 & 42105800 & 3.78 & 2058.87 & $3.70 \mathrm{E}+08$ & 519 \\
\hline $\mathrm{w}_{1}$ (labor price) & 0.013 & 0.013 & 3.69 & 0.0003 & 0.11 & 519 \\
\hline$w_{2}$ (financial capital price) & 0.041 & 0.039 & 4.89 & 0.0013 & 0.38 & 519 \\
\hline $\mathrm{w}_{3}$ (physical capital price) & 0.012 & 0.014 & 4.22 & 0.0003 & 0.13 & 519 \\
\hline$z$ (cquity/assets) & 0.083 & 0.093 & 3.84 & 0.01 & 0.66 & 519 \\
\hline ASSETS (total assets) & $6.44 \mathrm{E}+07$ & $1.19 \mathrm{E}+08$ & 2.7 & 1012440 & $7.51 \mathrm{E}+08$ & 519 \\
\hline \multicolumn{7}{|l|}{ U.S. Banks* } \\
\hline Variable & Mean & Std.Dev. & Skew. $^{a}$ & Minimum & Maximum & $\mathrm{N}$ \\
\hline TC (total cost) & 2684750 & 9692600 & 6.28 & 18426 & 98457300 & 476 \\
\hline PBT (profit before taxes) & 854247 & 3124390 & 6.76 & 3654 & 34826600 & 476 \\
\hline $\mathrm{y}_{1}$ (loans) & 24701600 & 89628300 & 6.69 & 42092 & 953435000 & 476 \\
\hline $\mathrm{y}_{2}$ (investments) & 9270800 & 32095400 & 5.91 & 1715 & 282533000 & 476 \\
\hline $\mathrm{y}_{3}$ (off-balance sheet) & $3.51 \mathrm{E}+08$ & $2.50 \mathrm{E}+09$ & 9.53 & 24638 & $3.13 E+10$ & 476 \\
\hline $\mathrm{w}_{1}$ (labor price) & 0.011 & 0.004 & -0.92 & $8.29 \mathrm{E}-06$ & 0.03 & 476 \\
\hline $\mathrm{w}_{2}$ (financial capital price) & 0.024 & 0.007 & -1.47 & $4.65 \mathrm{E}-04$ & 0.05 & 476 \\
\hline $\mathrm{w}_{3}$ (physical capital price) & 0.003 & 0.001 & -0.07 & $5.39 \mathrm{E}-08$ & 0.01 & 476 \\
\hline z (cquity/assets) & 0.094 & 0.027 & 3.99 & 0.05 & 0.26 & 476 \\
\hline ASSETS (total assets) & 42986500 & 153938000 & 6.37 & 1020880 & $1.60 \mathrm{E}+09$ & 476 \\
\hline
\end{tabular}

Turning to input prices, it is not possible to calculate a traditional measure of the price of labor due to incomplete data on the number of employees in BankScope. Even if the number of employees were available, part-time employees are not counted despite their increasing usage in the banking industry. Also, given the dispersion in the types of jobs at large banks (from cashier to investment banker), the price of labor as measured by average labor cost is not likely an accurate proxy for the marginal cost of labor. In an effort to overcome these difficulties, I express prices as the input-specific cost per unit of total output. Therefore, I define the price of labor $\left(w_{1}\right)$ as total employee expenses divided by the sum of assets and off-balance sheet activities. As such, difficulties related to missing employee data, part-time workers, and average labor costs are mitigated.

Likewise, the price of financial capital $\left(w_{2}\right)$ equals total interest expenses divided by the sum of assets and off-balance sheet activities, and the price of physical capital $\left(w_{3}\right)$ equals non-interest operating expenses divided by the sum of assets and off-balance sheet 
activities. As justification for this approach, I argue that, to the extent that inputs are substitutes for one another, they individually contribute to the cost per dollar output in the same way. Because all input prices have the same denominator, I checked for multicollinearity but found it was not important among input prices. I also performed a robustness check by re-running the models using observations that had data available for the number of employees but the results were unchanged for the most part. Finally, the control variable equity/total assets $(z)$ is included in the model to adjust for differences in equity capital risk across banks.

Table 6.2 contains descriptive statistics for input prices, outputs, and dependent variables. Total costs, profit before tax, outputs, and input prices as well as total assets are in thousands of 1995 PPP dollars. The samples consist of 519 European banks and 476 U.S. banks, or 995 banks in total. As shown in Table 1, the size distributions of European and U.S. banks in the samples differ to some extent. Compared to U.S. banks, the European bank distribution has a larger mean size (i.e., on average $\$ 20$ billion larger), is less skewed, and has a lower maximum size.

\subsection{Results}

I now discuss the estimation results. In order to find out how the X-efficiency of large European and U.S. banks compares in the period 1995-1999. I proceed as follows. First, I estimate separate frontiers for Europe and the U.S. respectively. ${ }^{19}$ I compare these frontier estimations with OLS estimations of the same translog models and interpret the model coefficients. Next, I calculate economies of scale and compare economies of scale as measured at the frontier for both Europe and the U.S., respectively. I assess whether the scale estimates are similar enough to validate the estimation of a single profit frontier and cost frontier. Then I compare profit and cost efficiency of each of the European countries separately and for Europe as a whole with cost- and profit-efficiency of U.S. banks.

Also, I should mention that the price of financial capital $\left(w_{2}\right)$ is used to ensure linear homogeneity in input prices.

\subsubsection{European Banks}

Table 6.3 reports the estimated SFA cost and profit models for large European banks. Since estimated coefficients for $\lambda$ (i.e., the ratio of the variance of the truncated normal inefficiency term to the variance of random noise) are significantly greater than zero (at the 0.01 level) in both models, I infer support for the frontier approach relative to OLS. The total variance of the error term ( $\sigma$ in the table) is low. This holds for all the es-

${ }^{19}$ OLS models were initially estimated as well to examine goodness of fit. In all cases adjusted $R^{2}$ values exceeded 95 percent. These results provide support for the model design. Since the focus is on frontier analyses, to conserve space I only report the SFA models and results (i.e., OLS results are available from the authors upon request). 
timations. Importantly, X-efficiency estimates for the cost model average 0.936, which implies that frontier efficient European banks could further reduce operating costs by 6.4 percent on average. As in other SFA studies, the distribution of efficiency scores is highly skewed (e.g., the minimum is 0.064). Relative to the cost results, X-efficiency estimates for the profit model are on average considerably lower at 0.736 , which implies potentially large profit improvements of 26.4 percent on average are possible for frontier banks. With a standard deviation of 0.219 (i.e., approximately twice that of the cost model), the distribution of profit efficiency scores is quite dispersed. Apparently, large banks in Europe had wide disparities in profit X-efficiency but much smaller disparities in cost X-efficiency during the sample period. These results are generally consistent with previous European studies of bank cost and profit X-efficiency (e.g., see Ruthenberg and Ellias (1996); Dietsch, Ferrier, and Weill (1998); and Vennet, Vander (1998)). Assuming that profit efficiency is a function of not only internal production (as in the case of cost efficiency) but external market forces, higher cost efficiency and lower profit efficiency could be attributable in part to differences in market power among large banks. Alternatively, Sheldon (1999) has argued that these results could be due to high-cost outputs with service and quality features that are not in demand by bank customers.

Selected results in table 6.3 with respect to individual variables are difficult to interpret due to second order and interaction variable effects. For example, the negative and significant estimated coefficient for loans $\left(y_{1}\right)$ in the cost model would appear to imply lower operating costs as loans are increased, all else the same. However, this interpretation does not take into account the nonlinear cost implications of loans captured in squared loans $\left(y_{1} y_{1}\right)$ and multiple interactions of loans with other variables in the model. For these reasons it is not possible to accurately interpret individual estimated coefficients in the cost and profit models. I observe that the estimated value for $\mu / \sigma_{v}$ is significant and negative at -2.009 for the cost model, indicating that a relatively large number of observations are in the tail of the density. This means that a relatively large proportion of European banks is inefficient.

Table 6.4 contains the average scale estimates derived from the cost and profit SFA models for the top 10 percent of X-efficient banks for Europe. As discussed earlier, scale estimates are derived from the estimated coefficients for the entire cost or profit equation, rather than a single estimated coefficient. Consistent with prior studies of large banks, cost model estimates suggest decreasing and significant economies of scale for outputs except loans $\left(y_{1}\right)$, which exhibits increasing (but insignificant) returns to scale. Consequently, overall economies of scale are negative and significant, which implies cost diseconomies of scale. 
TABLE 6.3: Cost and Profit Frontier Models for European Banks

\begin{tabular}{|c|c|c|c|c|c|}
\hline Cost Model & & & Profit Model & & \\
\hline Mean (SE) & $0.936(0.104)$ & & Mean (SE) & $0.736(0.219)$ & \\
\hline Range & $0.064-0.994$ & & Range & $0.023-0.986$ & \\
\hline $\mathrm{LOGL}=206.72$ & Obs. $=519$ & & $\mathrm{LOGL}=-160.66$ & Obs. $=519$ & \\
\hline$\sigma_{\omega}^{2}=0.0092$ & $\sigma_{v}^{2}=0.0757$ & & $\sigma_{\omega}^{2}=0.0400$ & $\sigma_{v}^{2}=0.2473$ & \\
\hline Variable & Coeff. (SE) & & Variable & Coeff. (SE) & \\
\hline INTERCEPT & $2.348(0.542)$ & **** & INTERCEPT & $-1.015(0.855)$ & \\
\hline$w_{1}$ & $0.841(0.165)$ & $* * *$ & $\mathrm{w}_{1}$ & $2.499(0.299)$ & $* * *$ \\
\hline$w_{3}$ & $-0.266(0.158)$ & $*$ & $\mathrm{w}_{3}$ & $-1.806(0.284)$ & $* * *$ \\
\hline$y_{1}$ & $-0.199(0.083)$ & $* *$ & $y_{1}$ & $0.361(0.154)$ & $* *$ \\
\hline $\mathrm{y}_{2}$ & $0.591(0.039)$ & $* * *$ & $\mathrm{y}_{2}$ & $0.534(0.097)$ & $* * *$ \\
\hline$y_{3}$ & $0.558(0.054)$ & $* * *$ & $y_{3}$ & $0.206(0.110)$ & $*$ \\
\hline$\%$ & $-0.572(0.132)$ & $* * *$ & $z$ & $-1.566(0.222)$ & $* * *$ \\
\hline $1 / 2 y_{1} y_{1}$ & $0.140(0.009)$ & $* * *$ & $1 / 2 y_{1} y_{1}$ & $0.182(0.017)$ & $* * *$ \\
\hline $1 / 2 \mathrm{y}_{1} \mathrm{y}_{2}$ & $-0.182(0.008)$ & $* * *$ & $1 / 2 \mathrm{y}_{1} \mathrm{y}_{2}$ & $-0.144(0.022)$ & $* * *$ \\
\hline $1 / 2 y_{1} y_{3}$ & $-0.063(0.012)$ & $* * *$ & $1 / 2 \mathrm{y}_{1} \mathrm{y}_{3}$ & $-0.172(0.023)$ & $* * *$ \\
\hline $1 / 2 \mathrm{y}_{2} \mathrm{y}_{2}$ & $0.142(0.005)$ & $* * *$ & $1 / 2 \mathrm{y}_{2} \mathrm{y}_{2}$ & $0.043(0.011)$ & $* * *$ \\
\hline $1 / 2 y_{2} y_{3}$ & $-0.137(0.006)$ & $* * *$ & $1 / 2 \mathrm{y}_{2} \mathrm{y}_{3}$ & $-0.027(0.016)$ & $*$ \\
\hline $1 / 2 y_{3} y_{3}$ & $0.096(0.004)$ & $* * *$ & $1 / 2 y_{3} y_{3}$ & $0.110(0.012)$ & $* * *$ \\
\hline $1 / 2 w_{1} w_{1}$ & $0.244(0.035)$ & $* * *$ & $1 / 2 w_{1} w_{1}$ & $0.415(0.056)$ & $* * *$ \\
\hline $1 / 2 w_{1} w_{3}$ & $-0.231(0.065)$ & $* * *$ & $1 / 2 w_{1} w_{3}$ & $-0.041(0.113)$ & \\
\hline $1 / 2 w_{3} w_{3}$ & $0.212(0.032)$ & $* * *$ & $1 / 2 \mathrm{w}_{3} \mathrm{w}_{3}$ & $0.015(0.063)$ & \\
\hline $\mathrm{y}_{1} \mathrm{w}_{1}$ & $-0.021(0.017)$ & & $\mathrm{y}_{1} \mathrm{w}_{1}$ & $-0.040(0.035)$ & \\
\hline $\mathrm{y}_{1} \mathrm{w}_{3}$ & $0.013(0.017)$ & & $y_{1} w_{3}$ & $0.112(0.036)$ & $* * *$ \\
\hline $\mathrm{y}_{2} \mathrm{w}_{1}$ & $0.015(0.009)$ & * & $y_{2} w_{1}$ & $0.067(0.032)$ & $* *$ \\
\hline $\mathrm{y}_{2} \mathrm{w}_{3}$ & $-0.007(0.009)$ & & $\mathrm{y}_{2} \mathrm{w}_{3}$ & $-0.191(0.020)$ & $* * *$ \\
\hline$y_{3} w_{1}$ & $0.021(0.012)$ & $*$ & $\mathrm{y}_{3} \mathrm{w}_{1}$ & $-0.051(0.035)$ & \\
\hline$y_{3} w_{3}$ & $-0.016(0.012)$ & & $y_{3} w_{3}$ & $0.092(0.033)$ & $* * *$ \\
\hline $1 / 2 \mathrm{zZ}$ & $-0.327(0.021)$ & $* * *$ & $1 / 2 \mathrm{zz}$ & $-0.425(0.039)$ & $* * *$ \\
\hline$y_{1} z$ & $-0.114(0.009)$ & $* * *$ & $y_{1} z$ & $0.102(0.023)$ & $* * *$ \\
\hline$y_{2} z$ & $0.007(0.004)$ & $*$ & $y_{2} z$ & $-0.033(0.011)$ & $* * *$ \\
\hline $\mathrm{y}_{3} z$ & $0.081(0.007)$ & $* * *$ & $\mathrm{y}_{3} \%$ & $-0.048(0.017)$ & $* * *$ \\
\hline$w_{1} z$ & $0.159(0.029)$ & $* * *$ & $\mathrm{w}_{1} z$ & $0.358(0.062)$ & $* * *$ \\
\hline$w_{3} z$ & $-0.191(0.029)$ & $* * *$ & $w_{3} z$ & $-0.549(0.064)$ & $* * *$ \\
\hline $\mathrm{T}$ & $0.025(0.019)$ & & $\mathrm{T}$ & $0.200(0.044)$ & $* * *$ \\
\hline $1 / 2 \mathrm{~T}^{2}$ & $-0.008(0.006)$ & & $1 / 2 \mathrm{~T}^{2}$ & $-0.043(0.016)$ & $* * *$ \\
\hline$\mu / \sigma_{v}$ & $-2.009(0.716)$ & $* * *$ & $\mu / \sigma_{v}$ & $1.053(0.570)$ & \\
\hline$\lambda$ & $2.869(0.220)$ & $* * *$ & $\lambda$ & $2.486(0.227)$ & $* * *$ \\
\hline$\sigma$ & $0.291(0.022)$ & $* * *$ & $\sigma$ & $0.536(0.038)$ & $* * *$ \\
\hline
\end{tabular}

Mean (SE) - X-efficiency (and standard error), LOGL - the log likelihood ratio test, $\sigma_{\omega}^{2}$ - the variance of random noise, $\sigma_{v}^{2}$ - the variance of the truncated efficiency term, $\mu / \sigma_{v}$ - the truncation point for $v$ divided by the standard deviation of the truncated efficiency term, $\lambda$ - the ratio of standard deviation of the truncated normal efficiency term and random noise, or $\sigma_{v} / \sigma_{\omega}$, and $\sigma$ - the total standard deviation of the error term $-\sigma^{2}=\sigma_{\omega}^{2}+\sigma_{v}^{2}{ }^{*} /^{* *} / /^{* * *}=$ significant at $10 / 5 / 1 \%$ level. 
Contrary to the cost model findings, the profit model estimates exhibit significant decreasing returns to scale for loans $\left(y_{1}\right)$ and significant increasing returns to scale for investments $\left(y_{2}\right)$ and off-balance sheet activities $\left(y_{3}\right)$. Overall scale economies are increasing and significant. These results indicate that large banks can increase profits via output expansion, especially in the nontraditional areas of investments and off-balance sheet activities. ${ }^{20}$

TABLE 6.4: Economies of Scale Results for European Banks

\begin{tabular}{lrrrr}
\hline & Cost Frontier & & Profit Frontier \\
\hline Outputs & Estimate (SE) & $\mathrm{N}$ & Estimate (SE) & $\mathrm{N}$ \\
\hline $\mathrm{y}_{1}$ (loans) & $-5.46(4.61)$ & 51 & $-10.46(5.11)$ & 52 \\
$\mathrm{y}_{2}$ (investments) & $6.01(3.53)$ & 51 & $10.82(3.51)$ & 52 \\
$\mathrm{y}_{3}$ (off-balance sheet) & $13.89(3.90)$ & 47 & $13.23(4.23)$ & 52 \\
$\mathrm{y}$ (overall output) & $14.44(1.19)$ & 47 & $13.59(1.93)$ & 52 \\
\hline
\end{tabular}

\subsubsection{U.S. Banks}

Table 6.6 gives the cost and profit SFA models' estimation results for large U.S. banks. For the cost model the average X-efficiency score is 0.873 with a standard deviation of 0.047 , both of which are lower than for European banks. ${ }^{21}$ The estimated value for $\mu / \sigma_{v}$ indicates truncation at zero. This is reflected by the fact that the standard deviation for U.S. cost efficiency is far lower than for European cost efficiency. When evaluated at their respective cost frontiers, I infer that large U.S. banks have lower cost efficiency on average compared to European banks. However, for the profit model the average Xefficiency score is relatively high compared to European banks and equals 0.952 with a standard deviation of 0.092 . This result closely parallels those of Miller and Noulas (1996), who conducted a DEA analysis of large U.S. banks and found profit X-efficiency of 0.970 with almost half the banks 100 percent technically efficient. As expected, the U.S. market is more homogeneous than the European one, as can be observed from the lower standard deviation for both cost and profit X-efficiency.

${ }^{20}$ The negative relationship between cost and profit scale economies as bank output expands is consistent with work by Berger and Mester (1997), who found that cost and revenue inefficiencies can be negatively correlated (i.e., cost inefficiencies do not necessarily imply profit inefficiencies). On the other hand, the results reported here differ from Sheldon (1999), who reported decreasing returns to scale for both costs and profits.

${ }^{21}$ For the U.S. data, I observe a very high kurtosis for the dependent variables and outputs. The variable 'assets', used for weighted least squares (WLS) also has a high kurtosis, potentially aggravating any inefficiency problems arising as a result of heteroskedasticity. This appears to be the case for our U.S. cost model. I checked for robustness of our results by using different WLS estimations. We note that this does not significantly affect our efficiency estimates and our coefficients. Our estimators are still unbiased and consistent. In addition, mean efficiency and efficiency rankings are not significantly affected. 
Table 6.5 gives details of average scale economies estimated from the U.S. cost model. The scale estimates for loans $\left(y_{1}\right)$ and investments $\left(y_{2}\right)$ are insignificant, such that no inferences can be made. Economies of scale significantly decrease for off-balance sheet activities $\left(y_{3}\right)$. Overall economies of scale significantly decrease and are close in magnitude to those for the European cost model (i.e., 14.44 and 14.15 for European and U.S. banks, respectively). ${ }^{22}$

Average scale economies for U.S. banks generated from the profit model are also similar to those for European banks; that is, significant decreasing returns to scale for loans $\left(y_{1}\right)$, as well as significant increasing returns to scale for investments $\left(y_{2}\right)$, off-balance sheet activities $\left(y_{3}\right)$, and overall. As in Europe, it appears that U.S. banks' expansion of nontraditional financial services such as securities and off-balance sheet activities tends to boost profits.

In general, the efficiency results for large European and U.S. banks reflect more similarities than differences. Estimates of scale economies for costs and profits reveal functional relationships between output level and efficiency that are strikingly comparable to one another.

TABLE 6.5: Economies of Scale Results for U.S. Banks

\begin{tabular}{lrlrl}
\hline & Cost Frontier & & Profit Frontier \\
\hline Outputs & Estimate (SE) & $\mathrm{N}$ & Estimate (SE) & $\mathrm{N}$ \\
\hline $\mathrm{y}_{1}$ (loans) & $0.34(2.77)$ & 47 & $-7.11(3.00)$ & 47 \\
$\mathrm{y}_{2}$ (investments) & $1.03(1.41)$ & 47 & $.8 .84(2.17)$ & 47 \\
$\mathrm{y}_{3}$ (off-balance sheet) & $12.76(3.90)$ & 47 & $14.22(4.24)$ & 47 \\
$\mathrm{y}$ (overall output) & $14.15(1.38)$ & 47 & $15.95(1.50)$ & 47 \\
\hline
\end{tabular}

However, on average European banks have greater (lower) cost (profit) X-efficiencies compared to U.S. banks, and the dispersion of both profit and cost efficiency scores is considerably smaller for U.S. banks than for European banks. These differences do not imply that U.S. banks are more efficient than European banks, as each sample of banks is evaluated against its own efficient frontier. It is possible that the most efficient U.S. banks are only average when compared to the European banks. In order to compare efficiency results for European and U.S. banks, I next turn to a combined analysis of both samples.

${ }^{22}$ Our finding of decreasing returns to scale is consistent with numerous prior studies of large U.S. banks (e.g., see Noulas, Ray, and Miller 1990; Hunter, Timme, and Yang 1990; Jagiani and Khanthavit 1996; and Miller and Noulas 1996). 
TABLE 6.6: Cost and Profit Frontier Models for U.S. Banks

\begin{tabular}{|c|c|c|c|c|}
\hline Cost Model & & Profit Model & & \\
\hline Mean (SE) & $0.873(0.047)$ & Mean (SE) & $0.953(0.092)$ & \\
\hline Range & {$[0.386-0.977]$} & Range & {$[0.265-0.996]$} & \\
\hline LOGL $=449.45$ & Obs. $=476$ & $\mathrm{LOGL}=323.9$ & Obs. $=476$ & \\
\hline$\sigma_{\omega}^{2}=0.0117$ & $\sigma_{v}^{2}=0.0340$ & $\sigma_{\omega}^{2}=0.0073$ & $\sigma_{v}^{2}=0.0264$ & \\
\hline Variable & Coeff. (SE) & Variable & Coeff. (SE) & \\
\hline INTERCEPT & $2.373(9.357)$ & INTERCEPT & $1.212(1.564)$ & \\
\hline$w_{1}$ & $-0.487(3.302)$ & $\mathrm{w}_{1}$ & $-4.312(0.416)$ & $* * *$ \\
\hline$w_{3}$ & $-0.477(3.346)$ & $w_{3}$ & $-1.149(0.377)$ & $* * *$ \\
\hline $\mathrm{y}_{1}$ & $1.045(1.507)$ & $\mathrm{y}_{1}$ & $1.721(0.229)$ & $* * *$ \\
\hline $\mathrm{y}_{2}$ & $0.080(1.174)$ & $\mathrm{y}_{2}$ & $0.336(0.211)$ & \\
\hline $\mathrm{y}_{3}$ & $-0.096(0.765)$ & $\mathrm{y}_{3}$ & $-0.468(0.112)$ & $* * *$ \\
\hline$z$ & $0.992(3.672)$ & $z$ & $6.311(0.574)$ & $* * *$ \\
\hline $1 / 2 \mathrm{y}_{1} \mathrm{y}_{1}$ & $0.048(0.159)$ & $1 / 2 y_{1} y_{1}$ & $0.134(0.019)$ & $* * *$ \\
\hline $1 / 2 \mathrm{y}_{1} \mathrm{y}_{2}$ & $-0.123(0.165)$ & $1 / 2 y_{1} y_{2}$ & $-0.303(0.031)$ & $* * *$ \\
\hline $1 / 2 y_{1} y_{3}$ & $-0.058(0.204)$ & $1 / 2 \mathrm{y}_{1} \mathrm{y}_{3}$ & $0.051(0.023)$ & $* *$ \\
\hline $1 / 2 \mathrm{y}_{2} \mathrm{y}_{2}$ & $0.156(0.167)$ & $1 / 2 y_{2} y_{2}$ & $0.264(0.022)$ & $* * *$ \\
\hline $1 / 2 \mathrm{y}_{2} \mathrm{y}_{3}$ & $-0.146(0.268)$ & $1 / 2 y_{2} y_{3}$ & $-0.292(0.040)$ & $* * *$ \\
\hline $1 / 2 \mathrm{y}_{3} \mathrm{y}_{3}$ & $0.124(0.087)$ & $1 / 2 \mathrm{y}_{3} \mathrm{y}_{3}$ & $0.131(0.013)$ & $* * *$ \\
\hline $1 / 2 w_{1} w_{1}$ & $0.165(0.435)$ & $1 / 2 w_{1} w_{1}$ & $0.109(0.076)$ & \\
\hline $1 / 2 \mathrm{w}_{1} \mathrm{w}_{3}$ & $-0.143(0.369)$ & $1 / 2 w_{1} w_{3}$ & $-0.432(0.055)$ & $* * *$ \\
\hline $1 / 2 w_{3} w_{3}$ & $0.018(0.308)$ & $1 / 2 w_{3} w_{3}$ & $0.035(0.034)$ & \\
\hline $\mathrm{y}_{1} \mathrm{w}_{1}$ & $0.002(0.233)$ & $\mathrm{y}_{1} \mathrm{w}_{1}$ & $-0.051(0.040)$ & \\
\hline $\mathrm{y}_{1} \mathrm{w}_{3}$ & $0.160(0.236)$ & $y_{1} w_{3}$ & $0.281(0.037)$ & $* * *$ \\
\hline $\mathrm{y}_{2} \mathrm{w}_{1}$ & $-0.036(0.334)$ & $\mathrm{y}_{2} \mathrm{w}_{1}$ & $0.063(0.048)$ & \\
\hline $\mathrm{y}_{2} \mathrm{w}_{3}$ & $0.020(0.331)$ & $\mathrm{y}_{2} \mathrm{w}_{3}$ & $-0.032(0.047)$ & \\
\hline $\mathrm{y}_{3} \mathrm{w}_{1}$ & $0.041(0.223)$ & $y_{3} w_{1}$ & $0.014(0.037)$ & \\
\hline$y_{3} w_{3}$ & $-0.124(0.222)$ & $y_{3} w_{3}$ & $-0.118(0.034)$ & $* * *$ \\
\hline $1 / 2 \mathrm{zz}$ & $0.087(1.624)$ & $1 / 2 \mathrm{zz}$ & $2.777(0.236)$ & $* * *$ \\
\hline $\mathrm{y}_{1} \mathrm{z}$ & $-0.103(0.425)$ & $\mathrm{y}_{1} \mathrm{z}$ & $0.407(0.071)$ & $* * *$ \\
\hline $\mathrm{y}_{2} \mathrm{z}$ & $0.019(0.372)$ & $\mathrm{y}_{2} \mathrm{z}$ & $-0.200(0.066)$ & $* * *$ \\
\hline$y_{3} z$ & $0.038(0.245)$ & $\mathrm{y}_{3} \mathrm{z}$ & $-0.174(0.035)$ & $* * *$ \\
\hline$w_{1} z$ & $-0.213(1.005)$ & $\mathrm{w}_{1} \mathrm{z}$ & $-1.627(0.169)$ & $* * *$ \\
\hline $\mathrm{w}_{3} \mathrm{z}$ & $0.063(0.074)$ & $\mathrm{w}_{3} \mathrm{z}$ & $0.520(0.145)$ & $* * *$ \\
\hline $\mathrm{T}$ & $0.011(0.081)$ & $\mathrm{T}$ & $0.016(0.018)$ & \\
\hline $1 / 2 \mathrm{~T}^{2}$ & $-0.005(0.042)$ & $1 / 2 \mathrm{~T}^{2}$ & $0.007(0.006)$ & \\
\hline$\mu / \sigma_{v}$ & $0.000(8.951)$ & $\mu / \sigma_{v}$ & $1.201(0.821)$ & \\
\hline$\lambda$ & $1.701(3.065)$ & $\lambda$ & $1.908(0.137)$ & $* * *$ \\
\hline$\sigma$ & $0.214(0.252)$ & $\sigma$ & $0.183(0.010)$ & $* * *$ \\
\hline
\end{tabular}

Mean (SE) - X-efficiency (and standard error), LOGL - the log likelihood ratio test, $\sigma_{\omega}^{2}$ - the variance of random noise, $\sigma_{v}^{2}$ - the variance of the truncated efficiency term, $\mu / \sigma_{v}$ - the truncation point for $v$ divided by the standard deviation of the truncated efficiency term, $\lambda$ - the ratio of standard deviation of the truncated normal efficiency term and random noise, or $\sigma_{v} / \sigma_{\omega}$, and $\sigma$ - the total standard deviation of the error term $-\sigma^{2}=\sigma_{\omega}^{2}+\sigma_{v}^{2}{ }^{*} /^{* *} /{ }^{* * *}=$ significant at $10 / 5 / 1 \%$ level. 


\subsubsection{European and U.S. Banks Combined}

Table 6.7 reports the results for a series of independent sample t-tests for mean differences in economies of scale estimates among European and U.S. banks. As discussed earlier, these tests are based on bank samples that progressively move closer to the frontier (i.e., from the $50^{t h}$ to the $90^{t h}$ percentile). The F-statistic is Levene's test for equal variances, while the t-statistics test for mean differences in average scale estimates for European and U.S. banks assuming equal (type I) and unequal (type II) variances. For the cost models the $t$-test results are mixed, with insignificant $t$-tests for the $50^{\text {th }}$ and $90^{\text {th }}$ percentile samples and significant t-tests for other percentile samples. Placing greater weight on the $90^{\text {th }}$ percentile banks that are closest to the cost frontier, due to insignificant differences in mean scale economies, I infer that there is evidence in favor of estimating a single cost frontier for European and U.S. banks. For the profit models the t-tests are significant in all cases, including $90^{\text {th }}$ percentile banks, which implies different profit frontiers for European and U.S. banks.

TABLE 6.7: Tests for Mean Differences in Economies of Scale in Europe and U.S.

A. Cost Models

\begin{tabular}{lclrlrrrrr}
\hline Percentile & $\begin{array}{l}\text { Europe } \\
\text { Obs. }\end{array}$ & Mean (SE) & $\begin{array}{l}\text { U.S. } \\
\text { Obs. }\end{array}$ & Mean (SE) & Type & F & t & df \\
\hline $50^{\text {th }}$ & 259 & $15.21(1.79)$ & 238 & $15.12(2.54)$ & I & 12.04 & -0.48 & 495 \\
& & & & & II & & -0.48 & 422 \\
$60^{\text {th }}$ & 207 & $14.92(1.58)$ & 191 & $15.26(2.68)$ & I & 29.75 & 1.52 & 396 \\
& & & & & II & & 1.49 & 303 \\
$70^{\text {th }}$ & 155 & $14.76(1.39)$ & 143 & $15.31(2.76)$ & I & 44.46 & 2.21 & 296 \\
& & & & & II & & 2.16 & 206 \\
$80^{\text {th }}$ & 104 & $14.61(1.26)$ & 95 & $15.13(2.83)$ & I & 24.69 & 1.69 & 197 \\
& & & & & II & & 1.64 & 127 \\
$90^{\text {th }}$ & 51 & $14.44(1.38)$ & 47 & $14.15(1.19)$ & I & 0.29 & -1.13 & 96 \\
\hline
\end{tabular}

B. Profit Models

\begin{tabular}{lrlrlrrrrr}
\hline Percentile & $\begin{array}{l}\text { Europe } \\
\text { Obs. }\end{array}$ & Mean (SE) & $\begin{array}{l}\text { U.S. } \\
\text { Obs. }\end{array}$ & Mean (SE) & Type & & t & df \\
\hline $50^{\text {th }}$ & 260 & $15.14(1.98)$ & 238 & $16.44(2.19)$ & I & 0.65 & 6.94 & 496 \\
& & & & & II & & 6.91 & 479 \\
$60^{\text {th }}$ & 208 & $15.08(2.03)$ & 190 & $16.43(2.13)$ & I & 2.35 & 6.48 & 396 \\
& & & & & II & & 6.47 & 389 \\
$70^{\text {th }}$ & 155 & $14.88(2.05)$ & 143 & $16.31(1.98)$ & I & 5 & 6.14 & 296 \\
& & & & & II & & 6.14 & 295 \\
$80^{\text {th }}$ & 104 & $14.51(2.12)$ & 95 & $16.19(1.65)$ & I & 16.32 & 6.21 & 197 \\
& & & & & II & & 6.28 & 192 \\
$90^{\text {th }}$ & 52 & $13.59(1.93)$ & 47 & $15.96(1.51)$ & I & 5.63 & 6.74 & 97 \\
& & & & & II & & 6.83 & 95 \\
\hline
\end{tabular}

Independent Sample t-tests for mean differences. The F-statistic is Levene's test for the equality of variances. Type I and II refer to Levene's t-test (at the $5 \%$ level) for mean differences in average economies between European and U.S. banks assuming equal and unequal variances, respectively. 
Tables 6.8 and 6.9 report the estimated cost models for the combined sample with the addition of dummy variables for 17 countries in panel A and Europe (versus U.S.) in panel B. These models seek to capture national differences in cost scale estimates. In general, most of the country-specific dummy variables are significant; however, and more relevant to the present analysis, the Europe dummy variable is not significant. The latter result is consistent with the finding of a single cost frontier for European and U.S. banks. Also notice that average X-efficiency is 0.961 for the country dummy cost model and 0.958 for the Europe dummy cost model. Thus, overall cost efficiency results are not affected by the inclusion of country-specific dummy variables. In both estimations, $\mu / \sigma_{v}$ is significantly negative, as a relatively large part of the observation can be found in the tail of efficiency distribution.

TABLE 6.8: Dummy Cost Frontier Models (Dummies)

\begin{tabular}{|c|c|c|c|c|c|}
\hline Country & Dummy & & Country & Dummy & \\
\hline & Coeff. (SE) & & & Coeff. (SE) & \\
\hline Austria & $0.197(0.084)$ & ** & Ireland & $0.094(0.030)$ & ***** \\
\hline Bclgium & $-0.017(0.035)$ & & Italy & $-0.063(0.022)$ & $* * *$ \\
\hline Switzerland & $0.099(0.020)$ & $* * *$ & Luxembourg & $0.156(0.055)$ & $* * *$ \\
\hline Germany & $-0.110(0.024)$ & $* * *$ & Netherlands & $-0.067(0.031)$ & $* *$ \\
\hline Denmark & $0.167(0.032)$ & $* * *$ & Norway & $-0.092(0.054)$ & $*$ \\
\hline Spain & $0.173(0.018)$ & $* * *$ & Portugal & $-0.176(0.064)$ & $* * *$ \\
\hline Finland & $0.084(0.057)$ & & Sweden & $-0.023(0.033)$ & $* * *$ \\
\hline France & $0.270(0.027)$ & $* * *$ & Europe & Dummy & \\
\hline Great Britain & $-0.042(0.019)$ & $* *$ & & Coeff. (SE) & \\
\hline Grecce & $0.116(0.026)$ & $* * *$ & Europe & $0.031(0.019)$ & \\
\hline
\end{tabular}

Table 6.10 employs the results from the country dummy cost model to compare each European country's bank cost efficiency to the average U.S. bank cost efficiency of 0.974 . The F-statistic tests for the equality of variances fail to accept the null hypothesis (except for Italy); as such, type II $t$-tests under the assumption of unequal variances are most appropriate. A negative and significant t-statistic means a country's banks are less cost efficient than U.S. banks. I use weighted averages based on bank asset size to partially correct for differences in market structure. Excluding some countries due to relatively low sample sizes (i.e., Austria, Finland, Portugal, and Luxembourg), the type II t-test results are mixed, with five (eight) countries' banks having cost efficiency similar to (different from) U.S. banks. Only banks in Italy and the Netherlands had significantly higher average cost efficiency scores than U.S. banks. ${ }^{23}$ Banks in Belgium stand out as the least efficient among the European countries. Finally, while banks in Germany, Denmark, France, and Great Britain were less efficient than U.S. banks from a statistical standpoint, the magnitude of the difference appears to be fairly modest in economic terms.

\footnotetext{
${ }^{23}$ As shown in table 6.10 , these findings are not related to the individual coefficients for the country dummies, as these dummies capture country-specific effects but not X-efficiency.
} 
TABLE 6.9: Dummy Cost Frontier Models

\begin{tabular}{|c|c|c|c|c|c|}
\hline \multicolumn{3}{|c|}{ Country Dummy } & \multicolumn{3}{|c|}{ Europe Dummy } \\
\hline Mean (SE) & $0.961(0.090)$ & & Mean (SE) & $0.958(0.081)$ & \\
\hline Range & $\{0.044-0.995\}$ & & Range & [0.067-0.995] & \\
\hline Obs. $=995$ & LOGL $=743.85$ & & Obs. $=995$ & LOGL $=611.66$ & \\
\hline$\sigma_{\omega}^{2}=0.0065$ & $\sigma_{v}^{2}=0.0557$ & & $\sigma_{\omega}^{2}=0.0087$ & $\sigma_{v}^{2}=0.0483$ & \\
\hline Variable & Coeff. (SE) & & Variable & Coeff. (SE) & \\
\hline INTERCEPT & $4.767(0.368)$ & $* * *$ & INTERCEPT & $2.334(0.393)$ & *** \\
\hline $\mathrm{w}_{1}$ & $0.663(0.082)$ & $* * *$ & $\mathrm{w}_{1}$ & $0.582(0.077)$ & $* * *$ \\
\hline$w_{3}$ & $0.303(0.078)$ & *** & $\mathrm{w}_{3}$ & $0.270(0.073)$ & *** \\
\hline $\mathrm{y}_{1}$ & $-0.106(0.055)$ & $*$ & $\mathrm{y}_{1}$ & $0.110(0.065)$ & $*$ \\
\hline $\mathrm{y}_{2}$ & $0.374(0.035)$ & $* * *$ & $\mathrm{y}_{2}$ & $0.561(0.032)$ & $* * *$ \\
\hline$y_{3}$ & $0.384(0.033)$ & $* * *$ & $y_{3}$ & $0.243(0.037)$ & $* * *$ \\
\hline $\mathrm{z}$ & $-0.703(0.090)$ & $* * *$ & $\mathrm{z}$ & $-0.765(0.104)$ & $* * *$ \\
\hline $1 / 2 \mathrm{y}_{1} \mathrm{y}_{1}$ & $0.116(0.006)$ & $* * *$ & $1 / 2 \mathrm{y}_{1} \mathrm{y}_{1}$ & $0.131(0.006)$ & $* * *$ \\
\hline $1 / 2 y_{1} y_{2}$ & $-0.066(0.008)$ & *** & $1 / 2 \mathrm{y}_{1} \mathrm{y}_{2}$ & $-0.178(0.006)$ & $* * *$ \\
\hline $1 / 2 y_{1} y_{3}$ & $-0.143(0.006)$ & $* * *$ & $1 / 2 \mathrm{y}_{1} \mathrm{y}_{3}$ & $-0.088(0.008)$ & $* * *$ \\
\hline $1 / 2 y_{2} y_{2}$ & $0.048(0.004)$ & $* * *$ & $1 / 2 \mathrm{y}_{2} \mathrm{y}_{2}$ & $0.150(0.004)$ & $* * *$ \\
\hline $1 / 2 \mathrm{y}_{2} \mathrm{y}_{3}$ & $-0.044(0.005)$ & $* * *$ & $1 / 2 \mathrm{y}_{2} \mathrm{y}_{3}$ & $-0.147(0.005)$ & $* * *$ \\
\hline $1 / 2 \mathrm{y}_{3} \mathrm{y}_{3}$ & $0.104(0.002)$ & $* * *$ & $1 / 2 y_{3} y_{3}$ & $0.130(0.002)$ & *** \\
\hline $1 / 2 w_{1} w_{1}$ & $-0.014(0.011)$ & & $1 / 2 \mathrm{w}_{1} \mathrm{w}_{1}$ & $0.081(0.013)$ & $* * *$ \\
\hline $1 / 2 w_{1} w_{3}$ & $0.224(0.018)$ & $* * *$ & $1 / 2 w_{1} w_{3}$ & $0.158(0.016)$ & $* * *$ \\
\hline $1 / 2 w_{3} w_{3}$ & $0.003(0.010)$ & & $1 / 2 w_{3} w_{3}$ & $0.009(0.007)$ & \\
\hline $\mathrm{y}_{1} \mathrm{w}_{1}$ & $-0.106(0.009)$ & $* * *$ & $\mathrm{y}_{1} \mathrm{w}_{1}$ & $-0.067(0.009)$ & $* * *$ \\
\hline $\mathrm{y}_{1} \mathrm{w}_{3}$ & $0.091(0.009)$ & $* * *$ & $y_{1} w_{3}$ & $0.087(0.009)$ & $* * *$ \\
\hline $\mathrm{y}_{2} \mathrm{w}_{1}$ & $0.104(0.006)$ & $* * *$ & $\mathrm{y}_{2} \mathrm{w}_{1}$ & $0.074(0.006)$ & $* * *$ \\
\hline $\mathrm{y}_{2} \mathrm{w}_{3}$ & $-0.065(0.007)$ & $* * *$ & $y_{2} w_{3}$ & $-0.058(0.005)$ & $* * *$ \\
\hline$y_{3} w_{1}$ & $0.031(0.006)$ & $* * *$ & $\mathrm{y}_{3} \mathrm{w}_{1}$ & $0.016(0.007)$ & $* *$ \\
\hline $\mathrm{y}_{3} \mathrm{w}_{3}$ & $-0.049(0.007)$ & $* * *$ & $\mathrm{y}_{3} \mathrm{w}_{3}$ & $-0.052(0.007)$ & $* * *$ \\
\hline $1 / 2 \mathrm{zz}$ & $-0.317(0.017$ & $* * *$ & $1 / 2 \mathrm{zz}$ & $-0.355(0.017)$ & $* * *$ \\
\hline$y_{1} z$ & $-0.086(0.010$ & $* * *$ & $y_{1} z$ & $-0.089(0.009)$ & $* * *$ \\
\hline $\mathrm{y}_{2} \mathrm{z}$ & $-0.002(0.005)$ & & $y_{2} z$ & $0.003(0.006)$ & \\
\hline$y_{3} z$ & $0.070(0.007)$ & $* * *$ & $y_{3} z$ & $0.063(0.007)$ & $* * *$ \\
\hline$w_{1} z$ & $0.164(0.019)$ & $* * *$ & $\mathrm{w}_{1} \mathrm{z}$ & $0.061(0.020)$ & $* * *$ \\
\hline $\mathrm{w}_{3} \mathrm{z}$ & $-0.067(0.021)$ & $* * *$ & $w_{3} z$ & $-0.046(0.022)$ & $* *$ \\
\hline $\mathrm{T}$ & $0.020(0.013)$ & & $\mathrm{T}$ & $0.014(0.015)$ & \\
\hline $1 / 2 T^{2}$ & $-0.005(0.004)$ & & $1 / 2 \mathrm{~T}^{2}$ & $-0.004(0.005)$ & \\
\hline$\mu / \sigma_{v}$ & $-2.423(0.541)$ & $* * *$ & $\mu / \sigma_{v}$ & $-1.754(0.459)$ & $* * *$ \\
\hline$\lambda$ & $2.936(0.128)$ & *** & $\lambda$ & $2.362(0.112)$ & $* * *$ \\
\hline$\sigma$ & $0.249(0.011)$ & $* * *$ & $\sigma$ & $0.239(0.011)$ & $* * *$ \\
\hline
\end{tabular}

Mean (SE) - the mean X-efficiency (and standard error), LOGL - the log likelihood ratio test, $\sigma_{\omega}^{2}$ - the variance of random noise, $\sigma_{v}^{2}$ - the variance of the truncated efficiency term, $\mu / \sigma_{v}-$ the truncation point for $v$ divided by the standard deviation of the truncated efficiency term, $\lambda$ - the ratio of standard deviation of the truncated normal efficiency term and random noise, or $\sigma_{v} / \sigma_{\omega}$, and $\sigma$ - the total standard deviation of the error term $-\sigma^{2}=\sigma_{\omega}^{2}+\sigma_{v}^{2}$.

These results combined with the fact that many of the dummy variables are significant suggest that Europe itself is also far from homogenous. This conclusion however must be 
weakened since estimations of the Europe cost and profit model with country dummies (not reported here) revealed that the dummies as well as the efficiency scores of most European countries are very similar.

TABLE 6.10: Cost Efficiency: Independent Sample Tests

\begin{tabular}{|c|c|c|c|c|c|c|}
\hline Country & Mean & $\overline{\mathrm{N}}$ & Type & $\bar{F}$ & $\mathrm{t}$ & $\mathrm{df}$ \\
\hline \multirow[t]{2}{*}{ Austria } & 0.902 & 5 & I & 777.18 & -13.34 & 479 \\
\hline & & & II & & -1.23 & 4 \\
\hline \multirow[t]{2}{*}{ Belgium } & 0.877 & 16 & I & 813.72 & -15.68 & 490 \\
\hline & & & II & & -2.79 & 15 \\
\hline \multirow[t]{2}{*}{ Switzerland } & 0.974 & 46 & I & 1874.98 & 0.67 & 520 \\
\hline & & & II & & 0.23 & 45 \\
\hline \multirow[t]{2}{*}{ Germany } & 0.94 & 64 & I & 1363.42 & -11.5 & 538 \\
\hline & & & II & & -4.2 & 63 \\
\hline \multirow[t]{2}{*}{ Denmark } & 0.956 & 47 & $\mathrm{I}$ & 5848.73 & -17.13 & 521 \\
\hline & & & II & & -5.42 & 46 \\
\hline \multirow[t]{2}{*}{ Spain } & 0.973 & 52 & $I$ & 626.19 & -3.75 & 525 \\
\hline & & & II & & -1.6 & 51 \\
\hline \multirow[t]{2}{*}{ Finland } & 0.971 & 10 & I & 674.15 & -4.61 & 484 \\
\hline & & & II & & -0.76 & 9 \\
\hline \multirow[t]{2}{*}{ France } & 0.969 & 44 & I & 240.28 & -16.52 & 518 \\
\hline & & & II & & -6.09 & 43 \\
\hline \multirow[t]{2}{*}{ Great Britain } & 0.947 & 63 & $I$ & 714.38 & -11.81 & 537 \\
\hline & & & II & & -4.28 & 62 \\
\hline \multirow[t]{2}{*}{ Greece } & 0.973 & 22 & I & 215.42 & -4.02 & 496 \\
\hline & & & II & & -1.32 & 21 \\
\hline \multirow[t]{2}{*}{ Ireland } & 0.976 & 16 & I & 1222.1 & 2.99 & 490 \\
\hline & & & II & & 0.66 & 15 \\
\hline \multirow[t]{2}{*}{ Italy } & 0.976 & 54 & I & 0.06 & 13.2 & 528 \\
\hline & & & II & & 12.03 & 63 \\
\hline \multirow[t]{2}{*}{ Luxembourg } & 0.937 & 13 & 1 & 1905.46 & -26.12 & 486 \\
\hline & & & II & & -4.11 & 11 \\
\hline \multirow[t]{2}{*}{ Netherlands } & 0.981 & 24 & I & 205.55 & 12.21 & 490 \\
\hline & & & II & & 2.67 & 15 \\
\hline \multirow[t]{2}{*}{ Norway } & 0.971 & 16 & I & 205.55 & 12.21 & 490 \\
\hline & & & II & & 2.67 & 15 \\
\hline Portugal & 0.971 & 11 & 1 & 606.82 & -5.03 & 485 \\
\hline \multirow{2}{*}{ Sweden } & 0.974 & 18 & 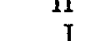 & 244.06 & -0.93 & $\begin{array}{r}10 \\
492\end{array}$ \\
\hline & & & II & & $\begin{array}{l}-0.92 \\
-0.31\end{array}$ & $\begin{array}{r}48 \\
17\end{array}$ \\
\hline
\end{tabular}

The F-statistic is Levene's test for the equality of variances. Type I and II refer to Levene's t-test (at the $5 \%$ level) for mean differences in average scale economies assuming equal and unequal variances, respectively. The reference country is the U.S. with an average cost efficiency of 0.974 . Efficiency scores are weighted by assets per country in each year.

With the help of the Europe dummy cost model, I also test whether the European countries' banks jointly are on average as cost efficient as U.S. banks. Mean efficiency for European banks is 0.958 , which is significantly less than U.S. banks, albeit by only 1.6 percent. I infer that European banks are slightly less cost efficient than U.S. banks on average but the difference is not economically meaningful. 
I next turn to the estimated profit models for the combined sample. Recall that earlier tests moving progressively closer to the profit frontier implied differences between European and U.S. banks. Thus, the results from estimating a single profit frontier have to be interpreted with care. An important motivation for pursuing with the estimation of this single frontier is that comparing profit efficiency of European and U.S. banks requires a common benchmark. The earlier tests however, indicate uncertainty with respect to the robustness of the results presented in tables 6.11 and 6.12 . This table shows the estimated models with the addition of dummy variables for 17 countries in panel A and Europe (versus U.S.) in panel B. Profit X-efficiency scores averaged 0.735 for the country dummy model and 0.853 for the Europe dummy model. Hence, relative to the cost model results, country-specific dummy variables (which again are generally statistically significant) provide incremental information that is averaged out upon lumping together the European countries. Focusing on panel B's Europe dummy variable t-test, X-efficient frontier U.S. banks' scale economies are consistently higher than those for European banks. And $\mu / \sigma_{v}$ is positive and significant, implying that a large portion of the observations is efficient. This evidence tends to confirm the earlier finding of differences in the profit frontier of European and U.S. banks. For U.S. banks the average profit efficiency score is 0.865 compared to 0.806 for European banks, which are significantly different at the 5 percent level.

TABLE 6.11: Dummy Profit Frontier Models (Dummies)

\begin{tabular}{llllll}
\hline Country & Dummy & & Country & Dummy & \\
\hline & Coeff. (SE) & & & Coeff. (SE) & \\
\hline Austria & $-0.160(0.176)$ & & Ireland & $0.452(0.109)$ & $* * *$ \\
Belgium & $-0.149(0.104)$ & & Italy & $-0.164(0.044)$ & $* * *$ \\
Switzerland & $0.016(0.050)$ & & Luxembourg & $-0.144(0.159)$ & \\
Germany & $-0.295(0.053)$ & $* * *$ & Netherlands & $-0.204(0.070)$ & $* * *$ \\
Denmark & $-0.237(0.065)$ & $* * *$ & Norway & $-0.440(0.217)$ & $* *$ \\
Spain & $0.102(0.049)$ & $* *$ & Portugal & $-0.330(0.124)$ & $* * *$ \\
Finland & $0.078(0.062)$ & & Sweden & $0.218(0.066)$ & $* * *$ \\
France & $-0.488(0.052)$ & $* * *$ & Europe & Dummy & \\
Great Britain & $0.187(0.044)$ & $* *$ & & Coeff. (SE) & \\
Greece & $0.676(0.075)$ & $* * *$ & Europe & $0.225(0.050)$ & $* * *$ \\
\hline \multicolumn{5}{c}{${ }^{* * *} /^{* *}=$ significant at the $10 / 5 / 1 \%$ level. }
\end{tabular}

In light of the aforementioned differences, it is interesting to consider the independent sample tests for mean differences in profit efficiency scores between individual European countries' banks and U.S. banks. Again excluding selected countries due to small sample sizes (i.e., Austria, Finland, Portugal, and Luxembourg), the type II t-test results in table 6.13 now clearly indicate that U.S. banks are significantly more profit efficient than banks in eleven countries, and only banks in Italy and Sweden had similar profit efficiency to U.S. banks. 
TABLE 6.12: Dummy Profit Frontier Models

\begin{tabular}{|c|c|c|c|c|c|}
\hline \multicolumn{3}{|c|}{ Country Dummy } & \multicolumn{3}{|c|}{ Europe Dummy } \\
\hline Mean (SE) & $0.735(0.207)$ & & Mean (SE) & $0.853(0.118)$ & \\
\hline Range & 0.015-0.990 & & Range & $0.079-0.985$ & \\
\hline Obs. $=995$ & $\mathrm{LOGL}=90.43$ & & Obs. $=995$ & LOGL $=-129.17$ & \\
\hline$\sigma_{\omega}^{2}=0.0209$ & $\sigma_{v}^{2}=0.3695$ & & $\sigma_{\omega}^{2}=0.0541$ & $\sigma_{v}^{2}=0.0782$ & \\
\hline Variable & Coeff. (SE) & & Variable & Coeff. (SE) & \\
\hline INTE & $11.074(0.658)$ & $* * *$ & INT & $0.048(0.708)$ & \\
\hline$w_{1}$ & $0.885(0.205)$ & $* * *$ & $w_{1}$ & $1.555(0.180)$ & *** \\
\hline$w_{3}$ & $0.09(0.174)$ & & $w_{3}$ & $-0.847(0.167)$ & *** \\
\hline$y_{1}$ & $-0.875(0.113)$ & $* * *$ & $\mathrm{y}_{1}$ & $0.384(0.120)$ & $* * *$ \\
\hline $\mathrm{y}_{2}$ & $0.179(0.078)$ & $* *$ & $y_{2}$ & $0.425(0.071)$ & $* * *$ \\
\hline$y_{3}$ & $0.628(0.074)$ & $* * *$ & $\mathrm{y}_{3}$ & $0.106(0.078$ & \\
\hline$\%$ & $-0.166(0.181)$ & & $\mathrm{z}$ & $-1.563(0.173)$ & $* * *$ \\
\hline $1 / 2 \mathrm{y}_{1} \mathrm{y}_{1}$ & $0.272(0.013)$ & $* * *$ & $1 / 2 \mathrm{y}_{1} \mathrm{y}_{1}$ & $0.182(0.012)$ & $* * *$ \\
\hline $1 / 2 y_{1} y_{2}$ & $-0.123(0.017)$ & $* * *$ & $1 / 2 y_{1} y_{2}$ & $-0.176(0.016)$ & $* * *$ \\
\hline $1 / 2 y_{1} y_{3}$ & $-0.257(0.017)$ & $* * *$ & $1 / 2 \mathrm{y}_{1} \mathrm{y}_{3}$ & $-0.168(0.014)$ & $* * *$ \\
\hline $1 / 2 \quad y_{2} y_{2}$ & $0.072(0.010)$ & $* * *$ & $1 / 2 \mathrm{y}_{2} \mathrm{y}_{2}$ & $0.069(0.009)$ & *** \\
\hline $1 / 2 y_{2} y_{3}$ & $-0.055(0.013)$ & *** & $1 / 2 y_{2} y_{3}$ & $-0.026(0.012)$ & $* *$ \\
\hline $1 / 2 y_{3} y_{3}$ & $0.136(0.007)$ & $* * *$ & $1 / 2 y_{3} y_{3}$ & $0.120(0.006)$ & $* * *$ \\
\hline $1 / 2 w_{1} w_{1}$ & $0.211(0.031)$ & $* * *$ & $1 / 2 \mathrm{w}_{1} \mathrm{w}_{1}$ & $0.315(0.029)$ & $* * *$ \\
\hline $1 / 2 w_{1} w_{3}$ & $0.107(0.039)$ & $* * *$ & $1 / 2 w_{1} w_{3}$ & $-0.023(0.035)$ & \\
\hline $1 / 2 w_{3} w_{3}$ & $0.038(0.017)$ & $* *$ & $1 / 2 w_{3} w_{3}$ & $0.059(0.014)$ & $* * *$ \\
\hline $\mathrm{y}_{1} \mathrm{w}_{1}$ & $0.099(0.020)$ & $* * *$ & $\mathrm{y}_{1} \mathrm{w}_{1}$ & $0.035(0.02)$ & $*$ \\
\hline$y_{1} w_{3}$ & $-0.045(0.021)$ & $* *$ & $\mathrm{y}_{1} \mathrm{w}_{3}$ & $0.038(0.022)$ & $*$ \\
\hline $\mathrm{y}_{2} \mathrm{w}_{1}$ & $-0.049(0.018)$ & $* * *$ & $\mathrm{y}_{2} \mathrm{w}_{1}$ & $-0.026(0.014)$ & $*$ \\
\hline $\mathrm{y}_{2} \mathrm{w}_{3}$ & $-0.049(0.018)$ & $* * *$ & $\mathrm{y}_{2} \mathrm{w}_{3}$ & $-0.100(0.014)$ & $* * *$ \\
\hline $\mathrm{y}_{3} \mathrm{w}_{1}$ & $0.011(0.014)$ & & $y_{3} w_{1}$ & $0.026(0.014)$ & $*$ \\
\hline $\mathrm{y}_{3} \mathrm{w}_{3}$ & $0.002(0.015)$ & & $\mathrm{y}_{3} \mathrm{w}_{3}$ & $0.016(0.015)$ & \\
\hline $1 / 2 \mathrm{zz}$ & $-0.336(0.039)$ & $* * *$ & $1 / 2 \mathrm{zz}$ & $-0.591(0.031)$ & $* * *$ \\
\hline$y_{1} z$ & $0.042(0.020)$ & $* *$ & $y_{1} z$ & $0.027(0.016)$ & $*$ \\
\hline $\mathrm{y}_{2} \mathrm{z}$ & $-0.009(0.012)$ & & $\mathrm{y}_{2} \mathrm{z}$ & $-0.031(0.008)$ & $* * *$ \\
\hline$y_{3} z$ & $-0.083(0.014)$ & $* * *$ & $y_{3} z$ & $0.004(0.012)$ & \\
\hline$w_{1} z$ & $0.42(0.047)$ & *** & $w_{1} z$ & $0.404(0.041)$ & $* * *$ \\
\hline$w_{3} z$ & $-0.597(0.045)$ & $* * *$ & $\mathrm{w}_{3} \mathrm{z}$ & $-0.568(0.040)$ & $* * *$ \\
\hline $\mathrm{T}$ & $0.094(0.032)$ & $* * *$ & $\mathrm{~T}$ & $0.129(0.036)$ & **** \\
\hline $1 / 2 \mathrm{~T}^{2}$ & $-0.012(0.011)$ & & $1 / 2 \mathrm{~T}^{2}$ & $-0.027(0.013)$ & $* *$ \\
\hline$\mu / \sigma_{v}$ & $2.139(0.622)$ & $* * *$ & $\mu / \sigma_{v}$ & $0.500(0594)$ & \\
\hline$\lambda$ & $4.208(0.315)$ & $* * *$ & $\lambda$ & $1.203(0.095)$ & *** \\
\hline$\sigma$ & $0.625(0.045)$ & $* * *$ & $\sigma$ & $0.364(0.015)$ & $* * *$ \\
\hline
\end{tabular}

Mean (SE) - the mean X-efficiency (and standard error), LOGL - the log likelihood ratio test, $\sigma_{\omega}^{2}$ - the variance of random noise, $\sigma_{v}^{2}$ - the variance of the truncated efficiency term, $\mu / \sigma_{v}$ the truncation point for $v$ divided by the standard deviation of the truncated efficiency term, $\lambda$ - the ratio of standard deviation of the truncated normal efficiency term and random noise, or $\sigma_{v} / \sigma_{\omega}$, and $\sigma-$ the total standard deviation of the error term $-\sigma^{2}=\sigma_{\omega}^{2}+\sigma_{v}^{2}$. 
TABLE 6.13: Profit Efficiency: Independent Sample Tests

\begin{tabular}{|c|c|c|c|c|c|c|}
\hline Country & Mean & $\mathrm{N}$ & Type & $F$ & $\mathrm{t}$ & $\mathrm{df}$ \\
\hline Austria & 0.518 & 5 & I & 2313.37 & $\begin{array}{r}-15.64 \\
-1.69\end{array}$ & $\begin{array}{r}479 \\
4\end{array}$ \\
\hline Belgium & 0.791 & 16 & 1 & 316.61 & -7.39 & 490 \\
\hline Switzerland & 0.824 & 46 & I & 26.14 & -8.92 & 520 \\
\hline Germany & 0.805 & 64 & $\begin{array}{r}\text { II } \\
\text { II }\end{array}$ & 386.44 & $\begin{array}{r}-4.94 \\
-12.44 \\
-6.09\end{array}$ & $\begin{array}{r}47 \\
538 \\
65\end{array}$ \\
\hline Denmark & 0.796 & 47 & I & 47.91 & $\begin{array}{r}-15.89 \\
-9.86\end{array}$ & $\begin{array}{r}521 \\
49\end{array}$ \\
\hline Spain & 0.849 & 52 & $\underset{\text { II }}{\text { I }}$ & 10.66 & $\begin{array}{l}-4.08 \\
-3.54\end{array}$ & $\begin{array}{r}525 \\
58\end{array}$ \\
\hline Finland & 0.772 & 10 & II & 176.69 & $\begin{array}{l}-8.72 \\
-1.89\end{array}$ & $\begin{array}{r}484 \\
9\end{array}$ \\
\hline France & 0.783 & 44 & II & 325.63 & $\begin{array}{r}-13.61 \\
-5.37\end{array}$ & $\begin{array}{r}518 \\
44\end{array}$ \\
\hline Great Britain & 0.831 & 63 & $\begin{array}{l}\text { I } \\
\text { II }\end{array}$ & 60.53 & $\begin{array}{l}-9.07 \\
-6.83\end{array}$ & $\begin{array}{r}537 \\
70\end{array}$ \\
\hline Greece & 0.739 & 22 & II & 41.74 & $\begin{array}{l}-21.24 \\
-12.96\end{array}$ & $\begin{array}{r}496 \\
22\end{array}$ \\
\hline Ireland & 0.865 & 16 & II & 8.68 & $\begin{array}{l}0.02 \\
0.03\end{array}$ & $\begin{array}{r}490 \\
18\end{array}$ \\
\hline Italy & 0.803 & 54 & $\begin{array}{l}\text { I } \\
\text { II }\end{array}$ & 194.26 & $\begin{array}{r}-13.83 \\
-7.47\end{array}$ & $\begin{array}{r}528 \\
55\end{array}$ \\
\hline Luxembourg & 0.683 & 13 & II & 843 & $\begin{array}{r}-15.12 \\
-2.96\end{array}$ & $\begin{array}{r}486 \\
11\end{array}$ \\
\hline Netherlands & 0.845 & 24 & I & 17.94 & $\begin{array}{l}-3.63 \\
-2.38\end{array}$ & $\begin{array}{r}498 \\
24\end{array}$ \\
\hline Norway & 0.751 & 16 & II & 327.08 & $\begin{array}{r}-14.36 \\
-4.45\end{array}$ & $\begin{array}{r}490 \\
15\end{array}$ \\
\hline Portugal & 0.855 & 11 & $\begin{array}{l}\text { I } \\
\text { II }\end{array}$ & 0.18 & $\begin{array}{l}-1.22 \\
-1.03\end{array}$ & $\begin{array}{r}485 \\
10\end{array}$ \\
\hline Sweden & 0.823 & 18 & II & 218.79 & $\begin{array}{l}-4.93 \\
-1.35\end{array}$ & $\begin{array}{r}492 \\
17\end{array}$ \\
\hline
\end{tabular}

The F-statistic is Levene's test for the equality of variances. Type I and II refer to Levene's t-test (at the $5 \%$ level) for mean differences in average scale economies assuming equal and unequal variances, respectively. The reference country is the U.S. with an average efficiency

of 0.865 . Efficiency scores are weighted by assets per country in each year.

In sum, the profit efficiency results for banks in Europe and the U.S. contrast sharply with the cost efficiency results. As a robustness check, I also estimated the cost and profit models using traditional labor prices for U.S. banks as well as using flow outputs (e.g., substituting interest earnings on loans for the stock of loans, securities earnings for the stock of investments, and noninterest income for the stock of off-balance sheet activities), but the cost and profit efficiency results remained qualitatively the same.

Figure 6.1 graphically summarizes the mean cost and profit efficiency scores for large banks by country. Viewing countries in the upper right quadrant of the graph as operating 
within a relevant range of cost and profit efficiency, there is considerable dispersion among sample countries' cost and profit efficiency.

FIGURE 6.1: Mean Cost and Profit Efficiency for Large Banks by Country

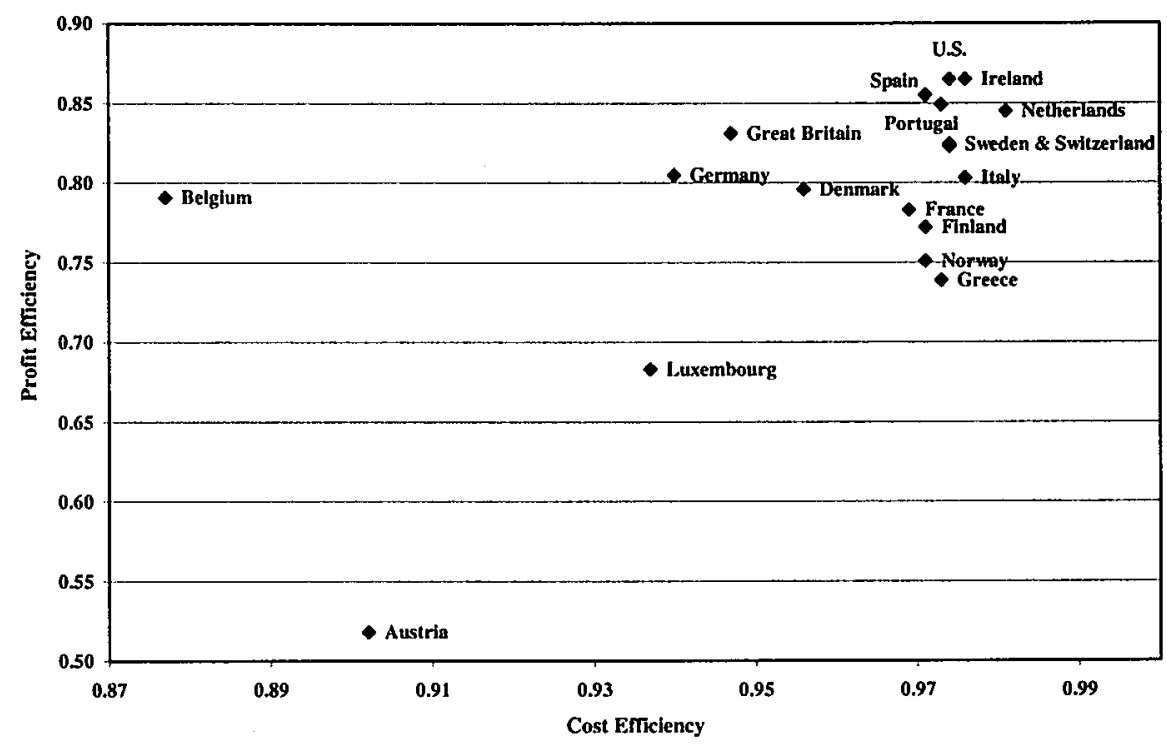

Banks in the U.S., Ireland, and the Netherlands tend to dominate other countries' banks in cost/profit efficiency space. The relative strength of U.S. banks is consistent with Berger, DeYoung, Genay, and Udell (2000), who found that U.S. banks tended to be relatively efficient compared to banks in France, Germany, Spain, and U.K. Belgian banks have relatively low cost efficiency but their profit efficiency is well within the range of profit efficiency of other countries' banks. Only banks in Luxembourg and Austria, for which the number of observations is small, appear to be outside relevant ranges for cost and profit efficiency. While differential regulatory and economic environments in the past no doubt influenced the relative efficiency of banks in these and other countries, harmonization of banking services as European countries move toward a single market will likely lead to increasing convergence of cost and profit efficiency among large banks in the future. In the meantime, differential competitive advantages exist for large banks located in different European countries. Taken together, this suggests the Single Market has not yet been fully realized, and puts the decision in this chapter to capture Western Europe under a single cost and profit frontier in perspective. Importantly, this result suggests there may be also be scope for intra-continental bank mergers on the European continent. Moreover, large banks in the U.S. are competitive relative to the most efficient countries in Europe. 


\subsection{Conclusion}

The last two decades of the $20^{\text {th }}$ century witnessed rapid bank consolidation around the world on an intra-continental basis, but for the most part within countries. At some point, regional concentration of bank resources becomes satiated. Then, inter-continental mergers may be the next phase in the merger movement. In this paper I examine whether this next phase will start on a level playing field by conducting stochastic frontier cost and profit analyses to estimate economies of scale as well as X-efficiency for multi-billion dollar European and U.S. banks. Comparable data for input prices and outputs are gathered for large banks for the period 1995-1999.

The empirical results with respect to separate analyses for large European and U.S. banks' cost and profit curves are strikingly similar. For the cost model in both regions, and consistent with extant literature on large bank efficiency, I found decreasing and significant returns to scale for investments and off-balance sheet activities, increasing returns to scale for loans, and decreasing returns to scale for total output. By contrast, in both Europe and the U.S. the profit model results imply increasing returns to scale for investments and off-balance sheet activities, decreasing returns to scale for loans, and increasing overall returns to scale. These results suggest that large banks in Europe and the U.S. can increase profit efficiency via output expansion, especially in the nontraditional areas of investments and off-balance sheet activities. Based on these cost and profit models, X-efficiency scores revealed that on average European banks have greater cost efficiencies compared to U.S. banks. Profit efficiency however is lower. The dispersion of both profit and cost efficiency scores is considerably smaller for U.S. banks than for European banks. This is to be expected, as the U.S. despite deregulation and liberalization in Europe is more of a unified market.

Further analyses evaluated the reasonableness of estimating a combined cost or profit frontier for European and U.S. banks. For this purpose I measured economies of scale moving progressively closer to the cost or profit frontier, as banks closest to the frontier are most important in terms of assessing the feasibility of a single cost or profit frontier. I found that mean scale economies for European and U.S. banks measured close to the cost frontier are not significantly different and, therefore, imply a single cost frontier. Not surprisingly, comparisons of cost X-efficiency scores for different European countries' banks relative to U.S. banks are mixed. However, the results for profit scale economies comparisons fail to accept the null hypothesis of a single profit frontier. Results of Xefficiency comparisons revealed that U.S. banks' profit efficiency is higher than that of European banks as a group. In addition, profit efficiency of U.S. banks tends to dominate most individual European countries. Whether U.S. banks can benefit from this dominance however depends crucially on how it translates to different market circumstances. 


\section{Bank Efficiency: The Role of Local Market Conditions}

\subsection{Introduction}

In chapter 1, I described some of the most important factors that shape European banking dynamics. Grosso modo, deregulation, consolidation and disintermediation are trends that have significantly altered the face of Europe's banking markets from the early 1990s onwards. Noticeably, whereas some developments (e.g. deregulation, disintermediation) can be expected to increase competition, others (e.g. consolidation) are expected to have the opposite effect. The expected effect of some, e.g. technological advancements and disintermedation, is not clear-cut. Much in the same spirit, these developments taken together will force many banks to reconsider their strategic choices. Some will decide to become national or regional players, whereas others remain confident they can be active as universal, global banks.

Concomitantly, these developments spurred a broad and long strand of academic research into the competitiveness, stability and efficiency of banks and banking markets. The unequivocal outcomes of many competition studies as well as the increase in the availability of micro-data are responsible for the emphasis on comparative efficiency studies. ${ }^{1}$ With relatively (when comparing to the U.S.) few bank failures in Europe, much research is done into benchmarking the efficiency of banks presumed to be operating in one market or at the very least under one efficient frontier. ${ }^{2}$

This strand of research covers scale and scope efficiency as well as X-efficiency (or managerial efficiency). With respect to scope efficiency, results are far from uniform. Scope efficiency appears hard to measure and even harder to compare. ${ }^{3}$ Scale efficiency studies over time have evolved towards the same focal points. For banks larger than approximately USD 100 million in assets, scale efficiencies appear to be exhausted, and frequently 'diseconomies of scale' are found. Banks below this liberally set benchmark could benefit from scale efficiency, quite contradictory to the so-called mega-mergers taking place in many banking markets.

Importantly, as mentioned in chapter 3, many studies find that for banks of all sizes, X-efficiency appears to dominate both scale and scope efficiency." Regardless of how

\footnotetext{
'See Berger and Humphrey (1997) and Molyneux, Altunbas, and Gardener (1997), chapter 9 for overview studies.

2Idem.

${ }^{3}$ See Molyneux, Altunbas, and Gardener (1997), chapter 6 for an overview of European and US research.

${ }^{4}$ See Berger and Humphrey (1997), Berger, Demsetz, and Strahan (1998) and chapter 4.
} 
well they reap the fruits of an optimal size and/or product mix, banks still can benefit most from what is measured as 'best-practice', given their size and product mix. The resulting lower costs and higher profits can give banks the cutting edge they may very well need before a possible next merger/takeover wave. Likewise, for those interested in the competitive conditions in banking markets, these same discrepancies from bestpractice are an important indicator of the competitive pressures and incentives.

Almost all efficiency studies focus on banks or bank holding companies and employ aggregate, consolidated data to benchmark efficiency. As a matter of fact, chapters 4 and 6 provide examples of such an approach. However, many of the developments mentioned above and described before also have an important impact on a disaggregate level, as banks directly compete with each other in a city, town or village. Therefore, these local banking markets are in more than one way the perfect place to identify and analyze Xinefficiency. As a result of the worldwide consolidation process in the 1990s, many banks face significant overcapacity in their post-merger branching network and are forced to reconsider its size. The aforementioned technological advances have resulted in increased use of ATMs, telephone banking and internet banking, thus threatening the traditional bank branch. On the other hand, deregulation and the rise of universal banks have given local bank employees a new role selling insurances, mortgages, investment funds and holidays. The same diseconomies of scale and to - a lesser extent - scope that are found to exist frequently for large banks, could lead to a careful reconsideration of size and (geographic) scope of a bank's network.

There are several reasons why studies on the role of local bank efficiency are scarce and most studies use aggregate data. First, there is the problem of confidentiality. A second reason for the scarcity of bank branch efficiency studies is related to the range of products supplied by branches in a single branching network. When including branches in an estimation of a single frontier, zero inputs and/or outputs are hard to justify. From an empirical point of view, in a logarithmic model, there is no neutral transformation of zero values. As a consequence, any decision to include branches that do not offer some of the products other branches offer, creates a bias. In a deterministic model, the inclusion of zero inputs and/or outputs can also severely biases efficiency measurements as well as cast doubt on the treatment of slacks that results. ${ }^{5}$ From a theoretical point of view, the interest in comparing them grows as they are more different. However, the more heterogeneous the sample of branches, the less appropriate it is to assume they have the same production process - an ex ante condition for efficiency benchmarking.

A related, third reason for the scarcity of local bank efficiency studies is paradoxical. As explained above, the interest in local bank efficiency follows logically from recent developments in banking as well as in the academic literature. However, the very nature of the bank branches that are used in the studies that exist often makes it difficult

\footnotetext{
${ }^{5}$ See Coelli, Prasada Rao, and Battese (1998), paragraph 7.6.
} 
to study them. Efficiency models assume banks maximize profits or revenues and/or minimize costs, by choosing a certain input/output mix. They do so by setting prices, increasing or decreasing inputs, etc. In practice however, the degree of independence bank branches have in how they maximize or minimize their objectives (as well as those objectives themselves) is in most cases highly limited. For example, interest rates are generally set on a bank rather than on a branch level. Consequently, not only does bank practice run counter to theoretical assumptions, but also the variables that result - e.g. similar interest rates for all branches - are of little use in a study seeking to find and explain differences in bank branch efficiency.

The analysis in this chapter suffers from neither of the three problems mentioned. First, since I use data from a single bank the results reveal nothing of the efficiency of this bank vis-à-vis branches of other banks, as efficiency is measured relative to a unique best-practice frontier. Second, I study local banks of Rabobank Netherlands. All their local banks produce all of the outputs using all of the inputs I consider in this study.

With respect to the third problem mentioned above, the fact that I am dealing with a cooperative bank is convenient in several ways. Unlike branches of commercial banks, cooperative bank branches together own the national bank. Thus, managers have fewer incentives to over- or underreport the performance of their local bank. Also, cooperative bank branches have more degrees of freedom: to some extent, they set their own interest rates, have their own personnel policy and can open or close local branch offices. This freedom is essential for a benchmarking study in which each local bank is assumed to choose an optimal input/output mix in order to maximize profits or minimize costs. An additional advantage of using cooperative local banks in the light of this study is that there exists a very transparent transfer pricing system. Local banks can choose to supply some products (e.g. mortgages or holidays) themselves or provide them through the national head office. As a result, I can separate 'bank production' from 'local bank production' and have more realistic input/output mixes. A final advantage relates to the definition of the local markets in which bank branches operate. Chiappori, Perez-Castrilo, and Verdier (1995) demonstrated this advantage with the help of a Salop model of spatial competition. If branches of a bank operate on the same market they will to a certain extent compete with each other and erode profits, depending on the size of the market, their location and the number of competitors. For the local banks of the cooperative bank network in this study this is not the case, since each local bank operates on a clearly defined local market.

I can therefore estimate stochastic profit and cost frontiers for a balanced panel of 401 local rabobanks in the years 1998 and 1999 in the Netherlands. I derive cost and profit efficiency measures. My aim is to find out to what extent these measures are dependent on local market conditions such as market size, market presence, geographic location, competition and consumption patterns. In doing so, I try to separate bank-specific factors from market factors, in an effort to find out to what extent $\mathrm{X}$-efficiency can indeed be 
termed managerial efficiency. I try to use my findings to formulate policy advice with respect to branch presence and sales strategies.

This paper proceeds as follows. In section 7.2, I sketch current developments in branch banking. I put special emphasis on those studies describing the role of local market conditions. Next, in section 7.3 I present a review of bank branch efficiency studies. Section 7.4 contains an overview of the structure of Rabobank. Then, in section $7.5 \mathrm{I}$ introduce the methodology, highlight some of the model choices and describe the estimation procedure. The data are presented in section 7.6. Section 7.7 is reserved for an overview and analysis of the estimation results. In section 7.8 , I conclude.

\subsection{Developments in Local Banking Markets}

As I mentioned in the introduction, deregulation, consolidation, disintermediation and technological advancements are the main forces reshaping bank branching strategies. Not so long ago, the local bank branch was the main source of financing as well as the place to save and invest for most people. Likewise, most small- and medium-size companies relied on their local bank for commercial loans, etc. Most local markets were served by a limited number of banks. This number was especially low in the countryside, where cooperative banks, like the bank that is the subject of this study, specializing in farm loans and credit often operated in local monopolies.

In the Netherlands, the merger of ABN bank and AMRO bank and the establishment of ING Group in the early nineties created two large banks that were able to compete with the existing large cooperative Rabobank in terms of the size and reach of their branching networks. Also, local and medium-sized banks such as SNS bank began to increase their branching networks. As a result, many of the local monopolies broke down. Instead came an interesting array of local market conditions, with banks competing through the establishment of branches, offering a wider range of services (such as holidays and brokerage services), the spread of ATMs, and later in the 1990s the arrival of internet banking and 'virtual branches'.

According to Rubin (1999), "[O]ver the past 30 years, banks have diligently tried to offload banking transactions from their branches, primarily by introducing appealing retail delivery channels attractive to their customers. But alternative channel investments have not paid off, in terms of enabling banks to close costly branches" (p.48). In fact, in most countries the consolidation wave has been accompanied by a steady increase in the number of branches. ${ }^{6}$ Also, bank branches have developed into 'one-stop shopping' venues, illustrated best in the UK by the rise of supermarket banks. As a positive side effect, "[C]ombining full-service brokerage, business banking, insurance and discount brokerage

\footnotetext{
${ }^{6}$ The Netherlands is somewhat of an exception, because the aforementioned mergers were accompanied by a sharp decrease in the overlap in branching networks of the merging banks.
} 
with trust and personal banking operations can bring significant cost savings" [Howland (2000), p. 27]. On the negative side, the number of services provided requires a better trained, specialized and more expensive staff.

As a result of balancing both effects, there is a "growing trend towards large multidisciplinary branches, serving as hubs to smaller 'satellite' branches with an increased use of automation" [Howland (1999),p. 26]. The brick and mortar of the branch itself is changing anyway, as cashier functions are replaced by ATMs and banks try to lure customers into buying a wider range of products than just loans and deposits by setting up counseling desks. With the possibility of offering many of the same services online, many banks already try to "reduce (the) cost of physical delivery, while not alienating (their) most profitable clients" [Bielski (1999), p. 29].

Whether the bank branch will eventually be replaced by online banking remains debatable. The fact is that at present sales and revenue from online banking are still very small. Some predict branches "will eventually go away as the Internet takes off. But that will be a very gradual trend" [Thomas Brown of Tiger Management (NY), as quoted by Bielski (1999), p. 29]. Others observe a new role for the bank branch as an essential corner stone in a multi-channel sales network, a change from the "[B]ranch culture traditionally [...] reactive in terms of sales and more focused on operational and administrative tasks" [Cline (1999), p. 54].

With this new role come new challenges. One such challenge is channel fairness, also known as steering discrimination: as banks deliver their products through more and more different distribution channels (telephones, Internet, regular branches, etc.) they increase the possibilities for better tailored, cheaper services. However, at the same time they are more likely to discriminate - willingly or unwillingly - among customers depending on the distribution channel through which a product is supplied. Already, "[T]he emergence of a large subprime (lending) industry involving both bank affiliates and nonbanks has raised alarms among advocates for minorities and lower-income people" [Barefoot (2000), p. 35]. Another challenge is the "need to convert [...] branches from transaction-centered service delivery facilities to infrastructures that specialize in customer-centric services, becoming physical manifestations of Internet portals" [Lewis (2000), p. 71].

Again, the fact that the development of online banking is steady but slow, puts the urgency of these challenges into perspective. At the same time however, upon careful reading, most of the above-sketched developments merit a reorientation of the role of bank branches in local markets. At present, "branches have more information than ever about their customers and more technology to help them arrive at the right answers for their customers" [Albro (1999), p. 38]. As a result, banks are forced to reconsider the role of branches and assess how they can efficiently fulfill this role depending on local market conditions. For example, a branch operating in an urban area with a lot of commercial activity can decide to locate to one large building where it can best provide the face-toface service necessary to sell a package of wholesale banking products. At the same time, a 
branch in a rural area may decide that it most efficiently operates with a limited number of small buildings supplemented by strategically placed ATMs and an active mail and telephone service. A necessary prerequisite for such a strategic reorientation is therefore a thorough knowledge of how local market conditions affect bank branch efficiency.

\subsection{Literature}

Efficiency studies on banking are abundant, especially for the U.S. Most studies however, consider banks and bank holding companies and the number of studies on bank branch efficiency is limited. ${ }^{7}$

An early bank branch study is done by Sherman and Gold (1985). It uses a linearprogramming technique named Data Envelopment Analysis [DEA] to benchmark the efficiency of 14 branches of a U.S. savings bank. Although convenient for such a small sample and intuitive for use as a management tool, DEA as a non-parametric technique does not control for any measurement error and does not allow for any statistical testing. After applying a profit maximization model, the authors conclude that among the problems involved in a bank branch efficiency study is the inability to "indicate the cause or remedy for the identified inefficiencies" (p. 311).

Altunbas and Chakravarty (1998) find one way to overcome this problem by relating X-efficiency to the institutional structure in a sample of European countries. After identifying the number of commercial banks, savings banks, cooperative banks and other banks as a key indicator of this institutional structure, they fail to find a clear cut relationship and conclude that more research into the origins of the differences in banking structure is needed. A similar path is taken by Gilbert (2000), who analyzes the impact of nationwide branch banking in the U.S. on the local market conditions (mainly market structure) in rural markets. He concludes that although large, nationwide banks have not become the dominant banks in rural markets, "in rural areas, low population density is not an effective barrier to the entry by large banking organizations" (p. 26).

Heitfield (1999) studies the willingness of consumers to switch banks dependent on distance and price. For a sample of U.S. bank branches he estimates how deposit rates and geographic distance affect the choice of consumers to bank locally. His findings confirm that the geographic definition of deposit markets is still very small. He suggests as a possible explanation that "large banks find that the economies of scale or enhanced organization efficiencies associated with statewide pricing outweigh the benefits of optimizing interest rates with respect to the unique features of local markets" (.p. 341). For a panel of Norwegian banks for 1998-1995, Kim and Vale (1997) investigate whether non-price competition takes place in local markets through the establishment of bank-specific branch networks. In a dynamic oligopoly model, they find that since the informational gain from

\footnotetext{
${ }^{7}$ See Berger and Humphrey (1997), Berger, Demsetz, and Strahan (1998) and chapter 3 for overview studies.
} 
such a network is not shared, there exists no externality. Put differently, branching decisions of a bank in a local market can affect its market share but will not affect total market size.

A slightly different approach is taken by Jayaratne and Strahan (1996), Cyree, Wansley, and Boehm (2000), Fraser, Hooton, Kolari, and Reising (1997) and Hughes, Lang, and Mester (1996). They investigate the relationship between bank branching and wealth in local markets. Jayaratne and Strahan (1996), in an effort to find evidence for the socalled finance-growth nexus, seek to explain real, per capita growth in income through intrastate branch reform following the relaxation of branching laws in many U.S. states starting around 1970 and culminating in 1994 in the Riegle-Neal Act on interstate banking and branching. Cyree, Wansley, and Boehm (2000) on the other hand do the opposite and study the effect of income and labor prices on bank growth strategies. Jayaratne and Strahan (1996) find that states that allow intrastate branching are rewarded by an improvement in the quality of bank lending and thereby experience higher per capita income growth. These findings are in agreement with Cyree, Wansley, and Boehm (2000) who conclude that banks in areas with high income growth and high labor prices are more likely to (literally) branch out than to engage in a takeover. Fraser, Hooton, Kolari, and Reising (1997) distinguishes between large and small banks and finds that although the former benefited from branch deregulation, the opposite holds for the latter. Hughes, Lang, and Mester (1996) start from the premise that if interstate branching improves the risk-return tradeoff banks face, then interstate branching allows a bank to choose a higher level of risk in return for higher profits. They find large scale economies exist with geographic expansion and with local expansion. Interstate branching leads to risk diversification and increases expected return.

For the Italian market, Cerasi (1998)tries to predict bank branching decision of Italian banks between 1989 and 1995, after branching deregulation. Empirically testing a monopolistic competition model, they find no evidence that branch deregulation has led to the expected increase in local market competition through the establishment of more branches.

Insights in the relative efficiency of branches in a bank-specific network are gained from benchmarking studies. For a series of three cross-sections (1989, 1990 and 1991) of approximately 760 branches of a large U.S. bank, Berger, Leusner, and Mingo (1997) estimate a stochastic frontier cost model. First, they try to compare the 'intermediation approach' and the 'production approach'. On the one hand, the production approach distinguishes labor and physical capital as inputs and numbers of processed documents or transactions as output, and is mostly appropriate for bank branches with low autonomy in loan policy (see also Ferrier and Lovell (1990)). On the other hand, the intermediation approach starts from the traditional core function of financial institutions and takes 
deposits as inputs and defines loans and investments as output. ${ }^{8}$ They find that estimation results are mutually consistent between both approaches. ${ }^{9}$ As a second objective, they examine the relationship between branch-level scale and X-efficiency. As is the case in bank-level research, $\mathrm{X}$-efficiency is found to dominate scale efficiency.

Kolari (1992) and Zardkoohi and Kolari (1994) use a data set with 646 (respectively 615) branches of 43 Finnish savings banks in 1988. The former finds that "the size of the branching organization significantly affects the operating costs of individual branch offices' (p. 409). Upon comparing branches with (small) unit banks, small bank branches are found to operate at an inefficient scale. The latter study measures scale and scope economies. Scale economies are found to be increasing at the branch level regardless of the size of the whole branch network. Scope economies are negative but insignificant.

Athanassopoulos (1998) compares market efficiency and cost efficiency in a DEA model for 518 UK branches. The outputs used to measure market efficiency are liability sales, loans and mortgages, insurances and equities, and the number of bank cards. The two types of efficiency are seen as complements. Market efficiency is found to be on average 90 percent, whereas cost efficiency is 88 percent on average.

Finally, Dekker and Post (1999) use a DEA model to benchmark the efficiency of 314 branches of a large Dutch commercial bank. They argue that the concavity of the frontier in DEA models runs counter to both theoretical arguments and empirical evidence suggesting the existence of scale economies at the branch level. Their 'quasi-concave' model resolves this inconsistency and leads to a frontier that is monotonically increasing but not concave.

The literature reviewed here suggests there is an important and significant relationship between the performance and efficiency of bank branches and the environment in which these branches operate. Less clear is the impact and relative importance of these different local market conditions.

Most benchmarking studies mentioned use DEA to benchmark bank branch efficiency. Eisenbeis, Ferrier, and Kwan (1999) compare efficiency measures from a DEA study on U.S. bank holding companies with those of a Stochastic Frontier Analysis [SFA] using the same data set. They find similar patterns for the efficiency rankings of both methods. However, SFA scores are found to better reflect risk-taking behavior, managerial competence, and bank stock returns. Haag and Jaska (1995) use a small sample of data on U.S. bank branches to evaluate what is the required 'minimum simultaneous percentage perturbation' of inputs and outputs that will render a branch efficient in their DEA model. They find values that often exceed the inefficiencies they found earlier, casting doubt on the robustness of their DEA efficiency scores. These considerations together with the

\footnotetext{
${ }^{8}$ I refer to Freixas and Rochet (1997), Ferrier and Lovell (1990) and Berger and Humphrey (1997) for an overview of the debate.

${ }^{9}$ They also compare a translog specification with a Fourier Flexible Form. Again, results are found to be robust.
} 
convenience of statistical testing that allows for testing the significance of local market variables leads me to proceed with the introduction of my stochastic frontier model.

\subsection{Rabobank}

In this section, I describe Rabobank, the Dutch cooperative bank whose network of local banks is the focus of the analysis in this chapter. ${ }^{10}$ I first take a closer look at the role and mechanics of the local banks. Then I shortly turn to Rabobank Netherlands, the 'daughter company'.

\subsubsection{Local Banks}

The concept of cooperative banking was pioneered by Friedrich Wilhelm Raiffeisen in Germany around 1850. As mayor of Heddesdorf he realized that the farmers in his region could rum a more productive and less risky business by cooperating in collecting funds, granting loans and organizing projects. This idea of 'Raiffeisen Banken' or 'Boerenleen Banken' was a success, and later expanded beyond its traditional realm of agriculture.

One of Europe's largest cooperative banks is Rabobank. In the years 1998/1998, Rabobank has over 400 independent local cooperative banks united in the Rabobank network. Together, these local banks operate approximately 1700 offices, 2700 ATMs and employ approximately 37,500 people.

Each local Rabobank operates in its own geographical market, which is clearly delineated to avoid competition between banks in the Rabobank network. " Local banks are expected to maintain close ties with local organizations and use a portion of their profits to stimulate local economic and social developments. Together, the banks in the Rabobank network manage approximately 40 percent of the private savings deposits in the Netherlands as well as approximately $25 \%$ of the mortgages. On the wholesale front, the strength of local banks lies with small- and medium-sized companies. A historical emphasis on agriculture remains as the local banks combined count approximately $87 \%$ of the companies in this particular sector as their clients. As a result, Rabobank is most present in the northern, eastern and southern provinces of the Netherlands, where agriculture is most dominant [cf. figure 7.2]. ${ }^{12}$

More than $10 \%$ of the customers of the local banks is a member of the local cooperation. Until 1998, this membership was an obligation for all customers who applied for a business loan. Since then, membership is open to anyone who purchases one or more services from a local Rabobank, is not already a member of another Rabobank, is financially healthy and lives or works in the same city, town or village. Membership is encouraged and seen by the bank as a way to enhance customer loyalty. Rights obtained from membership mostly

\footnotetext{
"Ihis section is largely based on information kindly supplied by Rabobank Netherlands.

${ }^{11}$ This is a continuing process as a result of reorganizations and external changes.

${ }^{12}$ The data for figure 7.2 were taken from ESRI Arcview GIS.
} 
FIGURE 7.1: Organization Structure Rabobank

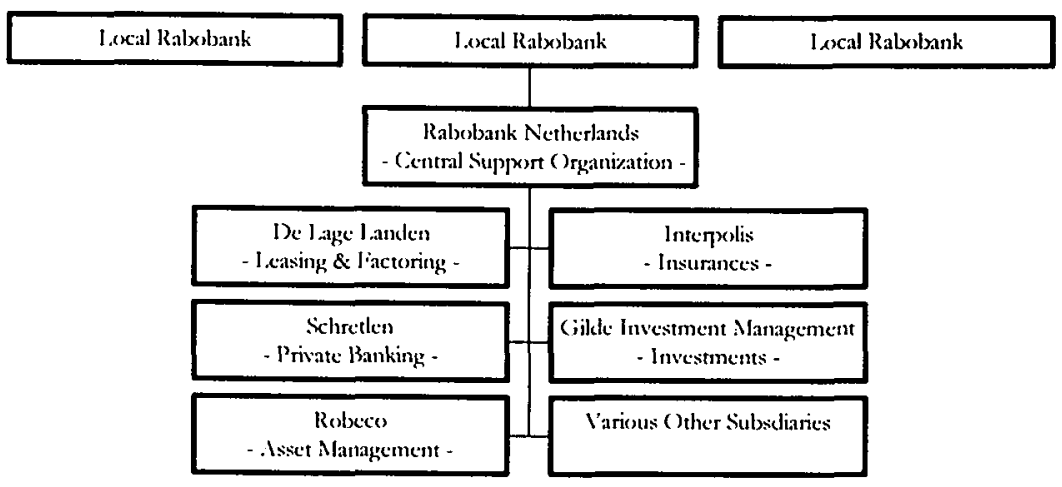

apply to local bank affairs. Members have voting powers in the local assembly and the right to invest in the local bank with so-called 'member certificates' (ledencertificaten) in order to share in the bank's profits.

\subsubsection{Rabobank Netherlands}

Rabobank Netherlands is the central support organization of the local cooperative banks (see figure 7.1). It employs approximately 5,500 people. Rabobank Netherlands supports and advises the local banks in areas such as strategy, product development and ICT. It is also a clearing house for the cooperative network, intermediating the liquidity needs of local banks. Whenever necessary, local banks access (outside) capital markets through Rabobank Netherlands. In this respect, it also supervises and coordinates the activities of its subsidiaries such as De Lage Landen and Interpolis (insurance) and Robeco (asset management). For many product areas, local banks have the choice between supplying products independently or purchasing them from Rabobank Netherlands (see also section 7.6).

On behalf of the Dutch Central Bank, the organization is responsible for the supervision and administration of the local banks. The high involvement of the members has resulted in an accumulation of own funds which is extraordinary. In addition, since the local banks do not have shareholders profits accrue entirely to reserves. As a result, Rabobank has become highly creditworthy and has a triple A-status. In this light, its overall performance is not surprising since - as described below- Rabobank Group (the combination of Rabobank Netherlands and its subsidiaries) has below average profitability, a price it may pay for its high creditworthiness. 
FIGURE 7.2: The Netherlands

\begin{tabular}{|c|c|c|c|}
\hline Promal & Region & 1)ensit." & \\
\hline Gruningen & $N$ & .187 .1 & \\
\hline linicsiand & $N$ & 1052 & \\
\hline 1)renthe & $N$ & 167.2 & \\
\hline Oecripsel & i: & 303.8 & \\
\hline Meroland & NW & 126 & \\
\hline Gikleddund & $\mathbf{H}$ & 357.7 & \\
\hline Uirodut & $N W$ & 729.9 & \\
\hline Noond-J lolland & NW & $(003.6$ & \\
\hline \%uid-Hulland & $\$ w$ & 956.3 & \\
\hline \%.colond & $s w$ & 123.1 & : \\
\hline Nound-Iscobant & $\$$ & 441.4 & \\
\hline 1 imbusg & $s$ & $50)(6.8$ & \\
\hline
\end{tabular}

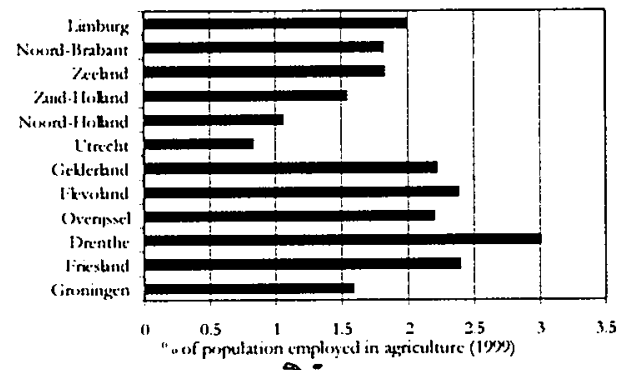

= population density (1\%)3) $\mathrm{km}^{2}$

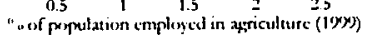

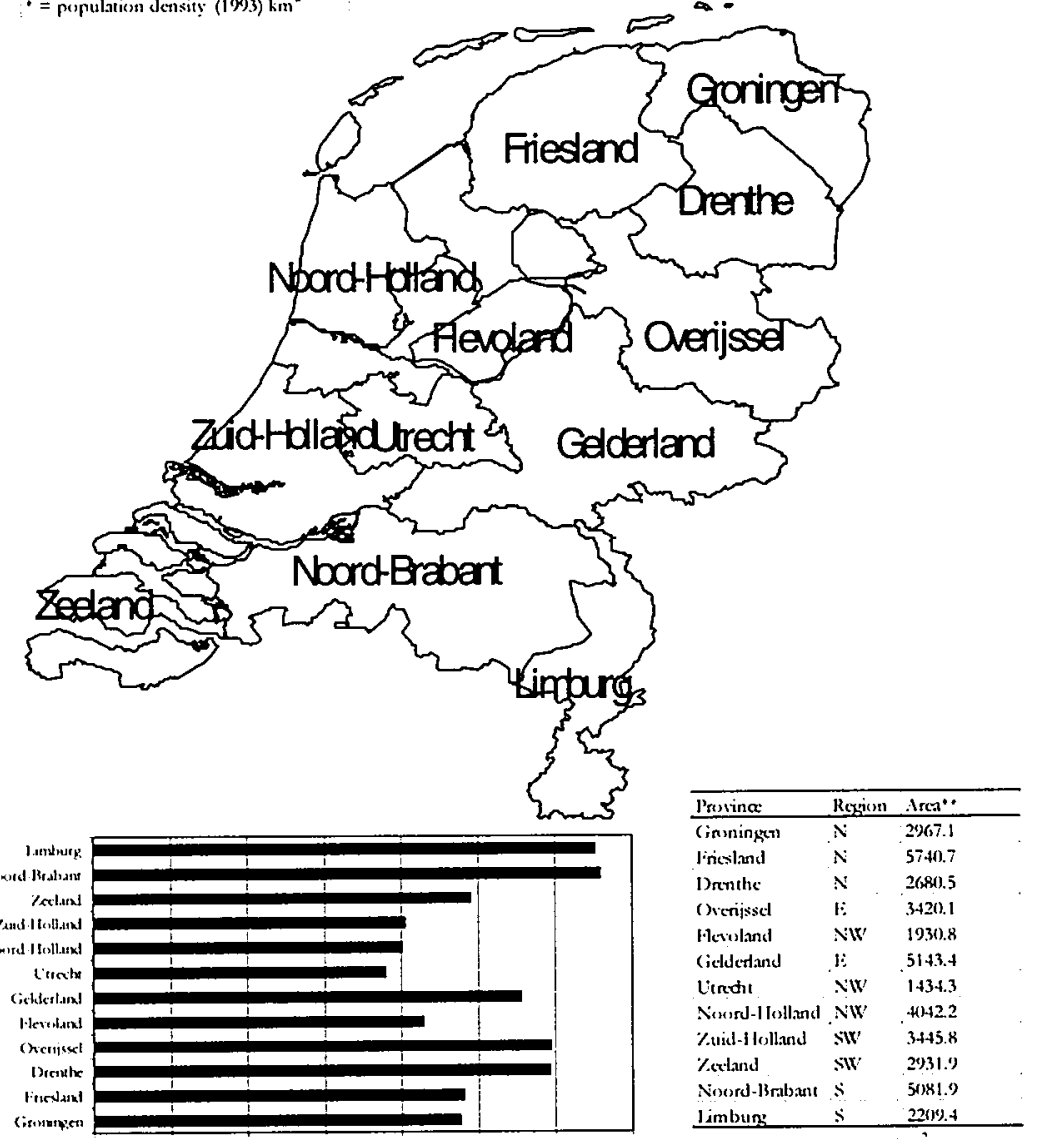

$\because$ of population cmplexyed in manufactuting (19\%)

$\because=\operatorname{surfax} \operatorname{ara}(1 \%) 3) \cdot \mathrm{km}=$ 


\subsection{Methodology}

I now develop the theoretical model and show how it can be used to estimate local bank efficiency. Since the local banks operate much like independent banks, I use the intermediation approach to banking in both the cost model and the profit model. In order to incorporate differences in the risk attitude of bank branch managers I include a solvability measure. ${ }^{13}$ A higher level of desired solvability indicates less risk and is expected to translate into lower profits.

I distinguish between cost minimization and profit maximization. When minimizing a cost function, cost-inefficiency measures the sub-optimal use of input quantities given input prices, output quantities and solvability. Maximization of a profit function results in profit-inefficiency measures due to a suboptimal choice of output quantities given output prices (or suboptimal output prices given quantities). I note that in a competitive market, the two approaches should yield identical results. However, in the case of imperfect competition market power might lead to a profit efficient bank that is inefficient in terms of costs or vice versa. The combined use of both cost and profit optimization will shed light on the character of inefficiencies.

As a second step I will then regress my cost- and profit-efficiency measures on a number of market variables in order to find out how local bank efficiency is affected by local market conditions.

I base my benchmarking study on the premise that local banks maximize profits and/or minimize costs. Since I am dealing with a cooperative bank, especially the former assumption descrves some attention. As observed in chapter 3 , microeconomic theory tells us that for a firm operating in a competitive environment cost minimization mirrors profit maximization. For a cooperative bank, cost minimization is a means to provide lowpriced services to its customers, who are often also its shareholders. On the other hand, profit maximization is not an explicit objective. In principle, a cooperative bank does not have to make a profit. But in practice, local cooperative banks have to show a healthy performance to secure future investments and to form a buffer against any pitfalls. Put differently, cooperative banks do maximize (or optimize) profits, but can put greater emphasis on other objectives once a certain level of profitability has been reached.

Empirical evidence subscribes to this notion. The sample period for the present study is 1998-1999. The average, unweighted ROAA for these years for Rabobank, the largest Dutch cooperative bank is 0.45 - compared to 0.965 for ING Group and 0.56 for ABN AMRO Holding, the two largest commercial banks. For a sample of large commercial and cooperative banks in the same period, Rabobank ranks 18 among 25 banks and with an unweighted average of 0.65 for 1998-1999 the bank is a slight underperformer. ${ }^{1.4}$ More recently, upon publication of its semi-annual figures for 2001, Rabobank was the

\footnotetext{
${ }^{13}$ More standard is the inclusion of equity. Given that this is not possible for cooperative bank branches, I opt for solvability.

". Data from IBCA/BankScope. Included are commercial banks and cooperative banks.
} 
only one of the three large Dutch banks to report a significant increase in profits. ${ }^{15}$ Likewise, in chapter 4 , when I compared profit efficiency and cost efficiency for Dutch banks in the period 1992-1998, there appeared to be three groups of banks: a large group of commercial cooperative banks with average cost and profit efficiency; a smaller group of specialized banks with slightly above average cost and above average profit efficiency; and a group consisting of Rabobank, ABN AMRO Holding and ING Group, who have above average profit efficiency but only average cost efficiency. Concluding, I think my profit maximization hypothesis is a reasonable approximation for the bank branches of this cooperative bank.

Both the cost frontier and the profit frontier are estimated using the models described in chapter 3. For the estimation of the cost and alternative profit frontier functions I again choose a translog functional form, now with four outputs and five inputs, one of which is used to ensure linear homogeneity of 1 in input prices.

As a second step in the analysis, I want to measure the marginal impact of a number of local market variables on cost efficiency (CE) and profit efficiency (PE). To this purpose, I regress CE and PE on a number of market variables. This allows for tests of the significance of each of these market variables as well as the combined impact of all market variables on $\mathrm{CE}$ and $\mathrm{PE}$ respectively. I use a truncated regression technique where the dependent variable - in accordance with its distribution as explained previously - is truncated at 1 .

\subsection{Data}

I follow the intermediation approach to banking and have a balanced panel for 401 local banks in 1998 and 1999 (a total of 802 observations). Raw data were provided by Rabobank Netherlands. Where possible and necessary, I correct for any inputs used and outputs provided from Rabobank Netherlands to the local banks.

The cost variable is constructed as follows (see also figure 7.3):

$$
\begin{aligned}
\text { Total Costs }= & \text { Personnel Costs }+ \text { Mailing Costs }+ \text { Housing Costs }+ \text { Bank-Level } \\
& \text { Administrative Costs }+ \text { Public Relations Costs }+ \text { Write-Offs }+ \\
& \text { Managerial Costs }+ \text { Commercial Interest Expenses }+ \\
& \text { Balance Sheet Management Costs }+ \text { Other Interest Expenses }
\end{aligned}
$$

\footnotetext{
${ }^{15} \mathrm{ABN}$ AMRO Holding and ING Group followed a European trend with stagnant or decreasing profits.
} 
Here housing costs are net of any buildings owned but rented out. Bank-Level Administrative Costs are transferred onto the local branch by the national headquarters for services provided to the local bank. Write-offs are net of housing.

FIGURE 7.3: Total Costs (20 equal groups (= Bins))

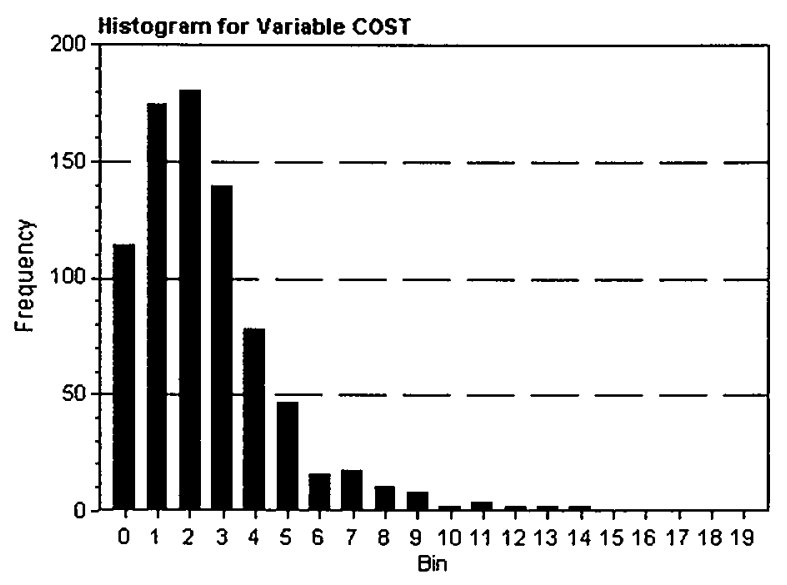

The profit variable is depicted in figure 7.4 and consists of profit before tax.

I identify five input prices. $w_{1}$ is the price of PR and is measured as public relations costs divided by FTE (the full-time equivalent of the number of personnel). $w_{2}$ is the price of labor, measured as total personnel costs divided by FTE. The price of housing is $w_{3}$, net housing costs divided by FTE. $w_{4}$ is the price of physical capital (excluding housing) and it is measured by the sum of bank-level administrative costs, bank-level administrative costs and write-offs, also divided by FTE. ${ }^{16}$ Finally, I identify the price of financial capital $w_{5}$, measured as commercial interest expenses divided by the sum of retail current account deposits, wholesale current account deposits, retail savings deposits, and total wholesale savings deposits. ${ }^{17}$ This price is also used to make the model linearly homogenous in input prices. Hence my dependent variables and all other input prices are divided by it.

The first output, $y_{1}$ consists of all retail loans (and other credit). $y_{2}$ is the sum of all wholesale loans (and other credit). Next, $y_{3}$ is the sum of all mortgages, both retail and

\footnotetext{
${ }^{16}$ To make sure the fact that the numerator for four of the five input prices does not bias the results, I check for correlation among the prices. Also, I check whether their distribution is not altered significantly. For all robustness checks the choice for FTE does not influence the results.

${ }^{17}$ I use 'retail' to refer to private customers and 'wholesale' to refer to businesses.
} 
FIGURE 7.4: Profit Before Tax (20 equal groups (= Bins))

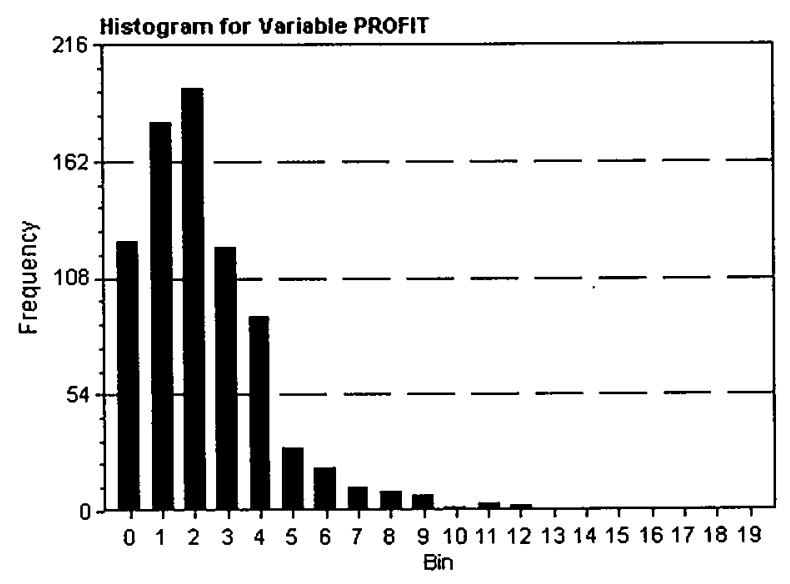

wholesale. $^{18}$ Finally, $y_{1}$ is the sum of all services: (life) insurance provisions, brokerage provisions and travel provisions. ${ }^{19}$

'Solvability' is an internal solvability measure used by the bank and included here as a control variable. It is the ratio of quasi-liquid assets (medium- and long-term loans and other earning assets) over total assets, controlling for interbank lending within the cooperative bank.

The independent variables that are used in the second step of the procedure can be divided between bank-specific variables, market-specific variables and geographic variables. In the first category I have 'Main Office', the number of main offices operated by a branch. Likewise, 'Local Branch Office' is the number of other offices operated. 'Main Office ATMs' is the number of ATMs at the main offices, 'Other ATMs' is number of other ATMs managed by the local bank.

In the second category I have for the wholesale market: 'Wholesale Market Share', the market share in the wholesale market; 'Wholesale Product Purchase', the average number of products demanded by wholesale clients; 'Wholesale Membership', the percentage of wholesale clients that are a member of the cooperative local bank; 'Wholesale Client Base', the number of wholesale clients in 1000s. Similarly, I have for the retail market: 'Retail Market Share', the market share in the retail market; 'Retail Product Purchase', the average number of products demanded by retail clients; 'Retail Membership', the percentage of wholesale clients that holds a stake in the cooperative local bank; 'Retail Client Base', the number of retail clients in 1000s.

\footnotetext{
${ }^{18}$ After discussion with the bank I decided against splitting up retail and wholesale mortgages since conditions and procedures for both are not materially different and it is considered by the bank itself to be more or less the same product.

${ }^{19}$ I assume that the level of services is proportional to income.
} 
TABLE 7.1: Descriptives

\begin{tabular}{|c|c|c|c|c|}
\hline Variables (802 Obs.)* & Mean & SD & Mininum & Maximum \\
\hline \multicolumn{5}{|l|}{ Dependents } \\
\hline PROFIT BEFORE TAX & 20218300 & 13806100 & 2289420 & 125180000 \\
\hline TOTAL COSTS & 35770200 & 24584900 & 3709260 & 212163000 \\
\hline \multicolumn{5}{|l|}{ Prices } \\
\hline$W_{1}$ (PUBLIC RELATIONS) & 7560.92 & 2233.90 & 2580.09 & 17351.70 \\
\hline $\mathrm{W}_{2}(\mathrm{LABOR})$ & 90914.00 & 7990.25 & 70836.50 & 155058 \\
\hline $\mathrm{W}_{3}$ (HOUSING) & 6994.39 & 3130.48 & 2841.29 & 21561.80 \\
\hline WA (PHYSICAL CAPITAL) & 54047 & 8564.08 & 36208.20 & 109561 \\
\hline $\mathrm{W}_{5}$ (FINANCIAL CAPITAL) & 0.38 & 0.18 & 0.05 & 1.57 \\
\hline \multicolumn{5}{|l|}{ Outputs } \\
\hline$Y_{1}$ (RETAIL LOANS) & 5364140 & 5684350 & 196 & 50180100 \\
\hline $\mathrm{Y}_{2}$ (WHOLESALE LOANS) & 157885000 & 125415000 & 4060800 & 1059340000 \\
\hline $\mathrm{Y}_{3}$ (MORTGAGES) & 327780000 & 239649000 & 16796700 & 2307920000 \\
\hline$Y_{4}$ (PROVISIONS) & 2740160 & 1933200 & 169460 & 16572200 \\
\hline \multicolumn{5}{|l|}{ Bank-specific } \\
\hline MAIN OFFICE & 1.06 & 0.26 & 1.00 & 3 \\
\hline LOCAL BRANCH OFFICE & 3.27 & 3.17 & 0 & 27 \\
\hline MAIN OFFICE ATMs & 1.66 & 1.02 & 0 & 9 \\
\hline OTHER ATMS & 3.82 & 4.59 & 0 & 44 \\
\hline \multicolumn{5}{|l|}{ Market-specific } \\
\hline WHOLESALE MARKET SHARE & 50.45 & 15.77 & 9.60 & 87.46 \\
\hline WHOLESALE PRODUCT PURCHASE & 2.50 & 0.36 & 0.67 & 3.84 \\
\hline WHOLESALE MEMBERSHIP & 42.19 & 20.90 & 0.03 & 99.03 \\
\hline WHOLESALE CLIENT BASE & 1.42 & 1.06 & 0.15 & 12.92 \\
\hline RETAIL MARKET SHARE & 59.82 & 17.79 & 11.55 & 98.51 \\
\hline RETAIL PRODUCT PURCHASE & 2.13 & 0.16 & 1.55 & 2.58 \\
\hline RETAIL MEMBERSHIP & 5.40 & 3.47 & 0.00 & 18.46 \\
\hline RETAIL CLIENT BASE & 16.31 & 13.12 & 1.42 & 123.86 \\
\hline \multicolumn{5}{|l|}{ Control } \\
\hline SOLVABILITY & 1.62 & 0.60 & 0.57 & 4.65 \\
\hline MARKET INHABITANTS & 26.36 & 60.40 & 0.50 & 962.83 \\
\hline
\end{tabular}

* = Dependent variables and outputs in guilders. Prices in guilders, expressed as a ratio over

FTEs, except for $w_{5}$. Bank-specific variables and product purchase variables expressed in units. Market shares and membership variables in \%. Client base in 10:000s people and market inhabitants in 1000 s of people.

Next, I have a number of urbanization dummies. Rabobank distinguishes the following typologies: Small Rural is less than 5000 inhabitants; Medium Rural is 2000-10000 inhabitants; Large Rural is 5000-15000 inhabitants; Small Urban is 10000-50000 inhabitants; Large Urban is 15000-50000 inhabitants; Cosmopolitan is $>50000$ inhabitants. Since there is obviously some overlap and some markets are larger than others, a further requirement 
the bank includes is that one or more (depending on the size) of the communities in the local market has to house at least $75 \%$ of the total number of inhabitants in the market. Thus, the urbanization dummies refer to the main settlement in the market. I include all but small rural as dummy variables. In addition, I also include the variable 'Market Inhabitants', which is a proxy of market size and measures in 1000 s the number of inhabitants in the main city, town or village in the market where the bank is located. As can be seen in figure 7.2 , population density itself varies in different parts of the Netherlands.

The third category of independent variables consists of a number of dummy variables for the different regions and provinces in the Netherlands (see also figure 7.2 ). In the second step estimation, I alternatively use 4 regional dummies (except North) and 11 provincial dummies (except Groningen).

\subsection{Results}

First I discuss the cost model. I start with the stochastic frontier estimation results. Then I present the results for the second step, first for an estimation including regions and then for an estimation including provinces. In the estimation results as they are reported here, I only report those independent variables that are (weakly) significant. In the second part of this section, I repeat each step for the profit model.

TABLE 7.2: Table Cost Efficiency

\begin{tabular}{llllll}
\hline & Mean & SD & Minimum & Maximum & Obs. \\
\hline CE & 0.974 & 0.019 & 0.704 & 0.991 & 802 \\
\hline
\end{tabular}

Tables 7.2 and 7.3 contain the estimation results for the stochastic frontier cost model. ${ }^{20}$ Average cost efficiency is high at 0.974 , which means there is only $2.6 \%$ room for improvement on average. The worst performing bank branch however can improve $29.6 \%$ on its current cost efficiency. As can be seen from figure 7.5 , the distribution of CE is highly skewed with most local banks operating relatively close to the frontier (see also in this respect the negative $\mu / \sigma_{v}$ in table 7.3). The high $\lambda$ means that a relatively large part of the residual $\varepsilon$ consists of inefficiency.

\footnotetext{
${ }^{20}$ As I argued in earlier chapters, interpreting individual variable coefficients is difficult because of the presence of so many interaction terms. In the light of the present analysis, individual variable coefficients are not very important as I am mostly interested in the total explanatory power of the models, which is very high.
} 
TABLE 7.3: Cost Frontier

\begin{tabular}{|c|c|c|c|c|c|c|}
\hline Obs.: & 802 & & $\sigma_{v}^{2}$ & 0.004 & $\mu / \sigma_{v}$ & -0.615 \\
\hline LLF: & 836.909 & & $\sigma_{v}^{2}$ & 0.013 & $\lambda$ & 1.799 \\
\hline \multirow[t]{2}{*}{$\mathrm{R}^{2}$ adj.: } & 0.988 & & Itcrations: & 18 & $\sigma$ & 0.132 \\
\hline & Coeff. & t-value & & & Cocff. & t-value \\
\hline INTERCEPT & 16.256 & 1.375 & & $1 / 2 W_{3} W 4$ & 0.119 & 0.655 \\
\hline$W_{1}$ & -3.222 & -1.595 & & $1 / 2 \mathrm{~W} 4 \mathrm{~W} 4$ & 0.000 & 0.001 \\
\hline$W_{2}$ & -3.086 & -0.743 & & $Y_{1} W_{1}$ & -0.002 & -0.061 \\
\hline $\mathrm{W}_{3}$ & -1.943 & -1.102 & & $Y_{1} W_{2}$ & 0.178 & 1.688 \\
\hline$W_{4}$ & 9.275 & 2.462 & & $Y_{1} W_{3}$ & -0.012 & -0.490 \\
\hline$Y_{1}$ & -2.437 & -2.282 & & $Y_{1} W_{4}$ & 0.008 & 0.149 \\
\hline$Y_{2}$ & -3.122 & -2.650 & & $\mathrm{Y}_{2} \mathrm{~W}_{1}$ & 0.033 & 1.029 \\
\hline$Y_{3}$ & -1.922 & -0.846 & & $\mathrm{Y}_{2} \mathrm{~W}_{2}$ & 0.230 & 1.967 \\
\hline$Y_{1}$ & 6.585 & 3.935 & & $\mathrm{Y}_{2} \mathrm{~W}_{3}$ & 0.042 & 1.633 \\
\hline $\mathrm{Z}$ & -0.563 & -0.333 & & $\mathrm{Y}_{2} \mathrm{~W}_{4}$ & -0.016 & -0.242 \\
\hline $1 / 2 Y_{1} Y_{1}$ & 0.039 & 3.340 & & $\mathrm{Y}_{3} \mathrm{~W}_{1}$ & 0.114 & 2.522 \\
\hline $1 / 2 Y_{1} Y_{2}$ & 0.004 & 0.109 & & $\mathrm{Y}_{3} \mathrm{~W}_{2}$ & 0.198 & 0.963 \\
\hline $1 / 2 Y_{1} Y_{3}$ & 0.077 & 1.242 & & $\mathrm{Y}_{3} \mathrm{~W}_{3}$ & -0.071 & -1.513 \\
\hline $1 / 2 \mathrm{Y}_{1} \mathrm{Y}_{1}$ & -0.113 & -2.497 & & $\mathrm{Y}_{3} \mathrm{~W}_{4}$ & -0.084 & -0.802 \\
\hline $1 / 2 Y_{2} Y_{2}$ & 0.022 & 1.295 & & $\mathrm{Y}_{4} \mathrm{~W}_{1}$ & -0.090 & -2.013 \\
\hline $1 / 2 Y_{2} Y_{3}$ & -0.020 & -0.290 & & $\mathrm{Y}_{4} \mathrm{~W}_{2}$ & -0.485 & -3.230 \\
\hline $1 / 2 Y_{3} Y_{3}$ & 0.101 & 1.382 & & $\mathrm{Y}_{4} \mathrm{~W}_{3}$ & 0.022 & 0.653 \\
\hline $1 / 2 Y_{3} Y_{4}$ & -0.236 & -2.192 & & $Y_{4} W_{4}$ & 0.039 & 0.428 \\
\hline $1 / 2 Y_{A} Y_{A}$ & 0.164 & 4.350 & & $1 / 2 \mathrm{ZZ}$ & 0.108 & 2.159 \\
\hline $1 / 2 W_{1} W_{1}$ & -0.004 & -0.051 & & $\mathrm{Y}_{1} \mathrm{Z}$ & 0.001 & 0.048 \\
\hline $1 / 2 W_{1} W_{2}$ & 0.443 & 1.126 & & $Y_{2} Z$ & -0.039 & -1.410 \\
\hline $1 / 2 W_{1} W_{3}$ & -0.176 & -2.013 & & $Y_{3} Z$ & 0.069 & 1.413 \\
\hline $1 / 2 W_{1} W_{4}$ & -0.019 & -0.091 & & $Y_{4} Z$ & 0.026 & 0.709 \\
\hline $1 / 2 W_{2} W_{2}$ & 0.328 & 0.474 & & $\mathrm{~W}_{1} \mathrm{Z}$ & 0.199 & 4.626 \\
\hline $1 / 2 W_{2} W_{3}$ & 0.434 & 1.241 & & $\mathrm{~W}_{2} \mathrm{Z}$ & 0.156 & 0.939 \\
\hline $1 / 2 W_{2} W_{4}$ & -1.490 & -1.895 & & $\mathrm{~W}_{3} \mathrm{Z}$ & 0.032 & 0.896 \\
\hline $1 / 2 \mathrm{~W}_{3} \mathrm{~W}_{3}$ & 0.009 & 0.202 & & $W_{4} Z$ & -0.396 & -4.623 \\
\hline
\end{tabular}

LOGL - the $\log$ likelihood ratio test, $\sigma_{\omega}^{2}$ - the variance of random noise, $\sigma_{v}^{2}$ - the variance of the truncated efficiency term, $\mu / \sigma_{v}$ - the truncation point for $v$ divided by the standard deviation of the truncated efficiency term, $\lambda$ - the ratio of standard deviation of the truncated normal efficiency term and random noise, or $\sigma_{v} / \sigma_{\omega}$, and $\sigma$ - the total standard deviation of the error term $-\sigma^{2}=\sigma_{\omega}^{2}+\sigma_{v}^{2}$.

I now turn to my second step and regress cost efficiency on a number of independent factors, first including region dummies and then including province dummies. Tables 7.4 and 7.5 show that local market conditions - including bank-specific variables - explain approximately $6 \%$ to $16.5 \%$ of variations in cost efficiency. Therefore, roughly $90 \%$ of cost efficiency is not explained through local market conditions: a possible justification 
for using the term 'managerial efficiency' as a synonym for X-efficiency. Reported in tables 7.4 and 7.5 are also the conditional mean and truncation factor used in the truncated regression: both depend on the degree on truncation of the dependent variable $\mathrm{CE}$ and are higher the more skewed $\mathrm{CE}$ is. ${ }^{21}$

FIGURE 7.5: Cost Efficiency (20 equal groups (= Bins))

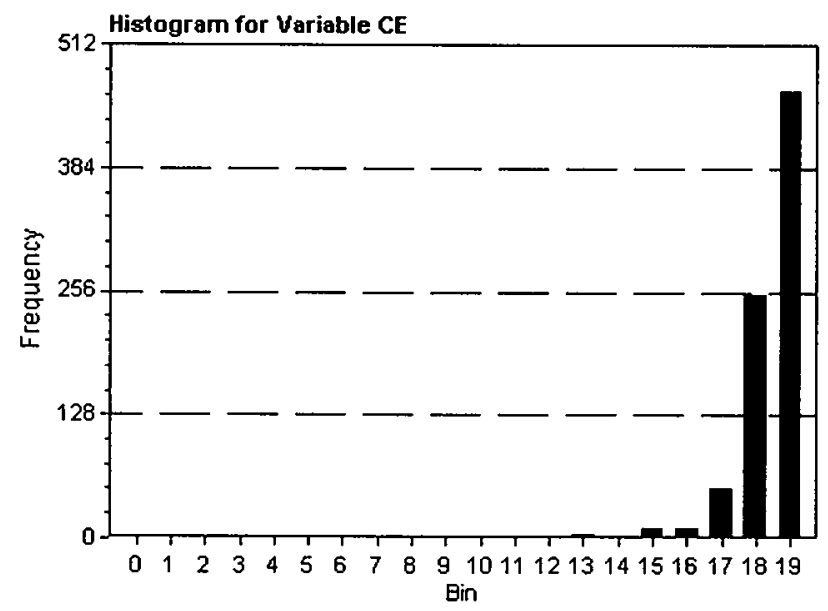

From table 7.4, local banks in the north of the Netherlands, the control group, outperform all other banks. The difference with the southwest is largest and most significant. In addition, the coefficient for 'small urban' is positive and significant, indicating that banks in these markets have a relatively high cost efficiency. This cost efficiency in turn could stem from these banks' wholesale business, as the coefficients for 'wholesale product purchase' and 'wholesale membership' are positive and significant as well. The more products/services businesses buy from the local bank, the higher its cost efficiency. The more committed businesses are, the higher a bank's cost efficiency is. An additional local branch office, on the other hand, decreases cost efficiency.

\footnotetext{
${ }^{21}$ Alternatively, Kumbhakar, Ghosh, and McGuckin (1991) and Battese and Coclli (1995) discuss single-stage estimation procedures where the efficiency measure $v_{k t}$ is an explicit function of a number of independent factors and a constant. However, these procedures have some important drawbacks. First, dependent on the number and scaling of the independent factors in the single-stage procedure the maximum likelihood optimization becomes very lengthy and unstable: different algorithms and small changes in the optimization rules lead to early abortion of the optimization procedure and/or very different estimation results. I note that rescaling the independent factors is not an option. It could solve some optimization problems but at the same time leads to model coefficients that are not very reliable. A second, technical problem with the single-stage procedure is that it does not allow us to adequately measure the marginal impact of the independent factors and their combined impact.
} 
TABLE 7.4: Cost Efficiency - Regional Impact

\begin{tabular}{llll}
\hline Obs: & 802 & Mean $^{*}$ & 0.974 \\
\hline LLF: & 2211.696 & Factor** & 0.496 \\
\hline & Coeff. & t-valuc & Mean \\
\hline INTERCEPT & 0.466 & 45.506 & irr. \\
LOCAL BRANCH OFFICE & -0.001 & -3.523 & 3.272 \\
WHOLESALE PRODUCT PURCHASE & 0.007 & 3.083 & 2.504 \\
WHOLESALE MEMBERSHIP & 0.004 & 3.376 & 1.422 \\
RETAIL MARKET SHARE & 0.000 & -1.599 & 59.818 \\
RETAIL PRODUCT PURCHASE & 0.007 & 1.272 & 2.130 \\
SMALL URBAN & 0.010 & 2.925 & 0.060 \\
EAST & -0.006 & -2.311 & irr. \\
NORTHWEST & -0.005 & -1.904 & irr. \\
SOUTHWEST & -0.012 & -4.577 & irr. \\
SOUTH & -0.006 & -2.239 & irr. \\
\hline * = Conditional Mean. ${ }^{* *}=$ Scale Factor. $R^{2}$ adj.. full model is 0.060
\end{tabular}

TABLE 7.5: Cost Efficiency - Provincial Impact

\begin{tabular}{llll}
\hline Obs: & 802 & Mean $^{*}$ & 0.974 \\
\hline LLF: & 2242.964 & Factor** & 0.555 \\
\hline & Coeff. & t-value & Mean \\
\hline INTERCEPT & 0.518 & 51.534 & irr. \\
WHOLESALE PRODUCT PURCHASE & 0.004 & 1.991 & 2.504 \\
RETAIL MARKET SHARE & 0.000 & -1.269 & 59.818 \\
RETAIL PRODUCT PURCHASE & 0.010 & 1.797 & 2.130 \\
LARGE RURAL & 0.006 & 1.913 & 0.060 \\
ZEELAND & -0.024 & -9.429 & irr. \\
LIMBURG & -0.003 & -1.328 & irr. \\
\hline${ }^{*}=$ Conditional Mean. & ${ }^{* *}=$ Scale Factor.. $R^{2}$ adj.. full model is 0.165
\end{tabular}

The results in table 7.5 largely confirm the results from table 7.4, although without much significance. A noteworthy case in fact is Zeeland, with a highly significant negative coefficient. This is interesting, since Zeeland is relatively rural as well. Apparently the difference between rural and urban areas is a strong but not foolproof indicator of cost efficiency. Also, high loyalty of a local bank's wholesale customers translates into a high cost efficiency. This suggests that fixed costs per customer are relatively important in wholesale banking and efficiency increases as these fixed costs can be spread over more products. Put differently, a local bank has to invest in attracting the businesses that operate in its market. Its investment pays off, however, once a company is lured in.

Now I turn to profit efficiency. Average profit efficiency $(0.945)$ is somewhat lower than average cost efficiency (0.97). The least profit efficient bank is $26.8 \%$ inefficient. As can 
FIGURE 7.6: Profit Efficiency (20 equal groups (= Bins))

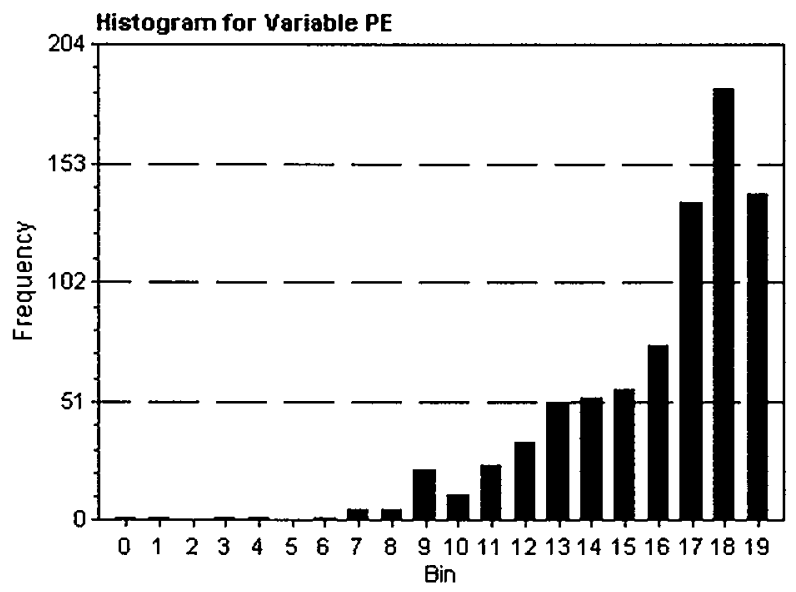

be seen by comparing figure 7.6 with figure 7.5 , profit efficiency is less skewed than cost efficiency. This is in line with findings in earlier chapters: profit efficiency is the combined result of on the one hand a bank's efficient management of its inputs and outputs and on the other hand that same bank's market position.

TABLE 7.6: Table Profit Efficiency

\begin{tabular}{llllll}
\hline & Mean & SD & Minimum & Maximum & Obs. \\
\hline PE & 0.945 & 0.038 & 0.732 & 0.990 & 802 \\
\hline
\end{tabular}

Also, similar to the cost model, results in table 7.7 demonstrate that the OLS fit is very high. Contrary to what was the case for the cost model however, the location decisions of the local banks appear to significantly affect their profit efficiency. In tables 7.9 and 7.9 , the coefficient for 'main office' is negative and significant. This suggests that local banks can increase profit efficiency by limiting the number of main offices they use. From table 7.9 , a better source of profit efficiency appears to be opening local branch offices: these relatively low-cost service stations (marginally) outperform the main offices. On the other hand, placing additional ATMs is not a healthy strategy, since it lowers profit efficiency (cf. table 7.9).

This is also confirmed by table 7.7, where $\mu / \sigma_{v}$ is positive. As was the case with the profit model, $\lambda$ indicates that a relatively large portion of the residual consists of inefficiency.

Summing up, banks that locate carefully benefit through a higher profit efficiency. Interesting in the light of the disintermediation trend is that this does not necessarily translate into a centralization strategy. Rather a healthy degree of decentralization appears 
to benefit profit efficiency, perhaps reflecting the high costs associated with full-fledged main offices that operate with expensive equipment and expensive personnel.

TABLE 7.7: Profit Frontier

\begin{tabular}{|c|c|c|c|c|c|c|}
\hline Olss:: & 802 & & $\sigma_{\nu}^{2}$ & 0.002 & $\mu / \sigma_{v}$ & 0.393 \\
\hline LLF: & 960.145 & & $\sigma_{v}^{2}$ & 0.014 & $\lambda$ & 2.711 \\
\hline \multirow[t]{2}{*}{$R^{2}$ adj. } & 0.992 & & Iterations: & 28 & $\sigma$ & 0.124 \\
\hline & Coeff. & t-value & & & Cocff. & t-value \\
\hline INTERCEPT & 21.128 & 2.407 & & $1 / 2 W_{3} W_{1}$ & 0.203 & 1.376 \\
\hline$W_{1}$ & -0.081 & -0.055 & & $1 / 2 W_{4} W_{4}$ & 0.893 & 4.695 \\
\hline$w_{2}$ & -1.205 & -0.388 & & $Y_{1} W_{1}$ & -0.012 & -0.505 \\
\hline $\mathrm{W}_{3}$ & -2.739 & -1.956 & & $Y_{1} W_{2}$ & 0.119 & 1.613 \\
\hline $\mathrm{W}_{4}$ & 5.048 & 1.624 & & $Y_{1} W_{3}$ & -0.035 & -1.944 \\
\hline $\mathrm{Y}_{1}$ & -1.479 & -2.016 & & $Y_{1} W_{4}$ & 0.073 & 1.586 \\
\hline$Y_{2}$ & -1.151 & -1.572 & & $Y_{2} W_{1}$ & 0.002 & 0.061 \\
\hline$Y_{3}$ & -3.349 & -2.135 & & $\mathrm{Y}_{2} \mathrm{~W}_{2}$ & -0.001 & -0.010 \\
\hline $\mathrm{Y}_{4}$ & 4.390 & 3.674 & & $\mathrm{Y}_{2} \mathrm{~W}_{3}$ & 0.018 & 0.860 \\
\hline $\mathrm{Z}$ & 1.843 & 1.452 & & $\mathrm{Y}_{2} \mathrm{~W}_{4}$ & 0.146 & 3.120 \\
\hline $1 / 2 Y_{1} Y_{1}$ & 0.034 & 3.593 & & $Y_{3} W_{1}$ & 0.078 & 1.941 \\
\hline $1 / 2 \mathrm{Y}_{1} \mathrm{Y}_{2}$ & -0.078 & -3.157 & & $Y_{3} W_{2}$ & 0.315 & 2.238 \\
\hline $1 / 2 Y_{1} Y_{3}$ & 0.055 & 1.269 & & $Y_{3} W_{3}$ & 0.062 & 1.834 \\
\hline $1 / 2 Y_{1} Y_{4}$ & -0.060 & -1.978 & & $Y_{3} W_{4}$ & -0.072 & -0.836 \\
\hline $1 / 2 Y_{2} Y_{2}$ & 0.086 & 5.632 & & $Y_{A} W_{1}$ & -0.066 & -1.864 \\
\hline $1 / 2 Y_{2} Y_{3}$ & -0.142 & -2.879 & & $Y_{4} W_{2}$ & -0.258 & -2.328 \\
\hline $1 / 2 \mathrm{Y}_{3} \mathrm{Y}_{3}$ & -0.014 & -0.244 & & $Y_{4} W_{3}$ & -0.013 & -0.464 \\
\hline $1 / 2 Y_{3} Y_{4}$ & 0.112 & 1.395 & & $Y_{4} W_{4}$ & -0.182 & -2.925 \\
\hline $1 / 2 Y_{4} Y_{4}$ & 0.058 & 1.834 & & $1 / 2 \mathrm{ZZ}$ & 0.201 & 4.565 \\
\hline $1 / 2 W_{1} W_{1}$ & -0.139 & -2.080 & & $Y_{1} Z$ & -0.041 & -2.435 \\
\hline $1 / 2 W_{1} W_{2}$ & 0.347 & 1.340 & & $Y_{2} Z$ & 0.025 & 1.334 \\
\hline $1 / 2 W_{1} W_{3}$ & -0.004 & -0.060 & & $\mathrm{Y}_{3} \mathrm{Z}$ & 0.077 & 2.197 \\
\hline $1 / 2 W_{1} W_{4}$ & -0.207 & -1.220 & & $Y_{A} Z$ & -0.023 & -0.919 \\
\hline $1 / 2 W_{2} W_{2}$ & 0.805 & 1.773 & & $W_{1} Z$ & 0.096 & 2.710 \\
\hline $1 / 2 \mathrm{~W}_{2} \mathrm{~W}_{3}$ & 0.091 & 0.340 & & $W_{2} Z$ & -0.105 & -0.854 \\
\hline $1 / 2 W_{2} W_{4}$ & -2.540 & -4.839 & & $W_{3} Z$ & -0.032 & -1.053 \\
\hline $1 / 2 W_{3} W_{3}$ & 0.041 & 1.167 & & $W_{1} Z$ & -0.193 & -2.300 \\
\hline
\end{tabular}

LOGL - the log likelihood ratio test, $\sigma_{\omega}^{2}$ - the variance of random noise, $\sigma_{v}^{2}$ - the variance of the truncated efficiency term, $\mu / \sigma_{v}$ - the truncation point for $v$ divided by the standard deviation of the truncated efficiency term, $\lambda$ - the ratio of standard deviation of the truncated normal efficiency term and random noise, or $\sigma_{v} / \sigma_{\omega}$, and $\sigma$ - the total standard deviation of the crror term $-\sigma^{2}=\sigma_{\omega}^{2}+\sigma_{v}^{2}$.

Regionally speaking, the rural areas again appear to outperform the rest. The coefficient for 'cosmopolitan' is also positive, but insignificant. The south and the southwest appear to do well, however. This is partly confirmed by table 7.9, where Zeeland, Noord-Brabant 
and Limburg have positive and significant coefficients. Perhaps this is a competition effect: the branch networks of ABN AMRO and ING are not as dense in these provinces as they are in the northwest. Moreover, in these southern provinces Rabobank lacks the competition of another agricultural cooperative bank like it has in the north with Friesland Bank. Meanwhile, the coefficient for Zeeland appears to again be positive and significant. Since the number of local banks in this province is limited, this could be to some extent the consequence of small sample bias.

TABLE 7.8: Profit Efficiency - Regional Impact

\begin{tabular}{llll}
\hline Obs: & 802 & Mean $^{*}$ & 0.947 \\
\hline LLF: & 1643.996 & Factor** $^{*}$ & 0.534 \\
\hline INTERCEPT & Cocff. & t-value & Mean \\
MAIN OFFICE & 0.573 & 26.647 & irr. \\
LOCAL BRANCH OFFICE & -0.014 & -3.026 & 1.061 \\
OTHER ATMs & 0.003 & 2.946 & 3.272 \\
WHOLESALE MEMBERSHIP & -0.001 & -2.143 & 3.823 \\
RETAIL MARIKET SHARE & 0.009 & 2.570 & 1.422 \\
RETAIL PRODUCT PURCHASE & 0.000 & 2.657 & 59.818 \\
MEDIUM RURAL & -0.040 & -3.716 & 2.130 \\
SMALL URBAN & 0.008 & 1.669 & irr. \\
COSMOPOLITAN & 0.011 & 3.120 & irr. \\
EAST & 0.009 & 1.565 & irr. \\
SOUTHWEST & 0.005 & 1.474 & irr. \\
SOUTH & 0.014 & 3.768 & irr. \\
* Conditional Mean. ${ }^{* *}=$ Scalc Factor. $R^{2}$ adj.. full model is 0.111
\end{tabular}

Upon comparing the wholesale market with the retail market, the story appears to be somewhat more intricate than was the case with the cost model. The commitment of wholesale customers, as reflected in their membership of the cooperative local bank, contributes positively and significantly to profit efficiency. This may reflect the fact that relationship banking enhances the ability of local banks to make a profit. It may decrease competition and stimulate long-term investment, as it decreases possible moral hazard problems.

Finally, the significant, negative coefficient for retail product purchase - the average number of products that customers purchase - is less intuitive. The analysis here suggests that, in terms of profit efficiency, the marginal benefits from selling additional services to retail customers are negative. Put differently, a local bank has an easier time making a profit on the typical (savings) deposit that it first offers its retail clients than on the mortgages, car insurances or holiday packages it tries to sell later. 
TABLE 7.9: Profit Efficiency - Provincial Impact

\begin{tabular}{llll}
\hline Obs: & 802 & Mean* $^{*}$ & 0.947 \\
\hline LLF: & 1607.906 & Factor** & 0.573 \\
\hline INTERCEPT & Coeff. & t-value & Mean \\
NAIN OFFICE & 0.622 & 30.672 & irr. \\
OTHER ATMs & -0.017 & -3.798 & 1.061 \\
WHOLESALE MEMBERSHIP & -0.001 & -2.344 & 3.823 \\
RETAIL MARKET SHARE & 0.014 & 4.151 & 1.422 \\
RETAIL PRODUCT PURCHASE & -0.004 & 4.421 & 59.818 \\
RETAIL CLIENT BASE & 0.000 & -4.455 & 2.130 \\
LARGE RURAL & -0.012 & -2.392 & irr. \\
SMALL URBAN & 0.009 & 2.931 & irr. \\
COSMOPOLITAN & 0.014 & 2.467 & irr. \\
ZEELAND & 0.023 & 3.242 & irr. \\
NOORD-BRABANT & 0.007 & 2.061 & irr. \\
LIMBURG & 0.020 & 4.397 & irr. \\
FLEVOLAND & -0.077 & -7.863 & irr. \\
\hline = Conditional Mean. ** $=$ Scale Factor. $R^{2}$ adj.. full model is 0.191
\end{tabular}

This result may reflect the fact that the disintermediation trend is to a significant extent a misnomer: as a result of deregulation and technological advances, banks are facing increasing competition in areas that are not related to their traditional role of a financial intermediary. Thus, although in absolute terms the markets for mortgages and other 'non-intermediary' products may be potentially very profitable, the extent to which banks are succesful on these markets is not particularly high when compared to the traditional 'intermediation' services.

\subsection{Conclusion}

In this chapter I have presented an analysis of the role local markets play in shaping bank efficiency. I used data from a profitable cooperative bank with a nationwide network. This allowed me to focus on the way local markets and the way a bank presents on these local markets interact. I estimated a cost and a profit frontier for a sample of 402 banks in the period 1998-1999.

Specifically, I tried to answer two questions. First, to what extent is X-efficiency really 'managerial efficiency'? The results of my analysis show that the local market factors included explain roughly $10-20 \%$ of the variation in efficiency of local banks. Taking into account the fact that some of these factors are endogenous to the bank's strategic 
behavior (c.g. the number of local branch offices) increases the perception that for the most part estimated X-cfficiency cannot be contributed to the environment in which local banks operate.

That enviromment itself influences cost and profit efficiency in much the same way when it comes to geographic location of local banks. In particular, local banks in the north and the south/southwest of the Netherlands are more efficient.

Cost efficiency benefits from a high market share in both the whosale market and the retail market. The commitment of wholesale customers stimulates cost efficiency. It may in turn lead to an increase in wholesale product purchase, which also boosts cost efficiency. Cost efficiency is relatively low in rural south and southwest, as well as in the east and northwest. It is also relatively high in the rural north. As a result, there is not a uniform picture that evolves. Local branch offices, however, are detrimental to cost efficiency.

Profit efficiency in turn benefits from local branch offices with low local overhead costs. This type of personal customer service and market penetration turns out to be a very health strategy. On the other hand, main offices and ATMs in other places are costly in terms of profit efficiency. Also relatively costly is the marginal consumption of the local bank's retail customers. Commitment of wholesale customers does neutralize this effect. And in rural areas, local banks have an easier time increasing profit efficiency.

Summing up, although not dominant in absolute terms, local markets do help shape local banks' efficiency. Banks that choose to focus on cost efficiency, customarily very important, overlook some important profit efficiency gains to be made. They may end up with the wrong strategy, opening too many main offices, and keeping too busy wooing clients in interesting but tough markets for non-traditional services. On the other hand, a healthy focus on wholesale clients and the concommitant investment in relationship banking pay off, both in profit and in cost efficiency. Market penetration and face-to-face customer contact may be expensive, but still pay for themselves through increases in profit efficiency - a result that certainly puts the discussion about disintermediation into perspective and suggest that local banking is far from dead. 


\section{.}




\section{Conclusion}

\subsection{Limitations}

The analysis in this thesis centers on the relationship between bank performance, market power and efficiency. As witnessed by the summary in the next section, results are homogenous and for the most part intuitive. However, the results presented here have their limitations, and understanding these limitations helps build confidence in the results. When seen in the correct light, they can lead to a cohesive answer and practical suggestions.

\subsubsection{Market Power}

A first limitation concerns the competition models in chapters 2 and 5 . As noted above, the absence of an accurate measure for the way banks react on each others decisions decreases the information content of market power hypotheses. Put differently, the role of bank behavior ('conduct') is not explicitly accounted for and thereby its impact on performance becomes less clear. Data over a longer period of time would enable us to estimate reaction functions and possibly solve this problem. At present, it is a recurring problem in the literature and one not absent from the analysis in this dissertation.

A second important limitation related to competition models concerns the definition of a banking market. The analyses in chapter 5 already confirm an issue raised earlier in chapter 2: it is debatable whether there is indeed one banking market. Indeed, the analysis in chapter 5 as well as in chapters 4 and 6 is the result of a trade-off. Taken to the extreme, each bank has its own frontier (even if it operates on a market with many other banks) since its set of inputs and outputs will never exactly mimic that of other banks. However, in order to benchmark we need a common frontier. The choice of banks in the chapters mentioned here is clearly aimed at balancing both objectives. The result is each time a set of banks with the same set of outputs and inputs, either operating within the same (national) boundaries (cf. chapter 4) or within the same size class (cf. chapter 6 ) or economic union (also chapter 6). In fact, this limitation is related to the previous one: as more data become available, we can more carefully measure demand elasticities and define markets.

\section{S.1.2 Efficiency}

In chapter 3, I discussed stochastic frontier modelling. In it, I already mentioned different approaches to bank production - an ongoing discussion in the literature. However, I paid particular attention to the optimization of stochastic frontiers. In chapters 6 and 
7, I returned to this issue. Both chapters thereby confirm two important limitations of stochastic frontier modelling, both of which are not entirely solved here.

In the literature, there is little or no discussion about the distributional assumptions and optimization routines of stochastic frontier modeling. These may be important ommissions, because they directly influence the magnitude and/or ranking of the efficiency scores. I try to overcome this by (briefly) discussing optimization routines in chapters 3 and 6. More needs to be done however with respect to distributional assumptions. Fat tails and different truncations may be promising advances in frontier modelling.

\subsubsection{Problem Statement}

A final, important limitation of course concerns the main question raised in this thesis: to what extent is bank performance driven by market power and to what extent is it driven by efficiency? Throughout I assume banks are profit maximizing entities, and bank performance is synonymous to profitability - or the extent to which a bank is efficient at maximizing profits (either directly or through cost minimization). As I mentioned in chapter 3 , the literature suggests a number of other objectives banks have when competing.

I defend this purposely chosen limitation with two arguments. First, there is a practical argument. As explained in chapter 3, measuring these ulterior objectives (perks, salary, etc.) is as yet still in a very premature state, with few empirical evidence available. Sccond, and in line with the opening remarks of this dissertation in the long run profitability whether achieved through market power or through efficiency - is a conditio sine qua non. A bank that is not profitable and/or not efficient will be punished by the stock market, is a takeover target and cannot continue to afford to have any ulterior motives.

\subsection{Recapitulating}

In this dissertation, I investigate European banking dynamics. In particular, I try to answer the question to what extent performance is driven by either market power or efficiency. In search for answers, I start in chapter 2 with a critical overview of past research into market power on European banking markets. I describe some of the characteristics of European banking. I also discuss the extent to which these characteristics influence a market power study. Furthermore, I criticize the most popular test for market power, the structure-conduct-performance hypothesis. After exploring its fundamental weaknesses, I review its empirical applications. My conclusion is that SCP studies lack a theoretical underpinning. As a consequence, tests of the SCP hypothesis are difficult to interpret and inconclusive. In addition, its emphasis on market structure as a measure of market power makes the SCP hypothesis (and related hypotheses) needlessly restrictive.

In chapter 3, I introduce efficiency as a possible alternative explanation for bank performance. I shortly discuss incentive and inefficiency problems. After introducing a bank 
as a rational economic agent, I define its (simple) production function and show how its dual can be used to measure efficiency. Distinguishing between cost minimization and profit maximization then allows me to relate efficiency to bank performance and bank behavior. Although it constitutes an indirect test as well (just like the SCP hypothesis), this test facilitates a clearer distinction between market power and efficiency. As a final exercise, I highlight some of the technical details involved in estimating efficient frontiers. In doing so, I emphasize robustness of estimations as well as the optimization technique.

Chapter 4 employs the stochastic frontier technique for an analysis of the Dutch banking market. I introduce this market as a forerunner in the European Union with respect to concentration and capitalization, and explain why this makes the Netherlands an interesting case study with an eye on the future. For the Dutch banking market, I estimate a cost frontier and a profit frontier for the period 1992-1998. Profit efficiency is found to vary more than cost efficiency, a result that is mirrored in much of the literature. In addition, the former is on average lower than the latter, and the correlation between both is low.

Upon more careful investigation, two conclusions emerge. First, the trend effect that is often expected as a result of the consolidation and deregulation is absent. Industry efficiency remained remarkably stable over the entire period. This result runs counter to many findings in the literature, where attention is often restricted to a simple trend term and/or a trend in efficiency is imposed rather than deduced. Second, when looking at different types of banks, there appear to be significant differences. Whereas all banks perform rather similarly in terms of cost efficiency, large general banks and specialized banks outperform the market in terms of profit efficiency. Importantly, this result remains standing when further comparing different combinations of size and specialization. Large banks appear to benefit from sheer size and possibly market power, wherea specialized banks operate in niche markets.

Results in this chapter teach some important lessons. First, they confirm the observation in chapter 2 that there is no longer a 'typical' bank, and with it no longer a typical banking market. Even when operating and - to a more or less extent - competing in the same market, the banks in the Dutch banking market do so under different circumstances. A second, related lesson is that the industry-wide trend effect that is generally found in the literature disappears when the trend is deduced rather than imposed and when the efficiency of different types of banks operating in the same industry is considered. Finally, evidence of market power exists - most convincingly (of course) with the large banks that dominate the Dutch banking market.

In chapter 5, I seek to find out if the same conclusion holds when a competition model is used to investigate competitive conditions on the Dutch banking market. The findings for a standard SCP model confirm the earlier observations with respect to the SCP model's fundamental flaws. Tests for the SCP hypothesis are insignificant. I then introduce a Cournot model that, at least theoretically, overcomes some of those flaws. 
Now, the hypothesis that market power exists can definitely not be rejected, a result that mimics that of the previous chapter. The question to which extent market power exists however, is left unanswered; a weakness of this model is the inability to directly measure conjectural variation, crucial in relating bank behavior to bank performance.

An advancement with respect to the literature is presented in the final part of chapter 5, where I return to the Efficiency hypothesis. I demonstrate why tests of this hypothesis as presented in the literature are bound to misrepresent the impact of the hypothesis itself. I solve the identification problems that lead to this misrepresentation. Importantly, estimation results for the Coumot model confirm the observation in chapter 1 that market power and efficiency are not mutually exclusive in explaining bank performance. In addition, as was the case before, results comply with those in chapter 4 and the hypothesis that market power exists cannot be rejected.

Taken together, conclusions from this chapter point in three directions. First, the "theoretical' analysis in chapter 2 is nicely reflected in the empirical analysis of the SCP model in this chapter. With it, the criticism of that model remains firmly standing. Second, the alternative model coined 'Cournot' model shows promising results. Fundamentally, it should be preferred over the SCP model. Empirically, its results are more cohesive, intuitive and significant. However, upon estimating this model I also find that it merits improvements. Most importantly, the implicit relationship between market share and the conjectural variation becomes crucial since the latter is absent when estimating the model. A third direction concerns the relevance of the analysis in chapter 4 , as well as in chapters 6 and 7. The conclusions derived with respect to market power from estimating both a cost and a profit frontier remain firmly standing when benchmarked against those of a competition model.

Next, in chapter 6, I compare cost and profit efficiency of European and U.S. banks, in order to establish whether there is a level playing field for banks on both continents. In particular, I focus on large, independent commercial banks on both sides of the Atlantic. I explain how this choice is compliant with the assumptions of the frontier models and is expected to increase the reliability of the efficiency measures derived. Also, throughout this chapter I emphasize attempts to test the robustness of the results, in order to find out to what extent model specifications and optimization routines can influence frontier estimation results. The latter are found to be very robust to alternate specifications, perhaps also reflecting the earlier sample choice.

In relation to the latter, cost frontiers in Europe and the U.S. are found to be of a similar shape and the hypothesis that a single cost frontier exists cannot be rejected. This is in itself not suprising, given the fact that sample data are limited to large, independent commercial banks. However, estimation of a single frontier confirms that the the European Union is still less homogenous than the U.S., where cost efficiency varies less. Comparisons of cost efficiency scores show a diverse picture, revoking results from the literature that U.S. banks are more efficient than European banks. 
For profit efficiency, the story is rather different. The hypothesis that a single profit fronticr exists can be rejected. Although I pursue it by still estimating such a frontier, results from this estimation have to be interpreted with caution. The main lesson from this exercise is that it confirms the notion that banks maximize profits differently in the U.S. than in Europe. Cautious evidence exists that the former has a higher profit efficiency. Although there is no clear difference between the efficiency of market-based (U.S. and Great Britain) and bank-based systems, in relation to the results from the cost frontier estimations this suggest that market conditions drive profit efficiency.

Cautious evidence with respect to future cross-Atlantic mergers therefore hints at the fact that, to the extent that they are expected to occur, they are mostly motivated by increases in profit efficiency. This suggest that in the future, I have to once again regard talk about 'synergy' and 'cost savings' with skepticism when used as a motivation for bank mergers. Interestingly however, the results in this chapter provide more convincing evidence of another phenomenon; the dynamics on banking markets in Europe and the U.S. are different, and a successful, efficient and profitable existence on one continent is by no means a guarantee for a successful entry on the other continent.' This may explain the scarce and often unsuccessful attempts to merge across the border. It once again confirms the necessity to assess cost and profit efficiency simultaneously.

Finally, in chapter $7 \mathrm{I}$ address an issue raised earlier in chapters 3 and 4 but most urgently in the previous chapter: the role of local market conditions. In this chapter, I analyze the relationship between bank efficiency and the market conditions. In particular, I try to assess to what extent local market conditions explain bank efficiency. Alternatively, I try to measure the extent to which $\mathrm{X}$-efficiency is indeed 'managerial' efficiency, and not the result of exogenous market forces.

I study a sample of 402 cooperative banks operating all over the Netherlands in the period 1998/1999. This allows me to focus on interaction between bank efficiency and local market conditions. X-efficiency is found to be explained for roughly $10-20 \%$ by local market conditions. This finding confirms the notion that banks can have significant impact on their own efficiency. Put differently, strategic choices of a bank, with respect to location and production, carry significant weight.

Not surprisingly, banks in rural areas benefit from lower competition and experience higher cost and profit efficiency. In particular, local banks in the north and south/southwest of the Netherlands are most efficient. Less intuitive, is the result that market share - both in wholesale and retail markets - is found to be more important in explaining cost efficiency than profit efficiency. Then again, evidence in the literature does suggest that most cost efficiency gains can be made at very moderate sizes.

\footnotetext{
${ }^{1}$ An exception may be investment banking, where U.S. banks have succesfully managed to penetrate Europe. The nature of investment banking is such however, that it constitutes an entirely different industry - as witnessed by the problems experienced by commercial banks trying to incorporate investment banking.
} 
Wholesale and retail banking are found to be played by different rules. Commitment and relationship banking are key to a local bank's success in the wholesale market as well as in the retail market. Marginal consumption of retail customers is costly however, especially in terms of profit efficiency.

Perhaps the most interesting results are found with respect to the location decisions of the local banks. Evidence here is convincing and runs counter to some of the current trends in banking. Main officies and ATMs are detrimental to profit efficiency. Low-cost local branch offices however lower cost efficiency but this effect is outweighed by the fact that they improve profit efficiency.

Summing up, banks' traditional role of financial intermediary is by no means dead. A bank that invests in customer relations and an increase in personal presence in the market is rewarded, especially in terms of profit efficiency. For the most part however, suboptimal X-efficiency results from the internal balance between inputs and outputs and price setting - in short, 'managerial' (in)efficiency.

\subsection{Future of banking}

What does the analysis in this dissertation say about the future of European banking?

In my view, there are four main lessons to be learned. First, evidence in favor of market power is convincing throughout this dissertation. Second, potential efficiency gains are found to amount to roughly $5-10 \%$ for many banks. Third, local market conditions play a modest but significant role in stimulating cost and profit efficiency. Fourth, efficiency differences persist internationally, despite increasing globalization.

Combined, the analysis here indicates that the role of small, general banks will be marginal. To survive, banks need either size or focus. Also, in the presence of sufficient market discipline banks should be able to realize significant efficiency gains - internally. International competition and regulation promoting that competition are both crucial to ensuring enough competitive pressure. Success, however, depends crucially on the ability of banks to adapt to market conditions. At the same time, the traditional role of banks as financial intermediaries is far from over. 


\section{References}

Aftalion, F., AND L. White (1977): "A Study of Monetary System with a Pegged Discount Rate under Different Market Structures," Journal of Banking and Finance, December, $349-371$.

Aigner, DJ, L. C., ANI) P. SChmidt (1977): "Formulation and Estimation of Stochastic Frontier Production Function Models," Journal of Econometrics, 6 (1), 21-37.

Akhavein, J. D., A. N. Berger, and D. B. Humpurey (1997): "The Effects of Megamergers on Efficiency and Prices: Evidence from a Bank Profit Function," Review of Industrial Organizalion, 12 (1), February, 95 - 139.

A s.irro, W. (1999): "How Branch Banks Can Play a Role in Improving Customer Loyalty," Bank Marketing, 31 (9), 38.

Alı, M., and S. Greenbaum (1977): "A Spatial Model of the Banking Industry," The Joumal of Finance, XXXII (4), 1283-1303.

Alles, L., AND A. RAI (1996): "Operational Efficiency in Banking: An International Comparison," Journal of Banking and Finance, 20, 655-672.

Altunbas, Y., and S. Chakravarty (1998): "Efficiency Measures and the Banking Structure in Europe," Economics Letters, 60 (2), 205-208.

Altunbas, Y., E. Gardener, P. Molyneux, and B. Moore (2001): "Efficiency in European Banking," European Economic Revicw, 45, 1931-1955.

Altunibas, Y., J. Goddard, and P. Molyneux (1999): "Technical Change in Banking," Economics Letters, 64 (2), 215-221.

Altunbas, Y., and P. Molyneux (1994): "The Concentration-Performance Relationship in European Banking - A Note," Institute of European Finance Research Papers in Banking and Finance, 12, 1-12.

(1996a): "Cost Economies in EU Banking Systems," Journal of Economics and Business, 48 (3), 217-230.

(1996b): "Economies of Scale and Scope in European Banking," Applied Financial Economics, 6, 367-375.

Altunbas, Y., P. Molyneux, and J. Thornton (1997): "Big-Bank Mergers in Europe: An Analysis of the Cost Implications," Economica, 64 (254), May, 317--29. 
Arrow, K. (1985): "The Economics of Agency," in Principals and Agents: The Structure of Business, ed. by J. Pratt, and R. Zeckhauser. Harvard Business School Press, Cambridge, Massachussets.

Ashton, J. (1999): "A Test of Perfect Competition in the UK Retail-Banking Deposit Market," Bournemouth University School of Finance and Law Working Paper Series, 15 .

Athanassopoulos, A. (1998): "Nonparametric Frontier Models for Assessing the Market and Cost Efficiency for Large-Scale Bank Branch Networks," Journal of Money, Credit and Banking, 30 (2), 172-192.

Avkiran, N. K. (1999): "The Evidence on Efficiency Gains: The Role of Mergers and the Benefits to the Public," Journal of Banking and Finance, 23, 991-1013.

BAIN, J. (1951): "Relation of Profit Rate to Industry Concentration: American Manufacturing, 1936-1940," Quarterly Journal of Economics, 65, 293-324.

(1956): Industrial Organization. Wiley, NY.

BAker, K., AND T. Bresnahan (1985): "The Gains from Merger and Collusion in Product Differentiated Industries," Journal of Industrial Economics, 33, 427-444.

Barefoot, J. (2000): "How Can Banks Avoid "Channel Discrimination"?," American Bankers Association Banking Journal, 92 (3), 33-38.

Barnet', W. P., H. R. Greve, ani) D. Y. Park (1994): "An Evolutionary Model of Organizational Performance," Strategic Management Journal, 15, 11-28.

BARneT', W. P., AND M. T. HANSEN (1996): "The Red Queen in Organizational Evolution," Strategic Management Journal, 17, 139-157.

BAtrese, G., and T. Coeldi (1993): "A Stochastic Frontier Production Functions Incorporating a Model for Technical Inefficiency Effects," Department of Econometrics, University of New England, Working Papers in Econometrics and Applied Statistics, 69.

(1995): "A Model for Technical Inefficiency Effects in a Stochastic Frontier Production Function for Panel Data," Empirical Economics, 20, 325-332.

Battese, G., A. Heshmati, ani L. Hualmarsson (1998): "Efficiency of Labour Use in the Swedish Banking Industry: A Stochastic Frontier Approach," CEPA Working Papers, 6/98.

Battese, G. E., and T. Coelu (1988): "Prediction of Firm-Level Technical Efficiencies with a Generalized Frontier Production Function and Panel Data," Journal of Econometrics, 38, 387-399. 
BatTese, G. E., AND G. S. Corra (1977): "Estimation of the Production Frontier Model: With Application to the Pastoral Zone of Eastern Australia," Australian Journal of Agricultural Economics, 21, 169-179.

Bauer, P. W., A. N. Berger, G. D. Ferrier, and D. B. Humphrey (1998): "Consistency Condition for Regulatory Analysis of Financial Institutions: A Comparison of Frontier Efficiency Methods," Joumal of Economics and Business, 50, 85-114.

Bauer, P. W., and B. A. Cromwel. (1991): "Local Banking Markets and Firm Location," Federal Reserve Bank of Cleveland Working Paper, 9114.

Beatte, B., anil C. Taylor (1985): The Economics of Production, vol. New York. John Wiley and Sons, New York.

Benink, H. (1996): "Financial Fragility," Ph.D. thesis, Maastricht University.

Benston, G., G. Hanweck, and D. Humphrey (1982): "Scale Economies in Banking: A Restructuring and Reassessment," Journal of Money, Credit and Banking, 14, 435-456.

Berg, S., F. Forsund, L. Hjalmarsson, and M. Suominen (1993): "Banking Efficiency in the Nordic Countries," Journal of Banking and Finance, 17, 371-388.

BERG, S., F. Forsund, AND F. JANSEN (1992): "Malmquist Indices of Productivity Growth During the Deregulation of Norwegian Banking 1980-89," Scandinavian Journal of Economics, 94, 211-228.

BERG, S. A., ANI M. KIM (1994): "Oligopolistic Interdependence and the Structure of Production in Banking: An Empirical Evaluation," Journal of Money, Credit and Banking, 26/2, 309-322.

(1998): "Banks as Multioutput Oligopolies: An Empirical Evaluation of the Retail and Corporate Banking Markets," Journal of Money, Credit and Banking, 30/2, 135-153.

Berger, A. (1995): "The Profit-Structure Relationship in Banking - Tests of MarketPower and Efficient Structure Hypothesis," Journal of Money, Credit and Banking, 27, $404-431$.

Berger, A., Ani R. DeYoung (1997): "Problem Loans and Cost Efficiency in Commercial Banks," Journal of Banking and Finance, 21, 849-870.

Berger, A., D. Hancock, and D. Humphrey (1993): "Bank Efficiency Derived from the Profit Function," Joumal of Banking and Finance, 17, 317--347. 
Bergler, A., and T. Hannan (1993): "Using Efficiency Measures to Distinguish Among Alternative Explanations of the Structure-Performance Relationship in Banking," Federal Reserve Board Working Paper.

Berger, A. N. (1998): "The Efficiency Effects of Bank Mergers and Acquisitions: A Preliminary Look at 1990s Data," in Bank Mergers and Acquisitions, ed. by Y. Amihud, and G. Miller, Boston. Kluwer Academic Publishers.

Berger, A. N., R. Demsetz, and P. Strahan (1998): "The Consolidation of the Financial Services Industry: Causes, Consequences, and Implications for the Future," Working Paper, Federal Reserve Bank of New York.

Berger, A. N., R. DeYoung, H. Genay, nni G. F. Udell (2000): "Globalization of Financial Institutions: Evidence from Cross-Border Banking Performance," in Brookings-Wharton Papers on Financial Services, ed. by R. E. Litan, and A. Santomero, chap. in R. E. Litan, and A. Santomero (eds.), Brookings-Wharton Papers on Financial Services, 3. Brookings Institute.

Bercer, A. N., and D. B. Humphrey (1991): "The Dominance of Inefficiencies over Scale and Product Mix Economies in Banking," Joumal of Monctary Economics, 28, 117-148.

(1992): "Megamergers in Banking and the Use of Cost Efficiency as an Antitrust Defense," Antitrust Bulletin., 37, 541-600.

(1997): "Efficiency of Financial Institutions: International Survey and Directions for Future Research," European Joumal of Operations Research, 98, 175-212.

Berger, A. N., W. Hunter, AND S. Timae (1993): "The Efficiency of Financial Institutions: A Review and Preview of Research Past, Present, and Future," Joumal of Banking and Finance, 17, 221-249.

Berger, A. N., J. H. Leusner, and J. J. Mingo (1997): "The Efficiency of Bank Branches," Journal of Monetary Economics, 40, 141-1-62.

Berger, A. N., AND L. J. Mester (1997): "Inside the Black Box: What Explains Differences in the Efficiencies of Financial Institutions," Journal of Banking and Finance, $21,895-947$.

(1999): "What Explains the Dramatic Changes in Cost and Profit Performance of the U.S. Banking Industry?," Federal Reserve Board Working Paper, 99-1 (February).

Bester, H. (1995): "A Bargaining Model of Financial Intermediation," European Economic Review, 39, 211-228.

Bielski, L. (1999): "Rethinking the Branch Experience," American Bankers Association Banking Journal, 91 (8), 28-34. 
BıkKer, J. (1997): "Efficiency in the European Banking Industry: An Exploratory Analysis to Rank Countries," De Nederlandsche Bank Working Paper, June 17.

Bikker, J. A., AN1) H. J. Groeneveld (1998): "Competition and Concentration in the EU Banking Industry," DNB Staff Reports, De Nederlandsche Bank NV, 26 (October).

Broek, J. V. D., F. Forsund, L. Hanmarsson, and W. Meeusen (1980): "On the Estimation of Deterministic and Stochastic Frontier Production Functions - A Comparison," Journal of Econometrics, 13, 117-138.

Burdisso, T., AND L. D'Amáo (2000): "Prudential Regulations, Restructuring and Competition: The Case of the Argentine Banking Industry," Quintas Jornadas de Economía Monetari e Internacional, May.

Calem, P., and G. Carlino (1990): "The Concentration/Conduct Relationship in Bank Deposit Markets," The Revicw of Economics and Statistics, 73 (2), 268-276.

Canals, J. (1994): Competitive Strategies in European Banking. Clarendon Press, Oxford.

Caprio, G., and B. Wilson (1997): "On Not Putting All Your Eggs in One Basket," World Bank Working Paper.

Cecchini, P. (1988): The European Challenge in 1992: The Benefits of a Single Market. Gower, Aldershot.

Cerasi, V., B. C. M. I. (1998): "Branching and Competitiveness Across Regions in the Italian Banking Industry," Università degli Studi di Milano Working Paper, 98.03.

Chamberlin, E. (1933): The Theory of Monopolistic Competition. Harvard University Press, Cambridge, MA.

CHIANG, A. C. (1984): Fundamental Methods of Mathematical Economics. McGraw-Hill, Singapore.

Chiappori, P. A., D. Perez-Castrilo, nNi) T. Verder (1995): "Spatial Competition in the Banking System: Localization, Cross-Subsidies and the Regulation of Deposit Rates," European Economic Review, 39, 889-918.

ClARK, J. (1986): "Single-Equation, Multi-Regression Methodology: Is It an Appropriate Methodology for the Estimation of the Structure Performance Relationship in Banking?," Journal of Monetary Economics, 16, 295-312.

Cline, K. (1999): "The Belief Factor," Banking Strategies, 75 (6), 54-58.

Coelli, T. (1996a): "A Guide to DEAP Version 2.1: A Data Envelopment Analysis (Computer) Program," Centre for Efficiency and Productivity Analysis, University of New England, CEPA Working Paper, 96/08. 
(1996b): "A Guide to FRONTIER Version 4.1: A Computer Program for Stochastic Frontier Production and Cost Estimation," Centre for Efficiency and Productivity Analysis, University of New England, CEPA Working Paper, 96/07.

- (1998): "A Multi-Stage Methodology for the Solution of Orientated DEA Models," Centre for Efficiency and Productivity Analysis, Department of Econometrics, University of New England, Working Paper (to appear in Operations Rescarch Letters).

Coelli, T., MNi S. Perelanan (1997): "A Comparison of Parametric and NonParametric Distance Function: With Application to European Railways," Centre de Recherche en Economie Publique et en Economie de la Population [CREPP] Working Paper, 96/11.

Coflli, T., D. Prasada Rao, and G. Battese (1998): An Introduction to Efficiency and Productivity Analysis. Kluwer Academic Publishers, Boston.

Cowling, K. (1976): "On the Theoretical Specification of Industrial StructurePerformance Relationships," European Economic Review, 8, 1-14.

Cowling, K., And M. Waterson (1976): "Price Cost Margins and Market Structure," Economica, 43 (171), 267-274.

Cyree, K., J. WANSley, and T. BoEhm (2000): "Determinants of Bank Growth Choice," Journal of Banking and Finance, 24, 709-734.

De LeEuw, J. (1996): Financiële Conglomeraten in Nederland. NIBE - Serie Bank- en Effectenbedrijf 38 .

Dekiker, D. J., ANI G. T. POST (1999): "A Quasi-Concave DEA Model with and Application for Bank Branch Performance Evaluation," Rotterdam Institute for Business Economic Studies [RIBES] Working Paper, 9906.

Densetz, H. (1973): "Industry Structure, Market Rivalry and Public Policy," Journal of Law and Economics, 16 (April), 1-9.

Dewatripoint, M., And J. Tirole (1994): The Prudential Regulation of Banks. MIT Press, Cambridge, Massachusetts.

Diamond, D. W. (1984): "Financial Intermediation and Delegated Monitoring," Review of Economic Studies, 51(3), 393-414.

Dianond, D. W., and P. H. DybviG (1986): "Banking Theory, Deposit Insurance, and Bank Regulation," Journal of Business, 59(1) January, 55-68. 
Dietscil, M., G. Ferrier, ani) L. Well, (1998): "Integration and Banking Performance in the European Union: Productivity, Technical Efficiency, Scale Efficiency, Cost Efficiency, and Profit Efficiency," Université Robert Schuman, Strasbourg (mimeo).

DNB (1986): "Financiële Instellingen in Nederland 1900-1985: Balansreeksen En Naamlijst Van Handelsbank," De Nederlandsche Bank - Statislische Cahiers, 2.

Economic: Research LTI. (1997): "Single Market Integration and X-Inefficiency," in The Single Market Review - Subseries II: Impact on Services, Volume 3: Credit Institutions and Banking, ed. by European Commission. Office for Official Publications of the European Communities, Luxembourg.

EDWARDS, F. (1977): "Managerial Objectives in Regulated Industries: ExpensePreference Behavior in Banking;" Journal of Political Economy, 85, pp. 147-162.

Edwards, F., and A. Hegciestad (1973): "Uncertainty, Market Structure and Performance: The Galbraith Caves Hypothesis and Managerial Motives in Banking)," Quarlerly Joumal of Economics, 87, 455-473.

Eisenbeis, R., G. Ferrier, and S. Kwan (1999): "The Informativeness of Stochastic Frontier and Programming Frontier Efficiency Scores: Cost Efficiency and Other Measures of Bank Holding Company Performance," Federal Rescrve Bank of Atlanta Working Paper Series, 99-23.

Färe, R., Nis C. A. K. Lovelt (1978): "Measuring the Technical Efficiency of Production," Journal of Economic Theory, 19:1, 150-162.

FASE, M. (1997): "On Substitutability Among Domestic Money and Cross-Border Deposits," in Economics, Welfare Policy and the History of Economic Thought, ed. by M. Fase, W. Kanning, and D. Walker, vol. 9, pp. 194-207, Cheltenlam, UK/Northampton, US. Edward Elgar.

Fase, M., and C. Winder (1993): "The Demand for Money in the Netherlands and the Other EC Countries," De Economist, 141 (4), 471-496.

Fecher, F., AND P. Pestiau (1993): "Efficiency and Competition in OECD Financial Services," in The Measurement of Productive Efficiency: Techniques and Applications, ed. by H. Fried, C. Lovell, and S. Schmidt, pp. 374-385. Oxford University Press, Oxford.

Ferrier, G. D., K. Kerstens, nNi) P. Vanden Eeckaut (1994): "Radial and Nonradial Technical Efficiency Measures on a DEA Reference Technology: A Comparison Using U.S. Banking Data," Université Catholique de Louvain CORE Discussion Paper; 9423 (May), 23. 
Ferrier, G. D., AND C. A. K. Lovel. (1990): "Measuring Cost Efficiency in Banking: Econometric and Linear Programming Evidence," Journal of Econometrics, 46, 229245.

FlanNer, M. J. (1983): "Correspondent Services and Cost Economies in Commercial Banking," Joumal of Banking and Finance, 7, 83-99.

Fraser, D., J. HoOton, J. Kolari, nND J. Reising (1997): "The Wealth Effect of Interstate Branching," Journal of Banking and Finance, 21, 589-611.

Freixas, X., AND J.-C. RocheT (1997): Microeconomics of Banking. MIT Press, Massachusetts.

Fuentelsaz, L., and V. Salas (1994): "Spatial Competition in Retail Banking: Theory and Empirical Evidence from Spain and Other European Countries," SUERF Papers on Monetary Policy and Financial Systems (Tilburg University), 18.

Gardener, E., and P. Molyeneux (1990): Changes in Western European Banking. Allen Unwin, London.

GilberT, R. (1984): "Bank Market Structure and Competition: A Survey," Journal of Money, Credit and Banking, 21, 589-611 (including comments by A.A. Heggestad, S. Peltzman and P.J. Schmidt).

GILBIERT, R. (2000): "Nationwide Branch Banking and the Presence of Large Banks in Rural Areas," Federal Rescrve Bank of St. Louis Review, May/Jun, 13-28.

Goldberc, L., ANi) A. RAi (1996): "The Structure-Performance Relationship for European Banking," Journal of Banking and Finance, 21, 589-611.

Graddy, D., AND R. I. KYlE (1979): "The Simultaneity of Bank Decision-Making; Market Structure, and Bank Performance," Journal of Finance, vol. XXXIV (March), $1-18$.

Greene, W. (1980a): "Maximum Likelihood Estimation of Econometric Frontier Functions," Journal of Econometrics, 13, 27-56.

Greene, W. (1980b): "On the Estimation of a Flexible Frontier Production Model," Journal of Econometrics, 13, 101-115.

HAAF, K. (2000): "Measures of Competition and Concentration: A Review of the Literature," De Nederlandsche Bank, Directorate Supervision, Research Series Supervision, 27 (May).

HAAG, S., AND P. JASKA (1995): "Interpreting Efficiency Ratings: An Application of Bank Branch Operating Efficiencies," Managerial and Decision Economics, 16, 7-14. 
Hannan, T. (1991): "Bank Commercial Loan Markets and the Role of Market Structure: Evidence from Surveys of Commercial Lending," Journal of Banking and Finance, 15, 133-149.

Hanweck, G. A., and S. A. Rhondes (1984): "Dominant Firms, Deep Pockets and Local Market Competition in Banking," Journal of Economics and Business, 36, 391402.

Hassan, I., A. Lozano-Vivas, and J. Pastor (2000): "Cross-Border Performance in European Banking," Bank of Finland Discussion Papers, 24/2000.

Haynes, M., ANI S. Thompson (1999): "The Productivity Effects of Bank Mergers: Evidence from the UK Building Societies," Journal of Banking and Finance, 23, 825846.

Hegiestad, A. (1979): "A Survey of Studies on Bank Competition and Performance," in Issues in Financial Regulation, ed. by F. Edwards, chap. 9, pp. 449-490. McGrawHill, New York.

- (1984): "Comment on Bank Market Structure and Performance: A Survey," Journal of Money, Credit and Banking, 16, 645-650.

Heggestad, A. A., AND J. J. Mingo (1976): "Prices, Nonprices, and Concentration in Commercial Banking," Journalof Money, Credit and Banking, 8 (1), pp. 107117.

(1977): "The Competitive Condition of US Banking Markets and the Impact of Structural Reform," Journal of Finance, XXXII (3), 649-661.

Heitfield, E. (1999): "What Do Interest Rate Data Say About the Geography of Retail Banking Markets?," Antitrust Bulletin, Summer, 333-347.

Howland, A. (1999): "The Evolution of the Branch Manager," Canadian Banker, 106 (3), 24-26.

(2000): "The Evolution of the Bank Branch," Canadian Banker, 107 (1), 25-29.

Hughes, J., W. LANG, and L. Mester (1996): "Efficient Banking under Interstate Branching," Federal Reserve Bank of Philadelphia Working Paper, 96-9/R, 1-35.

Hughes, J., AND L. Mester (1993): "Accounting for the Demand for Financial Capital and Risk-Taking in Bank-Cost Functions," Federal Reserve Bank of Philadelphia, Economic Research Division, 93-17.

HuiziNGA, P. (1998): "De Toetreding Van Buitenlandse Banken [The Entry of Foreign Banks]," Economische en Statistische Berichten, Jume 26, 519-522. 
Humphrey, D., and L. Pulley (1997): "Banks' Response to Deregulation: Profits, Technology and Efficiency," Journal of Money, Credit and Banking, 29 (1), 73-93.

Jagtinni, J., ani A. Khanthavit (1996): "Scale and Scope Economies At Large Banks: Including Off-Balance Sheet Products and Regulatory Effects (1984-1991)," Journal of Banking and Finance, 20 (7), 1271-1287.

Jayaratne, J., ANi P. Strahan (1996): "The Finance-Growth Nexus: Evidence from Bank Branch Deregulation," Quarterly Journal of Economics, August, 639-670.

Jondrow, J., C. Knox Lovell, I. Materov, and P. Schmidt (1982): "On the Estimation of Technical Efficiency in the Stochastic Frontier Production Function Model," Journal of Econometrics, 19, 233-238.

JUDD, K. L. (1999): Numerical Methods in Economics. MIT Press, Massachusetts.

Kin, M., AND B. VAle (1997): "Branch Banking in Dynamic Oligopoly," ArbeidsNotat, Norges Bank, 7.

Kirstrer, K. P. (1981): Produktions- und Kostentheorie. Physica Verlag, Würzburg, Wien.

KODdE, D. A., AND F. C. PALM (1986): "Wald Criteria for Jointly Testing Equality and Inequality Restrictions," Econometrica, 54, 1243-1248.

Koları, J.W., A. Z. T. S. A. S. (1992): "Branch Bank Operating Costs: Evidence from Savings Banks in Finland," Applied Economics, 24, 401-410.

Kumbhakar, S., S. Ghosh, and J. MCGuCkin (1991): "A Generalized Production Frontier Approach for Estimating Determinants of Inefficiency in U.S. Dairy Farms," Journal of Business and Economic Statistics, 9, 279-286.

LANG, G. (1996): "Efficiency, Profitability and Competition: Empirical Analysis for a Panel of German Universal Banks," IFO-Studien, 42(4), 537-561.

Lang, G., And P. Welzel (1999): "Mergers Among German Cooperative Banks A Panel Based Stochastic Frontier Analysis," Journal of Small Business Economics, forthcoming.

LewIS, R. (2000): "Change Your Branches to "Physical Portals"," American Bankers Association Banking Journal, 92 (6), 71-72.

Liso, J., T. Balaguer, and M. Soler (1999): "Colección Estudios E Informes (16)," in El Sector Bancario Europeo: Panorama Y Tendencias. Caja de Ahorros y Pensiones de Barcelona. 
Lloyd-Williams, D. M., P. Molyneux, and J. Thornton (1994): "Market Structure and Performance in Spanish Banking," Journal of Banking and Finance, 18, 433443.

Lovell, C. (1993): "Production Frontiers and Productive Efficiency," in The Measurement of Productive Efficiency: Techniques and Applications, ed. by H. Fried, C. Lovell, and S. Schmidt, pp. 3-67, New York. Oxford University Press.

Mayer, C., ANi X. VIves (1992): Capital Markets and Financial Intermediation. CEPR - Cambridge University Press, New York.

MCAldister, P. H., AND D. MCManus (1993): "Resolving the Scale Efficiency Puzzle in Banking," Journal of Banking and Finance, 17, 389-405.

Melusen, W., AND J. VAN DEn Broeck (1977): "Efficiency Estimation from CobbDouglas Production Functions with Composed Error," International Economic Review, $18,435-444$.

Melit', J. (1990): "Financial Deregulation in France," European Economic Review, 34, 394-402.

Mendes, V., and J. Rebelo (1997): "Productive Efficiency in Portuguese Banking: Agricultural Banks vs Universal Banks," University of Porto (Mimeo).

Mester, L. (1991): "Agency Costs Among Savings and Loans," Journal of Financial Intermediation, 1 (3), 257-278.

(1992): "Traditional and Nontraditional Banking: An Information Theoretic Approach," Journal of Banking and Finance, 16 (3), 545-566.

(1996): "Measuring Efficiency at US Banks: Accounting for Heterogeneity is Important," Federal Reserve Bank of Philadelphia Research Working Paper, 96/11, 14.

Milbourn, T., W. Boot, and A. Thakor (1999): "Megamergers and Expanded Scope: Theories of Bank Size and Activity Diversity," Journal of Banking and Finance, 23, 195-214.

Milgrom, P., and J. Rober'ts (1982a): "Limit Pricing and Entry Under Incomplete Information: An Equilibrium Analysis," Econometrica, 50, 443-460.

(1982b): "Predation, Reputation and Entry Deterrence," Journal of Economic Theory, 27, 280-312.

Miller, S., AND A. Noulas (1996): "The Technical Efficiency of Large Bank Production," Journal of Banking and Finance, 20, 495-509. 
Mingo, J. J., AN1) B. Wolkowitz (1977): "The Effects of Regulation on Bank Balance Sheet Decisions," Jounnal of Finance, 33, 1605-1616.

Mitchell, K., and N. Onvural (1996): "Economies of Scale and Scope at Large Commercial Banks: Evidence from the Fourier Flexible Functional Form," Journal of Money, Credit and Banking, 28 (2), 178-199.

Molyend, P, L.-W. D., and J. Thonnton (1994): "Competitive Conditions in European Banking," Journal of Banking and Finance, 18, 445-459.

Molyneux, P. (2000): “'Does Size Matter?' Financial Restructuring under EMU," Working Paper, pp. Part of this paper has appeared in European Investment Bank Papers 4, 1 (1999).

Molyneux, P., Y. Altunbas, and E. Gardener (1997): Efficiency in European Banking. John Wiley and Sons, New York.

Molyneux, P., And W. Forbes (1995): "Market Structure and Performance in European Banking," Applied Economics, 27, 155-159.

Molyneux, P., AN1) J. Thornton (1992): "Determinants of European Bank Profitability: A Note," Journal of Banking and Finance, 16, 1173-1178.

Pastor, J. M., F. PÉrez, aNI) J. Quesada (1997): "Efficiency Analysis in Banking Firms: An International Comparison," European Journal of Operational Research, 98, 395-407.

Polius, T., AND W. SAmuel (2001): "Banking Efficiency in the Eastern Caribbean Currency Union: An Examination of the Structure-Conduct-Performance Paradigm and the Efficiency Hypothesis," Mimeo.

Price Waterhouse (1988): "The Cost of Non-Europe in Financial Services," in Research on the Cost of Non-Europe: Basic Findings (Vo.L. 9), ed. by E. Union. European Union, Brussels.

Pulley, L., Ani D. Humphrey (1993): "The Role of Fixed Costs and Cost Complementarities in Determining Scope Economies and the Cost of Narrow Banking Proposals," Journal of Business, 66 (July), 437-462.

Resti, A. (1997): "Evaluating the Cost-Efficiency of the Italian Banking System: What Can Be Learned from the Joint Application of Parametric and Non-Parametric Techniques," Journal of Banking and Finance, 21, 221-250.

RHOA DES, S. (1977): "Structure-Performance Studies in Banking. A Summary and Evaluation," US Federal Reserve Board Staff Economic Papers, 92. 
(1994): "A Summary of Merger Performance Studies in Banking, 1980-1993, and Assessment of the 'operating Performance' and 'event Study' Methodologies," Board of Governors of the Federal Reserve System, System Staff Study, 167.

(1998): "The Efficiency Effects of Bank Mergers: An Overview of Case Studies of Nine Mergers," Journal of Banking and Finance, 22, 273-291.

Rose, P. (1999): Commercial Bank Management. Irwin, McGraw-Hill, Boston.

Rose, P. S. (1987): "The Impact of Mergers in Banking: Evidence From a Nationwide Sample of Federally Chartered Banks," Journal of Economics and Business, 39, 289312.

(1995): "The Distribution of Outcomes from Corporate Mergers: The Case of Commercial Banking," Journal of Accounting, Auditing, and Finance, X (2).

Rubin, I. (1999): "Automation Technologies Offer Branches a New Strategic Life," Bank Systems and Technology, 36 (8), 48.

RuthenberG, D., and R. Ellins (1996): "Cost Economies and Interest Rate Margins in a Unified European Banking Market," Journal of Economics and Business, 48, pp. 231-249.

Saunders, A., AND I. Watter (1994): Universal Banking in the United States: What Could We Gain? What Could We Lose? Oxford University Press, New York.

Schmidt, P., anis C. A. K. Lovell (1979): "Estimation Technique and Allocative Inefficiency Relative to Stochastic Production and Cost Functions," Journal of Econometrics, 9, 343-366.

Sil FFer, S. (1993): "Can Megamergers Improve Bank Efficiency?," Journal of Banking and Finance, 17, 423-436.

Sheldon, G. (1999): "Costs, Competitiveness and the Changing Structure of European Banking," Fondation Banque de France pour la Recherche - Working Paper.

Sherman, H., and F. Gold (1985): "Bank Branch Operating Efficiency: Evaluation with Data Envelopment Analysis," Journal of Banking and Finance, 9, 297-315.

Siems, T. (1996): "Bank Mergers and Shareholder Wealth: Evidence from 1995's Merger Deals," Federal Reserve Bank of Dallas, Financial Industry Studies, August.

SMIRLOCK, M. (1985): "Evidence on the (Non-)Relationship Between Concentration and Profitabity in Banking," Journal of Money, Credit and Banking, 17 (1), 69-83.

Soares de Pinho, P. (1994): "Economies of Scale and Scope and Productive Efficiency in Portuguese Banking: A Stochastic Frontier Approach," Ph.D. thesis, City University Business School, London, UK. 
Steinherr, A. E. (1992): "The New European Financial Market Place," New York. Longman.

Stevenson, R. E. (1980): "Likelihood Functions for Generalised Stochastic Frontier Estimation," Journal of Econometrics, 13, 57-66.

STICH, A. (1995): "Insurance and Concentration: The Change of Concentration in the Swedish and Finnish Insurance Market 1989-1993," University of Cologne-Discussion Papers in Statistics and Econometrics, 10/95 (November).

Strilier, G. (1964): "A Theory of Oligopoly," Journal of Political Economy, 72, 44-61.

Swank, J. (1996): "How Stable is the Multi-Product Translog Cost Function? Evidence from the Dutch Banking Industry," Kredit und Kapital, 29, 153-172.

Tirole, J. (1993): The Theory of Industrial Organization. MIT Press, Cambridge, Massachusetts.

VANHoOSE, D. (1983): "Monetary Policy and Alternative Bank Market Structures," Journal of Banking and Finance, 7, 383-404.

(1985): "Bank Market Structure and Monetary Control," Journal of Money, Credit and Banking, 17 (3), 298-311.

VANHoOSE, D. D. (1988): "Deregulation and Oligopolistic Rivalry in Bank Deposit Markets," Journal of Banking and Finance, 12, 379-388.

VENNET, VANDER, R. (1994): "Concentration, Efficiency and Entry Barriers as Determinants for EC Bank Profitability," Journal of International Financial Markets, Institutions, and Moncy, 4, 21-46.

(1996): "The Effects of Mergers and Acquisitions on the Efficiency and Profitability of E.C. Credit Institutions," Journal of Banking and Finance, 20, 1531-1558.

- (1998): "Determinants of EU Bank Takeovers: A Logit Analysis," The Changing European Financial Landscape - A CEPR/ESI Conference, Brussels, September 24/26, $1-21$.

(1999): "Cost and Profit Dynamics in Financial Conglomerates and Universal Banking in Europe," University of Ghent (Mimeo).

Waldman, D. M. (1982): "A Stationary Point for the Stochastic Frontier Likelihood," Journal of Econometrics, 18 (2), pp. 275-279.

Weinstein, M. (1964): "The Sum of Values from a Normal and a Truncated Normal Distribution," Technometrics, 6, 104-105 and 469-470. 
YANelde, M.-O. (1989): "The Strategic Analysis of Intermediation," European Economic Review, 33, 294-301.

ZardKOOHI, A., AND J. KOLARI (1994): "Branch Office Economies of Scale and Scope: Evidence from Savings Banks in Finland:" Journal of Banking and Finance, 18, 421432 .

Zardkooni, A., J. Kolari, ANI) F. DAHM (1995): "Economies of Scale and Scope in Commercial Banks with Different Output Mixes," Texas ABM Working Paper. 


\section{Samenvatting (Summary in Dutch)}

De meeste sectoren van de economie kenmerken zich door een opeen volgende reeks van consolidatie- en expansiegolven. Bedrijven treden toe, gaan failliet, fuseren of worden overgenomen. Na een periode van consolidatie doen zich nieuwe groeimogelijkheden voor, en terwijl de markt in grootte toeneemt verandert de marktstructuur. Bedrijven zijn op zoek naar hun strategische positie op deze markt en vinden die in een niche, als 'marktmaker' of simpelweg als anonieme speler. Na een periode van agressieve groei volgt dan wederom een periode van consolidatie, waarna het spel opnieuw een aanvang neemt.

Deze archetypische cycli beïnvloeden in belangrijke mate investeringen, werkgelegenheid en uiteindelijk de economische structuur van een land. Dit geldt vooral wanneer de sector waarbinnen het spel wordt gespeeld de bankensector is. Door hun traditionele rol als intermediair en hun rol bij het (her)verdelen van kapitaal spelen banken een cruciale rol. In Europa, waar deze rol relatief groot is, zijn banken van bijzonder belang in het functioneren van een economie.

Het is derhalve opvallend dat een groot deel van het kapitaal dat banken (her)verdelen in handen is van cen zeer beperkt aantal spelers. Op de depositomarkt van veel Europese landen bij voorbeeld bedraagt het aandeel van de vijf grootste banken meer dan $70 \%$. En in Nederland is deze situatie nog extremer: de grootste drie banken bestrijken meer dan $85 \%$ van de depositomarkt. Voor (hypothecaire) leningen is de situatie al niet veel anders.

Daar komt nog bij dat klanten van banken vaak zeer sterk gebonden zijn. De kosten verbonden aan het verhuizen van de financiële huishouding van bank a naar bank b zijn hoog, zowel voor consumenten als voor bedrijven.

Tot slot is het zo dat de eerder genoemde cycli grotendeels voorbij zijn gegaan aan het traditionele bankwezen. Diversificatie en deregulering hebben weliswaar geleid tot een toename in het aantal aangeboden diensten en tot toetreding van nieuwe aanbieders van die diensten. Maar gedurende de hele twintigste eeuw lijkt de bankensector van de meeste Europese landen in de greep van een lange consolidatietrend.

De creatie van een Europese markt in de Europese Unie zorgde er begin van de jaren '90 voor dat een periode van deregulering gestalte kreeg. Samen met technologische veranderingen en een toegenomen rol voor kapitaalmarkten bereidde dit de weg voor een mogelijke herinrichting van het Europese financiële landschap. Tegelijkertijd ging de creatie van deze Europese markt vergezeld van een nieuwe golf fusies en overnames in de financiële wereld, waarvan in Nederland onder andere ABN AMRO en de ING Groep het resultaat waren. Tezamen zorgden deze ontwikkelingen ervoor dat zowel door toezichthouders als 
door academici met een hernieuwde interesse en zorg werd gekeken naar het presteren van banken in een verder consoliderende markt.

In dit proefschrift sympathiseer ik met die interesse en zorg. In het bijzonder stel ik de volgende vraag centraal: in welke mate zijn verschillen in het presteren van banken toe te schrijven aan relatieve marktmacht en in welke mate aan relatieve efficiëntie? Enerzijds onderzoek ik daarbij de mogelijkheid dat banken hum relatieve grootte en marktpositie gebruiken om buitensporige winsten te behalen. Anderzijds onderzoek ik de mogelijkheid dat diezelfde winsten het gevolg zijn van een meer dan gemiddelde efficiëntie. Vanzelfsprekend kan het een (marktmacht) goed samengaan met het ander (superieure efficiëntie). Belangrijk is het wel te constateren dat de mate waarin banken hun presteren te danken hebben aan hetzij marktmacht, hetzij superieure efficiëntic gevolgen heeft voor de manier waarop de eerder geschetste consolidatie in het bankwezen beschouwd dient te worden. Zo zal een regelgevende/regulerende instantie een fusie die ingegeven wordt door te behalen efficiëntie voordelen goed willen keuren. Zo'n fusic zal - ceteris paribus - leiden tot lagere prijzen en een verbetering van de dienstverlening. Wanneer diezelfde fusie echter cnkel het vergroten van de marktmacht tot doel heeft zullen - opnieuw ceteris paribus - stijgende prijzen en een verslechtering van de dienstverlening het gevolg zijn.

Om bovenstaande vraag te beantwoorden verbind ik twee stromingen in de literatuur. De eerste stroming omvat studies naar de aanwezigheid van marktmacht in het Europese bankwezen. Deze studies trachten een directe maatstaf te vinden voor de mate waarin marktmacht verschillen in het presteren van banken verklaart. Op een indirect manier derhalve proberen deze studies het gedrag van banken te meten, aangezien marktmacht gelegenheid biedt voor concurrentieverlagend gedrag.

Dit type studie is zeer populair, met name voor onderzoek naar Amerikaanse banken, veelal met toegepaste analyses zonder theoretische onderbouwing. Het meest populair zijn testen van het zogeheten 'structuur-gedrag-prestatic' paradigma, ook wel SCP paradigma. Deze testen verklaren prestaties van banken in een markt aan de hand van (veranderingen in) de structuur van die markt. Een belangrijke veronderstelling hierbij is dat naarmate de marktconcentratie hoger is, banken meer concurrentieverlagend gedrag vertonen (prijsafspraken, het opdelen van de markt, etc.). De toename in de concentratie in veel Europese bankenmarkten alsmede de toegenomen beschikbaarheid van bankspecifieke data hebben ertoe geleid dat vanaf eind jaren ' 80 ook Europese bankenmarkten steeds vaker onderwerp van een dergelijke studie zijn. Resultaten van deze studies zijn echter verre van eensluidend.

Een tweede stroming die in dit proefschrift een belangrijke rol speelt behelst efficiëntie studies. Doel van deze studies is het meten van de efficiëntie van banken ten opzichte van een efficiënte grens. Deze benchmark technieken worden in toenemende mate gebruik, mede onder invloed van econometrische en technologische ontwikkelingen en door de toegenomen beschikbaarheid van microdata. 
In dit proefschrift probeer ik het beste van beide werelden te verenigen. Om een zo accuraat mogelijk antwoord te krijgen op de centrale vraag hierboven gesteld gebruik ik marktmacht modellen en efficiẻntie modellen, zowel gezamenlijk als apart.

Hoofdstuk 2 begin ik met een kritische analyse van marktmacht modellen voor Europese bancaire markten. Ik verklaar mogelijke problemen bij het testen van de structuur-gedragprestatie hypothese. Bovendien sta ik stil bij de veronderstellingen die bij deze modellen een belangrijke rol spelen, en leg uit in hoeverre ze relevant zijn voor Europa. Kort behandel ik in dit kader de belangrijkste veranderingen in de Europese regelgeving. Tenslotte behandel ik methodologische problemen bij het meten van marktmacht.

Efficiëntie modellen zijn het onderwerp van hoofdstuk 3 . Ik begin met een kort overzicht van het gedrag van banken, in een poging uit te vinden waarom marktmachtmodellen dit gedrag niet volledig kunnen verklaren. Vervolgens introduceer ik een relatief eenvoudig model waarmee de relatie tussen het (strategische) gedrag van banken, hun productie en de daarmee gepaard gaande efficiëntie gemodelleerd kan worden. Hierbij maak ik onderscheid tussen kostenminimalisatie enerzijds en winstmaximalisatie anderzijds. In een markt met volledige mededinging zal een bank die zijn winst efficiënt maximaliseert, ook efficiënt zijn in het minimaliseren van zijn kosten. Speelt marktmacht een rol, vanwege bijvoorbeeld relatieve grootte of productverscheidenheid, dan ontstaat er een ander spel. Om winstefficiëntie en kostenefficiëntie adequaat te meten introduceer ik stochastische grens modellen. Hiermee kan ik in latere hoofdstukken de relatieve efficiëntie van banken vergelijken, zowel qua winstmaximalisatie als qua kostenminimalisatie.

In hoofdstuk 4 pas ik deze stochastische grens modellen toe op de Nederlandse bankenmarkt in de jaren ' 90 . Zoals eerder vermeld is Nederland bij uitstek een land waar de bankenmarkt zeer geconcentreerd is. Bovendien liep Nederland voorop bij de belangrijkste Europese trends - deregulering, consolidatie en technologische vooruitgang (bijvoorbeeld het gebruik van geldautomaten). De Nederlandse bankenmarkt leent zich derhalve goed voor een onderzoek naar de relatie tussen het presteren van banken, mogelijke marktmacht en efficiëntieverschillen.

In de analyse in dit hoofdstuk maak ik onderscheid tussen drie types banken. Allereerst is daar een grote groep van kleine en middelgrote, algemene banken. Deze groep blijkt zowel qua winstefficiëntie als qua kostenefficiëntie gemiddeld te presteren. Als tweede groep onderscheid ik de meer gespecialiseerde banken, met name zakenbanken. Deze groep presteert ietwat beter dan gemiddeld op het gebied van kostenefficiëntie. Maar vooral zijn de banken in deze groep meer dan gemiddeld in staat hun winst efficiënt te maximaliseren, wellicht als gevolg van hun niche positie. Als laatste analyseer ik in dit hoofdstuk de relatieve efficiëntie van de grote drie: ABN AMRO, ING en Rabobank. Deze banken blijken gemiddeld kostenefficiënt te zijn, maar qua winstefficiëntie boven de middelmaat uit te steken. Tezamen vormt dit een duidelijk signaal dat deze groep van drie dominante banken wel degelijk van marktmacht profiteert. 
Tot slot blijkt in dit hoofdstuk dat de in de litcratuur gesignaleerde trendmatige veranderingen in efficiëntie die vaak gerelateerd worden aan consolidatie- en deregulering grotendeels afhankelijk zijn van de manier waarop deze trends gemeten worden. In dit hoofdstuk wordt derhalve de trend niet opgelegd in het te schatten model, maar afgeleid van de efficiëntie maatstaven die resulteren van het model. Dan blijkt dat er zowel op het gebied van winst efficièntie als op het gebied van kosten efficiëntie hoegenaamd geen trend aanwezig is.

In hoofdstuk 5 vervolg ik de analyse van de Nederlandse bankenmarkt. In dit hoofdstuk introduceer ik een standaard structuur-gedrag-prestatie model. Ik behandel drie mogelijke verbeteringen aan het model. Ten eerste herhaal ik de reeds in hoofdstuk 2 geuite kritiek dat de keuze van zowel een prestatiemaatstaf als een marktstructuurmaatstaf gespeend is van een theoretische onderbouwing. Vervolgens wijs ik er op dat in het schatten van het SCP paradigma sprake is van een zogeheten 'weggelaten variabele' probleem. Als gevolg daarvan meet de marktstructuur variabele in het SCP model zowel marktconcentratie als de strategische reactic van banken op die marktconcentratie. Concreet leidt dit ertoe dat de hypothese dat marktmacht is wellicht te vaak verworpen wordt. Ten derde behandel ik de zogeheten Efficiëntic hypothese, die het presteren van banken verklaart door efficiëntieverschillen die vervolgens ook tot een geconcentreerde markt leiden. Ik leg uit waarom meetfouten optreden in het testen van deze hypothese en gebruik de in hoofdstuk 4 geschatte kosten efficiëntie om een poging te doen deze meetfouten te verkleinen.

Aan alle drie de punten van kritick kom ik tegemoet in een alternatief model, met een theoretische onderbouwing. Dit model alsmede het klassieke SCP model schat ik vervolgens voor de Nederlandse bankenmarkt om zodoende te kijken in hoeverre de resultaten consistent zijn. Op alle drie de kritiekpunten wint het alternatieve model, al is dit laatste vooralsnog verre van perfect. De schattingsresultaten bevestigen dan ook op grote lijnen de eerder beschreven resultaten van hoofdstuk 4 .

In hoofdstuk 6 verander ik van perspectief en vergelijk ik Europese banken met Amerikaanse banken. Ik concentreer me hierbij op grote, onafhankelijke algemene banken, en ik stel de vraag centraal hoe deze banken zich qua kostenefficiëntie en winstefficiëntie verhouden. Deze vraag beantwoord ik vervolgens in twee stappen. Eerst onderzoek ik of deze Europese en Amerikaanse banken vergeleken mogen worden. Specifiek analyseer ik of er sprake is van een vergelijkbare kostenminimalisatie, respectievelijk een vergelijkbare winstmaximalisatie. De hypothese dat grote, onafhankelijk banken aan beide zijden van de Atlantische Oceaan eenzelfde kostengrens delen kan niet verworpen worden. Echter, de hypothese dat hetzelfde geldt voor de winstgrens wordt wel degelijk verworpen. Zo blijkt derhalve dat Europese banken wel op eenzelfde manier als hun Amerikaanse tegenhangers kosten minimaliseren, maar dat maximaliseren van de winst anders geschiedt. Alhoewel nieuw in de literatuur, is dit resultaat nochtans niet verrassend gegeven de opmerking in hoofdstuk 3 dat bij winstmaximalisatie - meer dan bij kostemminimalisatie - marktom- 
standigheden een grote rol spelen. Dit resultaat vormt dan ook een mogelijke verklaring voor het gebrek aan (succesvolle) transatlantische fusies en overnames.

Hoofdstuk 7 neent opnieuw een ander perspectief, maar gaat desalniettemin door waar hoofdstuk 6 ophoudt. Hier analyseer ik de rol van lokale marktomstandigheden in het presteren van banken. Mecr specifiek probeer ik de vraag te beantwoorden in hoeverre lokale marktomstandigheden verschillen in respectievelijk kostenefficiëntic en winstefficiëntie kummen verklaren. Hiertoe bestudeer ik de relatieve efficiëntie van 402 Rabobanken in de periode 1998/1999. Voordeel van deze keuze is dat deze banken, hocwel vergelijkbaar, autonoom opereren over heel Nederland.

Banken die in een meer landelijke omgeving opereren hebben vaak baat bij de geringere concurrentie en zijn als gevolg hiervan winstefficiënter. Zakelijk bankieren en privé bankieren gebeurt volgens verschillende spelregels. Het meest opvallend hierbij is dat de marginale voordelen in termen van winstefficiëntie een stuk groter zijn bij zakelijk bankieren.

Wellicht het meest interessant is de relatie tussen locatic en efficiëntie. Banken met veel hoofdkantoren en geldautomaten zijn relatief weinig winstefficiënt. Daarentegen zijn bijkantoren weliswaar relatief inefficiënt op het gebied van kosten, maar compenseren zij dit ruimschoots door een superieure winstefficiëntic. Deze resultaten wijzen er dan ook op dat marktpenetratie in de vorm van cen wijdvertakt netwerk loont.

Samenvattend resulteert de analyse in dit proefschrift zo in vier belangrijke lessen. Ten ecrste, er is - mits op de juiste wijze getest - overtuigend bewijs ten faveure van marktmalht. Ten tweede, or is nog efficiëntiegroei te behalen in de omvang van $5-10 \%$, met name op het gebied van winstefficiëntie. Ten derde, lokale marktomstandigheden spelen een bescheiden, maar nict uit te vlakken rol in het verklaren van zowel kostenefficiëntie als winstefficiëntie. Hierbij blijkt dat de traditioncle rol van banken als financiële intermediair verre van uitgespeeld is. Als vierde les volgt tot slot dat efficiëntieverschillen, ondanks vergaande globalisering, voortduren.

Tezamen genomen, stelt liet hier gepresenteerde onderzock dat de rol van kleine, algemene banken marginaal zal zijn. On te overleven is grootte of focus nodig. Mits er clan genoeg concurrentiedruk overblijft zijn er echter nog altijd significante efficiëntiewinsten te behalen. Aangezien op nationale markten deze concurrentie druk steeds meer afneemt is internationale concurrentie en regelgeving die deze stimuleert van wezenlijk belang. In dat licht bezien kumnen fusies of overnames over de grenzen heen zelfs een positieve rol spelen. Op dit punt blijkt echter dat het succes van dergelijke fusies in belangrijke mate af zal hangen van het vermogen van banken zich aan nieuwe marktomstandigheden aan te passen. 


\section{Professional Curriculum Vitae}

I was born as Jaap Wilhelm Bernard Bos on November 15, 1973 in Hamont, Belgium. Between 1986 and 1992, I attended Gymnasium Rolduc in Kerkrade. Consecutively, I began studying economics at Maastricht University. In 1993, I cnrolled in the International Economic Studies program, with a specialization in monetary economics. I spent the academic year 1995/1996 studying industrial organization and (managerial) finance at the 'Université de Sciences Sociales' in Toulouse, France. My stay in Toulouse also resulted in the 'Diplôme d'Études de l'Union Européenne',. a mix of economics, law and political science. Back in 1997, upon completing my master's thesis entitled "SCP analyses of (European) banking markets, a critique", I graduated cum laude. I spent the months before enrolling in a Ph.D. program at Deutsche Bank Research in Frankfurt, working on E.M.U. issues, E.U. pension fund reforms and corporate governance. September 1997, I started working as a PhD student at METEOR, the research school of the Faculty of Economics and Business Administration of Maastricht University. In 1999, Prof. Dr. Clemens Kool and I started a research program on local bank efficiency, in collaboration with Rabobank Netherlands. Work on the relationship between bank efficiency and the cnviromment banks operate in culminated in chapter 7 of this thesis.

My collaborations with Prof. Dr. James Kolari resulted in 2001 in an extended stay as a visiting scholar at Texas A\&M University, U.S.A.. Financially supported by the Netherlands Organization for Scientific Research (NWO) and the Center for International Business Studies (Texas A\&M University) this collaboration led to joint research on bank efficiency, bank mergers and exchange rate stability. Chapter 6 of this thesis is the direct result of this joint work. Since September 2001, I am assistant professor of cconomics at Maastricht University. My research interests include bank efficiency, industrial organization, corporate governance, bank regulation and international finance. After defending this thesis, I start working as an researcher at the Department of Supervision of De Nederlandsche Bank (Dutch central bank). 